\title{
Engineering Development of Advanced Physical Fine Coal Cleaning For Premium Fuel Applications \\ Task 6 - Selective Agglomeration Laboratory Research and Engineering Development for Premium Fuels
}

\section{Topical Report \\ June 27, 1997}

\author{
By: \\ N. Moro \\ M. C. Jha
}

Work Performed Under Contract No.: DE-AC22-92PC92208

For

U.S. Department of Energy

Office of Fossil Energy

Federal Energy Technology Center

P.O. Box 880

Morgantown, West Virginia 26507-0880

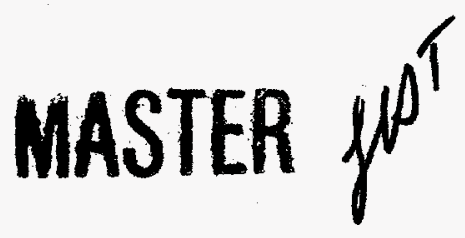

By

AMAX

Research \& Development Center

5950 McIntyre Street

Golden, Colorado 80403-7499

DOMTREATION OF THES DOCUMENT 6 UNLMUTED 


\section{Disclaimer}

This report was prepared as an account of work sponsored by an agency of the United States Government. Neither the United States Government nor any agency thereof, nor any of their employees, makes any warranty, express or implied, or assumes any legal liability or responsibility for the accuracy, completeness, or usefulness of any information, apparatus, product, or process disclosed, or represents that its use would not infringe privately owed rights. Reference herein to any specific commercial product, process, or service by trade name, trademark, manufacturer, or otherwise does not necessarily constitute or imply its endorsement, recommendation, or favoring by the United States Government or any agency thereof. The views and opinions of authors expressed herein do not necessarily state or reflect those of the United States Government or any agency thereof. 


\section{DISCLAIMER}

Portions of this document may be illegible electronic image products. Images are produced from the best available original document. 


\section{ABSTRACT}

The primary goal of this project is the engineering development of two advanced physical fine coal cleaning processes, column flotation and selective agglomeration, for premium fuel applications. The project scope included laboratory research and benchscale testing on six coals to optimize these processes, followed by the design, construction, and operation of a $2 \mathrm{t} / \mathrm{hr}$ process development unit (PDU). The project began in October, 1992, and is scheduled for completion by September 1997.

This report represents the findings of Subtask 6.5 Selective Agglomeration BenchScale Testing and Process Scale-up. During this work, six project coals, namely Winifrede, Elkhorn No. 3, Sunnyside, Taggart, Indiana VII, and Hiawatha were processed in a $25 \mathrm{lb} / \mathrm{hr}$ continuous selective agglomeration bench-scale test unit.

For this work, the coals were ground in pilot scale equipment and then cleaned by the selective agglomeration process. The process unit operations consisted of a highshear step to achieve inversion and microagglomerate formation, a low-shear step for agglomerate growth to 2 to $3 \mathrm{~mm}$ in size, and product recovery by screening. Both commercial and pure grades of heptane were used as the agglomerant during this testing. Asphalt in the form of an emulsion was also used as an agglomeration promoter for low rank and oxidized coals.

In order to meet the product ash specification of $2 \mathrm{lb} / \mathrm{MBtu}(1 \mathrm{lb} / \mathrm{MBtu}$ for the Taggart coal), the coals had to be ground to various sizes ranging from the coarsest grind for the Elkhorn No. 3 coal with an $80 \%$ passing size of 68 microns to the finest grind for the Winifrede coal with an $80 \%$ passing size of 12 microns. When ground to the appropriate size, the product ash specification was met for each coal tested at Btu recoveries generally in the 98 to $99 \%$ range. Typical operating conditions used during this testing provided 30 to 60 seconds of high-shear residence time at impeller tip speeds from 10 to $18 \mathrm{~m} / \mathrm{s}$. Low-shear growth was best achieved in 2 to 5 minutes residence time at impeller tip speeds of $5 \mathrm{~m} / \mathrm{s}$. Screening to recover the product was found to be most effected by the size of the agglomerates produced in low shear, with larger ( 2 to $3 \mathrm{~mm}$ ) agglomerates providing the lowest ash product.

Following agglomeration, the heptane was recovered from the product by direct contact steam stripping in two stages. The first stage of stripping recovered the bulk of the heptane and was carried out at about 5 minutes residence and ambient pressure boiling points. The second stage of steam stripping removed additional heptane during 10 minutes of residence time at elevated pressures and temperatures, typically $10 \mathrm{psi}$ and $117^{\circ} \mathrm{C}$, respectively. Residual heptane concentrations were typically in the 1000 to $3000 \mathrm{ppm}$ on a dry solids basis, with minimal heptane found in the process tailings when successful agglomeration was achieved. Recovered heptane and water vapor were then condensed, cooled, separated, and recycled to the process for reuse. 


\section{ACKNOWLEDGMENTS}

Thanks are offered to John Getsoian of Arcanum Corporation for his valuable help in the design, construction, testing, data evaluation, and reporting efforts during the course of this work. 


\section{TABLE OF CONTENTS}

Section

Page

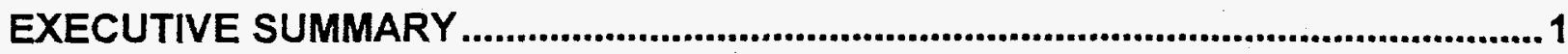

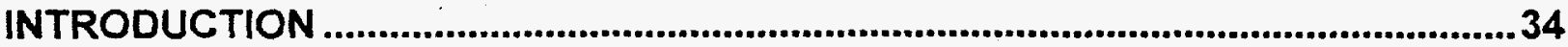

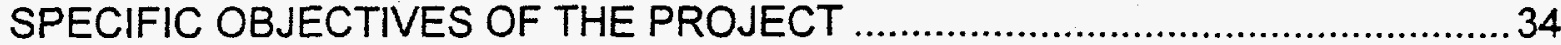

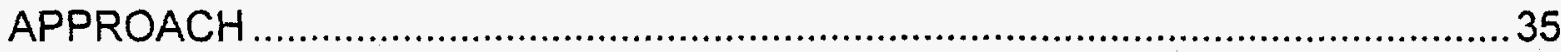

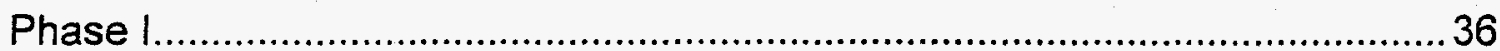

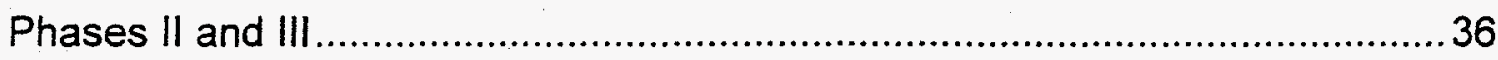

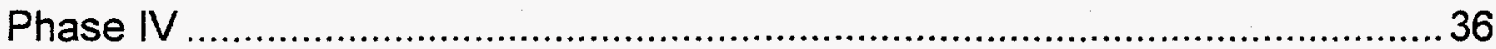

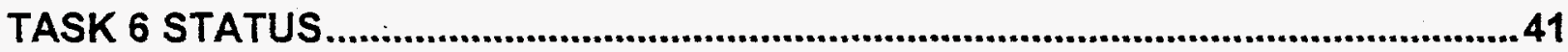

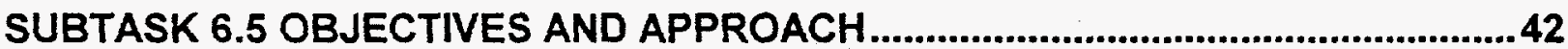

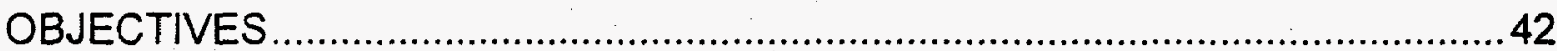

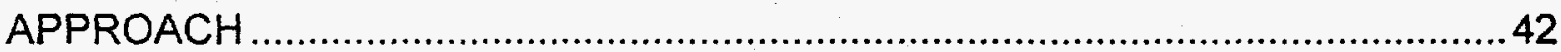

SELECTIVE AGGLOMERATION PROCESS DESCRIPTION.....................................44

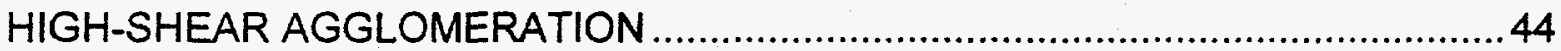

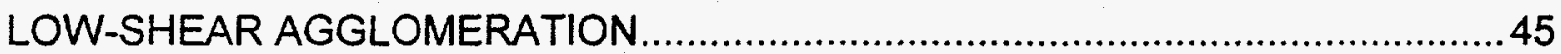

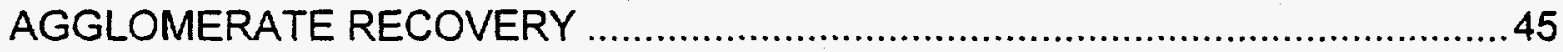

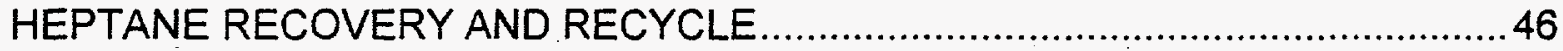

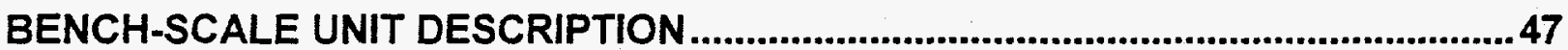

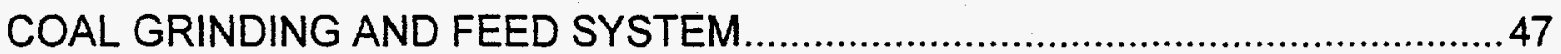

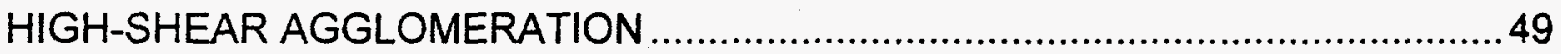

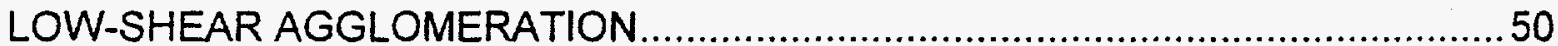

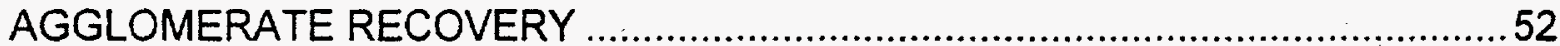

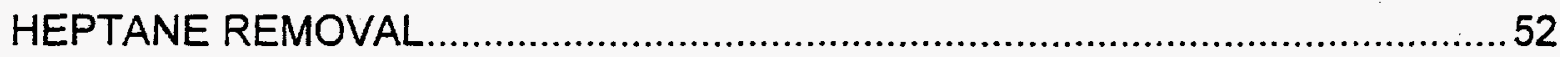

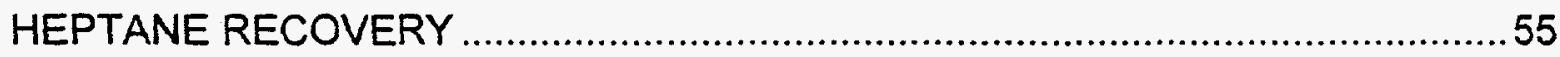

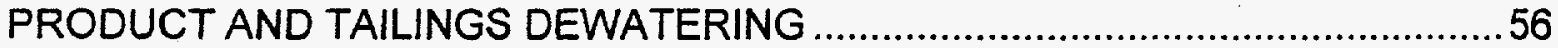

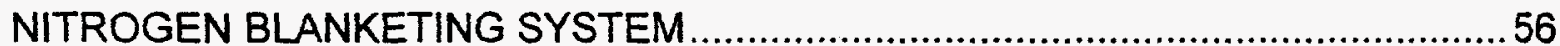

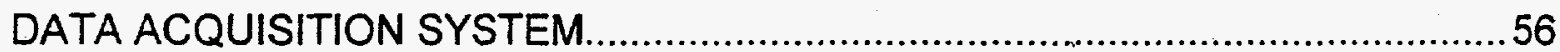

AGGLOMERATION TESTING AND CHARACTERIZATION EQUIPMENT ............57

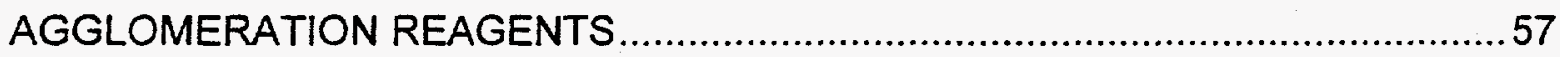

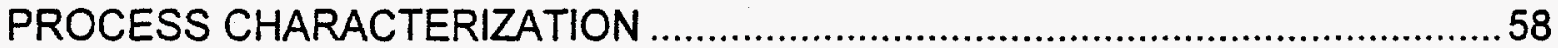




\section{TABLE OF CONTENTS (Cont'd)}

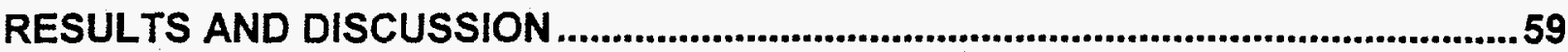

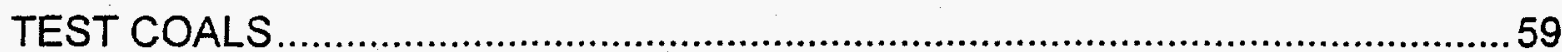

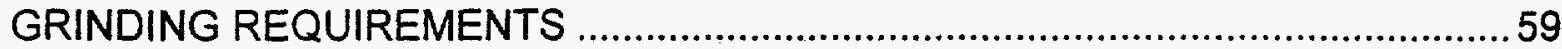

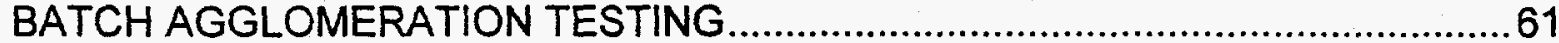

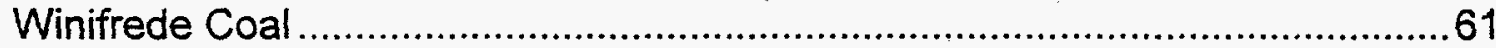

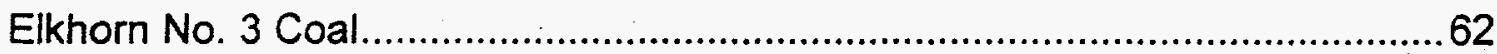

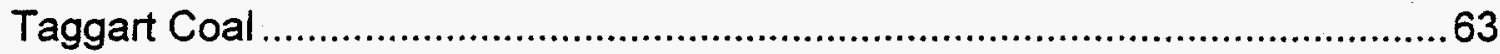

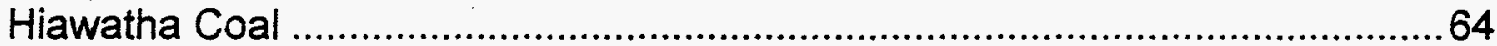

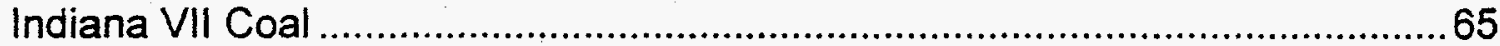

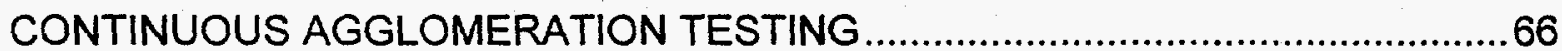

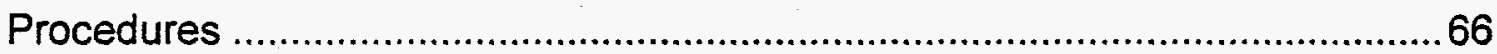

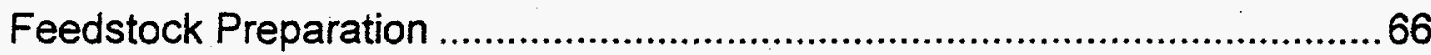

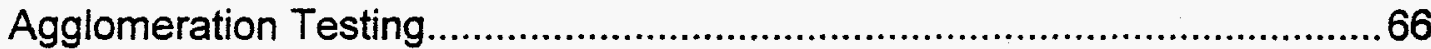

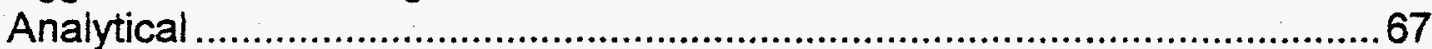

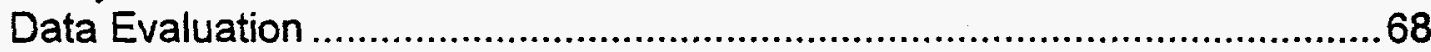

Start-Up Testing and System Modifications .....................................................68

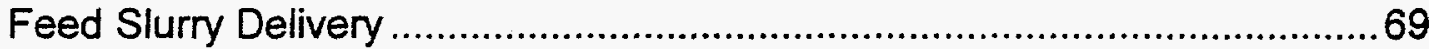

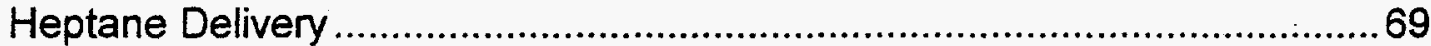

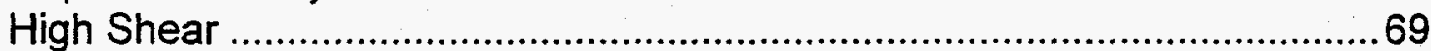

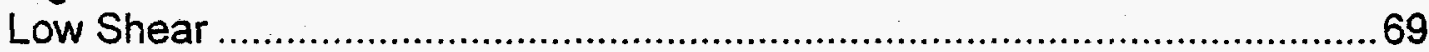

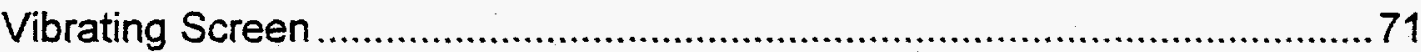

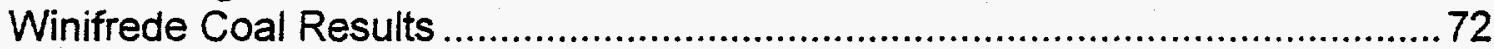

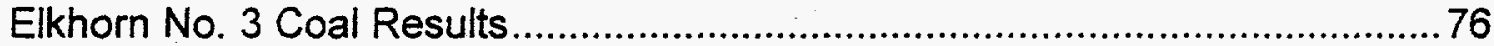

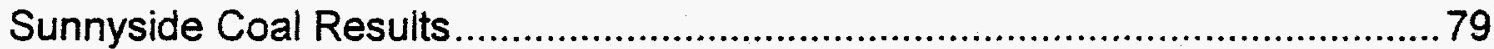

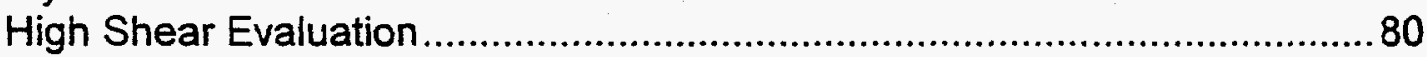

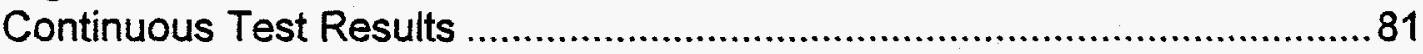

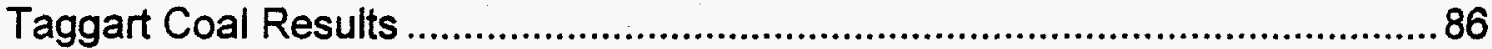

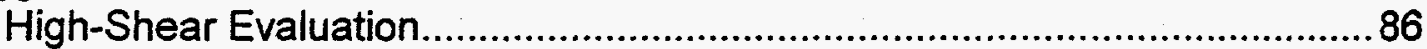

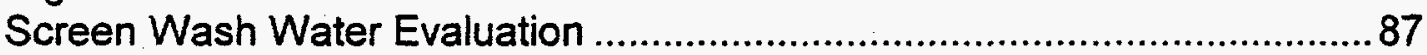

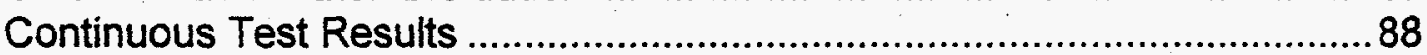

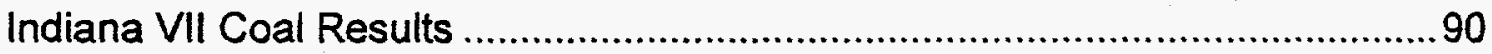

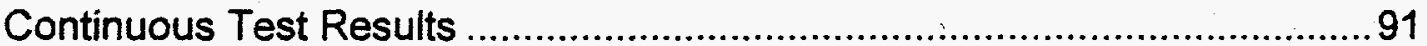

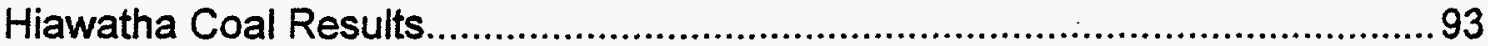

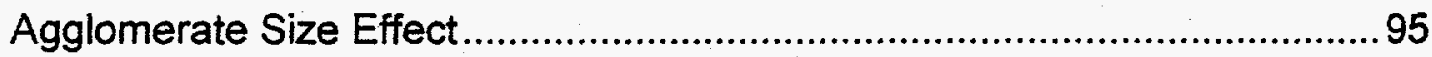

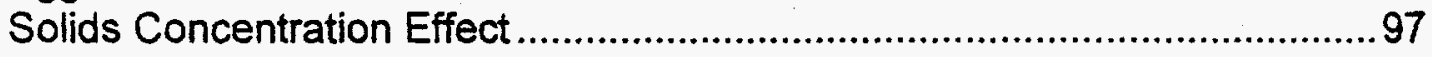




\section{TABLE OF CONTENTS (Cont'd)}

Section

Page

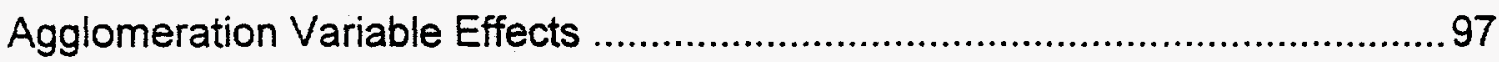

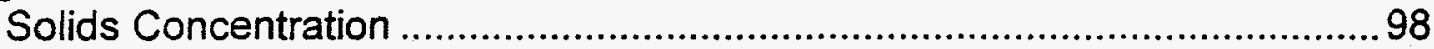

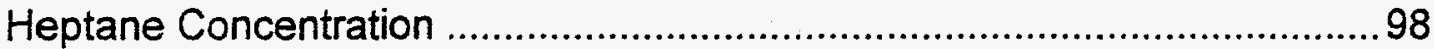

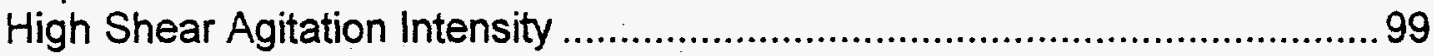

High Shear Residence Time....................................................................99

Low Shear Agitation Intensity .................................................................. 99

Low Shear Residence Time .................................................................100

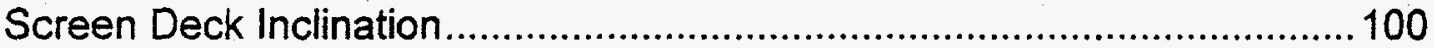

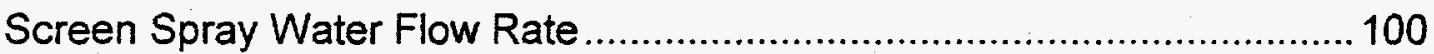

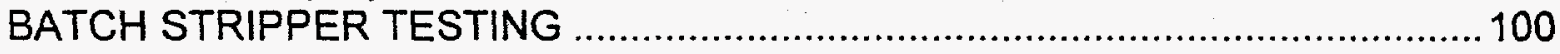

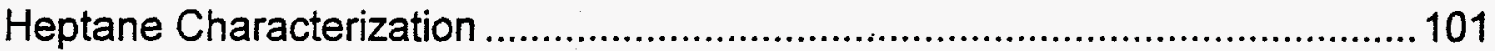

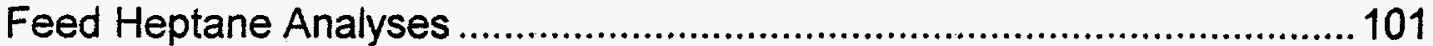

Residual Heptane Analyses .............................................................. 102

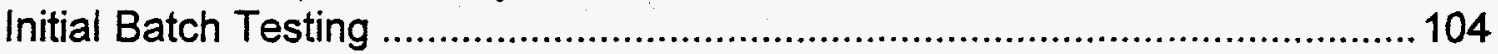

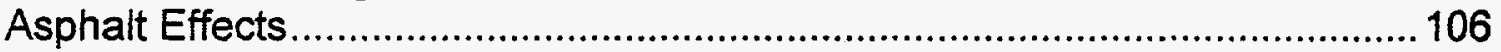

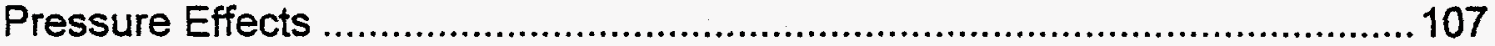

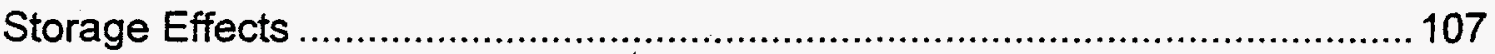

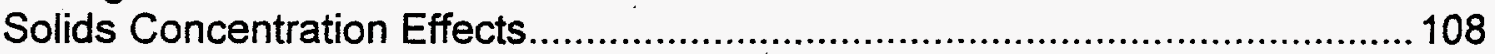

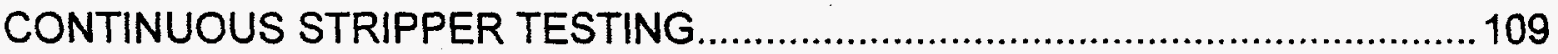

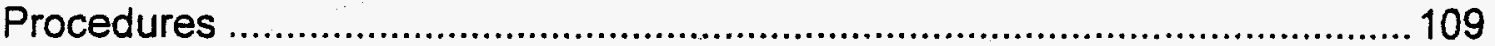

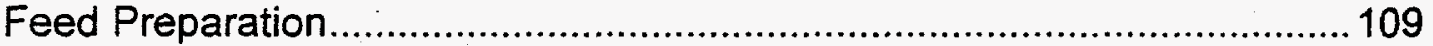

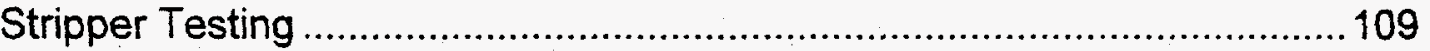

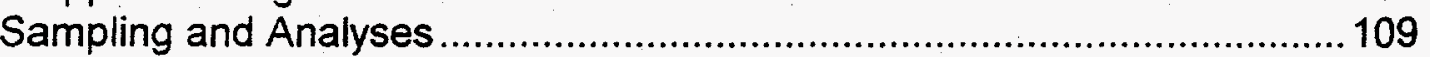

Start-Up Testing and System Modifications ................................................. 110

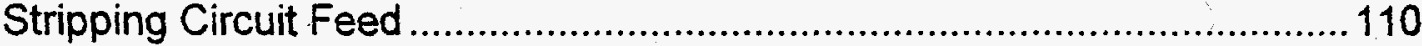

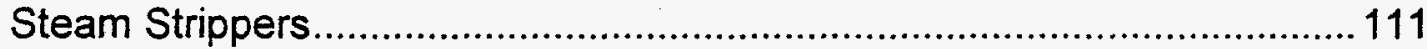

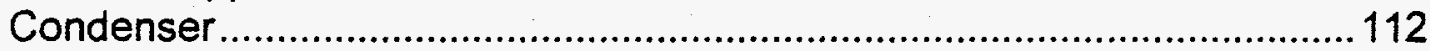

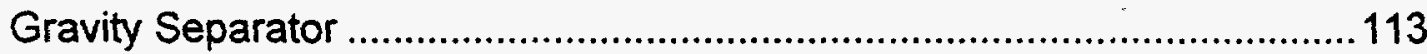

Preliminary Testing Results - Elkhorn No. 3 Coal ....................................... 113

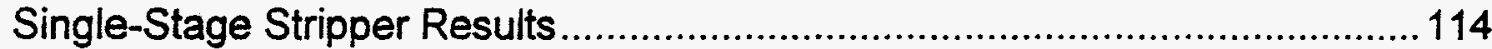

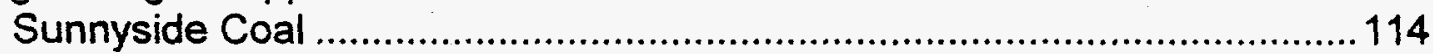

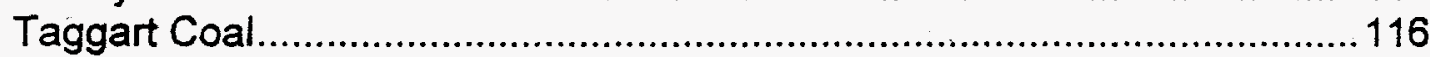

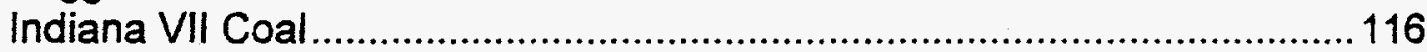

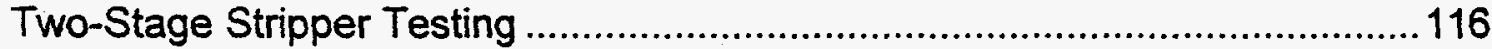

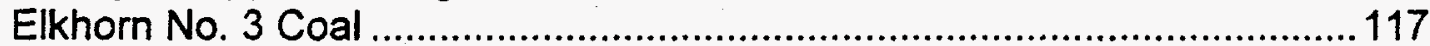

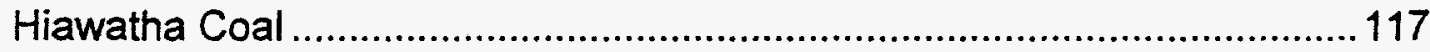

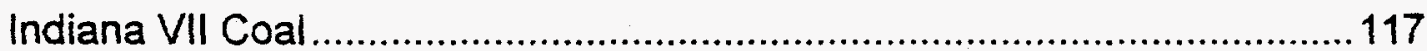

Steam Stripping Variable Effects Summary ..............................................118

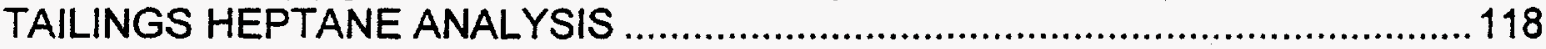

TOXIC TRACE ELEMENTS DISTRIBUTION ................................................118 


\section{TABLE OF CONTENTS (Cont'd)}

Section

Page

CONCLUSIONS 128

AGGLOMERATION

STEAM STRIPPING

TOXIC TRACE ELEMENTS DISTRIBUTION

REFERENCES 133

APPENDIX A WINIFREDE COAL AGGLOMERATION RESULTS A-1

APPENDIX B ELKHORN NO. 3 COAL AGGLOMERATION RESULTS B-1

APPENDIX C SUNNYSIDE COAL AGGLOMERATION RESULTS C-1

APPENDIX D TAGGART COAL AGGLOMERATION RESULTS .......................... D-1

APPENDIX E INDIANA VII COAL AGGLOMERATION RESULTS ............................ E-1

APPENDIX F HIAWATHA COAL AGGLOMERATION RESULTS ............................F-1 


\section{List of Tables}

\section{Table}

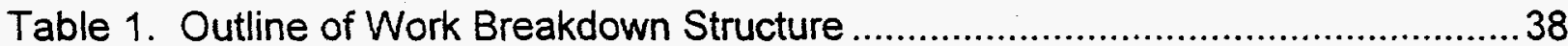

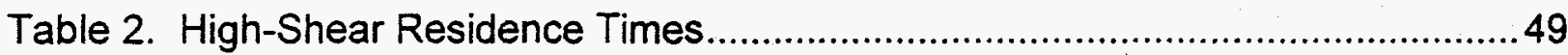

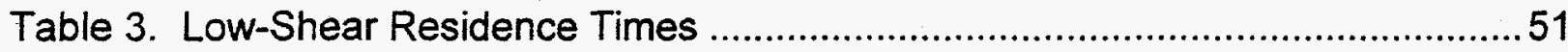

Table 4. Test Coal Selection and Characterization .................................................59

Table 5. Initial Test Coal PSD Liberation Requirements ..........................................60

Table 6. Subtask 6.5 Particle Size Distributions Evaluated .......................................60

Table 7. Winifrede Coal Grinding PSDs and Batch Test Product Ash Values .............66

Table 8. Winifrede Coal Particle Size Distribution ..................................................... 72

Table 9. Elkhorn No. 3 Coal Particle Size Distribution............................................... 76

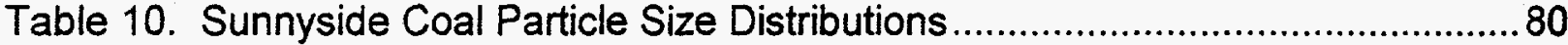

Table 11. Sunnyside Coal High-Shear Requirements for Inversion ..............................81

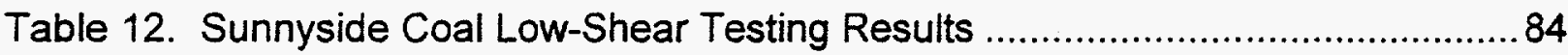

Table 13. Sunnyside Coal Batch Low-Shear Rinsing Results .................................. 85

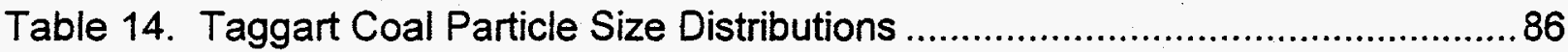

Table 15. Taggart Coal High-Shear Requirements for Inversion .................................87

Table 16. Taggart Coal Batch Low-Shear Rinsing Results ....................................... 88

Table 17. Indiana VII Coal Particle Size Distributions ................................................91

Table 18. Hiawatha Coal Particle Size Distributions.................................................94

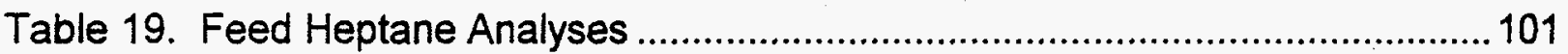

Table 20. Hydrocarbon Distribution for Various Stripped Products ...........................103

Table 21. Preliminary Batch Stripping Test Results ............................................. 105

Table 22. Batch Stripper Testing - Various Hydrocarbons ..................................... 105

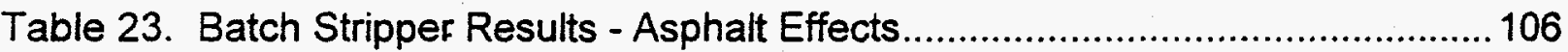

Table 24. Batch Stripper Results - Pressure Effects ........................................... 107

Table 25. CWF Residual Heptane Concentration .................................................108 


\section{List of Tables (Cont'd)}

Table

Page

Table 26. Batch Stripper - Solids Concentration Effect 108

Table 27. Preliminary Continuous Stripping Results 114

Table 28. Continuous Single-Stage Steam Stripping Conditions and Results 115

Table 29. Two-Stage Stripper Testing Results 117

Table 30. Subtask 6.5 Tests Used for Trace Elements Analysis 119

$\checkmark$ Table 31. Selective Agglomeration Trace Element Concentration Results 120

Table 32. Impurities in Clean Coals - Agglomeration / Flotation Comparison 126

Table 33. Agglomeration Results Summary 128 


\section{List of Figures}

Figure

Page

Figure 1. Project Management Organization Chart .37

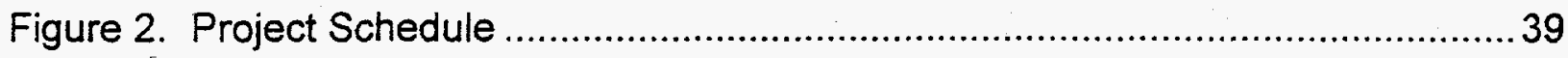

Figure 3. Bench-scale Unit Block Flow Diagram.................................................. 48

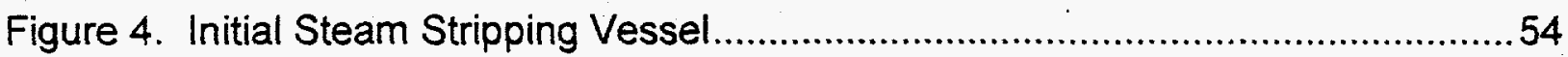

Figure 5. Taggart Coal Batch Testing - Product Ash vs Grind Size ............................63

Figure 6. Hiawatha Coal Batch Testing - Product Ash vs Grind Size .........................64

Figure 7. Indiana VII Coal Batch Testing - Product Ash vs Grind Size .......................65

Figure 8. Winifrede Coal Continuous Agglomeration Results.................................73

Figure 9. Winifrede Coal - Agglomerate Size vs Product Ash ..................................75

Figure 10. Winifrede Coal - Agglomerate Size vs Product Solids Concentration .........75

Figure 11. Elkhorn No. 3 Coal Continuous Agglomeration Results ............................77

Figure 12. Elkhorn No. 3 Coal - Agglomerate Size vs Product Ash .............................79

Figure 13. Sunnyside Coal Continuous Agglomeration Results ................................ 82

Figure 14. Sunnyside Coal - Agglomerate Size vs Product Ash................................85

Figure 15. Taggart Coal Continuous Agglomeration Results...................................... 89

Figure 16. Indiana VII Coal Continuous Agglomeration Results..............................92

Figure 17. Hiawatha Coal Continuous Agglomeration Results ....................................95

Figure 18. Hiawatha Coal - Aggiomerate Size vs Product Ash ...................................96

Figure 19. Hiawatha Coal - Product Solids Concentration vs Product Ash ...................96

Figure 20. Hiawatha Coal - Agglomeration Solids Concentration Effect.......................97

Figure 21. Residual Toxic Trace Elements in Clean Coals .................................... 121 


\section{EXECUTIVE SUMMARY}

This project is a major step in the Department of Energy's (DOE) program to show that ultra-clean coal-water-slurry fuel (CWF) can be produced from selected coals and that this premium fuel will be a cost-effective replacement for oil and natural gas now fueling some of the industrial and utility boilers in the United States, as well as for advanced combustors currently under development. The replacement of oil and gas with CWF can only be realized if retrofit costs are kept to a minimum and retrofit boiler emissions meet national goals for clean air. These concerns establish the specifications for maximum ash and sulfur levels and combustion properties of the CWF.

This multi-year cost-share contract started on October 1, 1992, and is scheduled for completion by September 30, 1997.

\section{SPECIFIC OBJECTIVES OF PROJECT}

The project has three major objectives:

- The primary objective is to develop the design base for prototype commercial advanced fine coal cleaning facilities capable of producing ultra-clean coals suitable for conversion to coal-water-slurry fuel for premium fuel applications. The fine coal cleaning technologies to be used are advanced column flotation and selective agglomeration.

- A secondary objective is to develop the design base for near-term application of these advanced fine coal cleaning technologies in new or existing coal preparation plants to efficiently process minus 28-mesh coal fines and convert them to marketable products in current market economics.

- A third objective is to determine the removal of toxic trace elements from coal by advance column flotation and selective agglomeration technologies.

\section{APPROACH}

The project team consists of Cyprus Amax Minerals Company through its subsidiaries Amax Research \& Development Center (Amax R\&D) and Cyprus Amax Coal Company (Midwest and Cannelton Divisions), Arcanum Corporation, Bechtel Corporation, Center for Applied Energy Research (CAER) of the University of Kentucky, and the Center for Coal and Mineral Processing (CCMP) of the Virginia Polytechnic Institute and State University. Entech Global manages the project for Amax R\&D and provides research and development services. Dr. Douglas Keller of Syracuse University and Dr. John Dooher of Adelphi University are both consultants to the project.

The project effort has been divided into four phases which are further divided into eleven tasks including coal selection, laboratory and bench-scale process optimization research and testing, along with design, construction, and operation of a 2 ton/hr 
process development unit (PDU). Tonnage quantities of the ultra-clean coals are being produced in the PDU for combustion testing. Near-term application of advanced cleaning technologies to existing coal preparation plants was also studied.

\section{TASK 6 STATUS}

Task 6 of this project, investigating the engineering development of the selective agglomeration process, consisted of six separate Subtasks. They have all been completed. The main finding of each subtask is summarized below.

During Subtask 6.1 Agglomerating Agent Selection, a wide range of agglomerating agents were evaluated for use during selective agglomeration. As a result of this work heptane and pentane, two light hydrocarbons, were selected for further investigation.

Subtask 6.2 Selective Agglomeration Grinding investigated various grinding circuit configurations, evaluating their applicability to the selective agglomeration process. Results from this subtask determined the degree of grinding necessary to insure that product grade requirements are met by the selective agglomeration process.

While some of the Subtask 6.3 Selective Agglomeration Process Optimization Research was carried out in the batch mode, most of the work was completed in a continuous laboratory agglomeration system. This work evaluated the effect of several process variables on agglomeration performance, operability, and product quality, resulting in the selection of heptane for further investigation.

The findings of Subtask 6.4 Selective Agglomeration CWF Formulation Studies indicated that coal loadings in the 60 to $62 \%$ range $(8800$ to $9300 \mathrm{Btu} / \mathrm{lb})$ are required for oil and gas retrofit applications, and that the slurry should have a viscosity of less than $500 \mathrm{cP}$. Slurry fuels meeting these requirements were prepared from all project coals except the Indiana VII and Winifrede, for which slurry loadings were less than $52 \%$ due to the fine grinding required.

The Subtask 6.5 Bench-Scale Testing and Process Scale-up test work has been completed and the document in hand represents the findings of this work. Specifically, this report presents the operating conditions and results for the continuous $25 \mathrm{lb} / \mathrm{hr}$ bench-scale test unit.

The Subtask 6.6 Conceptual Design of the PDU Selective Agglomeration Module was based on the past experience of project team members and the project results available at the time. This design was later revised during the detailed design of the $2 \mathrm{thr}$ PDU selective agglomeration module under Task 7 , taking into consideration additional data from the Subtask 6.5 testing. 


\section{SUBTASK 6.5 OBJECTIVES AND APPROACH}

Subtask 6.5 had three primary objectives:

1. Design, construct, and operate a continuous selective agglomeration system of about $25 \mathrm{lb} / \mathrm{hr}$ capacity to demonstrate the feasibility of the process.

2. Optimize the selective agglomeration process conditions to minimize product ash contents, and reduce process costs.

3. Generate design data of sufficient reliability to insure successful scale-up of the process to the process development unit (PDU) 2 thr scale.

These objectives were achieved through bench-scale testing on coals selected during Task 2. The basis for this work stemmed from the results obtained during Subtask 6.3 Process Optimization Research testing.

The bench-scale unit utilized during the Subtask 6.5 was of sufficient size to produce at least $25 \mathrm{lb} / \mathrm{hr}$ of agglomerated product (dry basis), and capable of processing all project coals. This testing utilized heptane as the agglomerant, or bridging liquid, which was recovered via steam stripping for recycle to the process.

To simplify operation of the continuous bench-scale unit, coal grinding was carried out independently of agglomeration testing. Once finely ground to achieve the required liberation, the coal slurry was subjected to a high-shear unit operation in which intense mixing dispersed the bridging liquid (heptane) and provided sufficient heptane/coal and coal/coal contact to achieve a phase inversion and form what are termed "microagglomerates". These microagglomerates were then subjected to additional mixing in a low-shear unit operation allowing the agglomerates to grow to a sufficient size for physical recovery by screening. Once formed, the agglomerates were dewatered, rinsed, and recovered on a vibrating screen. The mineral impurities remained dispersed in the water (screen underflow).

Recovery of the heptane from the agglomerated product was achieved in two stages of steam stripping. In the first stage, the reslurried agglomerates were steam stripped at ambient pressure boiling temperatures removing the bulk of the heptane. In the second stage, the slurry was subjected to additional steam stripping at elevated temperatures and pressures removing additional heptane. The recovered vapor (heptane and water) was then condensed, cooled, separated into separate heptane and water streams by gravity settling, and recycled for reuse in the process.

\section{SELECTIVE AGGLOMERATION PROCESS DESCRIPTION}

Selective agglomeration is based on the differences in surface properties of the coal and its associated mineral impurities. Generally, coal particles are hydrophobic or repel water, while the mineral impurities associated with coal are hydrophilic or easily wetted by water. As such, when a hydrocarbon based agglomerant is added to a finely divided 
coal water slurry, the carbon containing coal particles are coated by the agglomerant while the mineral matter remains dispersed in the water phase.

The agglomerant used during this process can range from "heavy" organic liquids like fuel oil No. 2, to "light" hydrocarbons such as heptane. The particular type of agglomerant used depends on a number of factors, but is primarily influenced by the feed coal characteristics, process economics, and the required product quality. Depending on the type and quantity of agglomerant used, it is either allowed to remain with the product or recovered and recycled to the process. When using heavier agglomerants such as fuel oil, the quantity used is minimized and allowed to remain with the product. When a light hydrocarbon such as heptane is used, however, the quantity used is not critical since it must be recovered from the product and recycled to the process for health, safety, environmental, and economic reasons.

The process consists of the following four major unit operations.

\section{High-Shear Agglomeration}

During high-shear agglomeration, a mixture of water, coal, and heptane is vigorously agitated, at impeller tip speeds in the 10 to $18 \mathrm{~m} / \mathrm{s}$ range, such that the heptane disperses and makes contact with the coal particles in the slurry. Throughout this agitation, hydrophobic coal particles are attracted to the heptane phase, while the hydrophilic mineral matter is repelled from the heptane and attracted to the water phase. With continued mixing, the heptane coated coal particles coalesce to form microagglomerates, while the mineral impurities remain dispersed in the water phase.

\section{Low-Shear Agglomeration}

Following high shear, the microagglomerates undergo low-shear agglomeration at shear rates in the 3 to $5 \mathrm{~m} / \mathrm{s}$ impeller tip speed range resulting in agglomerate growth. The low-shear heptane dosage, shear rate, solids concentration, and residence time are tailored to produce agglomerates of the desired size, typically 2 to $3 \mathrm{~mm}$.

\section{Agglomerate Recovery}

Agglomerates formed during low shear are then recovered on a vibrating screen with the primary goal of achieving high energy recovery minimizing both coal losses to the tailings and heptane contamination of the tailings. Secondary agglomerate recovery from the screen underflow (tailings) is achieved in a froth skimmer in which any floating carbonaceous material is recovered and combined with the product stream.

\section{Heptane Recovery and Recycle}

Once agglomerates are recovered by screening and froth skimming, the heptane is removed from this product by direct contact steam stripping in two stages. During this 
process, steam evaporates both heptane and water. From this vapor, the two liquids (heptane and water) are then condensed, cooled, separated, and recycled.

\section{BENCH-SCALE UNIT DESCRIPTION}

The bench-scale unit was designed to produce about $50 \mathrm{lb} / \mathrm{hr}$ of product on a dry basis. This design insured that a processing rate of $25 \mathrm{lb} / \mathrm{hr}$ could be achieved for coals requiring longer residence times. While the test unit was capable of evaluating the agglomeration process continuously, the grinding, steam stripping, and final product dewatering steps were normally carried out separately. As such, the test unit included storage for both the ground feedstock prior to agglomeration and the recovered product prior to steam stripping.

\section{Coal Grinding and Feed System}

Coals were typically ground to the appropriate size in large batches in a 4-foot $x$ 4-foot ball mill with additional size reduction achieved in a Drais stirred-ball mill. Some coals were also ground in the $2 \mathrm{t} / \mathrm{hr}$ Process Development Unit (PDU). Ground slurry was then transferred to one of two agitated 55-gallon feed drums where it was diluted to the desired solids concentration. From these feed drums, the slurry was metered to the process (high-shear agglomeration vessel).

\section{High-Shear Agglomeration}

The high-shear unit operation was designed to provide the following:

- Complete dispersion of the heptane agglomerant

- Sufficient heptane/coal contact to coat the coal with heptane

- Sufficient particle to particle contact, insuring formation of microagglomerates (phase inversion).

In order to meet these objectives for all project coals, the high-shear vessel design was based on the requirements for the Indiana VII coal, the coal needing the longest residence time ( 2 to 3 minutes). Shear in high shear was provided by a single radial flow impeller located in the center of the vessel. Impeller tip speeds evaluated were in the 5 to $18 \mathrm{~m} / \mathrm{s}$ range. Heptane was added prior to high shear. When necessary to promote agglomeration, asphalt in the form of an emulsion was also added.

\section{Low-Shear Agglomeration}

Based on previous experience, the low-shear vessel was designed to provide a residence time of 5 minutes, insuring agglomerate growth to sufficient size. This vessel, through the application of a centrally located horizontal baffle, provided two 
separate low-shear mixing zones. Shear was provided by two radial flow impellers on a single shaft, each located in the center of each mixing zone.

\section{Agglomerate Recovery}

Primary agglomerate recovery was carried out on a 10 -inch $\times 16$-inch vibrating screen with adjustable inclination, a 48- or 100-mesh screen deck, and water sprays. The tailings (screen underflow) discharged into a froth skimming column designed to recover any carbonaceous heptane bearing material from the tailings into the product. During typical bench-scale operations, however, the material recovered in the froth skimmer was collected for disposal and not evaluated continuously.

\section{Heptane Removal}

Heptane was removed from the agglomerated product by direct contact steam stripping in two stages, where both heptane and water were evaporated simultaneously. The heptane recovery circuit was capable, through the use of an intermediate feed tank, of complete integration with the preceding agglomeration system allowing the entire bench-scale unit to be operated simultaneously.

\section{Single-Stage Stripper}

During initial testing, a single stage of steam stripping was used. This stripping vessel was a 4-inch diameter column approximately 52 inches tall. A portion of this column was filled with packing (5/8-inch stainless steel pall rings). Steam entered the column below the packing and the vapor (heptane and water) exited from the top, while the agglomerated feed entered the top of the column and discharged from the bottom. This provided a steam flow counter-current to the process slurry.

\section{Two-Stage Stripper}

For later testing, the stripping circuit was modified to include a new stripping vessel installed prior to the above described column. This allowed the bulk of the heptane to be removed in the new first-stage stripper followed by additional heptane removal in the column, which was modified to operate at elevated pressures and temperatures. This two-stage circuit better simulated the developing 2 thr PDU stripping circuit design and also used a counter-current steam flow scenario.

\section{Heptane Recovery}

The exiting vapor stream from the steam stripping circuit was condensed in a tube coil submersed in a water bath that was serviced by sufficient utility water to also cool the condensed heptane/water stream. Once condensed and cooled, this heptane/water 
mixture was separated by gravity in a column where the heptane (s.g. $=0.7)$ overflowed from the top and the water was removed from the bottom.

\section{Product and Tailings Dewatering}

Due to the small scale of the test unit, a continuous integrated dewatering system was not provided. Therefore, bulk quantities of product were stored in existing tanks and later dewatered by available pilot-scale equipment. The process tailings were also dewatered in existing pilot-scale equipment.

\section{Nitrogen Blanketing System}

Due to the volatility and explosiveness of heptane and its vapor, respectively, a nitrogen blanketing system was included during initial construction of the bench-scale agglomeration unit. During operations, however, it was found that its application to the small bench-scale unit was impractical causing operational difficulties. Due to these problems and the small amounts of heptane present in the system, the nitrogen blanket system was not used for the bulk of the Subtask 6.5 testing.

\section{Data Acquisition System}

An on-line data acquisition system was included in the selective agglomeration test unit. This system allowed real-time data acquisition of operating temperatures and provided a data log into which manually obtained operating conditions were entered.

\section{Agglomeration Testing and Characterization Equipment}

Additional test equipment used during the course of Subtask 6.5, which were not an integral part of the test unit, included various grinding, dewatering, and analytical equipment.

\section{Agglomeration Reagents}

The primary reagent used was the agglomerant heptane which was added prior to high shear. Both a commercial grade heptane (about $28 \% \mathrm{n}$-heptane) and a pure grade heptane (>99\% n-heptane) were utilized. Asphalt, in the form an emulsion, was also used since it was found to be an effective agglomeration aid for oxidized or difficult to agglomerate coals like the Indiana VII.

\section{Process Characterization}

For each test run, feed, product, tailings, and other various streams were sampled and analyzed for ash and solids concentration to determine overall process as well as individual unit operation performance. Flowrates of various streams were also 
measured to allow calculation of operating conditions such as residence times. Heptane contents of product and tailings were also determined as required.

\section{RESULTS AND DISCUSSION}

\section{Test Coals}

Prior to the start of Subtask 6.5 testing, it was determined that the low-rank Dietz coal would not be evaluated due to the combination of the long high-shear residence time, high asphalt dosage, and low $\mathrm{pH}$ required to achieve agglomeration. As such, benchscale testing focused on the five remaining project coals as well as the Hiawatha coal which was chosen as a replacement for the no longer available Sunnyside coal. These six coals are shown below along with their ranks and sources.

\begin{tabular}{|c|c|c|c|}
\hline Coals Seam & Rank & State & Source Mine \\
\hline Taggart & hvA Bituminous & Virginia & h \\
\hline Indiana VII & hvC Bitu & India & Minnehaha \\
\hline $\begin{array}{l}\text { Sunnyside } \\
\text { Winifrede }\end{array}$ & hvA Bituminous & Utah & Sunnyside \\
\hline Winifrede & hvA Bituminous & West Virginia & Sandlick \\
\hline $\begin{array}{c}\text { Elkhorn No. } 3 \\
\text { Hiawatha }\end{array}$ & $\begin{array}{l}\text { hvA Bituminous } \\
\text { hvA Bituminous }\end{array}$ & $\begin{array}{l}\text { Kentucky } \\
\text { Utah }\end{array}$ & $\begin{array}{c}\text { Chapperal } \\
\text { Crandall Creek }\end{array}$ \\
\hline
\end{tabular}

\section{Grinding Requirements}

The table below summarizes all of the particle size distributions (PSDs) evaluated during Subtask 6.5 continuous testing by showing 20,50 , and 80 percent passing sizes $\left(D_{20}, D_{50}\right.$, and $\left.D_{80}\right)$, as well as the mass mean diameter (MMD) for each feedstock. Also shown is an indication as to whether each PSD provided sufficient mineral-matter liberation to meet the project ash target of $2 \mathrm{lb} / \mathrm{MBtu}$ ( $1 \mathrm{lb} / \mathrm{MBtu}$ for the Taggart coal).

\begin{tabular}{|c|c|c|c|c|c|}
\hline \multirow[b]{2}{*}{ Coal } & \multicolumn{4}{|c|}{ Microns } & \multirow[b]{2}{*}{ Ash Target Met } \\
\hline & $\underline{\mathrm{D}}_{20}$ & $\underline{\underline{D}}_{50}$ & $\underline{D}_{80}$ & MMD & \\
\hline \multirow{4}{*}{ Taggart } & 8.9 & 28.1 & 90.8 & 50.7 & No \\
\hline & 8.8 & 26.8 & 64.9 & 36.9 & No \\
\hline & 12.6 & 38.0 & 74.7 & 45.7 & No \\
\hline & 5.9 & 16.2 & 32.8 & 23.0 & Yes \\
\hline \multirow[t]{2}{*}{ Sunnyside } & 8.0 & 24.9 & 59.6 & 34.3 & Yes \\
\hline & 6.5 & 19.5 & 42.9 & 25.1 & Yes \\
\hline \multirow[t]{2}{*}{ Indiana VII } & 4.2 & 12.0 & 24.1 & 14.6 & Yes \\
\hline & 4.2 & 10.8 & 26.0 & 16.4 & No \\
\hline \multirow{4}{*}{$\begin{array}{l}\text { Elkhorn No. } 3 \\
\text { Winifrede } \\
\text { Hiawatha }\end{array}$} & 10.7 & 29.6 & 68.0 & 39.4 & Yes \\
\hline & 2.0 & 4.2 & 12.4 & 7.1 & Yes \\
\hline & 11.5 & 32.9 & 65.2 & 40.9 & Yes \\
\hline & 8.1 & 22.5 & 46.6 & 27.4 & Yes \\
\hline
\end{tabular}




\section{Batch Agglomeration Testing}

Batch agglomeration tests were performed on samples of various ground feedstocks to evaluate the liberation characteristics of each grind produced. Generally, slightly lower product ash levels were achieved in the continuous unit than during the batch tests.

\section{Winifrede Coal}

The Winifrede coal was ground in the 4-foot $x$ 4-foot ball mill in open circuit followed by additional grinding in a Drais stirred-ball mill. The resulting PSD had a $D_{80}$ of about 12 microns and was sufficiently fine to produce a batch testing product ash content of 1.8 $\mathrm{lb} / \mathrm{MBtu}$, surpassing the $2 \mathrm{lb} / \mathrm{MBtu}$ project goal. Due to the fineness of this grind, several tests were completed to determine if the agglomeration promoter 2-ethyl-1hexariol would reduce the time required to achieve inversion during high shear. Results indicated no significant reduction in inversion time.

\section{Elkhorn No. 3 Coal}

The Elkhorn No. 3 coal was ground in the 4-foot $x$ 4-foot ball mill in closed circuit with a 100 -mesh screen providing a PSD with a $D_{80}$ of 68 microns. Batch test results with this feedstock resulted in a product ash content of $1.7 \mathrm{lb} / \mathrm{MBtu}$, easily meeting the $2 \mathrm{lb} / \mathrm{MBtu}$ product ash content target.

\section{Taggart Coal}

Batch agglomeration testing for the Taggart coal focused on determining the liberation requirements to achieve a $1 \mathrm{lb}$ ash/MBtu product. The Taggart coal was ground by several methods including batch grinding in the attritor mill, closed-circuit grinding in the 4-foot $x$ 4-foot ball mill at two different top sizes, and continuous grinding in the $2 \mathrm{thr}$ PDU grinding circuit under a variety of conditions. Results of this work indicated that the poorest liberation (highest product ash content at a similar $D_{80}$ ) was achieved from the batch attritor grinding. In contrast, the best liberation (lowest product ash content at a similar $D_{80}$ ) was achieved from grinding in the $2 \mathrm{t} / \mathrm{hr}$ PDU. This improvement in mineral-matter liberation, at similar overall grind sizes, is attributed to selective regrinding of coarse higher ash material, via cyclone separation, in the PDU grinding circuit.

Of the various ground feedstocks evaluated, only the finest batch attritor grind $\left(D_{80}=15\right.$ microns) and the finest PDU grinds $\left(D_{80}=30\right.$ to 38 microns) met the $1 \mathrm{lb} / \mathrm{MBtu}$ product ash specification.

\section{Hiawatha Coal}

Batch agglomeration testing for the Hiawatha coal focused on determining the liberation requirements to achieve a $2 \mathrm{lb}$ ash/MBtu product. The Hiawatha coal was ground by 
several methods including closed-circuit grinding in the 4-foot $\times$ 4-foot ball mill at two different topsizes and continuous grinding in the $2 \mathrm{t} / \mathrm{hr}$ PDU under a variety of conditions. Batch tests results indicated that only one of the PDU ground feedstocks provided sufficient liberation to achieve the $2 \mathrm{lb} / \mathrm{MBtu}$ product ash specification. In contrast, both feedstocks prepared in the 4-foot $\times 4$-foot ball mill $\left(D_{80} S=65\right.$ and 47 microns) easily achieved the $2 \mathrm{lb} / \mathrm{MBtu}$ product ash specification.

\section{Indiana VII Coal}

Batch agglomeration testing for the Indiana VII coal evaluated feedstock prepared in the 2 thr PDU grinding circuit for the flotation module. Some additional work was completed on this same material further ground in a batch attritor mill. The results of these batch tests indicated that none of the PDU only ground feedstocks provided sufficient liberation to achieve the $2 \mathrm{lb} / \mathrm{MBtu}$ ash specification. However, when additional batch attritor mill grinding to a $D_{80}$ size of 20 microns was carried out, the product ash specification was met. This suggests that for the selective agglomeration module, the PDU grinding circuit will have to be operated in a way that will produce a finer grind.

\section{Continuous Agglomeration Testing}

\section{Procedures}

Ground slurry feedstock was prepared for continuous testing through a variety of grinding equipment and stored prior to its use. This slurry was then fed to the benchscale unit via a peristaltic pump with average feed slurry flowrate, ash, and solids concentration determinations used for process evaluation.

Once target operating conditions were set, the system was allowed to balance for a minimum of 45 to 60 minutes. During this time various process conditions were continually monitored to evaluate test progression. Once it was determined that the system had reached steady state, the low-shear discharge, screen overflow (product), and screen underflow (tailings) streams were measured and sampled. Typically, the ash, solids content, and PSD of these samples were determined as well as the size and shape of the agglomerates in the low-shear discharge.

In addition, the screen underflow or tailings samples were processed to separately determine the ash content of the material found floating on the sample, as well as the remaining portion of the sample. This floating material was then treated as froth skimmer product and included as part of the product stream for test performance determination. 


\section{Data Evaluation}

Based on the analytical results and operating data obtained for each test, process operating conditions and performance were calculated. Solids feed rate was based on the feed flowrate measurement and solids content, while test yield was calculated by ash balance from feed, product, and tailings ash values. Heptane dosage calculations were based on heptane flowmeter readings. System residence times were calculated based on solids flowrates and solids content determinations. Mixer impeller tip speeds were calculated from rpm measurements.

Test Btu recoveries were determined from feed and product Btu values which were calculated from an ash/Btu relationship developed for each coal. Run-of-Mine (ROM) performance, where applicable, was calculated based on preparation plant performance determined from the data provided by the coal supplier.

\section{Start-Up Testing and System Modifications}

The Taggart coal ground to a 62-mesh topsize was used for initial startup of the benchscale agglomeration unit. A variety of conditions were tested to evaluate system operability. Upon initial startup of the unit, the majority of the equipment was found to work well. The following is a description of major problems encountered and modifications made to improve the operability of the system.

Feed Slurry Delivery - While the agglomeration circuit slurry delivery system operated well with no plugging problems experienced, it was found that during testing the slurry feed rate decreased slightly from the beginning to the end of a test. As such, an average feed rate for the entire test run was used.

Heptane Delivery - During the initial test of the agglomeration unit, the heptane was overdosed due to problems with the heptane flowmeter. It was found that moving the heptane flowmeter to the suction side of the heptane pump resulted in accurate and consistent heptane flow readings, alleviating this problem.

High Shear - It was found upon initial startup that the high-shear vessel, when operated with the impellers and at the rpms anticipated, had a much greater power draw than expected. This was due to greater than anticipated system power losses attributed primarily to the drive motor inefficiency and shaft friction. However, the high-shear reactor still worked well over a wide range of feed conditions achieving inversion at coal feed rates of 25,50 , and $75 \mathrm{lb} / \mathrm{hr}$.

Low Shear - During initial testing it was found that depending on the impeller tip speed, residence time, and heptane/coal ratio used, the low-shear product varied in size from 0.5 to $5 \mathrm{~mm}$ and that agglomerate size could be controlled by the heptane dosage with higher dosages resulting in larger agglomerates.

Much difficulty was encountered when operating the low-shear vessel full, i.e., when using both mixing zones separated by the horizontal baffle to achieve longer residence 
times. Since the transfer of agglomerates from the lower to the upper mixing zone was the bottleneck, the horizontal baffle opening was increased from 1-1/2 to 5-1/2 inches in diameter. While this modification resulted in marginally better transfer from the lower to upper zone, plugging of the lower zone still occurred. As such, consistent day to day steady state operation of the low-shear vessel full was never achieved. When operating full, plugging of the lower zone occurred unless starvation quantities of heptane were used. Under these extended residence time conditions, however, lowshear growth was very sensitive to heptane dosage and proved uncontrollable. Also under these conditions, a cyclic low-shear agglomerate growth pattern was observed in which consistent agglomerate size was never achieved.

When the low-shear product approached 4 to $6 \mathrm{~mm}$ in size, it ceased to flow through the 1-inch discharge ports since it was approaching the critical size (1/4 to $1 / 6$ of the port diameter). Also since the overflow discharge arrangement used withdrew from a stagnant section of the vessel, even smaller agglomerates sometimes plugged the discharge. To remedy this problem, the discharge ports were relocated below the liquid surface and an up-flowing discharge pipe used to maintain the operating level. While this modification did improve discharge, some plugging still occurred.

To eliminate plugging of the low-shear vessel discharge, two other sets of discharge ports were installed. The first set was 2 -inches in diameter and located to allow an overflow discharge. While these worked well for agglomerate discharge, under half full operation excessive splashing disrupted the mixing pattern and no growth occurred.

The second set was 1 -inch in diameter and located at the same elevation as the impellers utilizing an up-flowing discharge to maintain the slurry level. Using these ports and half full operation, steady-state operation was consistently achieved. It should be noted that this successful operation of the low-shear vessel half full, utilizing the discharge port located at the impeller height, was not tested until near the end of the Subtask 6.5 work. As such, the discharge plugging problems described above hindered testing for some of the coals evaluated.

Low-shear discharge plugging problems were found to be more pronounced at higher solids concentrations where at the same volumetric system flowrate the solids flow through the discharge port increased thereby increasing the chance for plugging.

Vibrating Screen - Operation of the vibrating screen for recovery of the agglomerated low-shear product generally worked well with only minimal blinding of the 48-mesh screen deck observed. Generally, the use of spray water on the screen resulted in more coal reporting to the screen tailings. It was determined that both the amount of wash water used and the nature of the spray pattern influenced the amount of coal in the screen underflow. As such, finer spray nozzles (misting type) were installed reducing this problem. 


\section{Winifrede Coal Results}

Since at the time of testing, it was already known that the Winifrede coal would not be evaluated during $2 \mathrm{t} / \mathrm{hr}$ PDU testing, only limited test work was completed with this coal. Work focused on developing the continuous operating conditions necessary to meet the project $2 \mathrm{lb} / \mathrm{MBtu}$ product ash specification.

The Winifrede coal was ground in the 4-foot $x$ 4-foot ball mill in open circuit, followed by additional grinding in the Drais stirred-ball mill resulting in a $D_{80}$ of 12 microns. Sixteen continuous agglomeration tests were carried out with this feedstock using both fresh commercial grade heptane and recycled commercial grade heptane, i.e., heptane recovered from previous test work. Following is a list of primary operating condition ranges tested for the Winifrede coal:

- Feedstock $D_{80}-12$ microns

- Coal feed rate -12 to $32 \mathrm{lb} / \mathrm{hr}$

- Feed slurry solids concentration - 7 and $10 \%$

- Heptane dosage -52 to $62 \%$ on a dry ash free coal basis

- Asphalt addition level $-5 \mathrm{lb} /$ ton coal

- High-shear impeller tip speed - 15 to $20 \mathrm{~m} / \mathrm{s}$

- High-shear residence time - 1 to 2 minutes

- Low-shear impeller tip speed -5 to $10 \mathrm{~m} / \mathrm{s}$

- Low-shear residence time - 3 to 7 minutes

The $2 \mathrm{lb}$ ash/MBtu product specification was met in many of the tests completed, indicating that the 12 micron $D_{80}$ grind provided sufficient mineral-matter liberation, confirming the batch testing results. Results also indicated that very high Btu recoveries (>99\%) were achieved with tailings ash values in the 47 to $89 \%$ range, with most in the 78 to $89 \%$ range.

No difference in the operation of the unit was observed when fresh heptane was used as compared to recycled heptane, indicating that the quality of heptane did not degrade when vaporized, condensed and recycled to the process.

During virtually all of the Winifrede coal testing, only marginal phase inversion was achieved during high shear due to the extreme fineness of the coal and the inability of the high-shear reactor to provide higher energy inputs. Although good inversion could not be achieved, agglomerate growth during low shear was still sufficient to afford good recovery during screening as indicated by the high Btu recoveries achieved.

During this testing it was found that the greatest effect on product ash content was the size of the agglomerates produced with larger agglomerates resulting in lower product ash levels. This is due to better drainage of mineral matter bearing process water from the larger agglomerates than from the smaller agglomerates. Similarly, it was found 
that the screen product solids concentration was also a function of agglomerate size with the larger agglomerates having less moisture associated with them.

Unfortunately, the relationship between agglomerate size and product ash content masked any other variable effects on product ash levels. This is especially true since almost any other process variable change made, while holding all other conditions constant, affected agglomerate growth in low shear.

\section{Elkhorn No. 3 Coal Results}

The Elkhorn No. 3 coal was closed-circuit ground to a 100-mesh topsize in the 4-foot $x$ 4-foot ball mill resulting in a $D_{80}$ of 68 microns. A total of 32 agglomeration test runs were completed with this coal covering the following primary operating condition ranges:

- Feedstock $D_{80}-68$ microns

- Coal feed rate -17 to $33 \mathrm{lb} / \mathrm{hr}$

- Feed slurry solids concentration - 7, 10, and $13 \%$

- Heptane dosage - 23 to $35 \%$ on a dry ash free coal basis

- High-shear impeller tip speed - 12 to $18 \mathrm{~m} / \mathrm{s}$

- High-shear residence time - 1 to 2 minutes

- Low-shear impeller tip speed -4.8 and $8 \mathrm{~m} / \mathrm{s}$

- Low-shear residence time - 3.4 to 9.4 minutes

The $2 \mathrm{lb}$ ash/MBtu product specification was met for all but one of the tests completed (1.7 to $1.9 \mathrm{lb} / \mathrm{MBtu}$ ), indicating that the 100 -mesh topsize grind provided sufficient mineral-matter liberation. Btu recoveries achieved were in the 88 to $98 \%$ range, with corresponding tailings ash values in the 25 to $65 \%$ range. These relatively low Btu recoveries and tailings ash values are attributed to oxidation of the Elkhorn No. $3 \mathrm{coal}$ which had been stored for over two years prior to its use for this work. To overcome this effect, asphalt was used to enhance agglomeration resulting in higher Btu recoveries (98.7 to $99.1 \%$ ) and tailings ashes (67 to $73 \%$ ).

\section{Sunnyside Coal Results}

The Sunnyside coal was closed-circuit ground in the 4-foot $\times 4$-foot ball mill with 100 and 150 -mesh screens resulting in $D_{80}$ s of 60 and 43 microns, respectively.

High-Shear Evaluation - As part of the Sunnyside coal testing, an evaluation of highshear mixing requirements to achieve inversion was carried out. This testing utilized both the 100- and 150-mesh topsize feedstocks and two different high-shear impellers. Testing was completed to determine the minimum high-shear impeller tip speed required to achieve inversion at various coal feed rates and solids concentrations. Trends observed during this work included: 
- As residence time in high shear decreases, impeller tip speed must be increased to maintain inversion.

- As solids concentration increases, lower impeller tip speeds are required to achieve inversion.

- The 2.4-inch diameter impeller draws less power to achieve inversion than the 3.6-inch impeller.

Continuous Test Results - A total of 18 tests were completed with the Sunnyside coal utilizing both feedstocks. Following is a list of primary operating variable ranges tested:

- Feedstock $D_{80}-60$ and 43 microns (100- and 150-mesh topsizes)

- Coal feed rate -24 to $49 \mathrm{lb} / \mathrm{hr}$

- Feed slurry solids concentration $-5,7,10$, and $13 \%$

- Heptane dosage -25 to $30 \%$ on a dry ash free coal basis

- High-shear impeller tip speed - 12 to $22 \mathrm{~m} / \mathrm{s}$

- High-shear residence time -0.7 to 1.5 minutes

- Low-shear configuration - Half full and full

- Low-shear residence time -1.8 to 7.3 minutes

Two of the four 100-mesh topsize tests achieved the $2 \mathrm{lb} / \mathrm{MBtu}$ product ash specification at high Btu recoveries $(>98 \%)$. This testing showed that lower product ash contents were achieved at solids concentrations of 5 and $7 \%$ than at 10 and $13 \%$. All but one of the 150-mesh topsize tests achieved the product ash specification of 2 $\mathrm{lb} / \mathrm{MBtu}$, indicating that both grinds were sufficiently fine to meet the project goals.

Low-Shear Operation - During the Sunnyside coal testing, it was found that at impeller tip speeds of 3 to $5 \mathrm{~m} / \mathrm{s}$, agglomerates grew to 4 to $6 \mathrm{~mm}$ in diameter plugging the lowshear discharge. However, at 7 to $10 \mathrm{~m} / \mathrm{s}$ tip speeds these large agglomerates were not formed with low-shear growth proceeding in a cyclic manner with steady-state conditions never achieved. To eliminate this cyclic growth/reduction pattern, lower (starvation) heptane concentrations were tested and it was found that tip speeds of about $5 \mathrm{~m} / \mathrm{s}$ were required to produce well formed agglomerates, while tip speeds of 3 $\mathrm{m} / \mathrm{s}$ produced a powdery poorly formed product.

Agglomerate Size Effect - The lowest product ash contents were achieved when larger $(2$ to $4 \mathrm{~mm}$ ) agglomerates were produced, indicating that a product of this size has a lower water content, rejecting more of the mineral matter bearing process water during screen recovery.

Vibrating Screen - Testing to evaluate vibrating screen wash water requirements was completed by batch screening of low shear product samples at various wash water rates. This work was carried out to determine if substantially greater quantities of wash water would decrease the product ash content. For this work, a 1-liter sample of lowshear product was placed on an 8-inch 48-mesh test screen. Samples of this product were then taken after allowing the water to drain from the bed (no rinsing), rinsing the 
bed lightly with a spray bottle (about $500 \mathrm{ml}$ of water), and soaking the bed with a gentle water stream for 2 minutes.

Results indicated that some product washing (as represented by $500 \mathrm{ml}$ spray rinsing) was found to reduce the product ash by as much as $0.2 \%$. However, additional washing did not reduce the product ash content significantly.

\section{Taggart Coal Results}

Taggart coal testing was carried out using four different feedstocks. Two of these feedstocks were closed-circuit ground in the 4-foot $\times$ 4-foot ball mill with 62- and 100mesh screens resulting in PSDs with $D_{B O} S$ of 91 and 65 microns, respectively. The other two feedstocks were ground in the PDU grinding circuit producing feedstocks with $D_{80} S$ of 88 and 33 microns.

A total of 29 tests were completed with the various Taggart coal feedstocks. The following is a list of operating variable ranges tested:

- Feedstock $D_{80}-33,65,88$, and 91 microns

- Coal feed rate -17.5 to $50.5 \mathrm{lb} / \mathrm{hr}$

- Feed slurry solids concentration $-5,7,10$, and $13 \%$

- Heptane dosage - 22 to $35 \%$ on a dry ash free coal basis

- High-shear impeller tip speed -6.4 to $15.0 \mathrm{~m} / \mathrm{s}$

- High-shear residence time -0.5 to 1.5 minutes

- Low-shear impeller tip speed - 3 to $8 \mathrm{~m} / \mathrm{s}$

- Low-shear residence time -1.7 to 7.3 minutes

Results from this work showed that all four of the feedstocks met the $2 \mathrm{lb} / \mathrm{MBtu}$ product ash specification. However, only the finest grind tested $\left(D_{80}=33\right.$ microns) was able to achieve the $1 \mathrm{lb} / \mathrm{MBtu}$ product ash specification. The test unit operated well for the majority of the Taggart coal testing with all tests producing small but well formed agglomerates that screened easily. Btu recoveries were high $(>96 \%)$ for all of the tests with tailings ash values in the 32 to $83 \%$ range.

In comparing the two middle size grinds, 65 and 88 micron $D_{80}$ s, it is interesting to note that the coarser of these two feedstocks resulted in lower, product ash values. This trend was unexpected since typically, the finer the grind, the greater the mineral matter liberation. However, when comparing these two particular grinds, it should be noted that the coarser grind was produced in the PDU, where the bulk of the material being reground was the cyclone underflow stream. Conversely, the finer grind was produced in the 4-foot $x$ 4-foot ball mill operated in closed circuit with a 100-mesh screen, where the regrind material is the screen overflow stream. While the cyclone separation in the PDU grinding circuit is based primarily on size, the material specific gravity also affects the separation, with the underflow stream typically heavier and higher in ash. As such, 
selective regrinding of the higher ash material occurred, which in this case, resulted in a more liberated product as compared to the finer grind.

Low Shear Operation - As with operations utilizing other test coals, difficulties were encountered with plugging at the low-shear discharge. This plugging, however, was less pronounced when higher, $50 \mathrm{lb} / \mathrm{hr}$, coal feed rates were used indicating that the higher volumetric flowrate helped reduce plugging. As mentioned previously, low-shear discharge plugging was only eliminated by the use of discharge ports located at the same elevation as the impellers. In this scenario, the force of the impeller flow kept the agglomerates continuously discharging.

Difficulty was encountered when the low-shear vessel was operated full, i.e., when utilizing both mixing zones separated by a horizontal baffle. It appeared that the transfer of agglomerates from the lower to upper section of the low-shear vessel was a bottleneck. As such, the opening in the horizontal baffle was increased from 1-1/2 inches to 5-1/2 inches diameter to improve flow to the upper zone. While this modification proved moderately successful, steady operation of the low-shear vessel full was still not achieved.

\section{Indiana VII Coal Results}

Continuous agglomeration testing utilizing the Indiana VII coal was carried out using two different feedstocks. The first was ground in the 4-foot $\times$ 4-foot ball mill followed by additional grinding in the Drais stirred-ball mill $\left(D_{80}=22\right.$ microns). The second grind tested was produced in the PDU grinding circuit ( $D_{80}=26$ microns).

A total of 20 agglomeration circuit tests were completed using these two feedstocks. The following primary operating variable ranges were tested:

- Feedstock $D_{80}-22$ and 26 microns

- Coal feed rate -12.3 to $33.4 \mathrm{lb} / \mathrm{hr}$

- Feed slurry solids concentration $-7,10$, and $13 \%$

- Heptane dosage -30.0 to $35 \%$ on a dry ash free coal basis

- Asphalt dosage -7.5 to $20 \mathrm{lb}$ per ton feed coal

- High-shear impeller tip speed - 13.4 to $18.0 \mathrm{~m} / \mathrm{s}$

- High-shear residence time - 1 to 2 minutes

- Low-shear impeller tip speed - 3 to and $8 \mathrm{~m} / \mathrm{s}$

- Low-shear residence time -3.4 to 7.6 minutes

Results from this work showed that the product ash specification of $2 \mathrm{lb}$ ash/MBtu was met, at approximately $99 \%$ Btu recovery, for the $D_{80}=22$ micron feedstock, indicating that this grind size provided sufficient mineral-matter liberation. None of the tests carried out utilizing the PDU ground feedstock $\left(D_{80}=26\right.$ microns) met the $2 \mathrm{lb} / \mathrm{MBtu}$ product ash specification. 
The product ash specification was also not met for any of the tests completed using the 100 -mesh screen deck during agglomerate recovery, indicating that this finer screen size did not provide sufficient drainage of the mineral matter bearing process water as compared to the coarser 48-mesh screen. Other observations to be noted concerning agglomeration of the Indiana VII coal are as follows:

- The addition of 7.5 to $20 \mathrm{lb}$ asphaltton of coal was required to achieve phase inversion during high-shear agglomeration.

- Without this asphalt addition, no growth occurred during low shear resulting in no coal recovery.

- Approximately 30 to $35 \%$ heptane (dry ash free basis) was required to achieve high-shear inversion and low-shear growth.

- There was no clear effect of solids concentration on product ash content.

- The product ash content was most dependent on the agglomerate size, with larger better formed agglomerates having lower ash contents.

\section{Hiawatha Coal Results}

The Hiawatha coal was closed-circuit ground in the 4-foot $\times 4$-foot ball mill with 150 and 100- mesh screens resulting in $D_{80} s$ of 47 and 65 microns, respectively. A total of 27 tests were completed to evaluate Hiawatha coal covering the following range of primary operating variables:

- Feedstock $D_{80}-47$ and 65 microns

- Coal feed rate -17.5 to $75.8 \mathrm{lb} / \mathrm{hr}$

- Feed slurry solids concentration $-7,10$, and $13 \%$

- Heptane dosage -21.6 to $28.5 \%$ on a dry ash free coal basis

- High-shear impeller tip speed -6.7 to $18.0 \mathrm{~m} / \mathrm{s}$

- High-shear residence time -0.5 to 1.9 minutes

- Low-shear impeller tip speed -3.0 to and $8.0 \mathrm{~m} / \mathrm{s}$

- Low-shear residence time - 1.5 to 7.2 minutes

Results of this testing indicated that the product ash specification of $2 \mathrm{lb}$ ash/MBtu was met for both of these feedstocks. For the finer of these two grinds, Btu recoveries were all greater than $99 \%$ with tailings ash values in the 81 to $87 \%$ range. However, for the coarser grind, Btu recoveries were slightly lower, 96.6 to $99.6 \%$ with tailings ash values in the 56 to $80 \%$ range. This drop in Btu recovery for the coarser grind is attributed to the presence of more unliberated mineral-matter particles, which reported to the tailings stream along with their associated carbon content.

Agglomerate Size Effect - As seen for other coals tested, the general trend of decreasing product ash content with increasing agglomerate size was observed for the Hiawatha coal. The reason for this effect is that the larger agglomerates drain their 
associated mineral-matter bearing process water easier than the smaller agglomerates. This relationship is attributed to the carryover of more mineral-matter bearing process water with the product from the screen as agglomerate size decreases.

Solids Concentration Effect - Generally, it has been found throughout this testing, that when high- and low-shear agglomeration is carried out at high solids concentrations, a higher product ash is achieved than when agglomeration is completed at lower solids concentrations. Unfortunately, for the bulk of the Subtask 6.5 results, this effect is not obvious since the effect of agglomerate size on product ash, as discussed previously is more prominent, therefore masking the solids concentration effect. However, for the Hiawatha coal testing carried out with the 100 mesh topsize feedstock, relatively consistent agglomerated product size was achieved, typically in the 1 to $3 \mathrm{~mm}$ size. As such, for this set of data lower product ashes were clearly achieved when agglomeration was completed at $7 \%$ solids than at $10 \%$ and $13 \%$ solids. This is attributed to the greater concentration of mineral matter present in the aqueous phase during agglomeration at the higher solids loadings. Any water trapped within the agglomerates during low-shear growth, or entrained within the agglomerate bed during screening carries a greater amount of mineral matter to the product stream increasing its ash content.

\section{Agglomeration Variable Effects}

The general relationships between the various selective agglomeration parameters are discussed below. These trends are independent of the coals tested and are presented to illustrate the nature of the selective agglomeration process as tested during the course of Subtask 6.5.

Solids Concentration - The effect of solids concentration on the selective agglomeration process is two-fold. During high shear, higher solids concentrations are beneficial in that they reduce the total energy required to achieve inversion. This reduction in energy is due to the greater particle to particle contact achieved at higher solids concentration for the same energy input. There is no apparent increase in product ash as a result of using higher high-shear solids concentrations.

Considering low shear, it was found that lower solids concentrations resulted in lower product ash levels. This is due to the lower concentration of mineral matter in the aqueous phase, some of which gets trapped within the agglomerates themselves, and some of which is carried over to the product in the agglomerate bed during screening. It was also found that higher solids concentrations resulted in more agglomerate growth with all other low-shear conditions remaining constant, making heptane dosage more critical and agglomerate growth much more difficult to control.

Heptane Concentration - It was found that the heptane concentration used has no effect on the product ash content directly. However, the heptane dosage used must be sufficient to achieve inversion during high shear, which in the case of higher rank coals is often insufficient to achieve agglomerate growth during low shear. Typically, as the 
feed coal particle size distribution becomes finer, more heptane is required to achieve inversion. Also, as the coal rank becomes lower, more heptane is required.

It was also found that ultimately, the heptane dosage used determines the size of the agglomerates formed during low shear, which was found to affect product ash content drastically, with more heptane resulting in larger agglomerates and a lower product ash content.

If too little heptane is used, agglomerate growth is minimal resulting in poor drainage of mineral-matter bearing process water during screening and a higher product ash content. Also, If agglomerates are too small, incomplete formation occurs (powdery appearance) resulting in coal loss through the screen deck during agglomerate recovery. However, if too much heptane is used, the agglomerate growth is excessive and their handleability is poor. Agglomerates containing too much heptane also are generally poorly formed (sticky appearance), resulting in poor screening performance and a higher product ash content.

As such, heptane dosage must be tailored to the specific high- and low-shear operating conditions being used. In particular, heptane dosage should be such that well formed agglomerates in the 2 to $3 \mathrm{~mm}$ size range are consistently produced during low shear.

High-Shear Agitation Intensity - The amount of energy used during high-shear agglomeration must be sufficient to achieve inversion, such that aggiomerate growth will occur during the subsequent low-shear unit operation. Typically, impeller tip speeds in the 6 to $18 \mathrm{~m} / \mathrm{s}$ range are required to achieve inversion. The actual tip speed needed, however, is dependent primarily on the type of coal used, with lower rank coals requiring higher $(18 \mathrm{~m} / \mathrm{s})$ agitation intensity to achieve inversion and easy to agglomerate coals like the Taggart achieving inversion at tip speeds as low as $6 \mathrm{~m} / \mathrm{s}$. Other factors influencing the required agitation intensity include the slurry solids concentration (higher solids concentration requires less energy), coal particle size distribution (finer coal particles may require higher energy), and high shear residence time (more residence requires less power input).

For some coals that are particularly easy to agglomerate like the Taggart, complete inversion during high shear is not necessary to achieve growth during low shear. This is because the agitation intensity during low shear, in itself, is sufficient to promote growth for such coals. In cases like this, however, these reduced levels of high-shear agitation ultimately result in lower Btu recoveries due to the incomplete occurrence of inversion during high shear, i.e., some coal particles do not become completely coated with heptane and subsequently do not form larger agglomerates during low shear.

High-Shear Residence Time - The residence time required during high shear is dependent on the agitation intensity utilized. Generally, at higher impeller tip speeds, lower residence times produce the same results. The relationship between these two parameters is an important factor for consideration during the design of an agglomeration circuit. The critical parameters are that sufficient total energy is utilized during high shear and that the impeller tip speed be sufficient to achieve inversion. 
Low-Shear Agitation Intensity - The agitation intensity (impeller tip speed) utilized during low-shear agglomeration was found to affect both the size and quality of the agglomerates formed. In general, if the impeller tip speed used was too high, agglomerate growth would be minimal, resulting in small agglomerates $10.5 \mathrm{~mm}$ or less), from which drainage of the associated mineral matter bearing process water was difficult. However, if agitation intensity was too low, the agglomerates were generally poorly formed, had poor strength, and formed a thicker agglomerate bed during screening. These poorly formed agglomerates also contained more mineral-matter bearing process water resulting in higher product ash contents.

As such, it was found that a low-shear impeller tip speed of $5 \mathrm{~m} / \mathrm{s}$ produced well formed agglomerates of good strength for screening.

Low-Shear Residence Time - The effect of low-shear residence time on the overall performance of the selective agglomeration process was found to be minimal. Generally, for all of the coals tested, low-shear residence time variations were overcome by adjustments in heptane concentration. However, since longer residence times ( 4 to 7 minutes) were found to make heptane dosage very critical and agglomerate growth more difficult to control, low-shear residence times on the order of 2 to 3 minutes are recommended.

Screen Deck Inclination - The recovery of product agglomerates on a vibrating screen is easily achieved as long as the agglomerates are well formed, so that they afford good drainage of the mineral matter bearing process water discharging from the low shear vessel. While screen deck inclinations in the 35 to 45 degrees downhill from horizontal range were evaluated during Subtask 6.5 testing, these settings are purely a function of the screen utilized. It was found during the testing that the vibratory action of the screen used was insufficient to move the agglomerates across the screen. It is anticipated, however, that the use of a dewatering screen with a stronger forward linear motion and a slight downhill orientation would result in good agglomerate transport across the screen deck.

Screen Spray Water Flow Rate - Due to poor control of low-shear growth during much of the Subtask 6.5 testing, i.e., the production of inconsistently sized agglomerates, evaluation of screen spray water effect on product ash content was virtually impossible. It is anticipated, however, that given the production of well formed agglomerates in the 2 to $3 \mathrm{~mm}$ range and the use of a dewatering screen, spray water requirements would be minimal.

\section{Batch Stripper Testing}

In an effort to better quantify the residual heptane concentrations remaining with a stripped agglomerated product, a number of batch stripper tests were carried out. These batch tests were found to provide a better indication of some parameter effects on residual heptane concentrations since more control over the tests was possible. Several different types of batch stripper tests were completed as follows: 
- Boiling of recovered agglomerates in an open stirred beaker for a set period of time@ $94^{\circ} \mathrm{C}$.

- Thermal drying at $110^{\circ} \mathrm{C}$ for a set period of time.

- Autoclave treatment at 115 to $120^{\circ} \mathrm{C}$ for a set period of time.

\section{Heptane Characterization}

During the course of Subtask 6.5 testing, two types of heptane were used. The first type tested was a commercial grade heptane with a bulk cost of about $\$ 1.00$ per gallon. The second type tested was a pure grade heptane with a bulk cost of about $\$ 6.00$ per gallon.

Feed Heptane Analyses - Characterization of these two heptane types was carried out with the results indicating that the n-heptane content of the commercial grade heptane was in the 21 to $25 \%$ range, while the pure grade heptane contained greater than $99 \%$ n-heptane.

Residual Heptane Analyses - In an effort to achieve reliable analysis of residual heptane on steam stripped products, it was determined that given the many compounds present in the commercial grade heptane, it was not economical to analyze for all components regularly. As such, it was decided that the samples would be analyzed for $\mathrm{n}$-heptane only, and the amount of total residual hydrocarbon calculated, based on the percentage of total residual hydrocarbons that was n-heptane. As a first estimate, it was assumed that $n$-heptane remained on the product in approximately the same fraction, $25 \%$, as it was present in the original commercial grade heptane sample.

In order to confirm this assumption, the distribution of the various residual hydrocarbon components remaining on different stripped samples types was determined. The following is a summary of these residual hydrocarbon distribution analyses:

- The commercial grade heptane fed to the process contained between 21 and $25 \%$ n-heptane.

- The pure grade heptane fed to the process contained greater than $99 \% n$ heptane.

- When coal agglomerated with the commercial grade heptane was thermally dried, $n$-heptane represented only about $8 \%$ of the total residual hydrocarbons

- When coal agglomerated with the commercial heptane was treated in the continuous steam stripper, n-heptane represented from 30 to $33 \%$ of the total residual hydrocarbons.

- When plain coal slurry (no heptane) was boiled for 15 minutes, 50 to $59 \mathrm{ppm}$ of hydrocarbons on a dry coal basis were detected.

- The stripping of pure heptane from coal resulted in a residual hydrocarbon distribution of which over $90 \%$ was $n$-heptane. 
- Coal agglomerated with commercial heptane and then boiled at either ambient or increased pressures had a residual hydrocarbon distribution in which 44 to $49 \%$ was n-heptane.

- It was determined that the best way to consistently determine the quantity of residual heptane remaining on steam stripped products was to utilize a pure grade of heptane. By so doing, the analyses for residual n-heptane would most consistently reflect the total residual hydrocarbons present.

\section{Initial Batch Testing}

In an effort to better define residual hydrocarbon (n-heptane) concentrations, batch stripper testing was carried out. For this initial work, samples of product agglomerated with commercial heptane, pure heptane, and pentane were stripped in various ways including through the continuous stripper either once or twice, boiled for set periods of time, and thermally dried. The following is a summary of the initial batch stripper test results:

- Lower residual hydrocarbon concentrations were achieved as the residence time under stripping conditions was increased.

- Thermal drying achieved much lower residual heptane levels than boiling. This is believed to be due to a combination of the longer residence times used, the higher temperatures used, and the removal of virtually all water present.

- Storage of the product for 2 days prior to stripping resulted in higher residual hydrocarbon concentrations than immediate stripping.

- Pentane was removed to very low levels under all conditions tested.

\section{Asphalt Effects}

Batch testing was carried out to determine the effect of using asphalt during agglomeration on residual hydrocarbon concentrations. It was found that under virtually every set of conditions tested, the presence of asphalt in the stripper feed material resulted in lower residual hydrocarbon concentrations. This was found to hold true regardless of whether the stripping was done by boiling or thermally, and for both commercial and pure grades of heptane.

\section{Pressure Effects}

Since significantly lower trace heptane contents were realized when thermal drying at $110^{\circ} \mathrm{C}$ over boiling at $94^{\circ} \mathrm{C}$, batch stripper tests were carried out in which agglomerated products were boiled under pressure to maintain a slurry temperature in the range of 115 to $120^{\circ} \mathrm{C}$ for predetermined periods of time. Results from this work indicated that stripping at these increased temperatures and pressures resulted in reduced residual hydrocarbon concentrations. Based on these results, a two-stage stripping circuit was constructed as part of the bench-scale continuous test unit. 


\section{Storage Effects}

As part of the scope of this project, clean coal produced by selective agglomeration needs to be formulated into highly loaded coal-water-slurry fuels (CWF) to replace

premium fuels such as oil and gas. As an estimate to determine the fate of any heptane remaining on the coal after stripping, Sunnyside coal continuous stripper product was filtered and formulated into a slurry of approximately $55 \%$ solids. The heptane concentration of this slurry was monitored over a period of 14 days. It was found that with the slurry stored uncovered and mixed for 6 hours a day, there was no decrease in residual hydrocarbon concentration. This indicates that the storage of highly loaded CWF slurries formulated from agglomerated products should not pose safety and environmental related risks.

\section{Solids Concentration Effects}

To reduce the amount of steam required during heptane recovery from agglomerated products, it was planned to perform steam stripping at the 2 thr PDU scale at approximately $25 \%$ solids. As such, a brief series of tests was completed to determine if solids concentration had any effect on the residual heptane concentrations. It was found that, stripping (or boiling) at $25 \%$ solids concentration resulted in virtually the same levels of residual heptane as when the stripping was carried out at $10 \%$ solids concentration. This was found to be the case for samples agglomerated with both pure and commercial heptane.

\section{Continuous Stripper Testing}

\section{Procedures}

Feed Preparation - The bulk of the continuous steam stripping testing was carried out independently of the agglomeration circuit and as such, agglomerated product was stored in sealed 55-gallon drums until needed. Agglomerates were then manually transferred from these drums to a 15-gallon stripper feed tank and pulped to a solids concentration of $25 \%$. This tank was then agitated with a $4 \mathrm{hp}$ mixer for pumping to the first stage steam stripper. Typically, no greater than 10 to $15 \%$ solids could be achieved in the pumped stripper feed stream. This poor mixing and subsequent low stripper feed solids concentration was found to be the case for all mixer configurations tested and is attributed to the extreme buoyancy of the agglomerated product. It was anticipated, however, that higher stripper feed solids concentrations would be achieved at the $2 \mathrm{t} / \mathrm{hr}$ PDU scale with the application of more power during mixing.

Stripper Testing - When operating the two-stage stripper, feed to the system was delivered intermittently, via a peristaltic pump, to prevent the constant plugging that occurred in the stripper feed line at the low continuous volumetric target feed rate of approximately 1 liter per minute. As such, the feed was cycled on and off as required to maintain a first-stage stripper slurry temperature between 90 and $95^{\circ} \mathrm{C}$. Feed to the 
second-stage steam stripper was set at a fixed volumetric flow rate to control total system throughput.

The pressure and temperature in the second-stage stripper was controlled manually via a vapor discharge valve which was adjusted to maintain a target operating pressure and temperature, typically $10 \mathrm{psi}$ and $117^{\circ} \mathrm{C}$, respectively. The slurry level in the secondstage stripper, and therefore the residence time, was also controlled via a manual discharge valve which was adjusted manually as required. The steam feed rate to the stripping circuit was also set manually to maintain the appropriate first-stage stripper vapor stream temperature. In this manner, the use of excessive amounts of steam was avoided.

The vapor product from the stripping circuit was condensed and cooled followed by gravity separation (heptane from water) for heptane recovery prior to its recycle to the process.

Sampling and Analyses - Due to the intermittent nature of feed to the stripping circuit, feed samples were taken only for determination of feed solids concentration. Other samples taken included first- and second-stage stripper products for heptane and solids concentration determination, as well as gravity separator overflow (heptane) and underflow (water) samples for heptane purity and contamination determination, respectively. The flowrate of the final product stream was also measured for use in calculating stripper circuit solids throughput. In addition, all pertinent slurry and vapor temperatures were recorded, either automatically via the data acquisition system, or manually.

\section{Start-Up Testing and System Modifications}

Stripping Circuit Feed - Much difficulty was encountered in feeding the agglomerated product to the steam stripper during initial testing. The progressive cavity (Moyno) pump initially used for this task proved to be incapable of pumping the agglomerates, due to the tendency of the agglomerates to float and plug the pump suction line and the pump itself. To rectify this plugging problem, the Moyno pump was replaced with a peristaltic pump with a $3 / 8$-inch diameter hose. While this pump was able to provide feed to the steam stripper at high flow rates without any serious plugging problems, its operation at low flow rates was unstable, and as such the circuit was fed intermittently.

In order to allow testing of the stripper circuit independently of the agglomeration circuit, agglomerates were stored in a sealed 55-gallon drum prior to steam stripping. Initially, the material in this drum was diluted, mixed, and pumped to the stripping circuit. During testing, it was found that the agglomerates were very difficult to mix in the drum with a constant layer of agglomerates floating on the surface, regardless of the mixer configuration used. Ultimately, a smaller 15-gallon stripper feed tank was used. While mixing in this tank was still poor due to the extreme buoyancy of the agglomerates, stripper feed solids concentrations of 10 to $15 \%$ were achieved. 
Single-Stage Stripping Circuit - Initial stripper testing was carried out using a single column vessel operated at ambient pressure. This testing emphasized evaluation of stripper operability at various conditions. This testing utilized a packed bed of $5 / 8$-inch pall rings approximately 24-inches high with feed entering the vessel near the top and the slurry level maintained just below the bottom of the pall rings. In this scenario, the stripper operated with a continuous steam phase through which the agglomerates flowed down as discrete droplets or particles. Additional preliminary testing operated the vessel flooded, i.e., with a slurry level near the feed inlet point. In this scenario, the column contained a continuous slurry phase with steam bubbling through it. This operating scenario proved more controllable than the continuous steam phase scenario, allowing the testing of various slurry residence times in the stripper column.

Two-Stage Steam Stripping Circuit - As testing progressed, it was found via batch testing that heptane stripping at elevated pressures, allowing higher operating temperatures, removed more heptane than stripping at the ambient pressure boiling point. As such the stripping circuit was modified to include an additional stripping vessel prior to the above described column, which was also slightly modified. This allowed the bulk of the heptane to be removed in the first stage of stripping, producing a coal slurry that was more easily metered to the second-stage stripping column which was then operated at elevated temperatures and pressures $\left(115\right.$ to $120^{\circ} \mathrm{C} @ 15$ to 20 psig). This new two-stage circuit also better simulated the 2 t/hr PDU stripping circuit design being developed at that time.

Generally, operation of this two-stage stripping circuit proceeded smoothly. The main difficulties encountered were as follows:

- Manually maintaining the proper first-stage stripper operating temperature and level via intermittent feeding.

- Manually maintaining the target second-stage stripper temperature via the vapor discharge valve.

- Manually maintaining the target second-stage stripper operating level via the product discharge valve.

- Preventing the second-stage stripper discharge valve from plugging.

Condenser - Operation of the condenser, which condensed the evaporated heptane and its associated water vapor proceeded smoothly from initial startup. The condenser had sufficient capacity to both condense and cool the incoming vapor stream. It was found that under most stripper operating conditions evaluated, some coal was carried over to the condenser. This phenomenon, however, did not typically cause any plugging problems and was addressed by including a de-mister pad in the $2 \mathrm{thr}$ PDU design.

Gravity Separator - Once condensed, the water and heptane mixture entered the center of a gravity separator column. Operation of this separator proceeded smoothly with the water/heptane interface easily observed. Steady-state operation of the gravity separator was easily achieved with consistent flows of both water from the bottom and 
heptane from the top observed. Preliminary analysis of the recovered heptane indicated that it was virtually identical in composition to the fresh heptane. Analysis of water samples taken from the separatory column showed a total organic content of approximately $8 \mathrm{ppm}$, indicating minimal solubility of the heptane in water.

\section{Preliminary Testing Results - Elkhorn No. 3 Coal}

During preliminary testing utilizing a single stage of steam stripping, an estimate of the capacity of the stripper column was carried out. It was determined that this column could process a coal feed rate approaching $20 \mathrm{lb} / \mathrm{hr}$ without plugging. One preliminary stripper test, in which the stripper was operated with a continuous steam phase, was carried out to generate stripper product samples for residual heptane determination. During this test, there were significant fluctuations in both the product flowrate and solids concentration. However, the residual $n$-heptane in the product was relatively consistent ranging from 1369 to $2086 \mathrm{ppm}$ on a dry. coal basis (dcb), approximately 3000 to $6000 \mathrm{ppm}$ total hydrocarbons dcb.

\section{Single-Stage Stripper Results}

In an effort to quantify the effects of various stripper operating parameters on product heptane levels, a number of single-stage stripper tests were carried out. This work utilized Sunnyside, Taggart, and Indiana VII coals.

Sunnyside Coal - A total of 11 Sunnyside coal tests were completed resulting in residual hydrocarbon concentrations of 3500 to $8000 \mathrm{ppm}$ dcb when the commercial

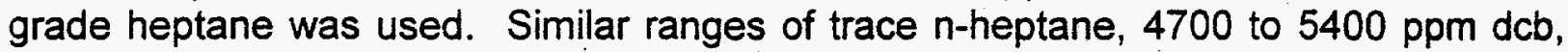
were determined for those three tests in which the pure grade of heptane was utilized.

Taggart Coal - Stripping of the 62-mesh topsize Taggart coal agglomerated product achieved residual total hydrocarbon concentrations in the range of 2000 to $6000 \mathrm{ppm}$ dcb. Generally, there were no obvious trends relating residence time to product heptane concentration. It was also determined that there was no difference in performance between operating the column flooded (with a high liquid level) or in a continuous steam mode (low liquid level). This data also indicated that a significant reduction in the exiting vapor temperature, from 95 to $78.3^{\circ} \mathrm{C}$ did not result in an increased product heptane content. The steam to coal ratio, which varied from as high as 12.5 to as low as 1.7 for the Taggart coal testing, indicated that no benefit was realized from the use of large quantities of excess steam.

Indiana VII Coal - Two continuous stripping tests were carried out using agglomerated Indiana VII coal. As anticipated, the results for these two tests, one a single pass and the other a double pass through the stripper, resulted in similar residual heptane levels as those achieved with the other two coals. Residual n-heptane detected for these two tests were about 2400 and $1800 \mathrm{ppm}$, respectively, equivalent to approximately 7000 and $5000 \mathrm{ppm}$ dcb of total residual hydrocarbons. 


\section{Two-Stage Stripper Testing}

Elkhorn No. 3 Coal - Three different tests were completed using the modified twostage stripping circuit with Elkhorn No. 3 coal. These results indicated that two stages of steam stripping achieved lower trace heptane concentrations than a single stage of steam stripping. This was due to the increased temperature in the second stage.

Hiawatha Coal - One continuous steam stripping test with agglomerated Hiawatha coal was completed. The results of this test indicated that the Stripper 1 and Stripper 2 products contained approximately 4300 and $3000 \mathrm{ppm}(0.43$ and $0.3 \%)$ of heptane on a dry coal basis, respectively.

Indiana VII Coal - One continuous steam stripping test utilizing the Indiana VII coal was carried out. The results of this test indicate that the Stripper 1 and Stripper 2 products contained approximately 5500 and $1800 \mathrm{ppm}(0.55$ and $0.18 \%)$ of heptane on a dry coal basis, respectively.

\section{Steam Stripping Variable Effects Summary}

In summary the following conclusions were drawn concerning the removal of heptane from agglomerated products via steam stripping:

- When steam stripping heptane from agglomerated products at ambient boiling temperatures, no benefit is gained by providing residence times greater than approximately five minutes.

- Steam stripping at elevated temperatures, as achieved by increased operating pressures, results in lower residual heptane concentrations.

- Increasing the solids concentration at which steam stripping is carried out has no detrimental effect on residual heptane concentrations.

- The presence of asphalt (used as an activator during agglomeration) results in lower residual hydrocarbon concentrations under otherwise similar stripping conditions.

- Regardless of whether a commercial or pure grade of heptane is utilized during agglomeration, total residual hydrocarbon concentrations are similar.

\section{Tailings Heptane Analysis}

For the design of a tailings disposal system, at both PDU and commercial scales, it is important to know the heptane content of the selective agglomeration process tailings. As such, one set of agglomeration tailings samples (froth skimmer underflow) was analyzed for residual heptane content. These samples originated from an Elkhorn No. 3 coal agglomeration test utilizing commercial grade heptane. The ash content of this tailings sample was approximately $50 \%$. Samples submitted included as produced tailings, tailings filter cake, tailings filtrate, and tailings samples that had been boiled for 5,10 , and 20 minutes. Less than $10 \mathrm{ppm}$ of n-heptane was detected in all of the 
tailings samples, except for the filter cake, which contained $380 \mathrm{ppm} n$-heptane, at $67 \%$ solids, or $567 \mathrm{ppm} n$-heptane on a dry solids basis. There was less than $1 \mathrm{ppm}$ of $n$-heptane detected in the tailings filtrate. These results indicate that tailings disposal in conventional waste disposal sites should not be a problem.

\section{Toxic Trace Elements Distribution}

The reduction in toxic trace element (TTE) concentrations accomplished by selective agglomeration was studied by assaying the products from selected parametric benchscale tests and calculating the distribution of the trace elements between the clean coal and tailings. The TTEs of interest were antimony, arsenic, beryllium, cadmium, chromium, cobalt, lead, manganese, mercury, nickel, selenium and chlorine. In tracking the TTEs through the selective agglomeration process, the average of all of the mass balance closures was $104 \%$, and the closures were generally within $20 \%$ of the amount reported in the agglomeration circuit feed.

The reductions in the various trace element concentrations accomplished during the selective agglomeration tests were calculated on a heating value basis and generally, the concentrations of arsenic, beryllium, cobalt, lead, manganese, mercury, and selenium in the raw coals were clearly reduced by the combined conventional washing and advanced cleaning steps. Much of the reduction, however, was accomplished during washing at the mine-site preparation plant.

Very definitely, selective agglomeration reduced the concentrations of arsenic, chromium, manganese, and nickel remaining in the ground washed coals. It appears that chromium and nickel may have been introduced into the coal slurries during grinding. Selective agglomeration had little impact upon the beryllium, cobalt, lead, mercury, and selenium concentrations, and it appears at times that the antimony and chlorine concentrations increased on a heating value basis. Overall, the residual amounts of the elements in the clean coals were found to be dependent upon the source coal. For example, there was about four times as much antimony in the Indiana VII clean coal as found in the other four clean coals and there was a third as much or less arsenic in the Sunnyside clean coal as in the other clean coals.

In comparing the toxic trace element reductions achieved by the selective agglomeration and advanced flotation processes, both resulted in about the same amounts of the trace elements in the final product.

Reductions from the concentrations found in the ROM parent coals were generally greater than the reductions from the as-received test coals, with substantial reductions, 25 to $90 \%$ on a heating value basis, in the concentrations of arsenic, beryllium, chromium, cobalt, lead, manganese, mercury, and selenium. On the other hand, there was little or no reduction, less than $25 \%$, in the amount of antimony and the reduction of nickel and chlorine varied from coal to coal. 


\section{CONCLUSIONS}

\section{Agglomeration}

The results of the Subtask 6.5 agglomeration test work indicate that the product ash specification of 1 to $2 \mathrm{lb} / \mathrm{MBtu}$, as well as the Btu recovery goal of at least $80 \%$ on a run-of-mine basis were met for all six of the coals tested. Of paramount importance in achieving these product ash levels is the size to which the coal is ground. As for any physical coal cleaning process, if sufficient mineral-matter liberation is not achieved, the desired product grade can not be attained, except at the expense of significant Btu losses to the tailings stream. The coarsest particle size distribution to which each coal was ground while still achieving the product ash specifications are summarized in the table below. Included in this table are typical product ash and Btu recovery values attained when operating at optimized conditions for the grind sizes shown.

\begin{tabular}{|c|c|c|c|c|c|c|c|}
\hline \multirow[b]{2}{*}{ Coal } & \multicolumn{4}{|c|}{ PSD Summary, Microns } & \multirow{2}{*}{$\begin{array}{c}\text { Ash } \\
\text { lb/MBtu }\end{array}$} & \multicolumn{2}{|c|}{ Btu Recovery, \% } \\
\hline & $\underline{\mathrm{D}}_{20}$ & $\underline{D}_{50}$ & $\underline{D}_{80}$ & MMD & & Agglomeration & Run-of-Mine \\
\hline Taggart & 5.9 & 16.2 & 32.8 & 23.0 & 0.95 & 99.1 & 93.5 \\
\hline Sunnyside & 8.0 & 24.9 & 59.6 & 34.3 & 1.79 & 98.3 & 88.6 \\
\hline Indiana VII & 4.2 & 10.4 & 21.9 & 14.5 & 1.95 & 99.0 & 89.6 \\
\hline Elkhorn No. 3 & 10.7 & 29.6 & 68.0 & 39.4 & 1.69 & 96.8 & 91.6 \\
\hline Winifrede & 2.0 & 4.2 & 12.4 & 7.1 & 1.91 & 99.2 & 88.8 \\
\hline Hiawatha & 11.5 & 32.9 & 65.2 & 40.9 & 1.85 & 99.6 & 89.7 \\
\hline
\end{tabular}

Operating conditions used to achieve these typical agglomeration results were found to be various, i.e., several combinations of residence times, energy inputs, and heptane levels could ultimately achieve similar results.

It was found however that the following guidelines should be followed to insure that consistent results are achieved:

1. Sufficient heptane must be used during high shear to achieve phase inversion and the formation of microagglomerates. Typically, the heptane required increases with decreasing coal particle size and decreasing coal rank.

2. Sufficient energy or impeller tip speed (10 to $18 \mathrm{~m} / \mathrm{s})$ must be applied during high shear to achieve complete dispersion of the heptane and enough particle to particle contact to form microagglomerates.

3. Sufficient residence time (typically 30 to 60 seconds) must be provided in high shear to form microagglomerates (achieve phase inversion). Normally the use of higher tip speeds will reduce residence time requirements which are primarily dependent on coal fineness and rank.

4. The use of higher solids concentration during high shear reduces energy input requirements. 
5. For lower rank and oxidized coals, an agglomeration promoter like asphalt may be required to achieve phase inversion during high shear.

6. Sufficient heptane must be provided to allow agglomerate growth during low shear to the 2 to $3 \mathrm{~mm}$ size range. However, too much heptane results in poor agglomerate formation.

7. The production of consistent agglomerates in the 2 to $3 \mathrm{~mm}$ size range is paramount to achieving good recovery during screening and low product ash levels.

8. Impeller tip speed (agitation intensity) during low shear needs to be in the $5 \mathrm{~m} / \mathrm{s}$ range for the growth of well formed agglomerates of sufficient strength for vibrating screen recovery. If agitation is too mild or intense, poorly formed agglomerates and higher product ash contents result.

9. Residence time in low shear was found to have little effect on agglomerate growth since ultimately, agglomerate formation is controlled by heptane dosage and low-shear agitation intensity. However, residence times no greater than 2 to 3 minutes are recommended since longer residence times make agglomerate growth very difficult to control.

10. The design of the low shear vessel should be such that the discharge is located at the same elevation as the impeller. This will insure that continual low-shear discharge occurs under all operating conditions.

11. The use of higher solids concentrations in low shear results in higher product ash levels and makes agglomerate growth very difficult to control.

12. The vibrating screen used for agglomerate recovery must have sufficient forward linear motion to provide good transport of agglomerates across the screen deck.

13. Screen spray water is required to rinse the mineral matter associated with the process water to the tailings stream.

14. The use of a froth skimmer to recover coal from the screen tailings may be required depending on the amount of coal contamination in the screen underflow stream.

Overall, the selective agglomeration process was found to be very robust in that it either works well or doesn't work at all. Therefore, as long as the coal grind provides sufficient mineral-matter liberation and a consistent low-shear product of the appropriate size is produced, the desired product grade along with consistently high Btu recoveries will be achieved.

\section{Steam Stripping}

In general, steam stripping to remove heptane from agglomerated products is a straight forward operation. The steam is applied directly to the reslurried agglomerates to evaporate heptane along with water, and the ratio of heptane to water in the exiting vapor phase from the stripping circuit is minimized to insure that steam consumption is kept as low as possible. 
It was determined that due to the advantage of carrying out steam stripping at elevated pressures and temperatures (lower residual heptane concentrations), a two-stage system should be used. In this scenario, the first-stage stripper was agitated to keep the buoyant agglomerates dispersed and operated at a low pressure to facilitate pumping of the difficult to handle agglomerate feed. With the removal of the bulk of the heptane in the first-stage stripper and subsequent disintegration of the agglomerates, the much more handleable product slurry could then be fed to and pumped through the second-stage stripper which was operated at a higher pressure and temperature. This vessel was of a plug flow packed column design for better mass transfer efficiency and removed small amounts of additional heptane. A counter-current steam flow was used with the fresh steam feeding the second stripper, and its vapor product feeding the first stripper. The first-stage stripper vapor product was then the feed to the condenser and gravity separation heptane recovery column.

Continuous two-stage stripper testing was carried out at operating temperatures of approximately $92^{\circ} \mathrm{C}$ and $115^{\circ} \mathrm{C}$ in the first- and second-stage strippers, respectively. Residence times in these strippers were 5 and 10 minutes for the first- and secondstages, respectively. Under these conditions, residual hydrocarbon concentrations on the order of 2000 to $6000 \mathrm{ppm}(0.2$ to $0.6 \%)$ and 1000 to $3000 \mathrm{ppm}(0.1$ to $0.3 \%)$ on a dry coal basis were achieved in the intermediate and final products, respectively. These residual concentrations appeared to be independent of the coal tested and the type of heptane used, pure grade or commercial grade.

The effect of various steam stripping operating variables on the residual heptane content of the stripped products is summarized as follows:

- When steam stripping heptane from agglomerated products at ambient boiling temperatures, no benefit is gained from residence times greater than 5 minutes.

- Steam stripping at elevated temperatures, as achieved by increased operating pressures, results in lower residual heptane concentrations with no longer than ten minutes residence time required.

- Increasing the solids concentration at which steam stripping is carried out has no detrimental effect on residual heptane concentrations.

- The presence of asphalt (used as an activator during agglomeration) results in lower residual hydrocarbon concentrations under otherwise similar stripping conditions.

- Regardless of whether a commercial or pure grade of heptane is used in agglomeration, total residual hydrocarbon concentrations are similar.

Beyond feeding the stripping circuit, no other major operational difficulties were encountered during the Subtask 6.5 stripper testing. Vapor condensation and liquid cooling were achieved in a tube coil submersed in a water bath serviced by utility water. Complete condensation was consistently achieved with minimal carryover of coal from the stripping circuit. Separation of the condensed water and heptane was easily accomplished in a gravity separator column with the heptane overflowing from the top 
and the water exiting the bottom. This separation was complete with only minimal solubility $(<10 \mathrm{ppm})$ of heptane into the water phase.

\section{Toxic Trace Elements Distribution}

The reduction in toxic trace element (TTE) concentrations accomplished by selective agglomeration was studied by assaying the products from selected parametric benchscale tests and calculating the distribution of the trace elements between the clean coal and tailings. In tracking the TTEs through the selective agglomeration process, the average of all of the mass balance closures was $104 \%$, and the closures were generally within $20 \%$ of the amount reported in the feed to the agglomeration circuit.

In general, the concentrations of arsenic, beryllium, cobalt, lead, manganese, mercury, and selenium in the raw coals were clearly reduced by the combined conventional washing and selective agglomeration steps. Much of the reduction, however, was accomplished during washing at the mine-site preparation plant. Selective agglomeration reduced the concentrations of arsenic, chromium, manganese, and nickel remaining in the ground washed coals (some chromium and nickel were introduced into the coal during grinding). Agglomeration had little effect upon the beryllium, cobalt, lead, mercury, and selenium concentrations, and possibly increased antimony and chlorine concentrations on a heating value basis. Such results indicate preferential association of these seven elements with the carbonaceous portion of the coal.

Overall, the residual amounts of the elements in the clean coals were found to be dependent upon the source coal. For example, there was about four times as much antimony in the Indiana VII clean coal as found in the other four clean coals and there was a third as much or less arsenic in the Sunnyside clean coal as in the other clean coals.

In comparing the toxic trace element reductions achieved by the selective agglomeration and advanced flotation processes, their performance was similar. There were 25 to $90 \%$ reductions in the concentrations of arsenic, beryllium, chromium, cobalt, lead, manganese, mercury, and selenium from the amounts in the ROM coals. On the other hand, there was little or no reduction, less than $25 \%$, in the amount of antimony with the reduction of nickel and chlorine varying from coal to coal. 


\section{INTRODUCTION}

The main purpose of this project is the engineering development of advanced column flotation and selective agglomeration technologies for premium fuel applications. Development of these technologies is an important step in the Department of Energy's program to show that an ultra-clean coal-water slurry fuel (CWF) can be produced from selected United States coals and that this fuel will be a cost-effective replacement for a portion of the oil and natural gas burned by electric utility and industrial boilers in this country, as well as for advanced combustors currently under development. Capturing even a relatively small fraction of the total utility and industrial oil-fired boiler fuel market would have a significant impact on domestic coal production and reduce national dependence on petroleum fuels. Significant potential export markets also exist in Europe and the Pacific Rim for cost-effective premium fuels prepared from ultra-clean coal.

The replacement of oil and natural gas with CWF can only be realized if retrofit costs and boiler derating are kept to a minimum. Also, retrofit boiler emissions must be compatible with national clean air goals. These concerns establish the specifications for the ash and sulfur levels and combustion properties of ultra-clean coal as discussed below.

This multi-year cost-shared contract effort began on October 1,1992, and is scheduled for completion by September 30,1997. This report presents the findings of the Subtask 6.5 Selective Agglomeration Bench-Scale Testing and Process Scale-up work. Specifically, this report contains the operating conditions and results for the continuous $25 \mathrm{lb} / \mathrm{hr}$ bench-scale selective agglomeration testing unit.

\section{SPECIFIC OBJECTIVES OF THE PROJECT}

The three main objectives of this project are discussed below.

The primary objective is to develop the design base for commercial prototype advanced fine coal cleaning facilities capable of producing ultra-clean coals suitable for conversion to stable, highly loaded coal-water-slurry fuels (CWF). These slurry fuels should contain less than $2 \mathrm{lb}$ ash/MBtu HHV (860 grams ash/gigajoule) and preferably less than $1 \mathrm{lb}$ ash/MBtu HHV (430 grams ash/gigajoule), and less than $0.6 \mathrm{lb}$ sulfur/MBtu HHV (258 grams sulfur/gigajoule). The advanced fine coal cleaning technologies to be employed are advanced column froth flotation and selective agglomeration. Operating conditions during the advanced cleaning processes should recover at least 80 percent of the heating value in run-of-mine (ROM) source coals at an annualized cost of less than $\$ 2.50 / \mathrm{MBtu}$ (\$2.37/gigajoule), including the cost of the raw coal.

A secondary objective of the work is to develop a design base for near-term commercial applications of these advanced fine coal cleaning technologies. These applications 
should be suitable for integration into new or existing coal preparation plants for the purpose of economically and efficiently processing minus 28-mesh coal fines. The design base will also include the auxiliary systems required to yield a shippable, marketable product such as a dry clean coal product.

A third objective of the work is to determine the distribution of toxic trace elements between clean coal product and refuse during the cleaning of various coals by advanced froth flotation and selective agglomeration technologies. Twelve toxic trace elements have been targeted. They are antimony, arsenic, beryllium, cadmium, chromium, cobalt, lead, manganese, mercury, nickel, selenium, and chlorine. The results will show the potential for removing these toxic trace elements from coal by advanced physical cleaning.

\section{APPROACH}

A team headed by Amax Research \& Development Center (Amax R\&D) was formed to accomplish the project objectives. Figure 1 shows the project organization chart. Entech Global, Inc. is managing the project for Amax R\&D (part of Cyprus Amax Minerals Company) and also performing laboratory research and bench-scale testing. Entech Global is also responsible for the operation and evaluation of the 2 thr process development unit (PDU). Cyprus Amax Coal Company is providing operating and business perspective, the site for the near-term testing, and some of the coals being used in the program. Bechtel Corporation is providing engineering and design capabilities, and the operating experience it gained while managing similar proof-ofconcept projects for DOE. The Center for Applied Energy Research (CAER) at the University of Kentucky and the Center for Coal and Mineral Processing (CCMP) at the Virginia Polytechnic Institute and State University are providing research and operating experience in the column flotation area. Arcanum Corporation is providing similar experience in the selective agglomeration area. Dr. Douglas Keller of Syracuse University served as a consultant in the area of selective agglomeration and Dr. John Dooher of Adelphi University served as a consultant in the area of coal-water-slurry formulation. Robert Reynouard was retained as a consultant to help with electrical and instrumentation systems in the PDU. The Industrial Company (TIC) and Mech EL Contracting, Inc. (MEI) constructed the Advanced Flotation and Selective Agglomeration Modules of the PDU, respectively.

The overall engineering development effort has been divided into four phases with specific activities as discussed below. As shown in Table 1, Work Breakdown Structure, the four phases of the project have been further divided into tasks and subtasks, with specific objectives which may be inferred from their titles. Figure 2 shows the project schedule. 


\section{Phase I}

Phase I encompassed preparation of a detailed Project Work Plan, selection and acquisition of the test coals, and laboratory and bench-scale testing. The laboratory and bench-scale work determined the cleaning potential of the selected coals and established design parameters and operating guidelines for a $2 \mathrm{t} / \mathrm{hr}$ PDU containing both advanced column flotation and selective agglomeration modules. A conceptual engineering design was prepared for a fully integrated and instrumented $2 \mathrm{t} / \mathrm{hr}$ PDU incorporating the features determined from the laboratory and bench-scale studies.

Additional activities during Phase I included:

- Production of ultra-clean coal test lots by bench-scale column flotation and selective agglomeration for end-use testing

- Determination of toxic trace element distribution during production of these test lots

- Evaluation of the rheological properties of slurry fuels prepared from ultra-clean coals

- Evaluation of methods for applying these advanced cleaning technologies to existing coal preparation plants in the near term

\section{Phases II and III}

Phases II and III cover the construction and operation of the $2 \mathrm{t} / \mathrm{hr}$ PDU. Phase II is for advanced column flotation while Phase III is for selective agglomeration. Process performance is to be optimized at the PDU-scale, and 100 ton lots of ultra-clean coal is to be produced by each process for each of the three test coals. The toxic trace element distribution is also to be determined during the production runs. The ultraclean coals are to be delivered to DOE or a designated contractor for end-use testing.

\section{Phase IV}

Phase IV activities will include decommissioning of the PDU, restoration of the host site, and preparation of the final project report, which will include a conceptual design and cost estimate for commercial plants based on the two technologies. 


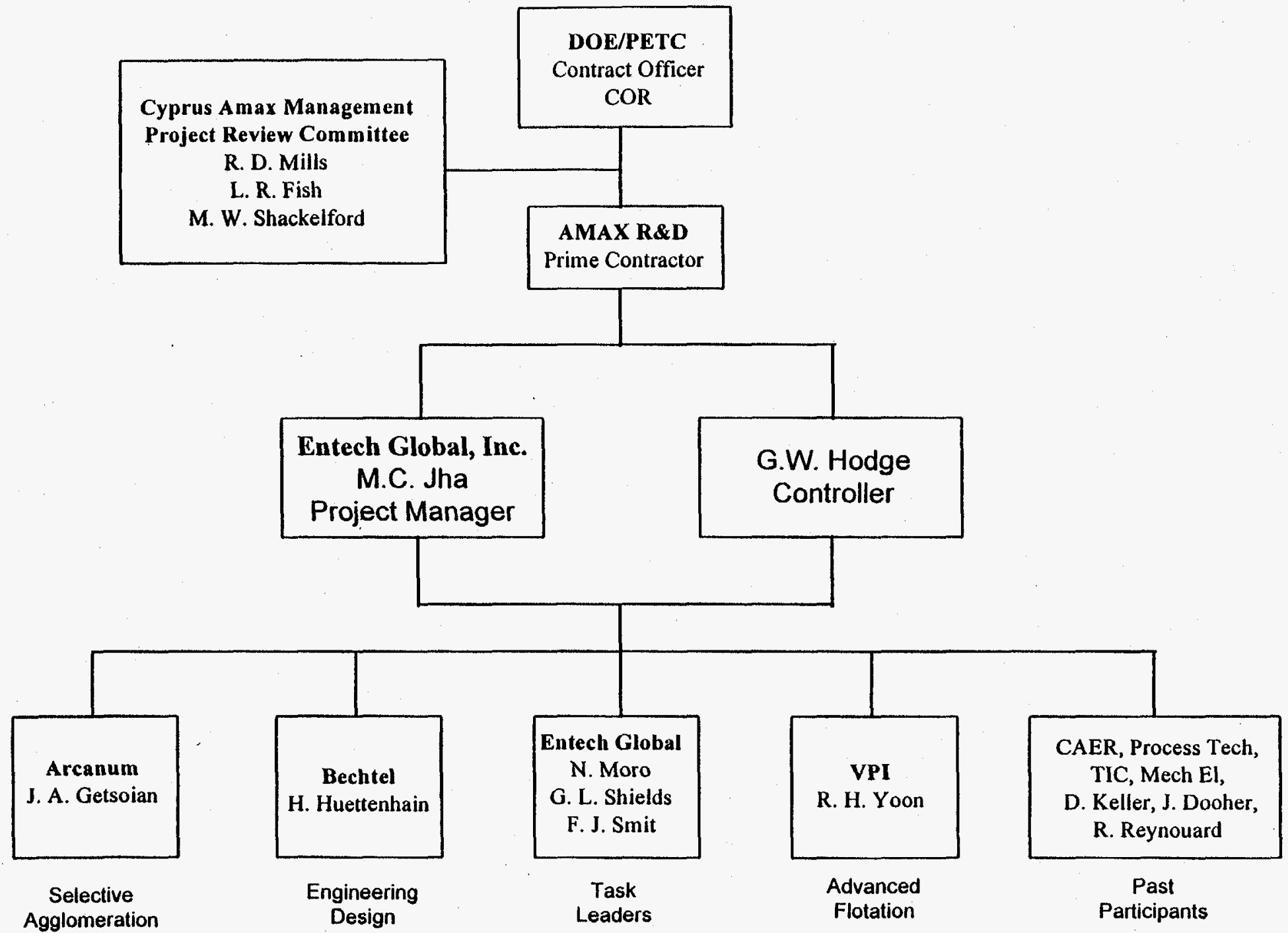

Figure 1. Project Management Organization Chart 


\section{Table 1. Outline of Work Breakdown Structure}

\section{Phase I. Engineering Analysis and Laboratory and Bench-Scale R\&D}

Task 1. Project Planning

Subtask 1.1. Project Work Plan

Subtask 1.2. Project Work Plan Revisions

Task 2. Coal Selection and Procurement

Subtask 2.1. Coal Selection

Subtask 2.2. Coal Procurement, Precleaning and Storage

Task 3. Development of Near-Term Applications

Subtask 3.1. Engineering Analyses

Subtask 3.2. Engineering Development

Subtask 3.3 Dewatering Studies

Task 4. Engineering Development of Advanced Froth Flotation for Premium Fuels

Subtask 4.1. Grinding

Subtask 4.2. Process Optimization Research

Subtask 4.3. CWF Formulation Studies

Subtask 4.4. Bench-Scale Testing and Process Scale-up

Subtask 4.5. Conceptual Design of the PDU and Advanced Froth Flotation Module

Task 5. Detailed Engineering Design of the PDU and Advanced Flotation Module

Task 6. Selective Agglomeration Laboratory Research and Engineering Development for Premium Fuels

Subtask 6.1. Agglomeration Agent Selection

Subtask 6.2. Grinding

Subtask 6.3. Process Optimization Research

Subtask 6.4. CWF Formulation Studies

Subtask 6.5. Bench-Scale Testing and Process Scale-up

Subtask 6.6. Conceptual Design of the Selective Agglomeration Module

Task 7. Detailed Engineering Design of the Selective Agglomeration Module

Phase Il. PDU and Advanced Column Flotation Module Testing and Evaluation

Task 8. PDU and Advanced Column Froth Flotation Module

Subtask 8.1. Coal Selection and Procurement

Subtask 8.2. Construction

Subtask 8.3. PDU and Advanced Coal Cleaning Module Shakedown and Test Plan

Subtask 8.4. POU Operation and Clean Coal Production

Subtask 8.5. Froth Flotation Topical Report

Phase Ill. Selective Agglomeration Module Testing and Evaluation

Task 9. Selective Agglomeration Module

Subtask 9.1. Construction

Subtask 9.2. Selective Agglomeration Module Shakedown and Test Plan

Subtask 9.3. Selective Agglomeration Module Operation and Clean Coal Production

Subtask 9.4. Selective Agglomeration Topical Report

Task 10. Disposition of the PDU

Phase IV. PDU Final Disposition

Task 11. Project Final Report 


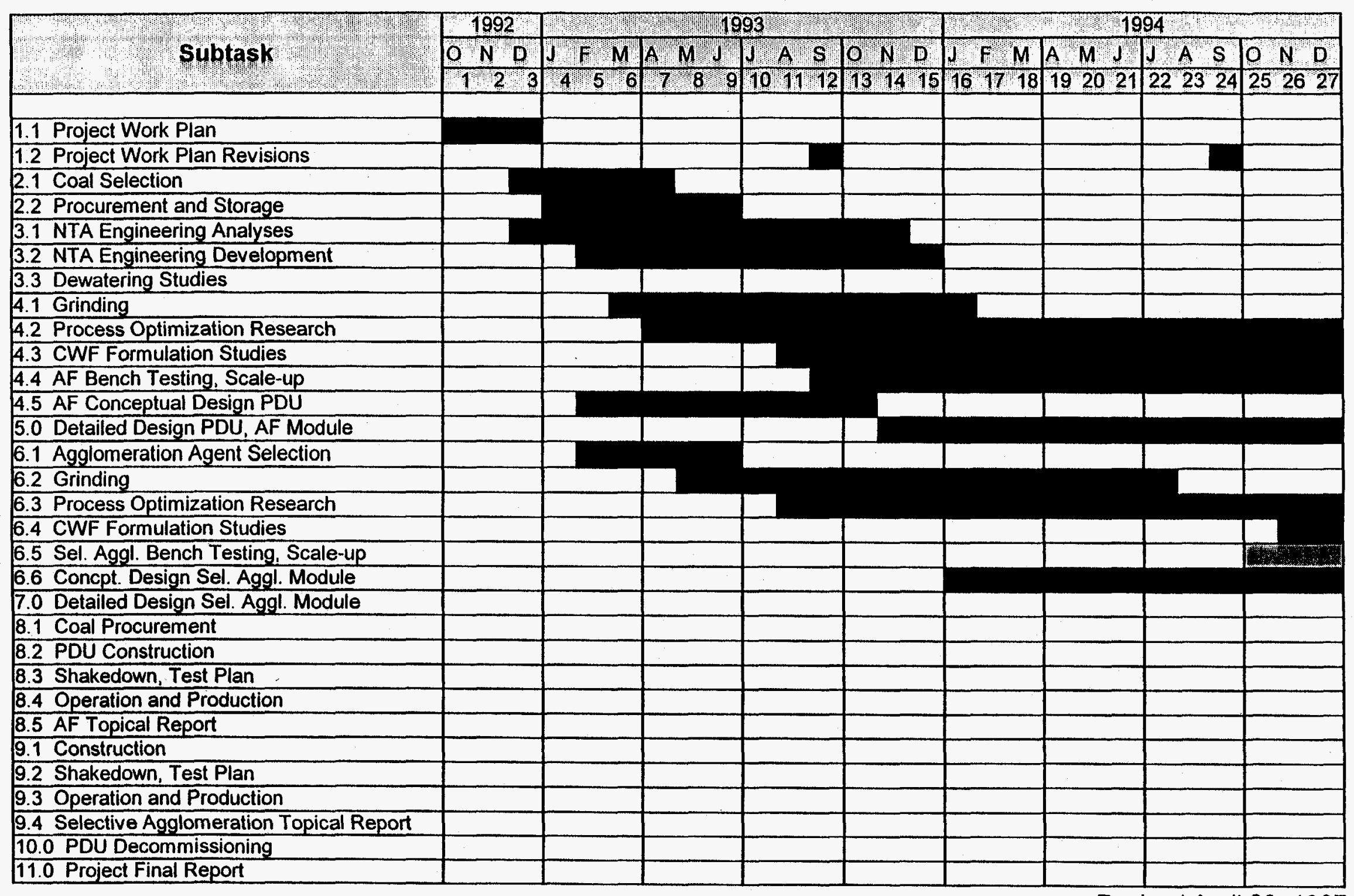

Figure 2. Project Schedule

Revised April 23, 1997 


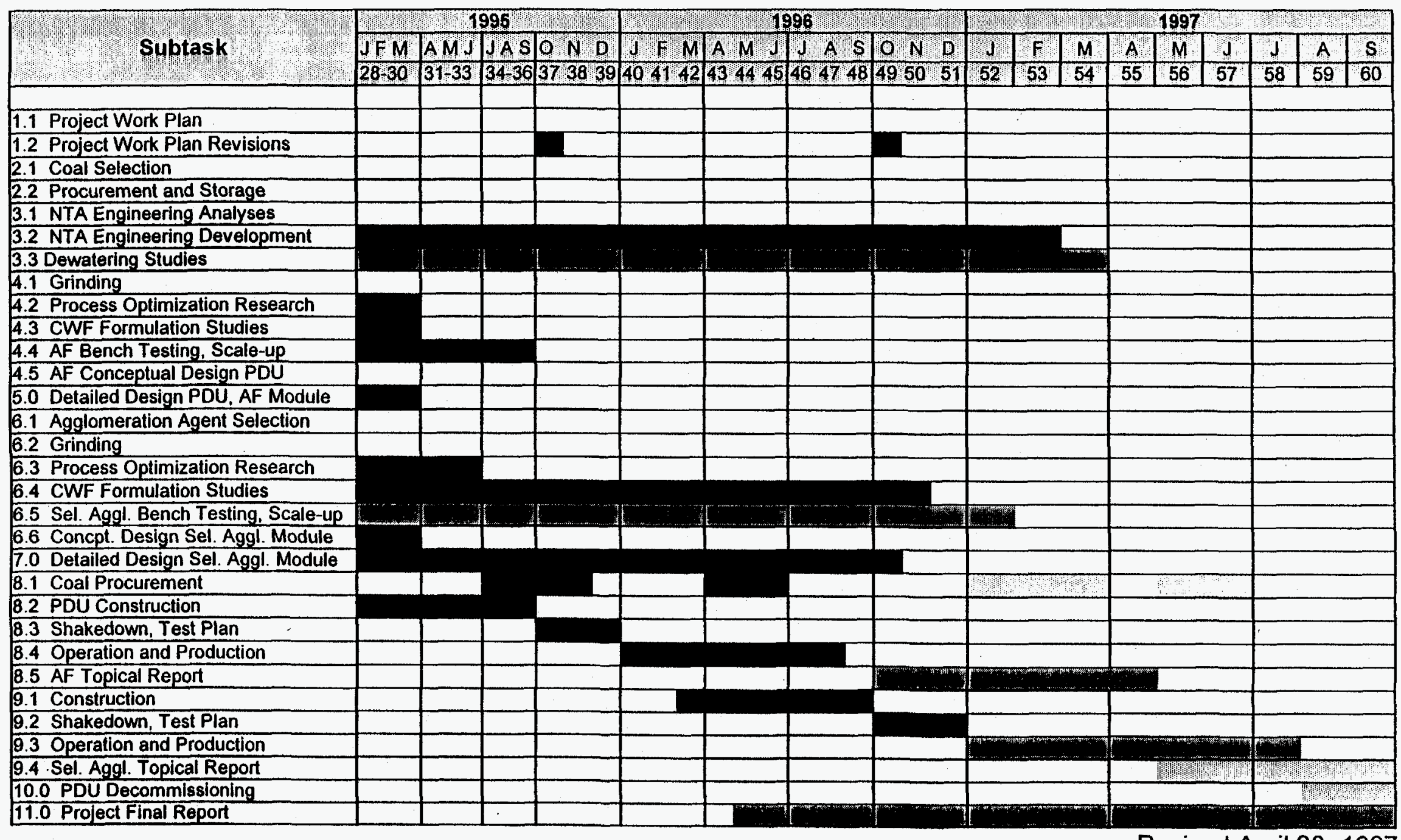

Figure 2. Project Schedule (Cont'd)

Revised April 23, 1997 


\section{TASK 6 STATUS}

Task 6 of this project, investigating the engineering development of the selective agglomeration process, consists of six separate Subtasks. The general scope and status of each of these Subtasks is presented below.

Subtask 6.1 - Agglomerating Agent Selection was completed in June, 1993 and a topical report was issued [1]. During this subtask a wide range of agglomerating agents were evaluated for use during selective agglomeration. As a result of this work heptane and pentane, two light hydrocarbons, were selected for further investigation.

Subtask 6.2 - Selective Agglomeration Grinding was completed, and a topical report issued in August, 1994 [2]. This subtask investigated various grinding circuit configurations, evaluating their applicability to the selective agglomeration process. Results from this subtask determined the degree of grinding necessary, through washability and selective agglomeration liberation testing, to insure that product grade requirements are met by the selective agglomeration process.

Subtask 6.3 - Selective Agglomeration Process Optimization Research was completed and a topical report issued in September, 1995 [3]. While some of this testing was carried out in the batch mode, most of the work was completed in a continuous laboratory agglomeration system. This subtask evaluated the effect of a number of process variables on selective agglomeration process performance, product quality, and operability. As a result of this work, heptane was chosen as the agglomerant to be used for further investigation

Subtask 6.4 - Selective Agglomeration CWF Formulation Studies was completed and a topical report issued in November, 1996 [4]. The findings of this report indicate that coal loadings in the 60 to $62 \%$ range $(8800$ to $9300 \mathrm{Btu} / \mathrm{b}$ ) are required for oil and gas retrofit applications, and that the slurry should have a viscosity of less than $500 \mathrm{cP}$. Slurry fuels meeting these requirements were prepared from the Taggart, Sunnyside, Elkhorn No. 3, and Hiawatha coals. For the Indiana VII and Winifrede coals, however, slurry loadings were less than $52 \%$ due to the fine grinding required, and in the case of the Indiana VII coal due to the high inherent moisture content.

Subtask 6.5 - Bench-Scale Testing and Process Scale-up test work has been completed and the document in hand represents the findings of this work. Specifically, this report presents the operating conditions and results for the continuous $25 \mathrm{lb} / \mathrm{hr}$ selective agglomeration bench-scale testing unit.

Subtask 6.6 - Conceptual Design of the PDU Selective Agglomeration Module was completed, and the design report issued in September, 1994 [5]. The design was based on the past experience of project team members and results available at the time. This design was revised during the detailed design of the $2 \mathrm{t} / \mathrm{hr}$ PDU selective agglomeration module, taking into consideration additional data obtained during Subtask 6.5 testing. 


\section{SUBTASK 6.5 OBJECTIVES AND APPROACH}

This section of the report presents the objectives of the Subtask 6.5 Bench-scale Testing and Process Scale-up work and the approach used to accomplish these objectives.

\section{OBJECTIVES}

Subtask 6.5 had three primary objectives:

1. Design, construct, and operate a continuous selective agglomeration system of about $25 \mathrm{lb} / \mathrm{hr}$ capacity to demonstrate the feasibility of the process.

2. Optimize the selective agglomeration process conditions to minimize product ash and sulfur contents, and reduce process costs.

3. Generate design data of sufficient reliability to insure successful scale-up of the process to the $2 \mathrm{t} / \mathrm{hr}$ process development unit (PDU) scale.

\section{APPROACH}

Subtask 6.5 objectives were achieved through bench-scale testing at Amax R\&D. The testing was confined to the test coals selected during Task $2[6,7]$, with the exception of the subituminous Dietz coal which was eliminated from the Task 6 work. The basis for this work stemmed from the results obtained during Subtask 6.3 Process Optimization Research testing carried out by Amax R\&D and Arcanum Corporation.

The bench-scale unit utilized during the Subtask 6.5 testing was of sufficient size to insure the production of at least $25 \mathrm{lb} / \mathrm{hr}$ of agglomerated product (dry basis), and capable of processing all project coals. The testing used heptane as the agglomerant or bridging liquid, which was recovered via steam stripping for recycle to the process.

To simplify operation of the Subtask 6.5 continuous bench-scale unit, coal grinding was carried out independently of the agglomeration testing. Primary grinding of the feedstock coals was carried out in a 4-foot by 4-foot ball mill in closed-circuit with a vibrating screen. If additional grinding was required, the ground slurries were subjected to additional size reduction in a Drais stirred-ball mill. Also in some cases, the feedstock used for testing was ground in the $2 \mathrm{t} / \mathrm{hr}$ PDU grinding circuit.

Once finely ground to achieve the required liberation, the coal slurry was subjected to a high-shear unit operation in which intense mixing dispersed the bridging liquid (heptane) and provided sufficient heptane/coal and coal/coal contact to achieve a phase inversion and form what are termed "microagglomerates". These microagglomerates were then subjected to additional mixing in a low-shear unit operation, at a substantially lower shear rate than in the high-shear vessel, allowing the agglomerates to grow to a size that could be physically recovered by screening. 
Once the agglomerates were formed, they were dewatered, rinsed, and recovered on a vibrating screen. Any floating material in the tailings from the vibrating screen (underflow) was also recovered to the product via a froth skimmer. At this point in the process, the critical separation of mineral matter from carbonaceous material was complete.

Recovery of the heptane from the agglomerated product was achieved in two stages of steam stripping. In the first stage, the reslurried agglomerates were subjected to steam stripping at ambient pressure boiling temperatures to remove the bulk of the heptane present. During the second stage of heptane recovery, the product slurry was subjected to additional steam stripping at elevated temperatures and pressures to promote the recovery of additional heptane.

Once removed from the product slurry, the heptane was condensed, cooled and recovered (separated from water by gravity) for reuse in the process. It should be noted that for the bulk of the Subtask 6.5 testing, steam stripping was carried out independently of agglomeration to facilitate ease of operation. 


\section{SELECTIVE AGGLOMERATION PROCESS DESCRIPTION}

Selective agglomeration is a coal cleaning process based on the differences in surface properties of the coal and its associated mineral impurities. Generally, coal particles are hydrophobic or repel water, while the mineral impurities associated with coal are hydrophilic or easily wetted by water. As such, when a hydrocarbon based agglomerant, or bridging liquid, is added to a finely divided coal water slurry, the carbon containing coal particles are coated by the agglomerant while the mineral matter remains dispersed in the water phase.

The bridging liquid utilized during selective agglomeration can range from "heavy" organic liquids like fuel oil No. 2, to "light" hydrocarbons such as heptane. The particular type of agglomerant used depends on a number of factors, but is primarily influenced by the feed coal characteristics, process economics, and the required product quality [1]. Depending on the type and quantity of bridging liquid used, the agglomerant will either be allowed to remain with the product, or be recovered and recycled back to the process. Generally, when using heavier agglomerants such as fuel oil, the quantity used is minimized and allowed to remain with the product. If, however, a light hydrocarbon such as heptane is used, the quantity used is not so critical since it must be recovered from the product and recycled to the process for health, safety, environmental, and economic reasons.

Based on the results of Subtask 6.1 Agglomerant Agent Selection [1] and Subtask 6.3 Process Optimization Research [3], heptane was selected for evaluation during the Subtask 6.5 testing.

\section{HIGH-SHEAR AGGLOMERATION}

During high-shear agglomeration a mixture of water, coal, and heptane is vigorously agitated, at impeller tip speeds in the 10 to $18 \mathrm{~m} / \mathrm{s}$ range, such that the heptane disperses and makes contact with the coal particles in the slurry. Throughout this agitation, hydrophobic coal particles are attracted to the heptane phase, while the hydrophilic mineral matter is repelled from the heptane and attracted to the water phase. With continued mixing, the heptane coated coal particles coalesce to form microagglomerates, while the mineral impurities remain dispersed in the water phase.

It is important that the high-shear unit operation provide mechanical agitation of sufficient intensity and duration to insure the formation of these microagglomerates, also described as a "phase inversion." During this inversion, two distinct phases are formed, a coal/agglomerant phase (microagglomerates), and a water phase containing the dispersed mineral matter.

The shear rate used during high shear must be sufficiently high to guarantee heptane dispersion to a very small droplet size. Once the heptane is dispersed, the high-shear residence time and total power input must then be sufficient to insure microagglomerate 
formation, i.e., provide enough energy for sufficient heptane to coal and particle to particle contacts.

It should be noted that in some cases, for aged (oxidized) or lower rank coals, an aid may be required to enhance agglomeration. Typically this agent would be asphalt, which has been shown to enhance agglomeration kinetics when present during the high-shear unit operation [3].

\section{LOW-SHEAR AGGLOMERATION}

Following high-shear agglomeration, the microagglomerates are subjected to a lowshear agglomeration step. During low shear, the slurry is mixed at a shear rate significantly less than that used during high shear, typically at impeller tip speeds in the 3 to $5 \mathrm{~m} / \mathrm{s}$ range, to promote agglomerate growth. If an agglomerated product of a particular size and/or strength is required, the low-shear heptane dosage, shear rate, solids concentration, and/or residence time may be tailored to generate the appropriate product.

For this project, the final process product is in the form of a highly-loaded slurry. As such, the formation of "large" agglomerates, say greater than 2 to 3 millimeters, with sufficient strength to withstand handling without degradation is not required. Therefore, the primary goal of the low-shear unit operation is to provide a product which can be easily recovered and dewatered on a screen.

Ideally, product agglomerate size should be just large enough to insure product recovery without the incorporation of tailings into the product, i.e., the screen size used should be only marginally larger than the topsize of the feed coal. This scenario ensures low power consumption during low shear. In practice, however, it is generally found that the larger the product agglomerates are, the easier it is to reject the tailings mineral matter during screening. This is due to the presence of larger voids within the agglomerate bed as agglomerate size increases. Subsequently, better drainage of the mineral-matter bearing process water occurs. Since agglomerate growth is carried out under low shear rates, the additional power consumption required to generate slightly larger agglomerates is small.

\section{AGGLOMERATE RECOVERY}

Once agglomerates are formed during low shear they must be physically recovered to the product. The goal of this unit operation is to achieve high energy recovery and a good separation between the product agglomerates and the mineral-matter bearing process water, i.e., minimize coal losses to the process tailings (screen underflow) while minimizing the contamination of both the product with mineral matter, and the process tailings with heptane bearing carbonaceous material.

Primary agglomerate recovery is carried out on a vibrating screen where the agglomerates are dewatered and report to the screen oversize. The screen is fitted 
with water sprays for product rinsing. The tailings or mineral-matter bearing process water report to the screen underflow.

Secondary agglomerate recovery, from the vibrating screen underflow, is achieved in a froth skimming device in which any floating carbonaceous material is recovered to the process product stream. If required to insure that all heptane bearing material is recovered, dispersion of nitrogen into the froth skimmer can be used to help float any additional carbonaceous material.

\section{HEPTANE RECOVERY AND RECYCLE}

Once agglomerates are recovered by screening and froth skimming, the heptane must be removed from the product. Heptane recovery from the agglomerated product is accomplished by direct contact steam stripping in two stages. During this process, heat provided by steam evaporates an azeotropic mixture of heptane and water.

From this vapor, the two liquids (heptane and water) are condensed, cooled, separated, and recycled to the process. 


\section{BENCH-SCALE UNIT DESCRIPTION}

The bench-scale unit was designed to produce at least $25 \mathrm{lb} / \mathrm{hr}$ of product agglomerates on a dry coal basis for all test coals evaluated. This design insured that a processing rate of $25 \mathrm{lb} / \mathrm{hr}$ could be achieved for more difficult to agglomerate coals like the Indiana VII, while easy to agglomerate coals like the Taggart could be processed at about $50 \mathrm{lb} / \mathrm{hr}$.

While this test unit provided the capability to evaluate the selective agglomeration process continuously, the grinding, steam stripping, and final product dewatering steps were carried out independently for the bulk of the test work. As such, the test unit included storage for the ground slurry feedstock prior to agglomeration and for the recovered product agglomerates prior to steam stripping. This allowed the main systems of the test unit to be de-coupled for ease of operation.

A block flow diagram of the entire bench-scale system is shown in Figure 3. Individual unit operations are described in the following sections of the report.

\section{COAL GRINDING AND FEED SYSTEM}

The grinding circuit utilized prior to agglomeration must provide sufficient mineral liberation such that the desired product grade can be achieved. Since liberation requirements vary from coal to coal, and different coal feed rates were to be tested, a continuous grinding system was not integrated with the test unit.

Coals that were tested were ground to the appropriate size in large batches, and stored in a 1000-gallon and/or a 400-gallon agitated tank. Primary coal grinding was carried out in a 4-foot $x$ 4-foot ball mill, typically in closed-circuit with a screen. For coals requiring fine grinding to achieve the necessary liberation, secondary grinding was carried out in a Drais stirred-ball mill.

The ground slurry was transferred to one of two agitated 55-gallon slurry feed drums where it was diluted to the desired solids concentration. From these feed drums, the slurry was metered to the process (high-shear agglomeration vessel) on a continuous basis. Two of these agitated tanks were provided so that while one was in use, the other could be replenished. A peristaltic pump was used to meter the coal slurry to the high-shear agglomeration unit operation. This type of pump was found to provide a relatively constant flow to the process, unaffected by the discharge head and only slightly affected by the suction head. 


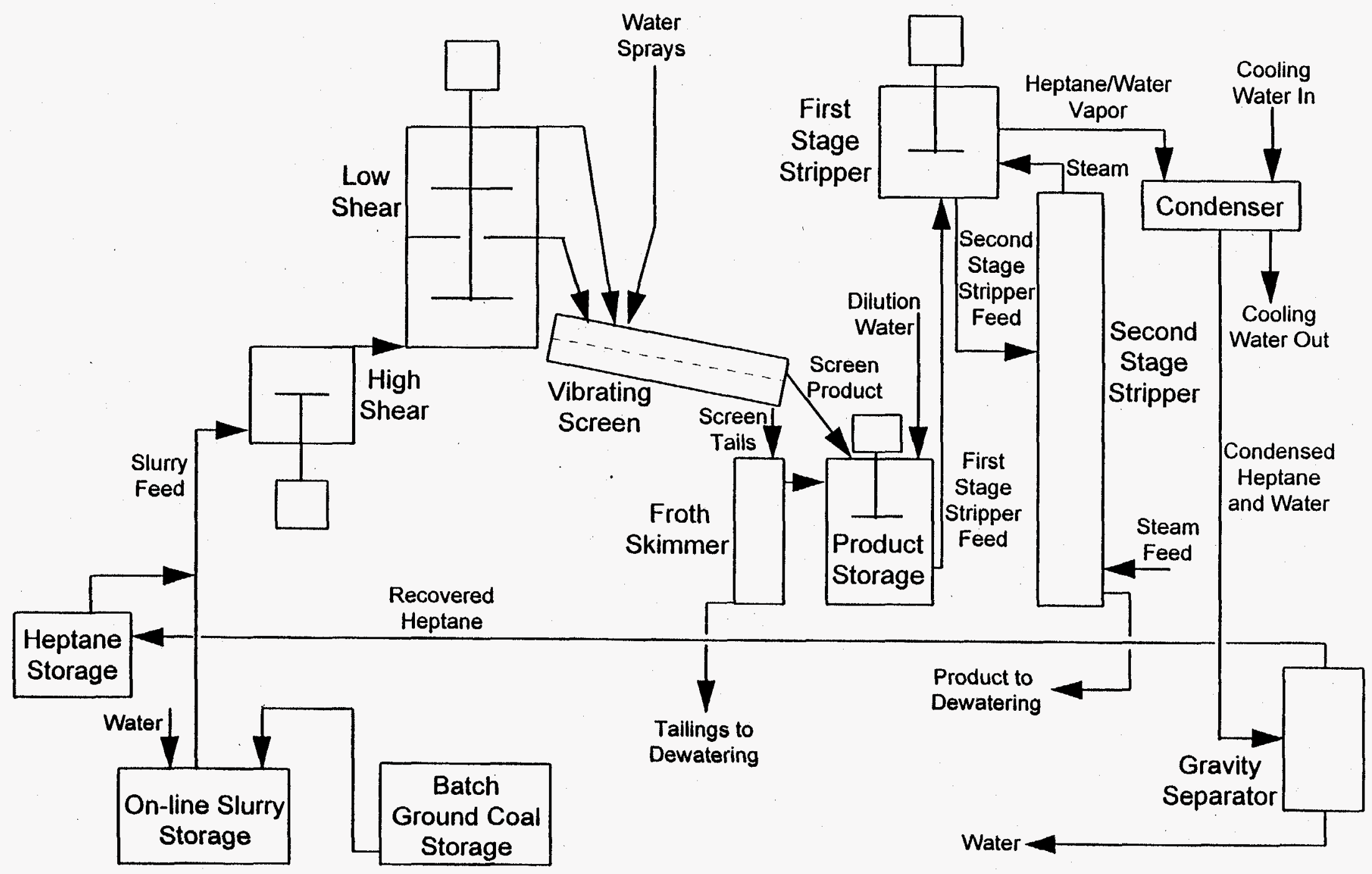

Figure 3. Bench-scale Unit Block Flow Diagram 


\section{HIGH-SHEAR AGGLOMERATION}

The high-shear step of the agglomeration test unit was designed to achieve the following:

- Complete dispersion of the heptane agglomerant.

- Provide sufficient heptane/coal contact to insure that the coal was coated with heptane.

- Provide sufficient particle to particle contact to achieve phase inversion and insure the formation of microagglomerates.

In designing the high-shear vessel, it was of paramount importance that the vessel be of the proper size and provide sufficient residence time to insure that all project coals could be tested. As such, the high-shear vessel design was based on the requirements for the Indiana VII coal, i.e., the coal needing the longest residence time (2 to 3 minutes). Based on this residence time requirement, a 6-inch diameter high-shear vessel was constructed. Maintaining a vessel height/diameter ratio of 1 , this vessel's effective operating height was 6 inches resulting in a volume of approximately 2.8 liters. The specifics of the high-shear vessel were as follows:

- 6-inch diameter by 6 -inches high

- Volume of 2.8 liters

- Fully baffled (4 baffles, $90^{\circ}$ apart)

- $1 / 2$-inch inlet on side of vessel bottom

- 3/4-inch outlet on side of vessel top, $180^{\circ}$ from inlet

Assuming the use of a $7 \%$ ash feed coal, and an approximate heptane to dry ash free coal ratio of 0.3 , this vessel provided the high-shear residence times shown in Table 2 for various coal feed rates and solids concentrations.

Table 2. High-Shear Residence Times

\begin{tabular}{cccc}
\hline & \multicolumn{3}{c}{ Coal Feed Rate, $\mathrm{lb} / \mathrm{hr}$} \\
\cline { 3 - 4 } Solids Concentration, \% & $\underline{25}$ & $\underline{50}$ & $\underline{75}$ \\
7 & $1.0(\mathrm{~min})$ & 0.5 & 0.3 \\
10 & 1.5 & 0.7 & 0.5 \\
15 & 2.2 & 1.1 & 0.7 \\
20 & 2.9 & 1.4 & 1.0 \\
\hline
\end{tabular}

As can be seen in Table 2, this high-shear vessel was able to provide a wide range of residence times over a range of solids concentrations by varying the coal feed rate. Typically, for all coals except the Indiana VII, 50 and $75 \mathrm{lb} / \mathrm{hr}$ feed rates provided residence times in the 30 to 60 second range as required. For the Indiana VII coal 
however, the $25 \mathrm{lb} / \mathrm{hr}$ feed rate was necessary to achieve the anticipated 2 to 3 minute residence times required.

Shear in this vessel was provided by a single impeller located at the vertical center of the vessel. Impellers utilized were of radial flow type having either 4 or 6 blades and of such a diameter to fall within the 0.4 to 0.6 range of impeller/vessel diameter ratio. Impeller rpm's tested provided impeller tip speeds in the 5 to $15 \mathrm{~m} / \mathrm{s}$ range. The highshear impeller was driven by a 1-1/2 Hp Waring blender base unit with a variable speed frequency controller that could provide speeds from several hundred to $12,000 \mathrm{rpm}$. This drive unit included a sealing mechanism to seal the shaft/vessel interface which was located at the vessel bottom.

Coal slurry was fed to high shear via a $1 / 2$-inch feed pipe located on the side of the vessel at the bottom. Discharge from high shear was through a horizontal 3/4-inch pipe connecting the top of the high-shear vessel to the bottom of the low-shear vessel. As such, the bottom of the low-shear vessel was on the same horizontal plane as the top of the high-shear vessel. This arrangement insured that all air was purged from the high-shear vessel during start up of the system.

Heptane was added to the high-shear feed line as required via a variable speed piston pump. When necessary, asphalt in the form of an emulsion was added to the feed coal slurry prior to high shear. Testing of various process conditions in the high-shear unit operation was relatively straight forward. Residence time was controlled by varying coal feed rate and/or solids concentration. Since the high-shear drive unit was variable speed, various shear rates were easily achieved by a combination of rpm settings and impeller configurations.

\section{LOW-SHEAR AGGLOMERATION}

For the low-shear unit operation, it was anticipated that a residence time of approximately 5 minutes would be required to achieve aggiomerates of the desired size. As such, the low-shear vessel was 8-inches in diameter and approximately 18inches high. This vessel, through the application of a centrally located horizontal baffle, provided two 8-inch diameter by 8-inch high, low-shear zones. When the full length of this vessel was used an effective volume of 14 liters was realized, with the horizontal baffle providing a separation between the two zones, reducing the bypass of material through the vessel. The use of an optional exit port at the top of the first 8-inch low shear zone allowed testing at the reduced effective volume of about 6.6 liters. The specifics of the low-shear vessel were as follows:

- 8-inch diameter by 18 -inches high

- Full volume of approximately 14 liters

- Half volume of approximately 6.6 liters

- Horizontal baffles with $1 / 2$ to $1-1 / 2$-inches clearance around the mixer shaft, located 9 inches from the vessel bottom 
- Fully baffled (4 baffles, $90^{\circ}$ apart)

- 3/4-inch inlet on side of vessel bottom

- Various 1-inch and 2-inch outlets located on the side of the vessel at elevations matching the impeller locations and/or the slurry level, for each mixing zone. All outlets were located $180^{\circ}$ from the vessel slurry inlet.

Assuming the use of a $7 \%$ ash coal, and an approximate heptane to dry ash free coal ratio of 0.3 , this low-shear vessel provided the two ranges of low-shear residence times as shown in Table 3 for the various coal feed rates and solids concentrations listed.

As can be seen in Table 3, the 8-inch diameter by 18-inch tall low-shear vessel provided the desired residence times for all coals to be tested over a wide range of solids concentrations by varying the coal feed rate. For coals tested in the 50 to 75 $\mathrm{lb} / \mathrm{hr}$ feed range, the full vessel volume provided residence times in the 1.7 to 7.2 minute range. For coals fed at a $25 \mathrm{lb} / \mathrm{hr}$ feed rate, the half vessel volume provided residence times in the 2.4 to 6.8 minute range.

Table 3. Low-Shear Residence Times

\begin{tabular}{cccc}
\hline & \multicolumn{3}{c}{ Coal Feed Rate, $\mathrm{lb} / \mathrm{hr}$} \\
\cline { 3 - 5 } Solids Concentration, \% & $\underline{25}$ & $\underline{50}$ & $\underline{75}$ \\
Full Volume (14 liters) & & & \\
7 & $5.1(\mathrm{~min})$ & 2.6 & 1.7 \\
10 & 7.3 & 3.7 & 2.4 \\
15 & 10.9 & 5.5 & 3.6 \\
20 & 14.5 & 7.2 & 4.8 \\
Half Volume (6.6 liters) & & & \\
7 & 2.4 & 1.2 & 0.8 \\
10 & 3.5 & 1.7 & 1.2 \\
15 & 5.1 & 2.6 & 1.7 \\
20 & 6.8 & 3.4 & 2.3 \\
\hline
\end{tabular}

Shear in this vessel was provided by two impellers on a single shaft, each located at the vertical center of their respective mixing zones. Impellers tested were of radial flow type having 4 blades and of such a diameter to fall within the 0.4 to 0.6 range of impeller/vessel diameter ratio. Impeller rpms tested provided impeller tip speeds in the 3 to $8 \mathrm{~m} / \mathrm{s}$ range. These impellers were driven by a $1 / 2 \mathrm{Hp}$ air motor mounted to the lid of this vessel. Variable speed capabilities were achieved by control of air pressure to the drive motor, and as such, the full range of rpms to be tested were available. The mixer shaft was sealed at the vessel lid by a compressed 0 -ring seal. 


\section{AGGLOMERATE RECOVERY}

Assuming an average production rate of $50 \mathrm{lb} / \mathrm{hr}$, it was conservatively estimated that a screen deck of approximately 1 square foot surface area would provide sufficient capacity for this dewatering application. Given the small scale of operation, a screen of the proper size was constructed in house to perform the required function. The specifics of the screen design were as follows:

- 10-inch x 16-inch screen deck.

- Ability to test both 48-mesh and 100-mesh screen decks.

- Screen designed to hang from a frame so that inclination from horizontal could be easily adjusted.

- Screen vibration provided by a high frequency vibrating motor welded directly to the lower screen pan.

- Two water spray nozzles with adjustable flowrates.

- Screen feed, overflow, and underflow connections were of flexible hoses to allow for screen vibration.

The low-shear discharge slurry was gravity fed to the screen with a splash plate providing distribution across the screen deck. Screen loading, or feed rate, and feed solids concentration were defined by agglomeration operating conditions, and as such not varied independently. The product or overflow discharge from the screen was into a 55-gallon storage drum for subsequent steam stripping testing.

The screen tailings or underflow discharged into a froth skimming column utilized to recover any carbonaceous heptane bearing material from this stream. This froth skimmer column was 4-inches in diameter and 18-inches tall. During typical benchscale unit testing, the material recovered in the froth skimmer was collected for disposal and not evaluated on a continuous operating basis. Evaluation of the froth skimmer performance was carried out separately during analysis of the vibrating screen tailings sample. In this procedure, any material floating on screen tails sample was analyzed separately to estimate froth skimmer performance.

\section{HEPTANE REMOVAL}

Once the agglomerates were recovered, heptane was removed from the product by direct contact steam stripping. During this process, heat provided by steam evaporated an azeotropic mixture of heptane and water. Once evaporated, these liquids were condensed, cooled, and separated with the heptane recycled back to the process.

The heptane recovery circuit was capable of, through the use of an intermediate feed tank, complete integration with the preceding agglomeration and screening unit operations. This allowed the entire system to be operated continuously. However, as discussed previously, during typical testing the agglomeration and steam stripping circuits were operated independently. 
Steam was provided to the steam stripping circuit by a $1-1 / 2 \mathrm{hp}$ electrically powered boiler. The steam was generated at pressures in the 15 to 50 psi range. It was generally found that the higher the boiler pressure was maintained, the more consistent the steam supply was due to less boiler pressure cycling as a result of make-up water additions.

Single-Stage Steam Stripping Circuit - During initial testing, a single stage of steam stripping was utilized. This stripping vessel was a 4-inch diameter column approximately 52 inches tall as shown in Figure 4. Recovered agglomerates entered the stripper approximately 14 inches from the top of the column. The top 5 inches of the stripper were occupied by 3 overlapping baffles, set at an angle of $5^{\circ}$ from horizontal, to help prevent the entrainment of solids in the vapor stream (heptane and steam) exiting the top of the vessel. Approximately 28 inches below the feed entry point, a 1/4-inch screen supported the column packing (5/8-inch stainless steel pall rings). The height of this packing material was varied from several inches to a maximum of 28 inches during the testing.

Steam entered the stripping column two inches below the 1/4-inch support screen. Four inches below this steam entry point the column tapered to a one-inch discharge at the bottom of the vessel. A slurry level was maintained in the column through the use of a U-tube discharge piping arrangement. In addition to these features, a number of thermocouples and pressure gauges were installed in the vessel. With this design, the agglomerate slurry feed entered the top of the column and discharged from the bottom, while the steam flow was counter-current, i.e., introduced into the bottom of the column and exited, along with evaporated heptane and water, from the top.

This stripping column was operated in two different modes. The first mode was to operate with a continuous steam phase, i.e., the slurry level was maintained below the steam entry point. In this scenario, the height of the pall-ring packing determined the coal residence time in the column as well as helped to disperse the steam flow through the column. In contrast, when the column was operated in the continuous slurry phase (flooded) mode, the slurry level was maintained at various levels between the steam entry and feed entry elevations. In this case, the pall rings helped prevent excessive turbulence and back mixing as the slurry moved down through the column.

Feed to this stripping column was supplied by a progressive cavity pump from a mixed 55-gallon drum.

Two-Stage Steam Stripping Circuit - As testing progressed, it was found that heptane stripping at elevated pressures, allowing higher operating temperatures, removed more heptane than stripping at ambient pressure. As such, the stripping circuit was modified to include an additional stripping vessel prior to the above described column, which was also modified. This new two-stage circuit better simulated the developing $2 \mathrm{thr}$ PDU stripping circuit design. 


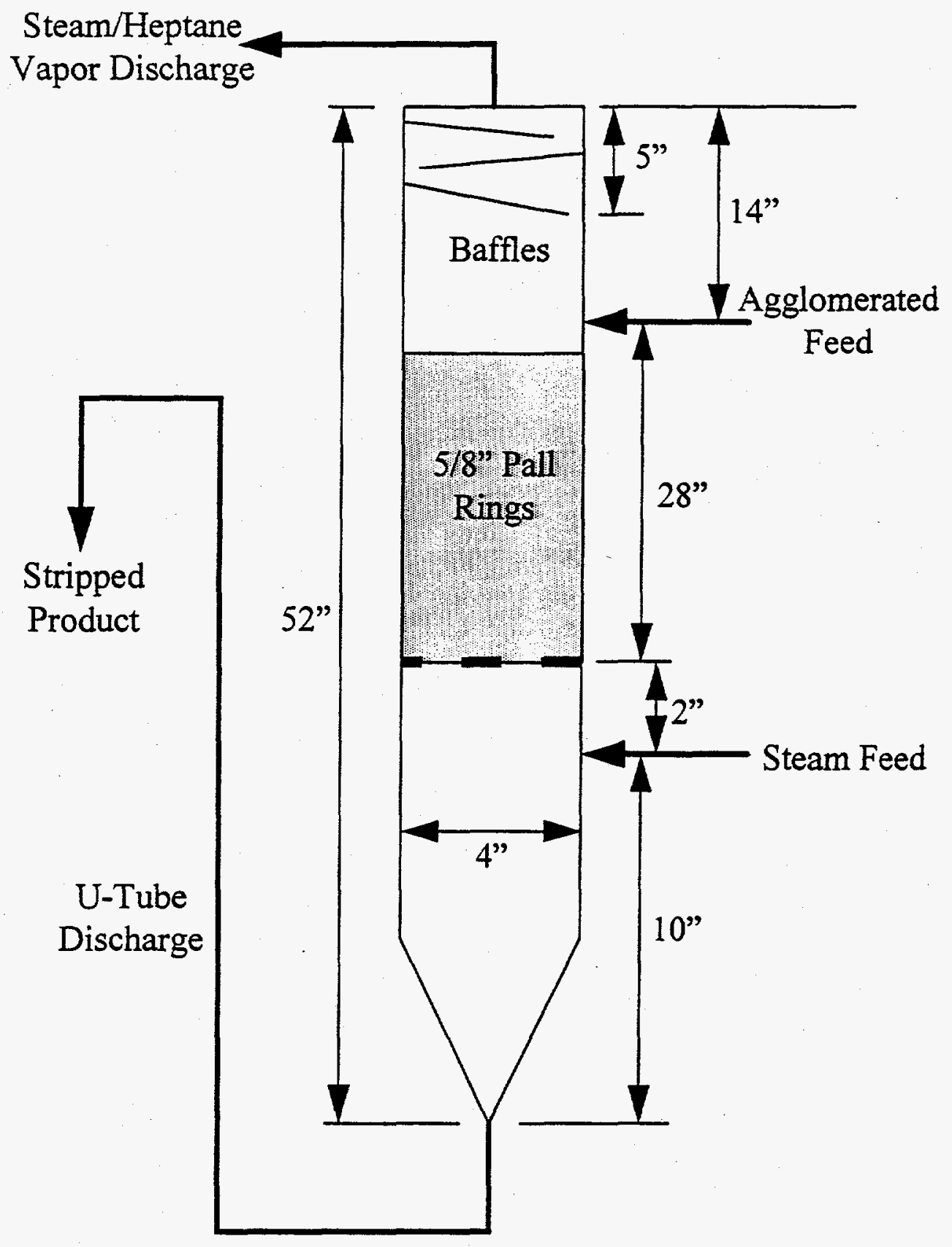

Figure 4. Initial Steam Stripping Vessel

This modified stripping circuit was fed with a peristaltic pump from a newly constructed feed tank. This feed tank had a capacity of approximately 15 gallons, and was fitted with a 4-hp air mixer to insure good mixing and a more consistent feed than from the original mixed 55-gallon feed tank. When possible, the circuit feed was operated continuously. However, due to feed line plugging problems at the low feed rates tested, an intermittent feed operating mode was also utilized. 
The new first-stage stripping vessel was 8 -inches in diameter by 24-inches tall and fitted with a sight glass. This vessel was agitated to keep the buoyant agglomerates dispersed throughout the vessel. With a normal operating level of about 6 to 8 inches, this unit provided 5 minutes residence time at a feed rate of 0.8 to 1.0 liter per minute. The first-stage stripping was carried out at ambient pressure and therefore operated in the 92 to $94^{\circ} \mathrm{C}$ temperature range. This low pressure helped facilitate pumping of the difficult to handle agglomerate feed, i.e., the feed did not have to be pumped into a pressurized vessel. The excess head space, (18 inches), was provided to reduce the amount of coal carryover in the vapor phase to downstream operations.

The feed to this first-stage stripper entered the vessel on the side of the tank, about 2inches from the bottom, and the product was withdrawn from the bottom of the vessel. During this stage of stripping, the bulk of the heptane was removed essentially disintegrating the agglomerates and producing an easily handled slurry stream. As such, the first-stage stripper product could then be pumped to the pressurized secondstage stripper by the progressive cavity (Moyno) pump used as the circuit feed pump in the original single-stage design. This intermediate pump was generally operated at a fixed speed. As mentioned above, the circuit feed pump operation was variable and/or intermittent, to maintain the desired first-stage stripper operating level and temperature.

The original single-stage stripping column was modified to serve as the second-stage stripper. It was lengthened to increase its residence time to approximately 10 minutes and modified to allow operation at a positive pressure of 10 to $15 \mathrm{psi}$. As such, the operating temperature in this second-stage stripper was maintained in the 115 to $120^{\circ} \mathrm{C}$ range. The plug flow packed column design provided greater mass transfer efficiency. The packing utilized was 5/8-inch pall rings which insured both minimal back-mixing and good steam distribution across the column's entire cross-section.

The feed entered the second-stage stripper in the upper portion of the column, and was discharged from the bottom. Since the bulk of the heptane had been removed in the first-stage stripper, disintegrating the agglomerates, the second-stage feed easily flowed through the packed column. The operating level of the second-stage stripper was maintained to provide 10-minutes residence time via manual operation of a product discharge valve. The desired operating pressure and temperature were maintained by manual operation of a vapor discharge valve.

This two-stage stripping circuit utilized a countercurrent steam flow in which fresh steam entered the bottom of the second-stage stripping column. The second-stage vapor product was then used as the steam feed to the first-stage stripper.

\section{HEPTANE RECOVERY}

The exiting vapor stream from the stripping circuit consisted of steam laden with heptane. This stream was condensed in a tube coil traveling through a water bath. The water bath was serviced by sufficient utility water to both condense the steam/heptane vapor and cool the liquids to about $38^{\circ} \mathrm{C}$. 
Once condensed and cooled, this water/heptane mixture was separated by gravity in a column. The condensate feed entered this column in the middle, with heptane (s.g.=0.7) overflowing the top of the column, and water removed from the bottom. The interface level in the gravity separator was maintained by a U-tube discharge arrangement for the water from the bottom of the column. This interface location was controlled by varying the elevation of the final water discharge point.

The heptane recovered in the gravity separator was filtered as required to remove any coal carried over in the process, and recycled to the heptane feed drum. The recovered water was processed through the Amax R\&D water treatment facility.

\section{PRODUCT AND TAILINGS DEWATERING}

Once the heptane was removed the product had to be dewatered. Due to the small scale of this test unit, a continuous integrated dewatering system was not provided. As such, bulk quantities of product were stored in existing tanks and subsequently dewatered by available pilot-scale equipment. The process tailings were also dewatered in existing pilot-scale equipment.

\section{NITROGEN BLANKETING SYSTEM}

Due to the volatility and explosiveness of heptane and its vapor, respectively, a nitrogen blanketing system was included during initial construction of the bench-scale agglomeration unit. This system consisted of a nitrogen gas supply tank with connections to all process equipment in which heptane was normally present.

Upon start up of the test unit it was found that application of the nitrogen blanketing system to the small bench-scale unit was impractical, causing operational difficuities. Due to these problems and the small scale of the unit, i.e., the small amounts of heptane present in the system, the nitrogen blanket system was abandoned and not used for the bulk of the Subtask 6.5 testing. The nitrogen blanket was, however, still used for the 55-gallon heptane supply drum since it was found that the additional head pressure on the heptane supply resulted in a more consistent heptane flowrate.

\section{DATA ACQUISITION SYSTEM}

An on-line data acquisition system was included in the selective agglomeration test unit. This system allowed real-time data acquisition of system temperatures during operation of the unit, and also provided a data log into which any manually obtained operating conditions could be entered. This data acquisition/recording system was divided into three parts for the agglomeration circuit, steam stripping circuit, and the condensation/heptane recovery circuit. For each of these circuits, the temperatures associated with the process were automatically logged, while other pertinent process information such as flowrates, pressures, and operating levels were manually entered. 


\section{AGGLOMERATION TESTING AND CHARACTERIZATION EQUIPMENT}

The test unit utilized during Subtask 6.5 consisted primarily of the selective agglomeration system described above. Additional test equipment used during the course of this subtask work, which were not an integral part of the test unit include:

- 4-foot $x$ 4-foot wet overflow ball mill

- Drais stirred-ball mill

- 3-foot diameter Sweco screen for closed circuit grinding

- Various agitated slurry tanks

- Pilot-scale filter presses for dewatering bulk quantities of both clean coal product and tailings

- Laboratory vacuum filtration equipment for dewatering samples of both process products and tailings

- Digital balances for weighing samples and calibrating flowrates

- Ro-Tap sieve shaking machine

- Leeds and Northrup Microtrac particle size analyzer

- Micrometrics SediGraph particle size analyzer

- Forced air ovens for sample drying

- Various analytical instruments including Fisher ash analyzer, Leco sulfur analyzer, and Parr Calorimeter for Btu determination

\section{AGGLOMERATION REAGENTS}

The primary reagent used during Subtask 6.5 testing was the agglomerant heptane, which was added prior to high shear agglomeration. The bulk of the testing was carried out utilizing a commercial grade heptane obtained from Phillips. This commercial grade heptane contained between 21 and $25 \%$ n-heptane, with the bulk of the remainder being other various $\mathrm{C}_{5}, \mathrm{C}_{6}$ and $\mathrm{C}_{7}$ hydrocarbons. The boiling point of this commercial grade heptane was in the 92 to $96^{\circ} \mathrm{C}$ range.

For comparison purposes, some testing was also carried out using a technical or pure grade heptane. This pure grade heptane contained at least $99 \% \mathrm{n}$-heptane and had a mild odor compared to the commercial grade heptane.

One additional reagent used during Subtask 6.5 testing was asphalt in the form of an emulsion. Asphalt was found to be an effective agglomeration aid for oxidized or difficult to agglomerate coals like the Indiana VII. As this Indiana coal aged, it was observed that longer high-shear residence times were required to achieve agglomeration. However, the addition of asphalt prior to high shear was found to reduce the required residence time to achieve inversion. 


\section{PROCESS CHARACTERIZATION}

Samples of feed, product, and tailings were characterized to determine process performance. The ash and moisture contents of these streams were routinely determined to allow evaluation of overall system performance. Process product and tailings heptane contents were also determined as required. Samples and flowrates of various streams, namely feed, low-shear product, screen overflow, screen underflow, steam stripping feed, and steam stripping product were also taken to allow evaluation of individual unit operation performances.

Various process conditions were monitored on line through the use of thermocouples, flow meters, and pressure gauges. Where possible, these instruments were connected to the data acquisition system for automatic data logging. 


\section{RESULTS AND DISCUSSION}

This section of the report presents and discusses the results of the Subtask 6.5 test work. The results are presented in the following order:

- Test coals evaluated

- Grinding requirements

- Batch agglomeration results

- Continuous agglomeration results

- Batch stripping results

- Continuous stripping results

- Tailings heptane analysis

- Toxic trace element distribution

\section{TEST COALS}

Prior to the start of Subtask 6.5 testing, it was determined that the low-rank Dietz coal would not be evaluated due to the combination of the long high-shear residence time, high asphalt dosage, and low $\mathrm{pH}$ required to achieve agglomeration.

As such, bench-scale testing focused on the five remaining project coals selected, acquired, and characterized during Task 2, Coal Selection and Procurement. Details of the selection process and criteria can be found in the Subtask 2.1 Coal Selection Plan and Recommendations Topical Report [6] and a published paper [7]. In addition to the original five remaining test coals, Hiawatha coal was also evaluated since it was chosen as a replacement for the no longer available Sunnyside coal for larger-scale PDU testing. Table 4 lists the six coals tested along with their ranks and sources.

\section{Table 4. Test Coal Selection and Characterization}

\begin{tabular}{|c|c|c|c|}
\hline Coals Seam & Rank & State & Source Mine \\
\hline $\begin{array}{c}\text { Taggart } \\
\text { Indiana VII } \\
\text { Sunnyside } \\
\text { Winifrede } \\
\text { Elkhorn No. } 3 \\
\text { Hiawatha }\end{array}$ & $\begin{array}{l}\text { hvA Bituminous } \\
\text { hvC Bituminous } \\
\text { hvA Bituminous } \\
\text { hvA Bituminous } \\
\text { hvA Bituminous } \\
\text { hvA Bituminous }\end{array}$ & $\begin{array}{c}\text { Virginia } \\
\text { Indiana } \\
\text { Utah } \\
\text { West Virginia } \\
\text { Kentucky } \\
\text { Utah }\end{array}$ & $\begin{array}{c}\text { Wentz } \\
\text { Minnehaha } \\
\text { Sunnyside } \\
\text { Sandlick } \\
\text { Chapperal } \\
\text { Crandall Creek }\end{array}$ \\
\hline
\end{tabular}

\section{GRINDING REQUIREMENTS}

Subtask 6.5 testing utilized these six coals ground to a variety of particle size distributions (PSD). The original target PSD specifications, shown in Table 5, were 
based on testing results from Subtask 6.2 Selective Agglomeration Grinding and Subtask 6.3 Selective Agglomeration Process Optimization Research, and represent those grinds which were anticipated to provide sufficient liberation to meet the project goal of 1 to $2 \mathrm{lb}$ ash/MBtu product.

Table 5. Initial Test Coal PSD Liberation Requirements

\begin{tabular}{|c|c|c|c|c|c|}
\hline Size, microns & Taggart & Sunnyside & Indiana \#7 & Elkhorn No. 3 & Winifrede \\
\hline $\mathrm{D}_{20}{ }^{*}$ & 12 & 7 & 3 & 7 & 2 \\
\hline$D_{50}{ }^{*}$ & 45 & 22 & 8 & 19 & 6 \\
\hline$D_{80}{ }^{*}$ & 100 & 60 & 22 & 45 & 14 \\
\hline$M M D^{\star \star}$ & 61 & 30 & 14 & 36 & 8 \\
\hline $\begin{array}{l}D_{20}, D_{50} \text {, and } \\
M M D \text { represe }\end{array}$ & $\begin{array}{l}\text { es rep } \\
\text { mass }\end{array}$ & $\begin{array}{l}t \text { the } 20,50 \\
\text { diameter }\end{array}$ & $80 w$ & passin & respective \\
\hline
\end{tabular}

As Subtask 6.5 testing progressed, various other PSDs were evaluated in the continuous bench-scale agglomeration unit. Table 6 presents a summary of all the PSDs evaluated during the testing. Also included in Table 6 is a description of how the ground slurries were prepared along with an indication of whether the particular grind size met the target ash content of $2 \mathrm{lb} / \mathrm{MBtu}(1 \mathrm{lb} / \mathrm{MBtu}$ for the Taggart coal).

Table 6. Subtask 6.5 Particle Size Distributions Evaluated

\begin{tabular}{|c|c|c|c|c|c|c|}
\hline \multirow[b]{2}{*}{ Coal } & \multirow[b]{2}{*}{ Grinding Method } & \multicolumn{4}{|c|}{ Microns } & \multirow[b]{2}{*}{ Ash Target Met } \\
\hline & & ${\underline{D_{20}}}$ & $\underline{D}_{50}$ & $\underline{D}_{80}$ & MMD & \\
\hline Taggart & 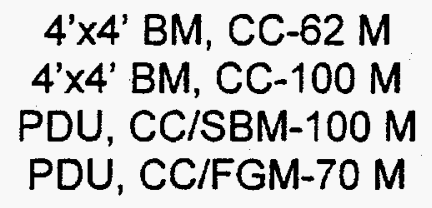 & $\begin{array}{c}8.9 \\
8.8 \\
12.6 \\
5.9\end{array}$ & $\begin{array}{l}28.1 \\
26.8 \\
38.0 \\
16.2\end{array}$ & $\begin{array}{l}90.8 \\
64.9 \\
74.7 \\
32.8\end{array}$ & $\begin{array}{l}50.7 \\
36.9 \\
45.7 \\
23.0\end{array}$ & $\begin{array}{l}\text { No } \\
\text { No } \\
\text { No } \\
\text { Yes }\end{array}$ \\
\hline Sunnyside & $\begin{array}{l}4^{\prime} \times 4^{\prime} B M, C C-100 M \\
4^{\prime} \times 4^{\prime} B M, C C-150 M\end{array}$ & $\begin{array}{l}8.0 \\
6.5\end{array}$ & $\begin{array}{l}24.9 \\
19.5\end{array}$ & $\begin{array}{l}59.6 \\
42.9\end{array}$ & $\begin{array}{l}34.3 \\
25.1\end{array}$ & $\begin{array}{l}\text { Yes } \\
\text { Yes }\end{array}$ \\
\hline Indiana VII & $\begin{array}{c}\text { AM, CC-325 M } \\
\text { PDU, CC/FGM-270M }\end{array}$ & $\begin{array}{l}4.2 \\
4.2\end{array}$ & $\begin{array}{l}10.4 \\
10.8\end{array}$ & $\begin{array}{l}21.9 \\
26.0\end{array}$ & $\begin{array}{l}14.5 \\
16.4\end{array}$ & $\begin{array}{l}\text { Yes } \\
\text { No }\end{array}$ \\
\hline Elkhorn No. 3 & $4^{\prime} \times 4^{\prime} \mathrm{BM}, \mathrm{CC}-100 \mathrm{M}$ & 10.7 & 29.6 & 68.0 & 39.4 & Yes \\
\hline Winifrede & AM-OC-5 passes & 2.0 & 4.2 & 12.4 & 7.1 & Yes \\
\hline Hiawatha & $\begin{array}{l}4^{\prime} \times 4^{\prime} B M, C C-100 \mathrm{M} \\
4^{\prime} \times 4^{\prime} B M, C C-150 \mathrm{~B}\end{array}$ & $\begin{array}{l}11.5 \\
8.1\end{array}$ & $\begin{array}{l}32.9 \\
22.5\end{array}$ & $\begin{array}{l}65.2 \\
46.6\end{array}$ & $\begin{array}{l}40.9 \\
27.4\end{array}$ & $\begin{array}{l}\text { Yes } \\
\text { Yes }\end{array}$ \\
\hline xplanations: & $\begin{array}{l}=\text { Ball mill } \\
-62 M=\text { Closed circuit grindi } \\
U=\text { Grinding in the } 2 \text { thr } P \\
\text { /SBM = Closed circuit grind } \\
\text { FGG = Closed circuit grind } \\
\text { = Attritor mill }\end{array}$ & & 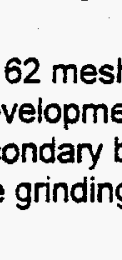 & $\begin{array}{l}\text { screen } \\
\text { t Unit } \\
\text { Ill mill } \\
\text { mill }\end{array}$ & & \\
\hline
\end{tabular}




\section{BATCH AGGLOMERATION TESTING}

As a matter of routine evaluation, batch agglomeration tests were performed on samples of various ground feedstocks. This batch testing procedure is outlined below:

1. Determine feed slurry solids concentration.

2. Weigh out appropriate amount of feed slurry to provide the target dry coal feed weight.

3. Calculate heptane weight required to achieve target heptane/coal ratio and weigh out.

4. Calculate asphail weight required to achieve target asphalt lb/ton coal target and weigh out.

5. Combine pre-weighed feed slurry, heptane, and asphalt in Waring blender.

6. Run high shear in Waring blender for 1 minute or until inversion is seen.

7. Run low shear in Waring blender for 1 minute.

8. Screen blender contents on 100 mesh screen and rinse.

9. Repulp material retained on screen in the Waring blender to the desired total weight.

10. Run high shear in Waring blender for 15 seconds.

11. Run low shear on Denver mixer until agglomerate growth approaches $2 \mathrm{~mm}$.

12. Rinse product on 48 mesh screen for 2 minutes.

13. Dry, weigh, and analyze final screen product for ash content.

14. Combine two sets of screen tailings and filter, dry, weigh, and analyze for ash content.

These batch test results provided a means to evaluate the liberation characteristics of any given ground feedstock generated as part of the Subtask 6.5 test work. In other words, the results of these batch tests provided an estimate of achievable product ash contents to be expected in the continuous agglomeration unit. It is interesting to note that in general, slightly lower product ash levels were achieved in the continuous unit than through the batch testing procedure.

The following sections provide the results for all of the batch agglomeration testing carried out under Subtask 6.5.

\section{Winifrede Coal}

To achieve the desired particle size distribution (PSD), the Winifrede coal was initially ground in the 4-foot $\times 4$-foot ball mill in open circuit. The product from this grind was then normally subjected to two or three passes through the Drais stirred-ball mill to achieve the appropriate PSD. However, during the first two passes through the Drais mill, a cooling water leak resulted in a drastic reduction in solids concentration from approximately 40 to $18 \%$ solids. The dilute slurry resulted in a less efficient grind, and 
therefore, three additional passes through the Drais mill were needed. These last three grinds were carried out at high feed rates to prevent overheating of the mill since the cooing water had to be turned off to avoid additional slurry dilution.

PSDs for the first, second, and fifth Drais mill pass products are shown in Table 7, along with the product ash content from batch agglomeration tests carried out with each. As can be seen from this data, the product ash target of $2.0 \mathrm{lb}$ ash/MBtu was achieved only with the fifth pass through the Drais mill.

Table 7. Winifrede Coal Grinding PSDs and Batch Test Product Ash Values

\begin{tabular}{|c|c|c|c|}
\hline & Drai & rinding $P$ & Jucts \\
\hline & First & Second & Fifth \\
\hline Microns & & ve Perce & \\
\hline 75 & 100.0 & 100.0 & 100.0 \\
\hline 53 & 99.8 & 100.0 & 100.0 \\
\hline 45 & 99.2 & 100.0 & 100.0 \\
\hline 38 & 98.7 & 100.0 & 100.0 \\
\hline 30 & 89.0 & 96.6 & 99.8 \\
\hline 20 & 77.1 & 82.4 & 92.0 \\
\hline 15 & 66.0 & 75.4 & 82.2 \\
\hline 10 & 50.7 & 63.5 & 78.0 \\
\hline 8 & 42.0 & 55.6 & 75.4 \\
\hline 6 & 31.9 & 44.9 & 65.9 \\
\hline 4 & 20.5 & 28.9 & 48.3 \\
\hline 3 & 14.1 & 20.4 & 35.0 \\
\hline 2 & 7.5 & 10.8 & 19.6 \\
\hline 1 & 1.5 & $\underline{2.1}$ & $\underline{4.3}$ \\
\hline$D_{80}$ & 22.3 & 18.3 & 12.4 \\
\hline $\begin{array}{l}\text { Batch Test Prod., } \\
\text { lb ash/MBtu }\end{array}$ & 2.45 & 2.11 & 1.80 \\
\hline
\end{tabular}

Due to the fineness of this Winifrede coal grind, several batch tests were also completed to evaluate the effect of 2-ethyl-1-hexanol as an agglomeration promoter. In particular, these tests were carried out to determine if the length of time required to achieve inversion during the initial high shear step could be reduced. The results of these tests indicated no significant reduction of inversion time with the addition of this agglomeration promoter.

\section{Elkhorn No. 3 Coal}

Only one batch test was completed utilizing the Elkhorn No. 3 coal. For this test, the feedstock was ground in the 4-foot $x$ 4-foot ball mill in closed circuit with a 100-mesh screen, providing a PSD with a $D_{80}$ of 68 microns. Results for this test indicated that a 
product ash content of $1.74 \mathrm{lb} / \mathrm{MBtu}$ was achieved, easily surpassing the $2 \mathrm{lb} / \mathrm{MBtu}$ product ash content target.

\section{Taggart Coal}

Batch testing with the Taggart coal focused on determining the liberation requirements to achieve a $1 \mathrm{lb}$ ash/MBtu product. For this work, Taggart coal ground feedstock was prepared by the following three methods:

1. Batch grinding in the attritor mill to various sizes

2. Closed-circuit grinding in the 4-foot $\times 4$-foot ball mill at two different top sizes

3. Continuous grinding in the 2 thr PDU grinding circuit under various conditions

The results for all of these batch tests are shown in Figure 5, which shows product ash content in $\mathrm{lb} / \mathrm{MBtu}$ vs the particle size distribution $80 \%$ passing size $\left(\mathrm{D}_{80}\right)$ in microns.

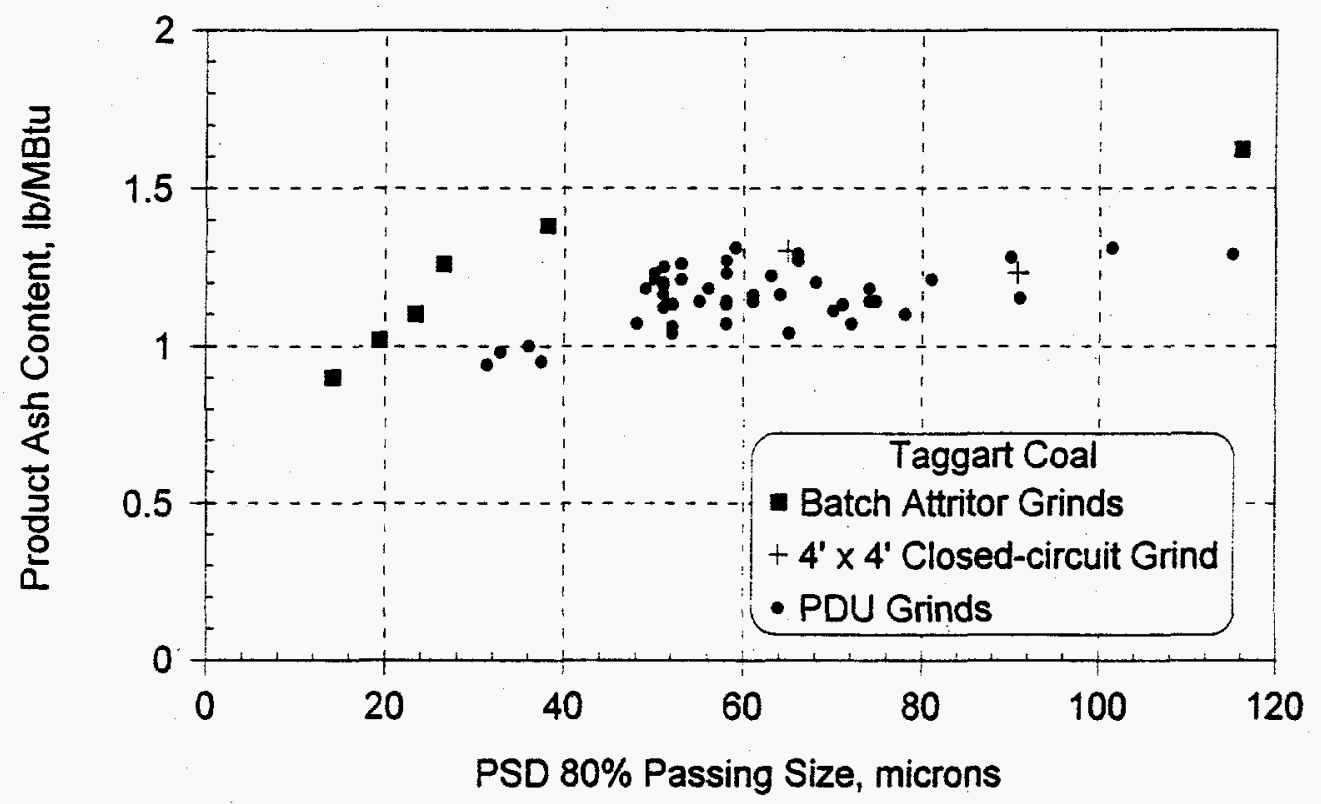

Figure 5. Taggart Coal Batch Testing - Product Ash vs Grind Size

As can be seen from this data, the poorest liberation (highest product ash content at similar $D_{80} s$ ) was observed in the batch attritor ground feedstock tests. In contrast, the best liberation (lowest product ash content at similar $D_{80} S$ ) was achieved when the coal was ground in the PDU grinding circuit. This improvement in mineral matter liberation, at similar overall grind sizes, is attributed to the selective regrinding of higher ash coarse material, via cyclone separation, in the PDU grinding circuit.

Based on these results, subsequent continuous testing with the Taggart coal was carried out utilizing feedstock generated in the PDU grinding circuit (closed circuit with the fine grinding mill with 70-mesh topsize control). As shown previously in Table 6, this 
grind had a $D_{80}$ of 32.8 microns, and was the only feedstock tested continuously, that provided sufficient liberation to meet the $1 \mathrm{lb} / \mathrm{MBtu}$ product ash specification.

\section{Hiawatha Coal}

Batch agglomeration testing for the Hiawatha coal focused on determining the liberation requirements to achieve a $2 \mathrm{lb}$ ash/MBtu product. For this work, the Hiawatha coal was ground by the following three methods:

1. Closed-circuit grinding in the 4-foot $\times 4$-foot ball mill with a 100-mesh screen.

2. Closed-circuit grinding in the 4-foot $\times 4$-foot ball mill with a 150-mesh screen.

3. Continuous grinding in the $2 \mathrm{t} / \mathrm{hr}$ PDU grinding circuit under various conditions.

The results for all of these batch test are shown in Figure 6, which shows product ash content in lb/MBtu vs the grind size $D_{80}$ in microns. As can be seen from this data, only one of the grinds generated in the PDU grinding circuit for the advanced flotation testing under Subtask 8.4 provided sufficient liberation to achieve the $2 \mathrm{lb} / \mathrm{MBtu}$ product ash specification. This was not unexpected since due to the high selectivity of the agglomeration process a finer grind would be required than for the flotation process.

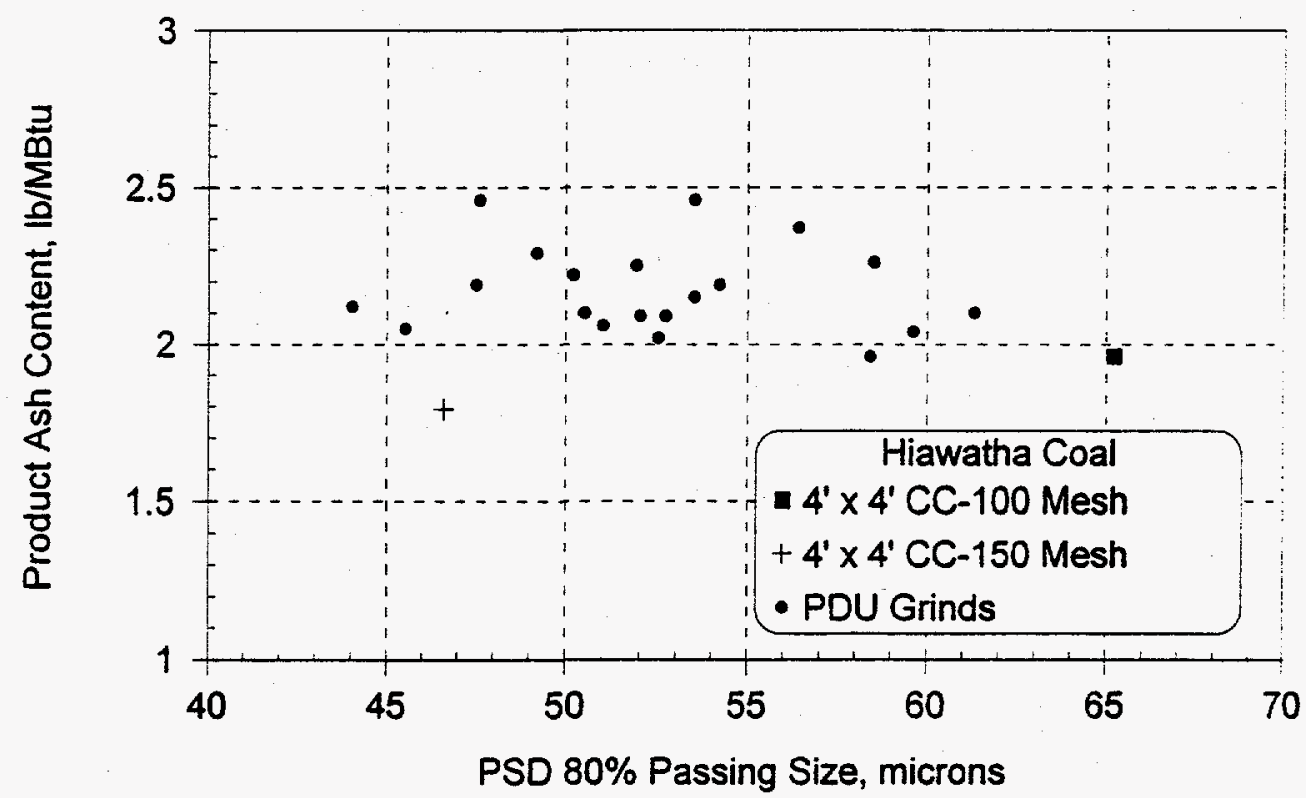

Figure 6. Hiawatha Coal Batch Testing - Product Ash vs Grind Size

As can be seen from the data in Figure 6, the PDU ground batch test results do not exhibit the trend seen for other coals indicating lower product ash content with decreasing grind size. This lack of size vs product ash relationship is surprising and attributed to a combination of varying feed coal characteristics and the wide range of process variable levels tested. In particular, batch testing parameters that varied from test to test included feedstock solids concentration, heptane concentration, high-shear residence time, low-shear residence time, and agglomerated product size. 
In contrast, the two feedstocks ground in the 4-foot $\times 4$-foot ball mill, in closed-circuit with 100- and 150-mesh screens, both achieved the target product ash specification of $2 \mathrm{lb} / \mathrm{MBtu}$. This better liberation at similar grind sizes is attributed to the feedstock originating from a different lot of coal. Based on these results, subsequent continuous agglomeration testing with the Hiawatha coal was carried out utilizing the feedstock closed-circuit ground in the 4-foot $x$ 4-foot ball mill with the 100-mesh screen. As shown previously in Table 6 , this grind had a $D_{80}$ of 65 microns, and when tested continuously, provided sufficient liberation to meet the $2 \mathrm{lb} / \mathrm{MBtu}$ product ash specification.

\section{Indiana VII Coal}

Batch agglomeration testing for the Indiana VII coal focused on evaluating the liberation characteristics of feedstock prepared in the 2 thr PDU grinding circuit under Subtask 8.4 operations. For this work, the Indiana VII coal ground feedstock was prepared as follows:

1. Continuous grinding in the $2 \mathrm{t} / \mathrm{hr}$ PDU grinding circuit under various conditions.

2. Continuous grinding in the $2 \mathrm{t} / \mathrm{hr}$ PDU grinding circuit followed by additional levels of grinding in the batch attritor mill.

The results for all of these batch tests are shown in Figure 7, which shows product ash content in $\mathrm{lb} / \mathrm{MBtu}$ vs the grind $\mathrm{D}_{80}$ in microns.

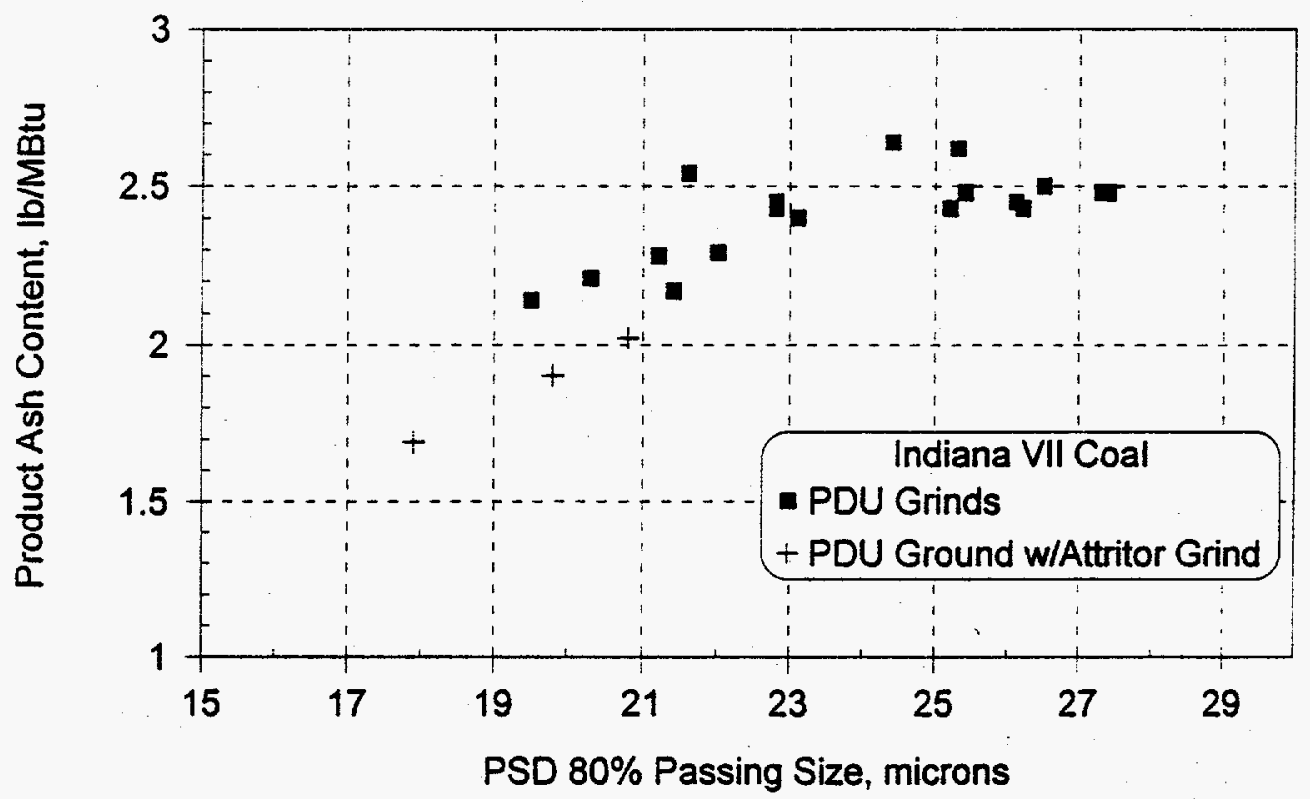

Figure 7. Indiana VII Coal Batch Testing - Product Ash vs Grind Size

As can be seen from this data, none of the Indiana VII coal grinds generated during the advance flotation PDU testing under Subtask 8.4 provided sufficient liberation to achieve the $2 \mathrm{lb} / \mathrm{MBtu}$ product ash specification. However, this data indicates that 
additional grinding to a $D_{80}$ of approximately 20 microns allowed the product ash specification to be met. This data also clearly shows the trend of decreasing product ash content with decreasing particle size.

\section{CONTINUOUS AGGLOMERATION TESTING}

This section of the report presents the findings of the Subtask 6.5 continuous agglomeration testing as follows:

1. Procedures utilized

2. Start up testing and system modifications

3. Test results for each coal

4. Summary of agglomeration variable effects

\section{Procedures}

Following is a brief description of the procedures used for the continuous selective agglomeration testing.

\section{Feedstock Preparation}

Ground slurry feedstock was prepared for bench-scale continuous testing through a variety of grinding equipment as discussed previously, and stored in a 1000-gallon agitated tank. As required, the ground feedstock was transferred to a 400-gallon agitated tank from which the slurry was transferred to either of two agitated 55-gallon slurry feed drums and diluted to the target solids concentration.

As any particular test progressed and the 55-gallon feed drum in use became depleted, the feed source was switched to the other 55-gallon drum so the depleted drum could be replenished. In this manner, feed was provided continuously for as long as required.

\section{Agglomeration Testing}

The bench-scale agglomeration unit was fed with a peristaltic pump from the 55-gallon feed drums described above. At the start of each test, the pump speed was set at the anticipated speed required. A flowrate check was then completed and the pump speed adjusted until the target feed rate was achieved. Upon completion of each test, a second flowrate was measured and the average of the starting and ending flow rates. was used for data evaluation.

Similarly, two feed slurry samples were taken for each test. One at the beginning and one at the end of each test. The average solids concentration and ash values of these two samples were then used for data evaluation. 
The operating parameters associated with the agglomeration unit itself were then set to the target levels as follows:

- Heptane delivery rate based on a flow meter reading

- High-shear impeller tip speed based on a variable speed drive setting and confirmed by a tachometer reading

- Low-shear impeller tip speed based on a tachometer reading

- Low-shear residence time based on piping arrangement

- Screen spray water flowrate based on a flowmeter reading

- Screen angle of inclination based on a physical measurement

Once target operating conditions were set, the system was allowed to balance for a minimum of 45 to 60 minutes. During this time the following were continually checked to evaluate how the test was proceeding:

- Presence and quality of inversion at the high-shear discharge

- Size of agglomerates produced in low shear

- Consistency of low-shear discharge

- Screen operation in terms of whether agglomerates were screening as discrete particles or in a bed of significant depth

- Drainage of mineral-matter bearing process water during screening

Once it was determined that the system had reached steady state, or as close to steady state as possible, samples of the low-shear product, screen overflow, and screen underflow were taken for analysis.

\section{Analytical}

This section of the report provides a list the analytical work carried out on each type of test sample. It should be noted that not all procedures were completed for every sample for every test.

Feed Sample - Feed samples were analyzed for solids concentration and ash content. In addition, intermittent feed samples were analyzed for particle size distribution (PSD).

Low-Shear Product Sample - Low shear product samples were evaluated to determine the size range of agglomerates, the shape of agglomerates, and the heptane content of agglomerates.

Screen Product Sample - Screen product samples were analyzed for ash and moisture contents. 
Screen Tailings Sample - In order to simulate the froth skimming unit operation, which was not tested continuously in the bench-scale unit, the screen underflow or tailings samples were processed as follows:

- Any material found floating on the sample was removed, filtered, dried, weighed, and analyzed for ash. These analyses were then used as the basis for projecting the quality and quantity of a continuous froth skimmer product.

- The remaining sample was filtered, dried, weighed, and analyzed for ash content separately. These analyses were then used to define final process tailings quality.

It should be noted that for all results reported in the Appendices of this report, the product and tailings ash values, as well as performance calculations, utilize composited samples from froth skimming simulation as described above.

\section{Data Evaluation}

Based on the analytical results and operating data obtained for each continuous benchscale agglomeration test, the following procedures were used to calculate process operating conditions and performance:

- The dry solids feed rate was calculated using the average of two (start and end of test) feed slurry flowrate and solids concentration determinations.

- The solids flowrates (yield) for all testing were calculated by ash balance using feed, product, and tailings ash values.

- Based on these solids flow rates and solids concentration results, residence times in the high and low shear vessels were calculated.

- Agglomeration mixer impeller tip speeds were calculated based on rpm determinations.

- Heptane dosage was calculated based on the heptane flowmeter reading.

- Btu recoveries were calculated from test feed and product Btu values, which were calculated from an ash/Btu relationship developed for each coal.

- Run-of-Mine (ROM) performance, where applicable, was calculated based on preparation plant performance determined from the data provided by the coal supplier.

\section{Start-Up Testing and System Modifications}

This section of the report summarizes the operational problems encountered during start-up testing of the continuous agglomeration bench-scale test unit. This information is presented by unit operation and also discusses the system modifications made throughout the test program to address any problems encountered. 
Taggart coal ground to a 62-mesh topsize was used as the feedstock for initial start-up testing. A variety of operating conditions were tested to evaluate the operability of the continuous bench-scale agglomeration circuit during start up.

\section{Feed Slurry Delivery}

Upon initial start up, the coal feed system to the agglomeration circuit appeared to operate well with no plugging problems experienced. It was found, however, that during typical testing, the coal slurry feed flowrate decreased approximately 5 to $10 \%$ from the beginning to the end of a test. This phenomenon was attributed to the decreasing suction head of the peristaltic slurry feed pump as the slurry level in the feed drum decreased. The net effect of this phenomenon was a slight increase in the heptane/coal ratio during testing. Whenever possible, the slurry feed drum level was kept to a high level to counteract this problem. However, due to the nature of the feed preparation procedure, i.e., batch filling of drums as required, this was not always possible, and as such, an average feed rate for the entire test run was utilized.

\section{Heptane Delivery}

During the initial test of the agglomeration unit, the heptane was overdosed due to problems with the heptane flowmeter. As a result, the low-shear vessel plugged damaging one of the low shear impellers, the mixing shaft seal, and the motor. It was found that moving the heptane flowmeter to the suction side of the heptane pump resulted in accurate and consistent heptane flow readings, alleviating this problem.

\section{High Shear}

It was found upon initial startup that the high-shear vessel, when operated with the impellers and at the rpms anticipated, had a much greater power draw than expected. This was due to greater than anticipated system power losses attributed primarily to the drive motor inefficiency and shaft friction. However, the high-shear reactor still worked well over a wide range of feed conditions achieving inversion at coal feed rates of 25 , 50 , and $75 \mathrm{lb} / \mathrm{hr}$.

While no serious high-shear plugging problems ever occurred, it was found that at times the high-shear vessel baffles seemed to fill with coal and then clean themselves out. This observation was based on noticeable drops in high-shear power draw for short periods of time. This phenomenon was not a concern, however, since inversion was still continually achieved.

\section{Low Shear}

Start Up - Following damage to the low-shear drive motor upon initial start up, subsequent testing used an air-powered motor for the low-shear vessel. While this 
motor seemed to work well, its speed fluctuated considerably as a function of the available air pressure. Another factor contributing to this low-shear speed fluctuation was the apparent cyclic build-up and discharge of solids from the low-shear vessel. The cause of this initial solids cycling phenomenon stemmed from the air pressure fluctuations in that, during periods of low air pressure, i.e., low impeller speeds, less solids were discharged from the vessel. Then as the air pressure increased, increasing the impeller speed, these retained solids were discharged. The root cause of this problem was found to originate from the compressor supplying the process air. By resetting the compressor settings higher to prevent the air pressure from dropping too low, the cycling of the low-shear impeller speed was reduced. In addition, if care was taken not to operate when large volumes of air were being consumed for other tasks in the facility, the low-shear speed cycling was eliminated completely.

In general it was found that depending on the impeller tip speed, residence time, and heptane/coal ratio utilized, the low-shear product varied in size from approximately 0.5 $\mathrm{mm}$ to $5 \mathrm{~mm}$. Initial findings indicated that the agglomerate size could be controlled by the heptane dosage used, with higher dosages resulting in larger agglomerates.

Full Operation - Much difficulty was encountered when operating the low-shear vessel full, i.e., when using both mixing zones separated by the horizontal baffle to achieve longer residence times. It appeared that the transfer of agglomerates from the lower to upper section of the low-shear vessel was a bottleneck. As such, the opening in the horizontal baffle was increased from 1-1/2 to 5-1/2 inches in diameter, in an attempt to improve the flow to the upper zone. While this modification resulted in marginally better transfer from the lower to upper zone, plugging of the lower zone still occurred.

As such, consistent day to day steady state operation of the low-shear vessel full was not achieved during Subtask 6.5 operations. Typically when operated full, plugging of the lower zone occurred unless starvation quantities of heptane were used. Under these extended residence time conditions, however, low-shear growth was very sensitive to heptane dosage and proved uncontrollable. Also under these conditions, a cyclic low-shear agglomerate growth pattern was observed in which consistent agglomerate size was not achieved.

Discharge - It was determined that when the low-shear product approached 4 to $6 \mathrm{~mm}$ in size, it ceased to flow through the 1-inch discharge port. This lack of flow was attributed to the fact that agglomerates 4 to $6 \mathrm{~mm}$ in diameter approached a critical size (1/4 to $1 / 6$ of the discharge port diameter), preventing exit from the vessel.

One other factor that contributed heavily to the poor discharge from the low-shear vessel was that the overflow discharge arrangement withdrew from a stagnant section of the vessel, i.e., from the top surface, where any floating agglomerates accumulated. To remedy this problem, the discharge ports were lowered such that they were located below the liquid surface. An up-flowing discharge pipe was then used to maintain the desired liquid operating level. While this modification did result in flow improvement, some discharge plugging still occurred. 
In an effort to further reduce plugging of the low-shear vessel discharge, two additional sets of discharge ports were installed in the vessel. One set was 2-inches in diameter, and located to allow an overflow discharge. The second set was 1-inch in diameter, and located at the same elevation as the impellers, utilizing an up-flowing discharge to maintain the correct operating level in the vessel.

Evaluation of these different discharge arrangements led to the following conclusions

- While the use of the 2-inch overflow discharge worked well when the vessel was operated half full, excessive splashing appeared to interrupt the desired mixing pattern. As such, no agglomerate growth was observed.

- The 2-inch overflow discharge, when utilized with the vessel full, provided good agglomerate discharge. However, it was found that the lower half of the vessel still packed full of agglomerates. As a result, the solids discharge reduced over. time, resulting in a buildup of solids and eventual plugging of the vessel.

- Use of the 1-inch discharge port located at the impeller height worked well when the vessel was operated half full. At these conditions, steady-state operation was consistently achieved.

- Use of the 1-inch discharge port located at the impeller height when the vessel was full resulted in plugging of the lower half of the vessel due to poor agglomerate transport through the horizontal baffle.

- Low-shear discharge plugging problems were more pronounced at higher solids concentrations (particularly above 10\%). This trend was expected since at higher solids concentrations and the same volumetric flowrate through the system, the solids flow through the discharge port increased, increasing the chance for plugging.

It should be noted that successful operation of the low-shear vessel half full, utilizing the discharge port located at the impeller height, was not tested until near the end of the Subtask 6.5 work. As such, the discharge plugging problems described above hindered testing for some of the coals evaluated.

\section{Vibrating Screen}

Operation of the vibrating screen for recovery of the low-shear product generally worked well. Only minimal blinding of the 48-mesh screen deck was observed, with more blinding occurring as the heptane concentration was increased. The screen was operated at a downward inclination of approximately $40^{\circ}$ from horizontal, which provided good agglomerate flow across the screen deck under most conditions tested.

In general, the use of spray water on the screen resulted in more coal reporting to the screen tailings. This problem was reduced, however, when more consistent and stronger agglomerates were produced during low shear. It was also determined that both the amount of wash water used and the nature of the spray pattern utilized influenced the amount of coal in the screen underflow. Both higher spray water rates 
and stronger (more forceful) spray patterns resulted in more lost coal. As such, finer spray nozzles (misting type) were installed for subsequent testing.

The screen overflow stream (product) varied in moisture content depending on the size of the agglomerates produced in low shear. When small agglomerates $(<0.5 \mathrm{~mm})$ were produced, the screen overflow stream contained about $55 \%$ water. In contrast when larger agglomerates (2 to $4 \mathrm{~mm}$ ) were produced, the screen overflow stream contained only about $35 \%$ water. Generally, the larger agglomerates contained less residual ash, due to less carryover of mineral-matter bearing process water to the product, i.e., the larger well formed agglomerates drained their associated process water easier.

\section{Winifrede Coal Results}

Since at the time of testing, it was already known that the Winifrede coal would not be evaluated in the $2 \mathrm{t} / \mathrm{hr}$ PDU selective agglomeration module, only limited test work was completed with this coal in the $25 \mathrm{lb} / \mathrm{hr}$ continuous bench-scale unit. This work focused on determining the liberation requirements and general operating conditions necessary to meet the $2 \mathrm{lb} / \mathrm{MBtu}$ product ash specification.

To achieve the desired particle size distribution (PSD), the Winifrede coal was initially ground in the 4-foot $\times 4$-foot ball mill in open circuit. The product from this grind was then subjected to five passes through the Drais stirred-ball mill to achieve the liberation required to meet the desired product ash specification. The complete PSD for this ground Winifrede feedstock is shown in Table 8.

\begin{tabular}{cc} 
Table 8. Winifrede Coal Particle Size Distribution \\
\hline Microns & Cumulative Weight Percent Passing \\
\cline { 2 - 2 } 38 & 100.0 \\
30 & 99.8 \\
20 & 92.0 \\
15 & 82.2 \\
10 & 78.0 \\
8 & 75.4 \\
6 & 65.9 \\
4 & 48.3 \\
3 & 35.0 \\
2 & 19.6 \\
1 & 4.3 \\
D20 & 2.0 \\
D50 & 4.2 \\
D80 & 12.4 \\
\hline
\end{tabular}

A total of sixteen continuous agglomeration tests utilizing this ground Winifrede feedstock were carried out during Subtask 6.5. This test work used both fresh commercial grade heptane and recycled commercial grade heptane, i.e., heptane 
recovered from previous test work. Test conditions and results for these sixteen continuous tests are shown in Appendix A.

The following presents a list of operating condition ranges tested in the continuous bench-scale unit for the Winifrede coal:

- Feed PSD - $D_{80}$ of 12.4 microns

- Coal feed rate -12.6 to $32.4 \mathrm{lb} / \mathrm{hr}$

- Feed slurry solids concentration - 7 and $10 \%$

- Heptane type - Commercial grade, both fresh and recycled

- Heptane dosage -51.8 to $62.4 \%$ on a dry ash free coal basis (daf)

- Asphalt addition level - $5 \mathrm{lb} /$ ton coal

- High-shear impeller - 2.4-inch, 4-blade, radial flow

- High-shear impeller tip speed - 15 to $19.8 \mathrm{~m} / \mathrm{s}$

- High-shear residence time - 1.1 to 2 minutes

- Low-shear impeller configuration - 4.8-inch, 4 blade, radial flow

- Low-shear impeller tip speed -4.8 to $9.6 \mathrm{~m} / \mathrm{s}$

- Low-shear configuration - Half full and full

- Low-shear residence time - 3.2 to 7.1 minutes

- Vibrating screen deck opening size - 48 mesh

- Vibrating screen inclination - $\mathbf{3 4}$ to $\mathbf{4 0}$ degrees downhill form horizontal

- Vibrating screen spray water rate -0 to $51.6 \mathrm{lb} / \mathrm{hr}$

The results for all of these tests are presented in Figure 8 which shows agglomeration Btu Recovery vs Product ash content.

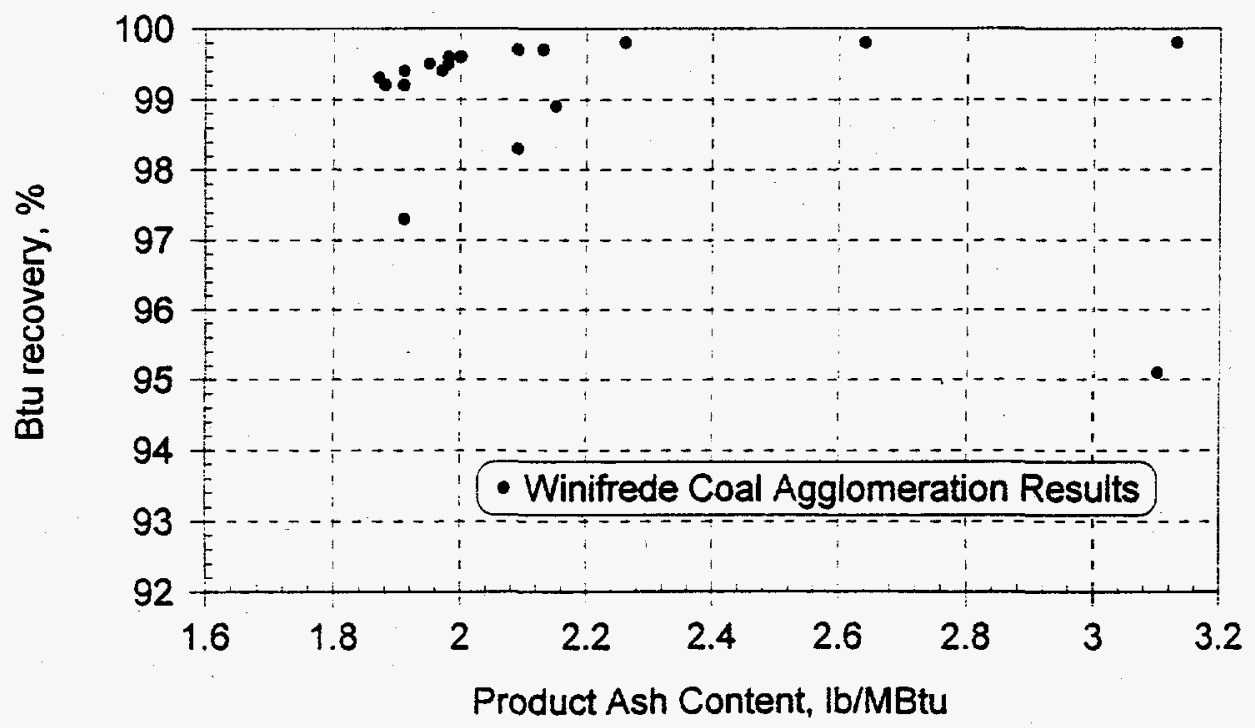

Figure 8. Winifrede Coal Continuous Agglomeration Results 
As can be seen from this data, the $2 \mathrm{lb}$ ash/MBtu specification was met for many of the tests completed, indicating that the 12.4 micron $D_{80}$ grind provided sufficient mineralmatter liberation. This data also indicates that very high Btu recoveries, $>99 \%$, were achieved in all but one of the tests in which the product ash specification was met. The tailings ash values for these tests were in the 47 to $89 \%$ range, with most in the 78 to $89 \%$ range.

No difference in the operation of the continuous agglomeration unit was observed when fresh commercial grade heptane was used as compared to recycled commercial grade heptane. This indicates that the quality of heptane did not degrade when vaporized, condensed and recycled to the process.

In virtually all of these tests, only marginal inversion was achieved during high shear. This is attributed to the extreme fineness of the grind and the inability of the high-shear reactor to provide higher energy inputs. As such, very clear inversions were not achieved, even when asphalt was used to help promote agglomeration.

It was found, during this testing, that even though a good inversion could not be achieved during high shear, agglomerate growth during low shear was sufficient to afford good recovery during screening. In fact, when sufficient heptane was utilized (55 to $60 \%$ daf coal basis), growth during low shear was easily achieved and in fact proved difficult to control under certain operating conditions.

In general, the selective agglomeration process for the Winifrede coal was not affected by changes in most operating variables as long as the following basic process requirements were met:

1. Sufficient energy was provided to achieve inversion during high shear.

2. Sufficient heptane was used to achieve agglomerate growth during low shear.

3. Sufficient drainage of mineral-matter bearing process water during agglomerate recovery by screening.

In testing of the selective agglomeration process, it was found that the greatest effect on product ash content was the size of the agglomerates produced, i.e., the larger the agglomerates the lower the product ash level. This effect is due to the ability of the larger agglomerates to drain their associated process water easier than the small agglomerates. And further, any spray water applied during screening provides better rinsing of mineral matter from large agglomerates than from small agglomerates.

This relationship between agglomerate size and product ash content is clearly shown in Figure 9. It should be noted that the data in Figure 9 includes results for all Winifrede testing, regardless of the operating conditions utilized.

Further, it was found that the screen product solids concentration was also a function of agglomerate size with the larger agglomerates having less moisture associated with them. This trend is expected since the larger agglomerates drain their associated process water easier. This relationship between agglomerate size and screen product 
solids concentration is shown in Figure 10. It should be noted that the data in Figure 10 includes results for all Winifrede testing, regardless of the operating conditions utilized.

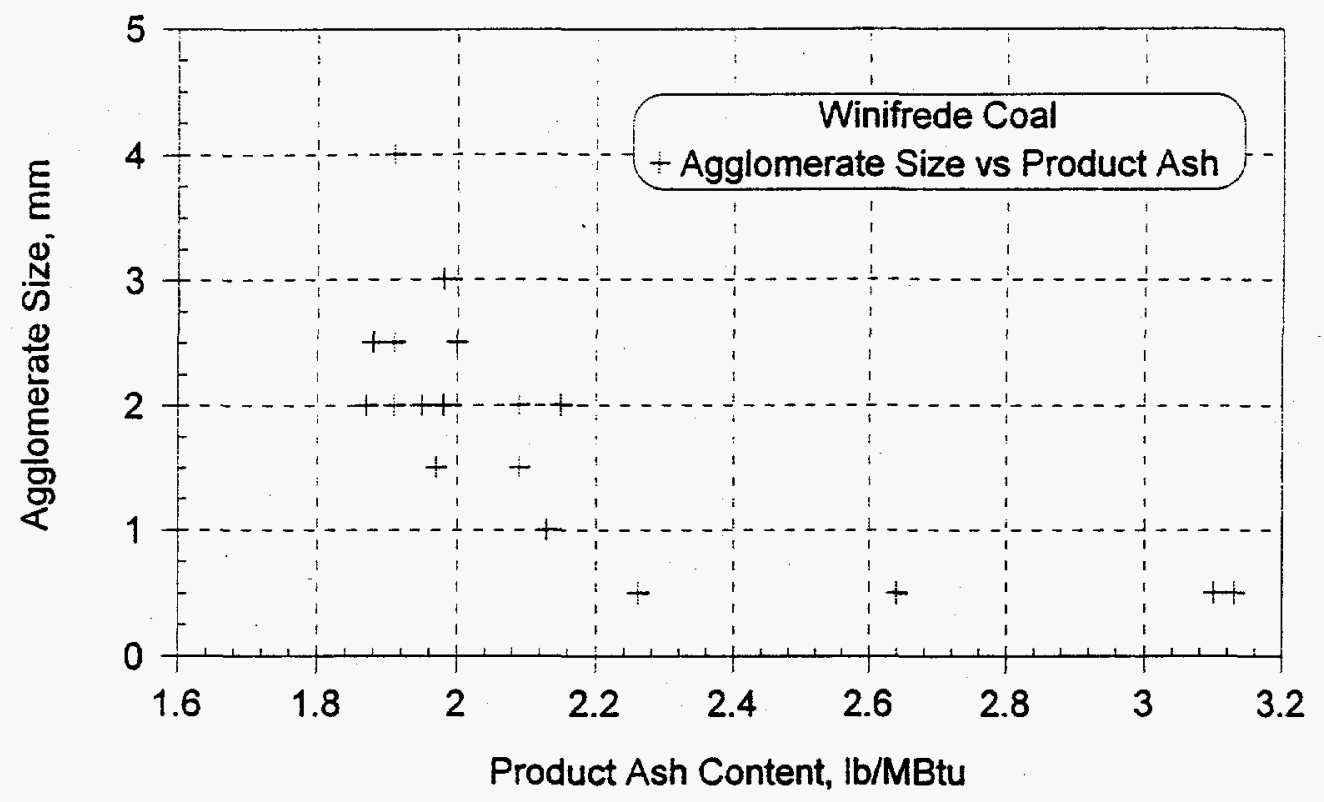

Figure 9. Winifrede Coal - Agglomerate Size vs Product Ash

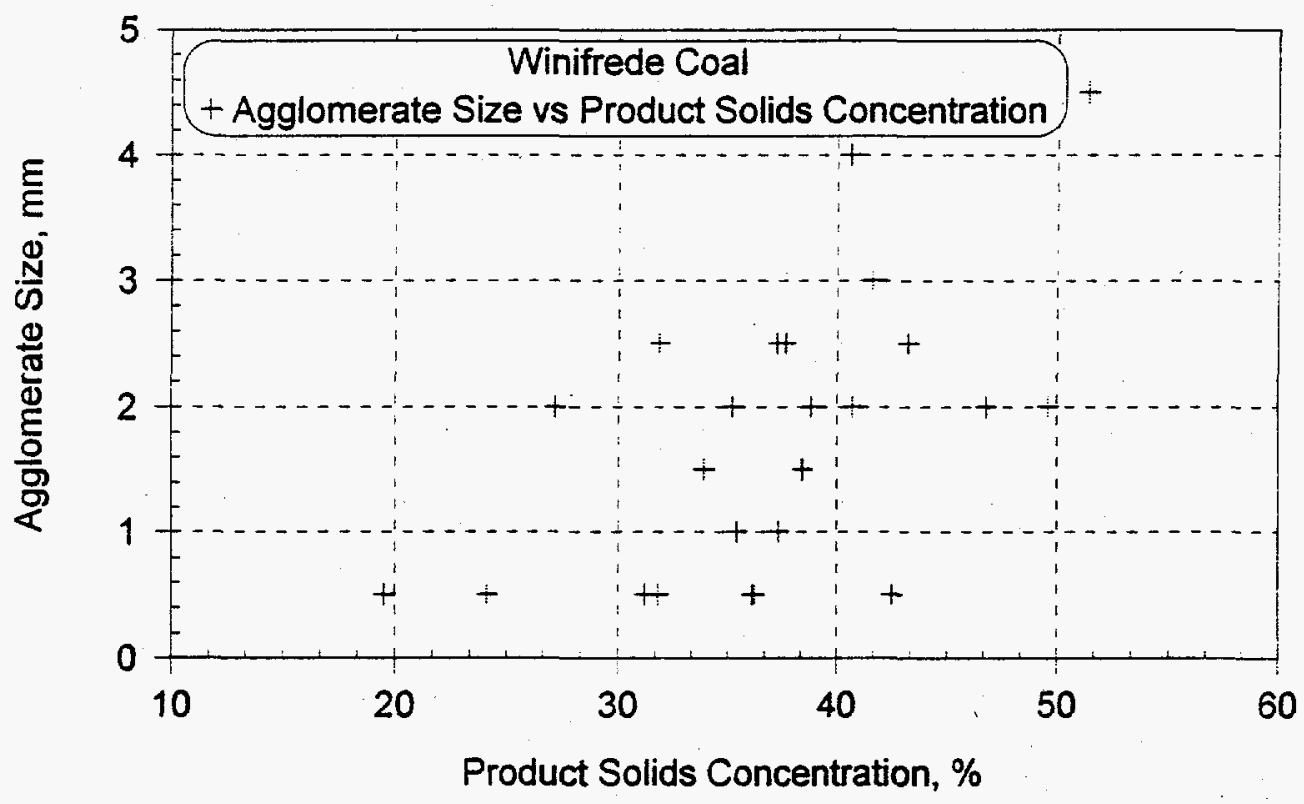

Figure 10. Winifrede Coal - Agglomerate Size vs Product Solids Concentration

Unfortunately, the relationship between agglomerate size and product ash content masked any other variable effects on product ash contents. This is especially true since almost any other process variable change made, while holding all other conditions constant, affected agglomerate growth in low shear. 
In particular, the following observations were made from the Winifrede coal testing:

- Lower, $4.8 \mathrm{~m} / \mathrm{s}$, low-shear impeller tip speeds resulted in continuous growth, i.e., the agglomerates would grow continuously until the discharge outlet plugged.

- Higher, $8 \mathrm{~m} / \mathrm{s}$, low-shear impeller tip speeds resulted in a cycling low-shear product size, i.e., agglomerates grew from the $<0.5 \mathrm{~mm}$ range to the 2 to $3 \mathrm{~mm}$ range and then degraded back to $<0.5 \mathrm{~mm}$ followed by repeating of this cycle.

- Operation of the low-shear vessel full resulted in a less stable low-shear size product than when operated half full.

For one test carried out with the Winifrede coal, production of well formed $2.5 \mathrm{~mm}$ agglomerates was achieved and maintained at steady state. For this test, the coal feed rate was $12.5 \mathrm{lb} / \mathrm{hr}$ and the solids concentration $7 \%$. These conditions provided 2 minutes of high-shear residence time and 4.6 minutes of low-shear residence time.

\section{Elkhorn No. 3 Coal Results}

Continuous agglomeration testing utilizing the Elkhorn No. 3 coal was carried out using a feedstock closed-circuit ground to a 100-mesh topsize in the 4-foot $\times$ 4-foot ball mill. This grind provided a PSD with a $D_{80}$ of 68 microns. The complete PSD for this ground feedstock is shown in Table 9.

Table 9. Elkhorn No. 3 Coal Particle Size Distribution

\begin{tabular}{cc}
\hline Microns & Cumulative Weight Percent Passing \\
\cline { 2 - 2 } 150 & 100.0 \\
106 & 96.9 \\
75 & 84.3 \\
53 & 70.6 \\
45 & 63.7 \\
38 & 59.6 \\
30 & 50.6 \\
20 & 35.8 \\
15 & 27.5 \\
10 & 18.8 \\
8 & 15.8 \\
6 & 12.1 \\
4 & 8.1 \\
3 & 5.7 \\
2 & 3.2 \\
1 & 0.4 \\
$D_{20}$ & 10.7 \\
$D_{50}$ & 29.6 \\
$D_{80}$ & 68.0 \\
\hline
\end{tabular}


A total of 32 continuous agglomeration tests were completed to evaluate the Elkhorn No. 3 coal. Operating conditions and results for all of these tests are shown in Appendix B.

The following presents a list of operating variable ranges tested in the continuous bench-scale unit for the Elkhorn No. 3 coal:

- Feed PSD - $D_{80}$ of 68 microns

- Coal feed rate -17.2 to $33.5 \mathrm{lb} / \mathrm{hr}$

- Feed slurry solids concentration - 7, 10, and $13 \%$

- Heptane type - Recycled commercial grade and fresh pure grade

- Heptane dosage -23.3 to $35.3 \%$ on a dry ash free coal basis

- Asphalt addition level $-0,1$, and $2.5 \mathrm{lb} /$ ton coal

- High-shear impeller - 2.4-inch diameter, 4-blade, radial flow

- High-shear impeller tip speed -12.1 to $18 \mathrm{~m} / \mathrm{s}$

- High-shear residence time - 1.1 to 1.9 minutes

- Low-shear impeller - 4.8-inch diameter, 4 blade, radial flow

- Low-shear impeller tip speed -4.8 and $8 \mathrm{~m} / \mathrm{s}$

- Low-shear configuration - Half full and full

- Low-shear residence time - 3.4 to 9.4 minutes

- Vibrating screen deck opening size - 48 mesh

- Vibrating screen inclination - 34 to 43 degrees downhill form horizontal

- Vibrating screen spray water rate $-51.6 \mathrm{lb} / \mathrm{hr}$

A plot of Btu recovery vs product ash content in lb/MBtu for all of these tests is shown in Figure 11.

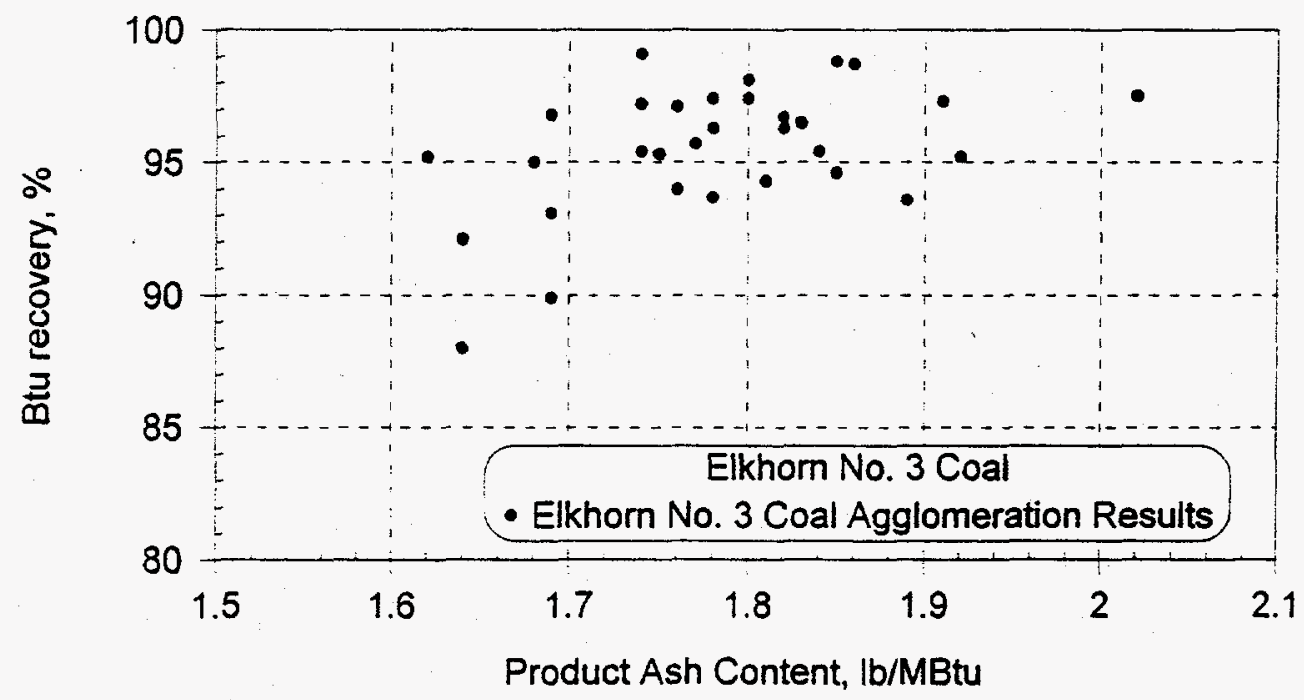

Figure 11. Elkhorn No. 3 Coal Continuous Agglomeration Results 
As can be seen from the data in Figure 11 and Appendix B, the $2 \mathrm{lb}$ ash/MBtu product specification was met for all but one of the tests completed. This indicates that the 100mesh topsize grind provided sufficient mineral-matter liberation and therefore no other grinds were evaluated for this coal.

Agglomeration yields for the Elkhorn No. 3 coal ranged from about 85 to $96 \%$. On a run-of mine (ROM) coal basis, yields were in the 44 to $50 \%$ range due to the original raw coal feed ash of approximately $45 \%$, which resulted in a raw coal precleaning yield of only about $52 \%$. Agglomeration Btu recoveries achieved were in the range of 88 to $99 \%$, equivalent to approximately 83 to $94 \%$ on a ROM basis. As such, sufficient energy recovery was achieved for all of the tests completed to meet the project goal of $80 \%$ energy recovery on a ROM basis.

While these tests achieved the project product ash and Btu recovery specifications, it proved difficult to achieve consistently high Btu recoveries, which is generally easy for the selective agglomeration process. This is indicated by the tailings ash values which ranged from 24.8 to $73.2 \%$ (mostly in the 35 to $55 \%$ range). These relatively low tailings ash values are attributed to aging (oxidation) of the Elkhorn No. 3 coal which had been stored for over two years prior to its use for this testing. To overcome this effect, asphalt was used to enhance agglomeration in three of the tests. With the use of asphalt, Btu recoveries of 98.7 to $99.1 \%$ were achieved, with associated tailings ash values ranging from 66.9 to $73.2 \%$. In contrast, when asphalt was not used, the highest Btu recoveries achieved were in the 96 to $98 \%$ range. These higher levels of Btu recovery were only achieved, however, when a combination of various operating conditions were utilized as discussed below.

Primary to achieving high Btu recoveries for the Elkhorn No. 3 coal was the total energy input to the combined high- and low-shear unit operations, with higher energy inputs achieving higher Btu recoveries. When higher impeller tip speeds and longer agglomeration residence times were used, higher Btu recoveries were achieved. As such, the energy input capability of the continuous agglomeration system was pushed to its limit for processing this aged Elkhorn No. 3, coal. It was also found that tests utilizing higher solids concentrations (13\%) achieved higher Btu recoveries than similar tests carried out at 10 and $7 \%$ solids concentration. This confirmed the trend that agglomeration carried out at a higher solids concentration requires less energy than at a lower solids concentration. This effect is due to the occurrence of more particle to particle contact at the higher solids loading given the same energy input.

One other important factor in achieving high Btu recoveries was the use of sufficient heptane. As can be seen from the data in Appendix B, the first 16 agglomeration tests used heptane dosages in the range of 24 to $29 \%$ on a dry ash free (daf) coal basis. Out of these tests, only one test (with the highest overall energy input) achieved a Btu recovery greater than $97 \%$. In contrast, for the remainder of the Elkhorn coal testing, which used heptane dosages in the 30 to $35 \%$ range on a daf coal basis, most achieved Btu recoveries greater than $97 \%$. In those latter tests that didn't achieve higher Btu recoveries, lower impeller tip speeds, particularly in low shear, were used. 
As discussed for the Winifrede coal, the size of the agglomerates formed determined the product ash content, with larger agglomerates achieving lower product ash values, due to better drainage of mineral-matter bearing process water. No other parameters evaluated had a noticeable effect on product ash content, except indirectly where they ultimately affected agglomerate size and strength. This effect of agglomeration performance as a function of agglomerate formation is illustrated in Figure 12, which plots all the data as a function of agglomerate size (poorly formed or well formed).

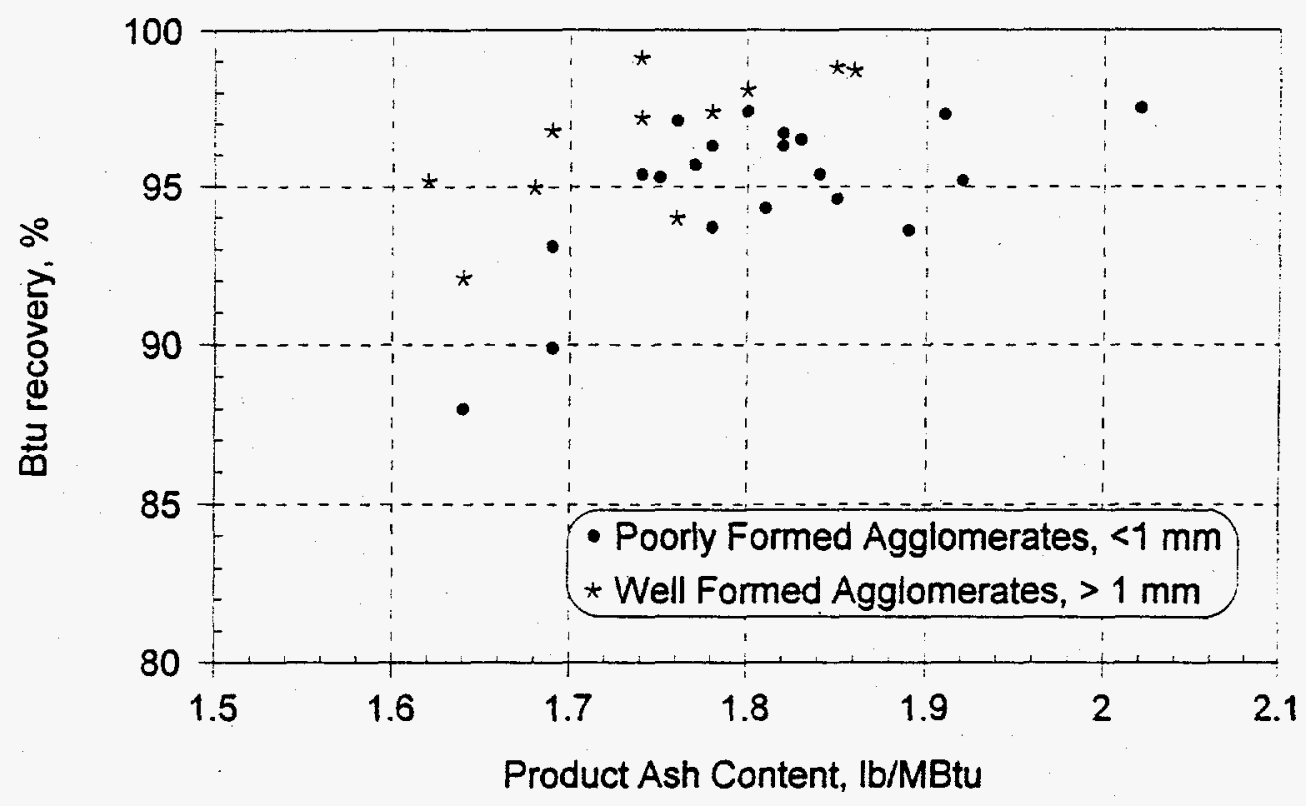

Figure 12. Elkhorn No. 3 Coal - Agglomerate Size vs Product Ash

Based on these results, both product ash content and Btu recovery specifications were met with the 100-mesh topsize ground Elkhorn No. 3 coal. The best results for agglomeration of this coal were achieved when sufficient bridging liquid and energy were utilized to insure the production of well formed agglomerates from low shear. When this was the case, the agglomerates screened well, resulting in product ash values of 2.5 to $2.7 \%$, equivalent to approximately 1.7 to $1.9 \mathrm{lb}$ ash/MBtu.

\section{Sunnyside Coal Results}

Continuous agglomeration testing with the Sunnyside coal was carried out using two different feedstocks, both closed-circuit ground in the 4-foot $\times$ 4-foot ball mill. The first feedstock tested was closed-circuit ground with a 100-mesh screen resulting in a PSD with a $D_{80}$ of 59.6 microns. The second feedstock tested was closed-circuit ground with a 150 -mesh screen resulting in a PSD with a $\mathrm{D}_{80}$ of 42.9 microns. Complete PSDs for both of these feedstocks are shown in Table 10. 
Table 10. Sunnyside Coal Particle Size Distributions

Cumulative Weight Percent Passing

\begin{tabular}{|c|c|c|}
\hline Microns & 100 Mesh Topsize & 150 Mesh Topsize \\
\hline 212 & 100.0 & 100.0 \\
\hline 150 & 99.9 & 100.0 \\
\hline 106 & 97.9 & 99.9 \\
\hline 75 & 88.4 & 97.2 \\
\hline 53 & 76.4 & 90.3 \\
\hline 45 & 70.3 & 81.4 \\
\hline 38 & 65.8 & 76.6 \\
\hline 30 & 57.6 & 69.8 \\
\hline 20 & 42.7 & 51.0 \\
\hline 15 & 34.3 & 40.1 \\
\hline 10 & 24.2 & 28.0 \\
\hline 8 & 20.0 & 23.9 \\
\hline 6 & 15.5 & 18.8 \\
\hline 4 & 10.3 & 12.6 \\
\hline 3 & 7.3 & 9.0 \\
\hline 2 & 4.2 & 5.0 \\
\hline 1 & 0.9 & 1.0 \\
\hline $\begin{array}{l}D_{20} \\
D_{50}\end{array}$ & $\begin{array}{c}8.0 \\
24.9\end{array}$ & $\begin{array}{c}6.5 \\
19.5\end{array}$ \\
\hline$D_{80}$ & 59.6 & 42.9 \\
\hline
\end{tabular}

\section{High Shear Evaluation}

As part of the Sunnyside coal testing, an evaluation of high-shear mixing requirements to achieve inversion was carried out. This testing utilized both the 100-and 150-mesh topsize feedstocks and two different high-shear impellers. One impeller was of 2.4-inch diameter with 4 blades, the other of 3.6-inch diameter with 6 blades.

Testing was completed to determine the minimum high-shear impeller tip speed required to achieve inversion under various coal feed rates and solids concentrations. Table 11 provides a brief summary of this data.

Several trends can be observed from this data:

- As residence time in the high-shear vessel decreased with increasing coal feed rate, the impeller tip speed had to be increased to maintain inversion. This trend is expected since at shorter residence times, higher power input is required to maintain similar energy/coal ratios.

- As the slurry solids concentration increased, less power input (lower tip speed) was required to achieve inversion. This trend is also expected since as the 
solids concentration increases, more particle to particle contact occurs at similar energy inputs.

- The 2.4-inch impeller drew less power to achieve inversion than the 3.6-inch impeller.

\begin{tabular}{|c|c|c|c|c|c|c|c|}
\hline $\begin{array}{l}\text { Impeller } \\
\text { Diameter } \\
\text { (in) }\end{array}$ & $\begin{array}{l}\text { Solids } \\
\text { Conc } \\
(\%)\end{array}$ & $\begin{array}{c}\text { Coal } \\
\text { Rate } \\
\text { (lb/hr) }\end{array}$ & $\begin{array}{c}\% \\
\text { Hept } \\
\text { (maf) } \\
\end{array}$ & $\begin{array}{l}\text { Res } \\
\text { Time } \\
\text { (sec) } \\
\end{array}$ & $\begin{array}{c}\text { Impeller } \\
\text { (rpm) }\end{array}$ & $\begin{array}{l}\text { Imp Tip } \\
\text { Speed } \\
(\mathrm{m} / \mathrm{s})\end{array}$ & $\begin{array}{l}\text { Power } \\
\text { Draw* } \\
\text { (amps) }\end{array}$ \\
\hline \multicolumn{8}{|c|}{100 Mesh Topsize Grind } \\
\hline \multirow[t]{8}{*}{2.4} & 5 & 25.0 & 28.3 & 44 & 7000 & 22.3 & 2.4 \\
\hline & 7 & 24.9 & 26.5 & 62 & 6000 & 19.1 & 2.2 \\
\hline & 10 & 25.0 & 26.2 & 87 & 3800 & 12.1 & 1.6 \\
\hline & 10 & 24.8 & 26.5 & 88 & 4400 & 14.0 & \\
\hline & 10 & 37.4 & 25.2 & 58 & 5000 & 16.0 & \\
\hline & 13 & 33.0 & 24.5 & 86 & 4200 & 13.4 & 1.6 \\
\hline & 15 & 37.4 & 25.7 & 87 & 3800 & 12.1 & 1.5 \\
\hline & 15 & 37.4 & 22.8 & 86 & 3800 & 12.1 & 1.5 \\
\hline \multirow[t]{3}{*}{3.6} & 10 & 25.0 & 25.6 & 87 & 3000 & 14.4 & 2.8 \\
\hline & 10 & 20.2 & 24.7 & 108 & 2500 & 12.0 & 2.3 \\
\hline & 15 & 25.5 & 25.5 & 127 & 2200 & 10.5 & 2.0 \\
\hline \multicolumn{8}{|c|}{150 Mesh topsize Grind } \\
\hline \multirow[t]{3}{*}{2.4} & 7 & 25.2 & 26.9 & 61 & 4800 & 15.3 & 1.8 \\
\hline & 10 & 24.9 & 26.5 & 87 & 4300 & 13.7 & 1.7 \\
\hline & 13 & 32.7 & $25: 3$ & 86 & 3600 & 11.5 & 1.4 \\
\hline
\end{tabular}

Based on these test results, no additional test work was performed using the 6-bladed 3.6-inch diameter high-shear impeller. Utilizing these high-shear inversion results and the monitoring of slurry temperature rise through high shear during continuous testing, an estimate of energy requirements for scale up to the $2 \mathrm{t} / \mathrm{hr}$ PDU plant was made.

\section{Continuous Test Results}

A total of 18 continuous agglomeration tests were completed with Sunnyside coal. Of these 18 tests, 4 were carried out with the 100-mesh topsize feedstock and the remaining 14 with the 150-mesh topsize feedstock. Operating conditions and results for all of these tests are presented in Appendix C.

The following is a list of operating variable ranges tested for the Sunnyside coal:

- Feed PSD - $D_{80}$ of 59.6 and 42.9 microns

- Coal feed rate -24.4 to $48.9 \mathrm{lb} / \mathrm{hr}$

- Feed slurry solids concentration $-5,7,10$, and $13 \%$ 
- Heptane type - Commercial and pure grades

- Heptane dosage - 25.5 to $29.9 \%$ on a dry ash free coal basis

- High-shear impeller - 2.4-inch diameter, 4-blade, radial flow

- High-shear impeller tip speed -11.8 to $22.3 \mathrm{~m} / \mathrm{s}$

- High-shear residence time -0.7 to 1.5 minutes

- Low-shear impeller - 4.8-inch diameter, 4 blade, radial flow

- Low-shear impeller tip speed -4.8 and $8 \mathrm{~m} / \mathrm{s}$

- Low-shear configuration - Half full and full

- Low-shear residence time -1.8 to 7.3 minutes

- Vibrating screen deck opening size - 48 mesh

- Vibrating screen inclination - 38 degrees downhill form horizontal

- Vibrating screen spray water rate $-51.8 \mathrm{lb} / \mathrm{hr}$

A plot of Btu recovery vs product ash content in Ib/MBtu, for all of the Sunnyside coal tests, is shown in Figure 13. This data is separated by feedstock PSD.

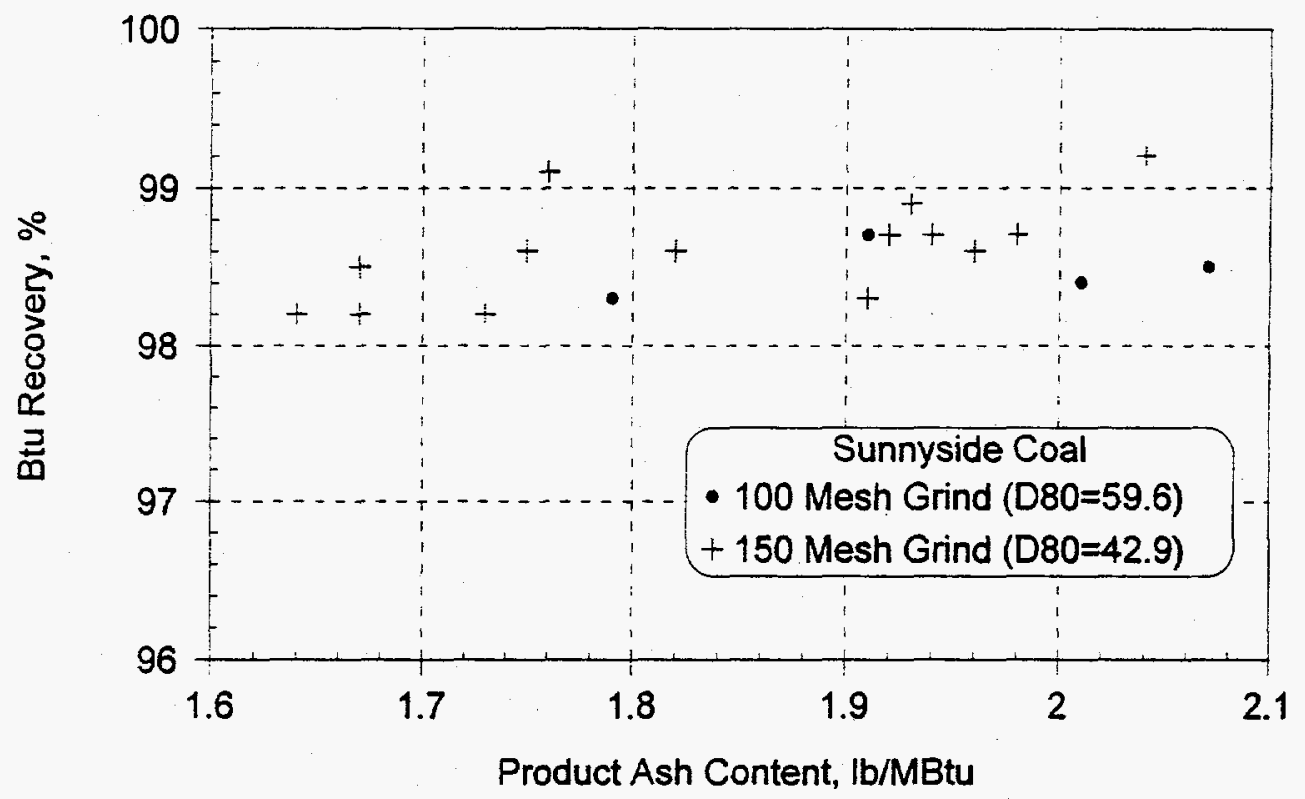

Figure 13. Sunnyside Coal Continuous Agglomeration Results

As can be seen from the data in Figure 13, of the four 100-mesh tests completed, the product ash specification of $2 \mathrm{lb}$ ash/MBtu was met for 2 of them, with the other two considered borderline. Agglomeration Btu recoveries were very high, generally in the 98 to $99 \%$ range. Results for these four 100 -mesh tests indicated that lower product ash contents were achieved when operating at 5 and $7 \%$ solids concentrations than when operating at 10 and $13 \%$ solids concentration. It should be noted, however, that other operating conditions varied also, in particular, for the two lower solids concentration tests, higher heptane dosages were used. 
All except one of the 150-mesh topsize Sunnyside tests carried out achieved the product ash specification of $2 \mathrm{lb} / \mathrm{MBtu}$. The one test which did not achieve this specification utilized pure rather than commercial grade heptane and achieved the highest Btu recovery of all the tests. The bulk of these tests were completed at a $10 \%$ solids concentration with one test carried out at $7 \%$ solids and 3 tests at $13 \%$ solids.

Low-Shear Operation- During testing it was found that at low-shear impeller tip speeds of 3 to $5 \mathrm{~m} / \mathrm{s}$, the product agglomerates grew to $>4$ to $6 \mathrm{~mm}$ in diameter, i.e., to the critical size plugging the low-shear discharge. As such, the low-shear mixer was operated in the $7-10 \mathrm{~m} / \mathrm{s}$ tip speed range to prevent excessive growth. At these higher impeller tip speeds, low-shear growth typically proceeded in a cyclic manner as follows:

1. From start-up, approximately 20 minutes was required to form spherical $1-\mathrm{mm}$ agglomerates at the low shear discharge.

2. During the next 20 minutes of operation, the product remained monosized as it grew to approximately 3 to $4 \mathrm{~mm}$ in diameter.

3. During the next 20 minutes, smaller agglomerates $(<0.5$ to $1.0 \mathrm{~mm})$ started to appear and eventually constituted the majority of the product.

4. These small agglomerates then grew to 3 to $4 \mathrm{~mm}$ in size once again repeating the cycle.

Under these operating conditions, the low-shear unit operation never achieved a steady-state discharge in terms of product size and consistency. It should be noted, however, that throughout this growth/reduction cycle, the product remained screenable and could therefore be recovered. While this is an acceptable mode of operation, the production of a consistent monosized product is desirable to provide a consistently low ash and moisture product.

In an effort to reduce the occurrence of this cyclic growth/reduction cycle during low shear, lower heptane concentrations were tested. To achieve these conditions, the high-shear rpm was set at an $18 \mathrm{~m} / \mathrm{s}$ tip speed, and the heptane level reduced such that inversion was just maintained. Operating under these conditions, the results shown in Table 12 were obtained. The following parameters were held constant for these tests:

- 150-mesh Sunnyside coal

- Approximately $26 \mathrm{lb} / \mathrm{hr}$ coal feed

- $10 \%$ solids concentration

- 7.3 minute low-shear residence time

This data indicates that the higher $(4.8 \mathrm{~m} / \mathrm{s})$ tip speed is required to produce well formed spherical agglomerates, with the lower tip speed $(3.2 \mathrm{~m} / \mathrm{s})$ producing a powdery product not very well formed. This data also indicates that a slight increase in heptane dosage, from 23.6 to $25.4 \%$ on a daf basis, has a great effect on product size. In particular, the product changed from a consistent $0.5 \mathrm{~mm}$ product (steady state) to a product that reached 3 to $4 \mathrm{~mm}$ in size and was continuing to grow. 
Table 12. Sunnyside Coal Low-Shear Testing Results

\begin{tabular}{ccccc}
\hline $\begin{array}{c}\text { Heptane } \\
\% \text { maf }\end{array}$ & $\begin{array}{c}\text { LS Tip Speed } \\
\text { m/s }\end{array}$ & $\begin{array}{c}\text { Product Size } \\
\text { mm }\end{array}$ & $\begin{array}{c}\text { Product } \\
\% \text { Solids }\end{array}$ & $\begin{array}{c}\text { Product } \\
\% \text { ash }\end{array}$ \\
23.6 & 4.8 & 0.5 & 33.0 & 2.86 \\
23.6 & 3.2 & 0.5 - Powdery & NA & NA \\
25.4 & 3.2 & 0.5 - Powdery & 30.7 & 2.76 \\
25.4 & 4.8 & $3-4$ - increasing & 64.1 & 2.55 \\
\hline
\end{tabular}

The following general conclusions were drawn from the low-shear testing with the Sunnyside coal:

- At typical heptane dosage levels, the low-shear product grows to large sizes (4 to $6 \mathrm{~mm}$ diameter) at impeller tip speeds of 3 to $5 \mathrm{~m} / \mathrm{s}$. However, lower heptane ratios (starvation levels) provided better control over low-shear product size.

- At typical heptane levels, high impeller tip speeds $(7$ to $10 \mathrm{~m} / \mathrm{s}$ ) were required to maintain agglomerates of a size $(2$ to $3 \mathrm{~mm}$ ) that would discharge from the lowshear vessel. Under these conditions, a cyclic growth and size reduction of the low-shear product was observed.

- Low-shear discharge plugging problems were more pronounced at higher solids concentrations (particularly above 10\%). This trend was expected since at higher solids concentrations more particle to particle contact is expected for the same energy input. Also, at the same volumetric flowrate through the system, a higher solids loading increases the solids flow through the discharge port, which increases the chance for plugging to occur.

Agglomerate Size Effect - While various operating conditions changed from test to test, the lowest product ash contents were achieved when relatively large $(2$ to $4 \mathrm{~mm})$ monosized agglomerates were produced. This indicates that a product with these characteristics has a lower water content, rejecting more of the mineral-matter bearing process water. This trend is seen in Figure 14 which presents product ash content as a function of product agglomerate size.

Vibrating Screen - Testing to evaluate vibrating screen wash water requirements was completed by batch screening of low-shear product samples at various wash water rates. This work was carried out to determine if substantially greater quantities of wash water would decrease the product ash content.

For this work a 1 -liter sample of low shear product was placed on an 8-inch 48-mesh test screen. Samples of this product were then taken for ash analysis after each of the following:

- Allowing the water to drain from the bed (no rinsing)

- Rinsing the bed lightly with a spray bottle, using approximately $500 \mathrm{ml}$ of water

- Soaking the bed with a gentle water stream for 2 minutes 


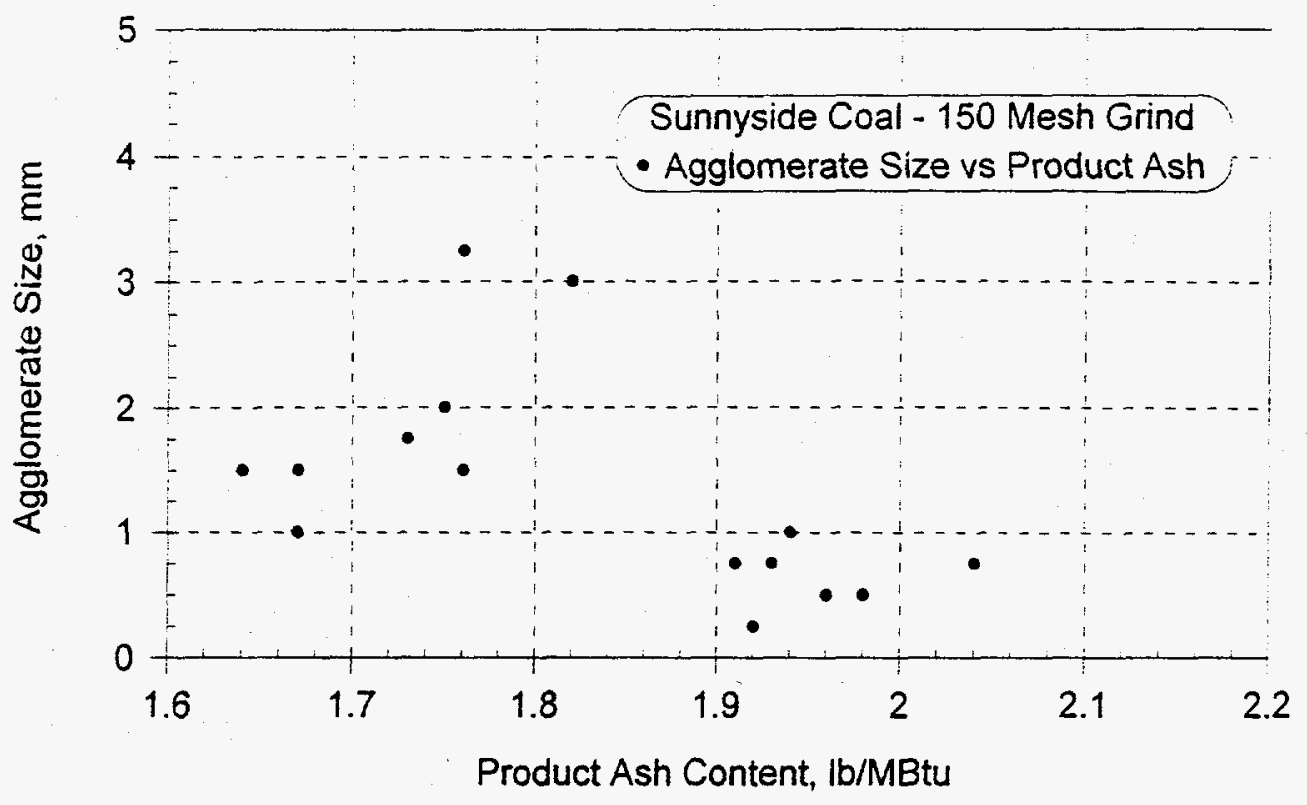

Figure 14. Sunnyside Coal - Agglomerate Size vs Product Ash

Results for these low-shear rinsing tests are shown in Table 13 which indicates that some product washing (as represented by $500 \mathrm{ml}$ spray rinsing) was found to reduce the product ash by as much as $0.2 \%$ with additional washing generally having less effect on product ash. Therefore, a small quantity of wash water was used during typical vibrating screen operation in all subsequent test work.

Table 13. Sunnyside Coal Batch Low-Shear Rinsing Results

\begin{tabular}{ccccc}
\hline & & \multicolumn{3}{c}{ Product Ash, \% } \\
Coal & $\begin{array}{c}\text { Agglomerate } \\
\text { Size (mm) }\end{array}$ & $\begin{array}{c}\text { Drain } \\
\text { No Rinse }\end{array}$ & $\begin{array}{c}\text { Spray } \\
\text { Rinse }\end{array}$ & $\begin{array}{c}\text { Soak } \\
\text { Sinse }\end{array}$ \\
\cline { 2 - 2 } Sunnyside (100 Mesh) & 1.0 & 2.83 & 2.60 & 2.49 \\
& $1.0-2.5$ & 3.00 & 2.87 & 2.76 \\
& $2.0-2.5$ & 2.75 & 2.61 & 2.61 \\
Sunnyside (150 Mesh) & $1.0-3.0$ & 2.93 & 2.91 & 2.82 \\
& 0.5 & 3.01 & 2.82 & 2.70 \\
& 1.0 & 2.77 & 2.78 & 2.74 \\
& 2.0 & 2.63 & 2.54 & 2.51 \\
& $1.0-3.0$ & 2.67 & 2.63 & 2.57 \\
\hline
\end{tabular}

It should be noted that the amount of wash water required depends on the size and nature of the agglomerates formed. When well-formed monosized agglomerates are generated, less wash water is required since this material will drain well. However, when the agglomerated product is poorly formed, wash water requirements increase since the associated mineral-matter bearing process does not drain as well. 


\section{Taggart Coal Results}

Continuous agglomeration testing of the Taggart coal was carried out using four different feedstocks. The first two feedstocks were closed-circuit ground in the 4-foot $x$ 4-foot ball mill, the first with a 62-mesh screen resulting in a PSD with a $D_{80}$ of 90.8 microns and the second with a 100-mesh screen resulting in a PSD with a $D_{80}$ of 64.9 microns. The other two feedstocks were ground in the PDU grinding circuit during Subtask 8.4 operations. The first of these was produced by operating the PDU grinding circuit in closed-circuit with cyclones and a 100-mesh screen, with the oversize material recycled to the secondary ball mill, and resulted in a PSD with a $D_{80}$ of 74.7 microns. The second was produced by operating the PDU grinding circuit in closed-circuit with cyclones and a 70-mesh screen, with the oversize material recycled to the Netzsch finegrinding mill, and resulted in a PSD with a $D_{80}$ of 32.8 microns.

Complete PSDs for all four of these Taggart coal feedstocks are shown in Table 14.

Table 14. Taggart Coal Particle Size Distributions

\begin{tabular}{|c|c|c|c|c|}
\hline \multirow[b]{2}{*}{ Microns } & \multicolumn{4}{|c|}{ Cumulative Weight Percent Passing } \\
\hline & 62 Mesh & 100 Mesh & PDU Grind 1 & PDU Grind 2 \\
\hline 300 & 100.0 & 100.0 & 100.0 & 100.0 \\
\hline 212 & 99.1 & 100.0 & 100.0 & 100.0 \\
\hline 150 & 95.0 & 100.0 & 99.4 & 99.5 \\
\hline 106 & 85.5 & 97.3 & 92.8 & 98.5 \\
\hline 75 & 74.3 & 85.7 & 80.1 & 96.1 \\
\hline 53 & 65.3 & 73.3 & 68.2 & 93.1 \\
\hline 45 & 56.4 & 67.4 & 57.2 & 88.8 \\
\hline 38 & 53.1 & 63.5 & 50.0 & 84.3 \\
\hline 30 & 52.7 & 54.9 & 43.9 & 77.6 \\
\hline 20 & 38.4 & 39.6 & 30.1 & 59.1 \\
\hline 15 & 30.2 & 29.8 & 23.6 & 47.3 \\
\hline 10 & 22.0 & 22.1 & 16.2 & 32.6 \\
\hline 8 & 18.6 & 18.5 & 13.3 & 26.5 \\
\hline 6 & 14.7 & 14.4 & 9.9 & 20.4 \\
\hline 4 & 10.0 & 9.1 & 5.9 & 12.6 \\
\hline 3 & 7.1 & 6.5 & 3.9 & 8.4 \\
\hline 2 & 4.0 & 3.5 & 2.1 & 3.7 \\
\hline 1 & $\underline{0.8}$ & $\underline{0.7}$ & $\underline{0.5}$ & $\underline{0.5}$ \\
\hline$D_{20}$ & 8.9 & 8.8 & 12.6 & 5.9 \\
\hline$D_{50}$ & 28.1 & 26.8 & 38.0 & 16.2 \\
\hline$D_{80}$ & 90.8 & 64.9 & 74.7 & 32.8 \\
\hline
\end{tabular}

\section{High-Shear Evaluation}

As part of the Taggart coal testing, an evaluation of high-shear mixing requirements to achieve inversion was carried out. The 62 -mesh topsize grind ( $D_{80}=90.8$ microns) was 
used for this work and two different high-shear impellers were evaluated. One was a 2.4-inch diameter impeller with 4 blades, the other a 3.6-inch diameter impeller with 6 mixing blades. Testing focused on determining the minimum high-shear impeller tip speed required to achieve inversion under various coal feed rates and solids concentrations. Table 15 provides a brief summary of this data.

Table 15. Taggart Coal High-Shear Requirements for Inversion

\begin{tabular}{|c|c|c|c|c|c|c|}
\hline $\begin{array}{c}\text { Impeller } \\
\text { Diameter } \\
\text { (in) }\end{array}$ & $\begin{array}{c}\text { Solids } \\
\text { Conc. } \\
(\%)\end{array}$ & $\begin{array}{c}\text { Coal } \\
\text { Rate } \\
\text { (lb/hr) } \\
\end{array}$ & $\begin{array}{c}\text { Percent } \\
\text { Heptane } \\
\text { (dcb) }\end{array}$ & $\begin{array}{c}\text { Residence } \\
\text { Time } \\
\text { (sec) }\end{array}$ & $\begin{array}{c}\text { Tip } \\
\text { Speed } \\
(\mathrm{m} / \mathrm{s})\end{array}$ & $\begin{array}{l}\text { Power } \\
\text { Draw* } \\
\text { (amps) }\end{array}$ \\
\hline 2.4 & $\begin{array}{l}10 \\
15\end{array}$ & $\begin{array}{l}25 \\
50 \\
92 \\
50\end{array}$ & $\begin{array}{l}24.5 \\
24.4 \\
24.5 \\
20.5\end{array}$ & $\begin{array}{l}88 \\
44 \\
24 \\
65\end{array}$ & $\begin{array}{c}7.2 \\
8.8 \\
11.2 \\
8.3\end{array}$ & $\begin{array}{l}1.3 \\
1.3 \\
1.5 \\
1.4\end{array}$ \\
\hline 3.6 & $\begin{array}{c}5 \\
10 \\
\\
18.4\end{array}$ & $\begin{array}{l}25 \\
25 \\
48 \\
24 \\
50\end{array}$ & $\begin{array}{l}25.0 \\
24.2 \\
25.0 \\
25.3 \\
24.4\end{array}$ & $\begin{array}{c}44 \\
87 \\
44 \\
160 \\
80\end{array}$ & $\begin{array}{l}11.0 \\
7.7 \\
9.6 \\
7.2 \\
7.7\end{array}$ & $\begin{array}{l}2.2 \\
1.8 \\
2.0 \\
1.7 \\
1.7\end{array}$ \\
\hline
\end{tabular}

The same trends found during the Sunnyside coal high-shear evaluation testing were observed for the Taggart coal and are summarized below:

- As residence time in the high-shear vessel decreases with increasing coal feed rate, the impeller tip speed must be increased to maintain inversion.

- As the slurry solids concentration increases, less power input (lower tip speed) is required to maintain inversion.

- The 2.4-inch diameter impeller draws less power to achieve inversion than the 3.6-inch diameter impeller.

Based on these results, no testing was completed using the 6-bladed 3.6-inch highshear impeller.

It should also be noted that the Taggart coal proved very easy to agglomerate as compared to the other coals evaluated. This can be seen by comparing the range of impeller tip speeds required to achieve inversion with the Taggart coal $(7.2$ to $11 \mathrm{~m} / \mathrm{s})$ to the range of impeller tip speeds required to achieve inversion with the Sunnyside coal $(10.5$ to $22.3 \mathrm{~m} / \mathrm{s})$.

\section{Screen Wash Water Evaluation}

Testing was carried out to evaluate vibrating screen wash water requirements. This work was done by batch screening of low-shear product samples at various wash water 
rates. The focus of this testing was to determine if substantially greater quantities of wash water would decrease product ash content. Results are shown in Table 16.

Table 16. Taggart Coal Batch Low-Shear Rinsing Results

\begin{tabular}{cccc} 
& $\begin{array}{c}\text { Drain } \\
\text { No Rinse }\end{array}$ & $\begin{array}{c}\text { Spray } \\
\text { Rinse }\end{array}$ & $\begin{array}{c}\text { Soak } \\
\text { Rinse }\end{array}$ \\
\cline { 2 - 4 } Ash content, \% & 1.57 & 1.51 & 1.51 \\
& 1.52 & 1.48 & NA \\
& 1.51 & 1.47 & 1.46 \\
& 1.47 & 1.43 & 1.43 \\
& 1.41 & 1.40 & 1.38 \\
\hline
\end{tabular}

These tests were carried out by placing a 1-liter sample of low-shear product on an 8inch diameter 48-mesh test sieve. Samples of this product were then taken for ash analysis after allowing the water to drain from the bed (no rinsing), rinsing the bed lightly with a spray bottle using approximately $500 \mathrm{ml}$ of water, and soaking the bed with a gentle water stream for 2 minutes.

As this data indicates, some product washing (as represented by $500 \mathrm{ml}$ spray rinsing) was found to reduce product ash marginally (only about $0.04 \%$ ) with additional washing having little effect. These reductions in ash content are significantly lower than those achieved with the Sunnyside coal (up to $0.3 \%$ ) due to the coarser size, lower ash content, and better formed agglomerates of the Taggart coal.

\section{Continuous Test Results}

A total of 29 agglomeration tests were completed to evaluate the Taggart coal. Of these tests, 5 were carried out with the 62-mesh topsize grind, 2 with the 100-mesh topsize grind, 10 with the 87.7 micron $D_{80}$ PDU generated grind, and the remaining 12 with the 32.8 micron $D_{80}$ PDU generated grind.

Operating conditions and results for all of these tests are shown in Appendix D.

The following is a list of operating variable ranges tested for the Taggart coal:

- Feed PSD - $D_{80}$ of $90.8,64.9,87.7$, and 32.8 microns

- Coal feed rate -17.5 to $50.5 \mathrm{lb} / \mathrm{hr}$

- Feed slurry solids concentration $-5,7,10$, and $13 \%$

- Heptane type - Commercial grade

- Heptane dosage -21.9 to $35.3 \%$ on a dry ash free coal basis

- High-shear impeller - 2.4-inch diameter, 4-blade, radial flow

- High-shear impeller tip speed -6.4 to $15.0 \mathrm{~m} / \mathrm{s}$

- High-shear residence time -0.5 to 1.5 minutes 
- Low-shear impeller - 4.8-inch diameter, 4 blade, radial flow

- Low-shear impeller tip speed -3.0 to $8.0 \mathrm{~m} / \mathrm{s}$

- Low-shear configuration - Half full and full

- Low-shear residence time -1.7 to 7.3 minutes

- Vibrating screen deck opening size - 48 mesh

- Vibrating screen inclination - 36 to 42 degrees downhill form horizontal

- Vibrating screen spray water rate -37.7 to $58.9 \mathrm{lb} / \mathrm{hr}$

A plot of Btu recovery vs product ash content in $\mathrm{Ib} / \mathrm{MBtu}$, for all of the Taggart coal test results, is shown in Figure 15. This data is separated by feedstock PSD.

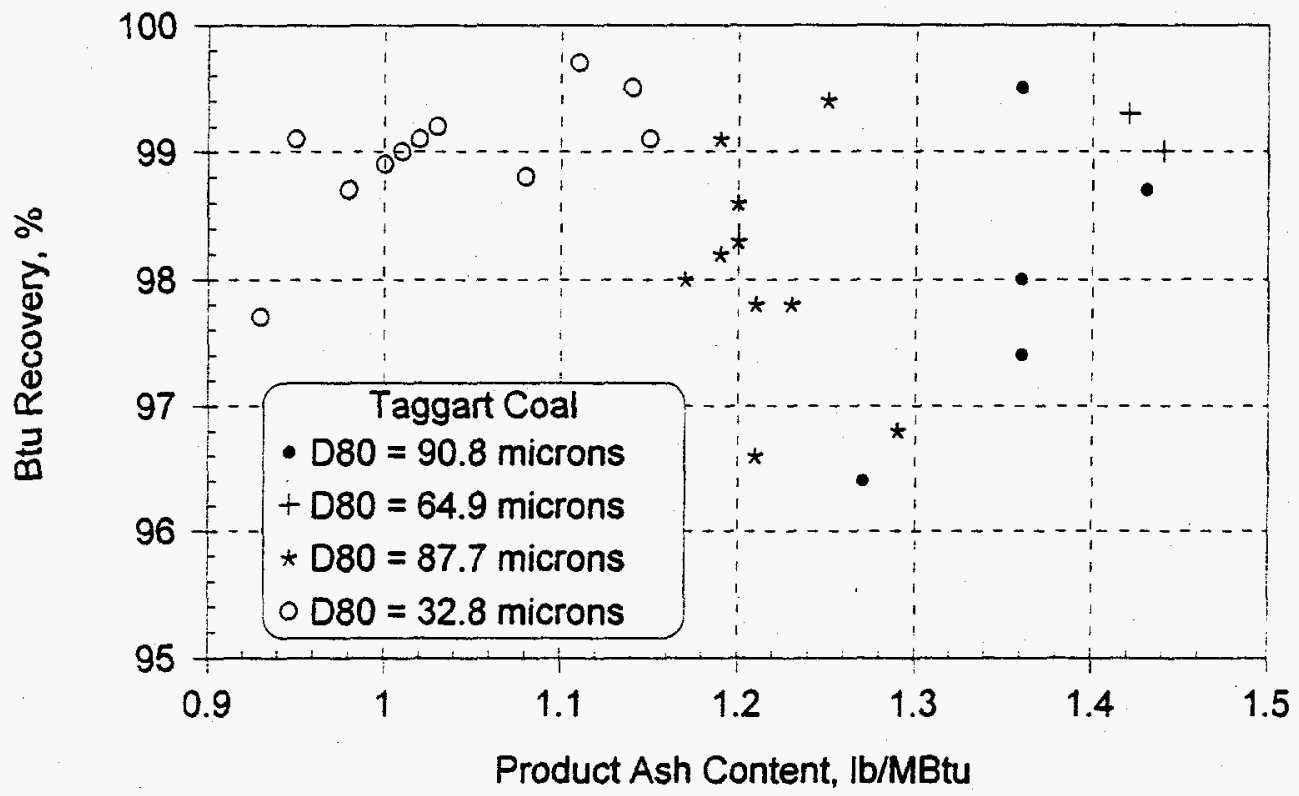

Figure 15. Taggart Coal Continuous Agglomeration Results

As can be seen from the data in Figure 15, all four of these ground feedstocks met the $2 \mathrm{lb} / \mathrm{MBtu}$ product ash specification. However, only the finest grind tested $\left(D_{80}=32.8\right.$ microns), met the $1 \mathrm{lb} / \mathrm{MBtu}$ product ash specification.

In comparing the two middle size grinds tested, 64.9 micron and 87.7 micron $D_{80}$ s, it is interesting to note that the 87.7 micron $D_{80}$ feedstock, while coarser than the 64.9 micron $D_{80}$ feedstock, still achieved lower product ash values. This trend was unexpected since typically, the finer the grind, the greater the mineral matter liberation.

However, when comparing these two particular grinds, it should be noted that the coarser grind was produced in the PDU, where the bulk of the material being reground was the cyclone underflow stream. Conversely, the finer grind was produced in the 4foot $x$ 4-foot ball mill operated in closed circuit with a 100-mesh screen, where the regrind material is the screen overflow stream. 
While the cyclone separation in the PDU grinding circuit is based primarily on size, the material specific gravity also effects the separation, with the underflow stream typically heavier and higher in ash. As such, selective regrinding of the higher ash material occurred in this case, which resulted in a more liberated product as compared to the finer grind, even though the overall grind was coarser

The bench-scale agglomeration unit operated well for the majority of the Taggart coal testing carried out. In general, all of these tests produced well formed agglomerates that screened easily. However, for the bulk of these tests, the agglomerates were generally small, in the 0.5 to $2 \mathrm{~mm}$ range.

As with the bulk of previous testing, Btu recoveries were high (>96\%) for all of the Taggart coal testing. Tailings ash values were in the 32 to $83 \%$ range.

Low Shear - As with operations utilizing other coals, difficulties were encountered with plugging at the low-shear discharge point during the Taggart coal testing. This lowshear discharge plugging was less pronounced for tests in which a high $(50 \mathrm{lb} / \mathrm{hr})$ coal feed rate was used. For these tests, the higher volumetric flowrate was sufficient to prevent plugging of the low-shear discharge.

As noted before for other coals, difficulty was also encountered when the low-shear vessel was operated full, i.e., when utilizing both mixing zones separated by a horizontal baffle. It appeared that the transfer of agglomerates from the lower to upper section of the low-shear vessel was a bottleneck.

As such, the opening in the horizontal baffle was increased from 1-1/2 inches to 5-1/2 inches diameter in an attempt to improve agglomerate transport to the upper zone. This modification proved only marginally successful, with plugging of the lower mixing zone still occurring.

\section{Indiana VII Coal Results}

Continuous agglomeration testing with the Indiana VII coal used two different feedstocks, the first ground in open-circuit in the 4-foot $x$ 4-foot ball mill followed by open circuit grinding in the Drais stirred-ball mill. This grinding configuration produced a feedstock with a topsize of about 325 mesh (44 microns) and a $D_{80}$ of 21.9 microns.

The second grind was produced in the PDU grinding circuit operating with the cyclone underflow and 270 mesh screen overflow material recycled to the fine grinding mill. This feedstock had a $D_{80}$ of 26 microns.

Complete PSDs for both of these feedstocks are shown in Table 17. 
Table 17. Indiana VII Coal Particle Size Distributions

\begin{tabular}{|c|c|c|}
\hline \multirow[b]{2}{*}{ Microns } & \multicolumn{2}{|c|}{ Cumulative Weight Percent Passing } \\
\hline & $4^{\prime} \times 4^{\prime} /$ Attritor Ground & PDU Ground \\
\hline 88 & 100.0 & 100.0 \\
\hline 62 & 97.7 & 97.8 \\
\hline 44 & 96.0 & 93.4 \\
\hline 31 & 92.9 & 86.5 \\
\hline 22 & 80.3 & 74.9 \\
\hline 16 & 68.3 & 63.1 \\
\hline 11 & 52.8 & 50.7 \\
\hline 7.8 & 38.5 & 38.0 \\
\hline 5.5 & 28.6 & 27.5 \\
\hline 3.9 & 18.3 & 18.0 \\
\hline 2.8 & 10.5 & 11.3 \\
\hline 1.9 & 4.7 & 5.4 \\
\hline 1.4 & 1.4 & 1.7 \\
\hline$D_{20}$ & 4.2 & 4.2 \\
\hline$D_{50}$ & 10.4 & 10.8 \\
\hline $\mathrm{D}_{80}$ & 21.9 & 26.0 \\
\hline
\end{tabular}

\section{Continuous Test Results}

A total of 20 agglomeration circuit tests were completed to evaluate the Indiana VII coal. Of these 20 tests, 13 were carried out with the $D_{80}=21.9$ micron feedstock and the remaining 7 with the $D_{80}=26$ micron feedstock.

Operating conditions and results for all of these tests are presented in Appendix $E$.

The following is a list of operating variable ranges tested for the Indiana VII coal:

- Feed PSD - $D_{80}$ of 21.9 and 26.0 microns

- Coal feed rate -12.3 to $33.4 \mathrm{lb} / \mathrm{hr}$

- Feed slurry solids concentration - 7,10 , and $13 \%$

- Heptane type - Commercial and pure grades

- Heptane dosage -30.0 to $34.8 \%$ on a dry ash free coal basis

- Asphalt dosage - 7.5 to $20 \mathrm{lb}$ per ton feed coal

- High-shear impeller - 2.4-inch diameter, 4-blade, radial flow

- High-shear impeller tip speed -13.4 to $18.0 \mathrm{~m} / \mathrm{s}$

- High-shear residence time - 1 to 2 minutes

- Low-shear impeller - 4.8-inch diameter, 4 blade, radial flow

- Low-shear impeller tip speed -3.2 to $8 \mathrm{~m} / \mathrm{s}$

- Low-shear configuration - Half full and full 
- Low-shear residence time - 3.4 to 7.6 minutes

- Vibrating screen deck opening size -48 and 100 mesh

- Vibrating screen inclination - 38 and 42 degrees downhill form horizontal

- Vibrating screen spray water rate -37 to $61 \mathrm{lb} / \mathrm{hr}$

A plot of Btu recovery vs product ash content in Ib/MBtu for all of the Indiana VII coal tests is shown in Figure 16. This data is separated by feedstock PSD.

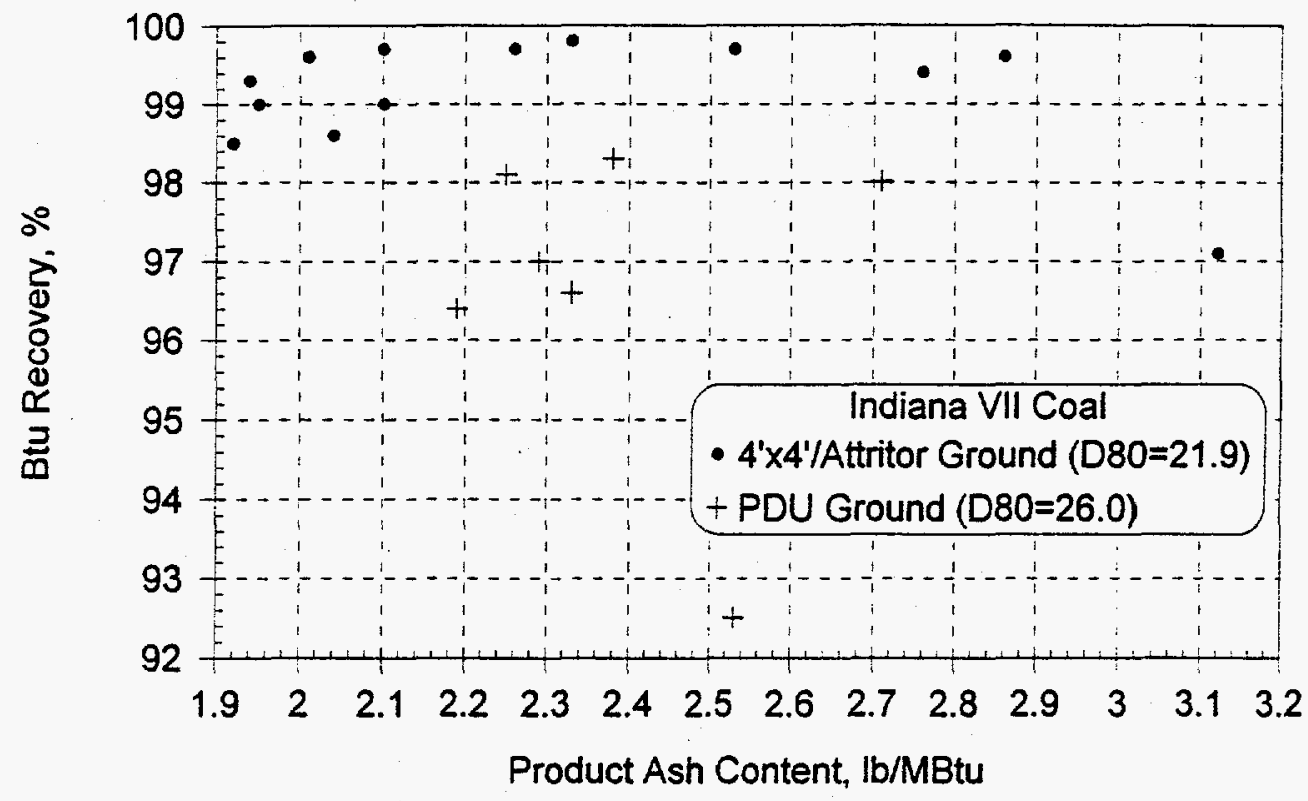

Figure 16. Indiana VII Coal Continuous Agglomeration Results

As can be seen from the results in Figure 16, the product ash specification of $2 \mathrm{lb}$ ash/MBtu was met, at approximately $99 \%$ Btu recovery, for three of the 13 tests carried out with the ground feedstock with a $D_{80}$ of 21.9 microns. All three of these tests utilized the 48-mesh screen deck. This indicates that this grind provided sufficient mineral-matter liberation.

It can also be seen from Figure 16 that none of the tests carried out utilizing the PDU ground feedstock ( $D_{80}=26$ microns) met the $2 \mathrm{lb} / \mathrm{MBtu}$ product ash specification, indicating that this grind did not provide sufficient mineral-matter liberation. This, however, was not unexpected since this grind was tailored to achieve project goals utilizing advanced flotation, which generally results in lower Btu recoveries, and therefore, correspondingly lower product ash contents. This suggests that for the selective agglomeration module, the PDU grinding circuit will have to be operated in a way that will produce a finer grind.

The product ash specification of $2 \mathrm{lb}$ ash/MBtu was not met for any of the tests completed using the 100-mesh screen deck during agglomerate recovery. This indicates that this finer screen size does not provide drainage of the mineral-matter 
bearing process water as well as the coarser 48 -mesh screen. Other observations to be noted concerning agglomeration of the Indiana VII coal are as follows:

- The addition of asphalt at the rate of 7.5 to $20 \mathrm{lb}$ per ton of coal is required to achieve inversion during high-shear agglomeration.

- Without the necessary asphalt, no growth will occur during the low-shear step resulting in no coal recovery during screening.

- Approximately 30 to $35 \%$ heptane (daf coal basis) is required to achieve highshear inversion and low-shear growth with the Indiana VII coal.

- There is no clear effect of solids concentration on product ash content.

- As noted for all testing to date, the product ash content appears most dependent on the agglomerate size distribution with larger better formed agglomerates having the lowest ash content.

Low-Shear - For the testing carried out with the Indiana VII coal, the low-shear operation and product can be characterized by one of the following:

1. Growth in the low-shear vessel started after about 20 minutes and continued indefinitely. Under these conditions, the increasing size eventually plugged the low-shear discharge port. This phenomenon occurred more prominently at lowshear impeller tip speeds in the 3 to $5 \mathrm{~m} / \mathrm{s}$ range.

2. Growth in the low-shear vessel was of a cyclic nature in which spherical $1 \mathrm{~mm}$ agglomerates formed, after which they grew to 3 to $4 \mathrm{~mm}$, followed by the formation of smaller agglomerates $(<0.5$ to $1.0 \mathrm{~mm})$ which then grew to 3 to 4 $\mathrm{mm}$ again, repeating the cycle. This cyclic growth and reduction pattern occurred primarily when higher impeller tip speeds $(6$ to $8 \mathrm{~m} / \mathrm{s})$ were used.

3. Growth in the low-shear vessel reached steady-state conditions after approximately one hour of operation. The final size of these agglomerates was usually small, 0.5 to $1 \mathrm{~mm}$. These conditions were achieved only when starvation heptane dosages were used.

\section{Hiawatha Coal Results}

Hiawatha coal testing used two different feedstocks, both closed-circuit ground in the 4foot $x$ 4-foot ball mill. The first grind used a 150-mesh screen resulting in a PSD with a $D_{80}$ of 46.6 microns. The second grind used a 100-mesh screen resulting in a PSD with $a D_{80}$ of 65.2 microns. Complete PSDs for these feedstocks are shown in Table 18.

A total of 27 agglomeration tests were completed with the Hiawatha coal. Of these tests, 13 used the 150-mesh topsize feedstock $\left(D_{80}=46.6\right.$ microns $)$, and the other 14 the 100 -mesh topsize feedstock ( $D_{80}=65.2$ microns).

Operating conditions and results for all of these tests are presented in Appendix $F$. 
Table 18. Hiawatha Coal Particle Size Distributions

Cumulative Weight Percent Passing

\begin{tabular}{|c|c|c|}
\hline Microns & 150 Mesh Topsize & 100 Mesh Topsize \\
\hline 300 & 100.0 & 100.0 \\
\hline 212 & 100.0 & 99.9 \\
\hline 150 & 100.0 & 99.8 \\
\hline 106 & 100.0 & 96.5 \\
\hline 75 & 96.9 & 85.0 \\
\hline 53 & 88.7 & 69.2 \\
\hline 45 & 77.9 & 62.1 \\
\hline 38 & 74.2 & 54.1 \\
\hline 30 & 63.4 & 47.7 \\
\hline 20 & 45.5 & 34.8 \\
\hline 15 & 35.1 & 26.1 \\
\hline 10 & 23.8 & 17.4 \\
\hline 8 & 19.8 & 14.0 \\
\hline 6 & 15.4 & 10.6 \\
\hline 4 & 10.1 & 6.9 \\
\hline 3 & 7.2 & 5.0 \\
\hline 2 & 4.1 & 2.9 \\
\hline 1 & 0.9 & 0.7 \\
\hline$D_{20}$ & 8.1 & 11.5 \\
\hline$D_{50}$ & 22.5 & 32.9 \\
\hline$D_{80}$ & 46.6 & 65.2 \\
\hline
\end{tabular}

The following is a list of operating variable ranges tested for the Hiawatha coal:

- Feed PSD - $D_{80}$ of 46.6 and 65.2 microns

- Coal feed rate -17.5 to $75.8 \mathrm{lb} / \mathrm{hr}$

- Feed slurry solids concentration $-7,10$, and $13 \%$

- Heptane type - Commercial grades

- Heptane dosage -21.6 to $28.5 \%$ on a dry ash free coal basis

- High-shear impeller - 2.4-inch diameter, 4-blade, radial flow

- High-shear impeller tip speed -6.7 to $18.0 \mathrm{~m} / \mathrm{s}$

- High-shear residence time - 0.5 to 1.9 minutes

- Low-shear impeller - 4.8-inch diameter, 4 blade, radial flow

- Low-shear impeller tip speed -3.0 to $8.0 \mathrm{~m} / \mathrm{s}$

- Low-shear configuration - Half full and full

- Low-shear residence time -1.5 to 7.2 minutes

- Vibrating screen deck opening size - 48 mesh

- Vibrating screen inclination - 34 to 42 degrees downhill form horizontal

- Vibrating screen spray water rate -30 to $52 \mathrm{lb} / \mathrm{hr}$ 
A plot of Btu recovery vs product ash content in lb/MBtu, for all of the Hiawatha coal test results, is shown in Figure 17. This data is separated by feedstock PSD.

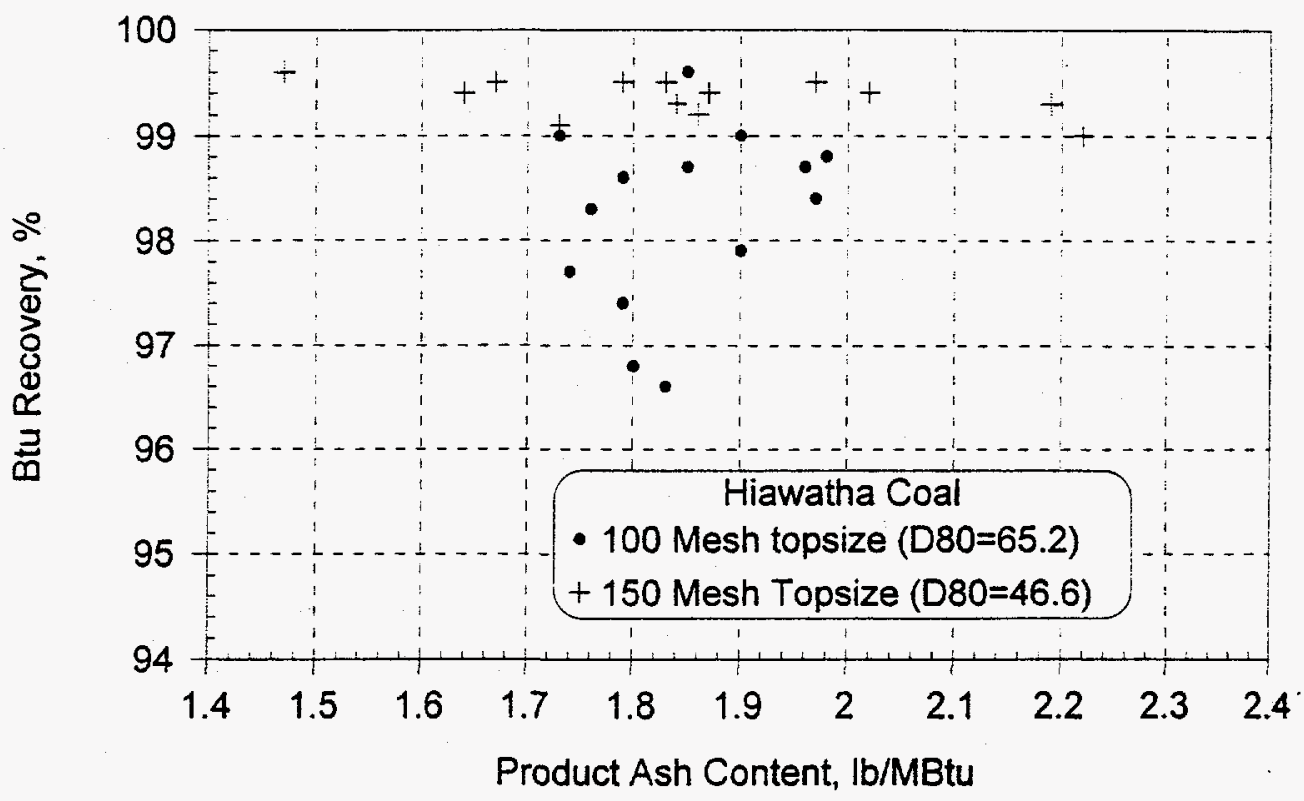

Figure 17. Hiawatha Coal Continuous Agglomeration Results

As can be seen from the results in Figure 17, the product ash specification of $2 \mathrm{lb}$ ash/MBtu was met for both of the grinds evaluated.

For the 150-mesh topsize feedstock, Btu recoveries were all greater than $99 \%$ with tailings ash values in the 81 to $87 \%$ range. For the 100-mesh topsize grind, Btu recoveries were slightly lower ( 96.6 to $99.6 \%$ ) with tailings ash values in the 56 to $80 \%$ range. This drop in Btu recovery for the coarser grind is attributed to the presence of more unliberated mineral-matter particles, which reported to the tailings stream along with their associated carbon content.

\section{Agglomerate Size Effect}

As discussed previously in this report, a general trend of decreasing product ash content with increasing agglomerate size has been observed throughout this work. The reason for this effect is that when the agglomerates are larger they drain there mineralmatter bearing process water easier, resulting in lower product ashes. This trend is illustrated in Figure 18, which presents product ash content as a function of agglomerate size, for the 150 -mesh $\left(D_{80}=46.8\right.$ micron $)$ Hiawatha testing.

Figure 18 clearly shows that as the agglomerate size increases the product ash content decreases. Since this effect is attributed to the carryover of more mineral-matter bearing process water with the product as agglomerate size decreases, the same effect on product ash can be seen as a function of product agglomerate solids concentration. This relationship is shown in Figure 19. 


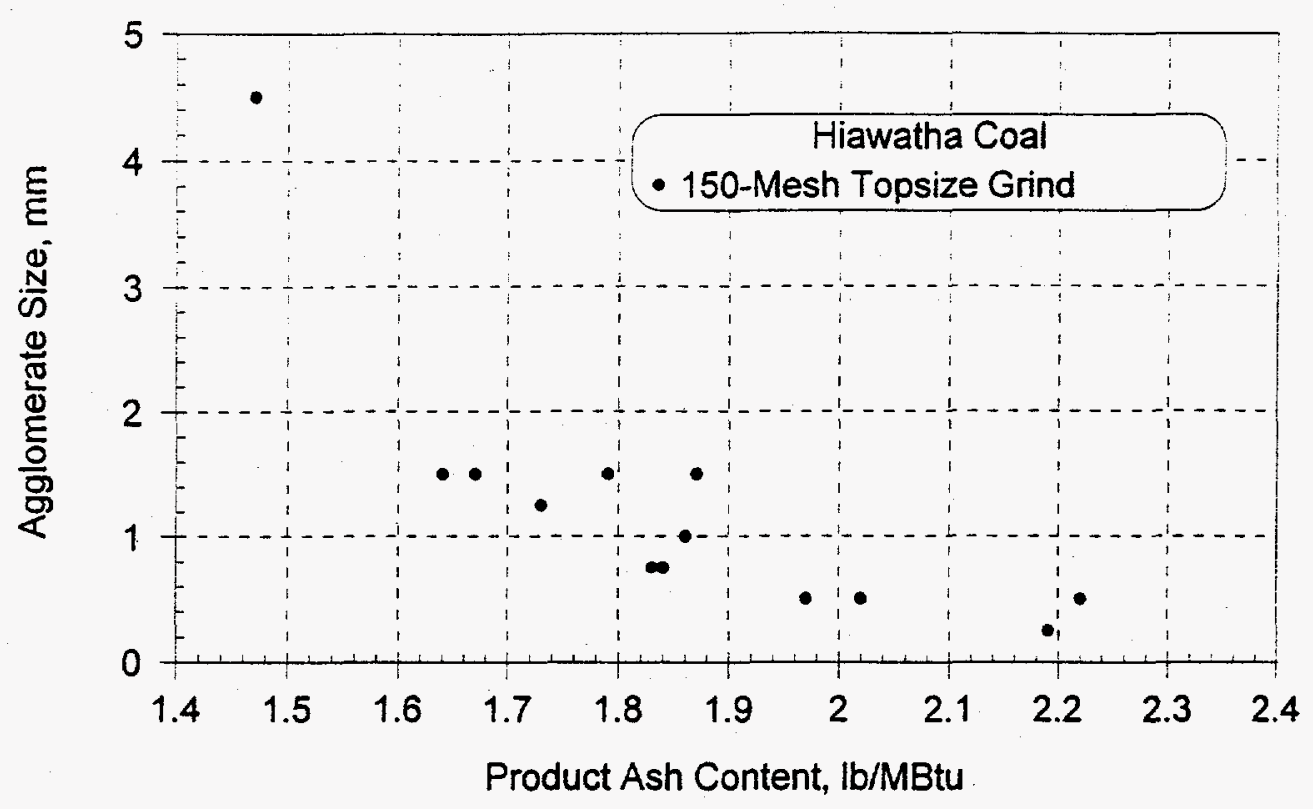

Figure 18. Hiawatha Coal - Agglomerate Size vs Product Ash

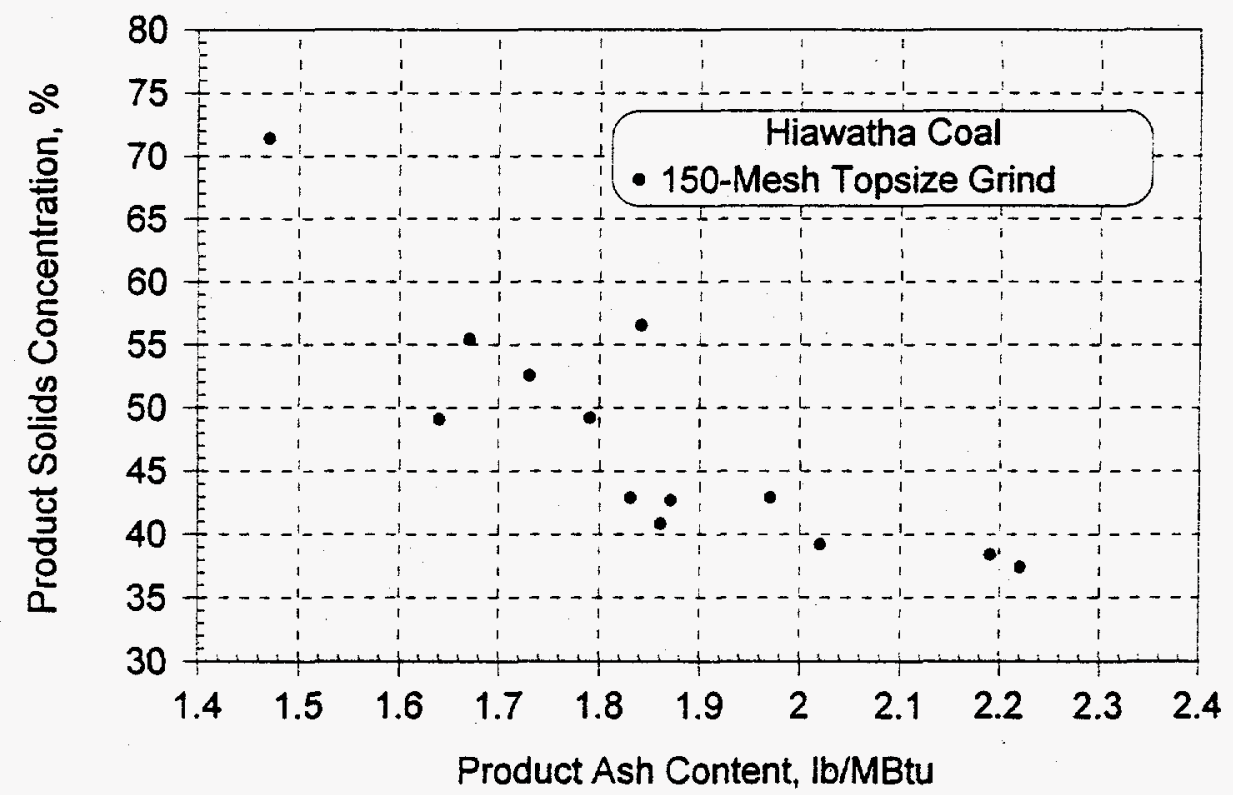

Figure 19. Hiawatha Coal - Product Solids Concentration vs Product Ash

A similar trend is not presented for the 100-mesh topsize grind tests since during that testing a much more consistent agglomerated product size was achieved, resulting in more consistent agglomerated product solids concentrations and product ash values. 


\section{Solids Concentration Effect}

In most cases, it was found that when high- and low-shear agglomeration is carried out at high solids concentrations, a higher product ash is achieved than when agglomeration is completed at lower solids concentrations. Unfortunately, for the bulk of the Subtask 6.5 results, this relationship is not evident since the agglomerate size effect on product ash is more prominent, masking the solids concentration effect. However, for the Hiawatha coal testing using the 100-mesh topsize feedstock, relatively consistent agglomerated product size was achieved, typically in the 1 to $3 \mathrm{~mm}$ size range. Figure 20 presents the product ash content as a function of agglomeration solids concentration.

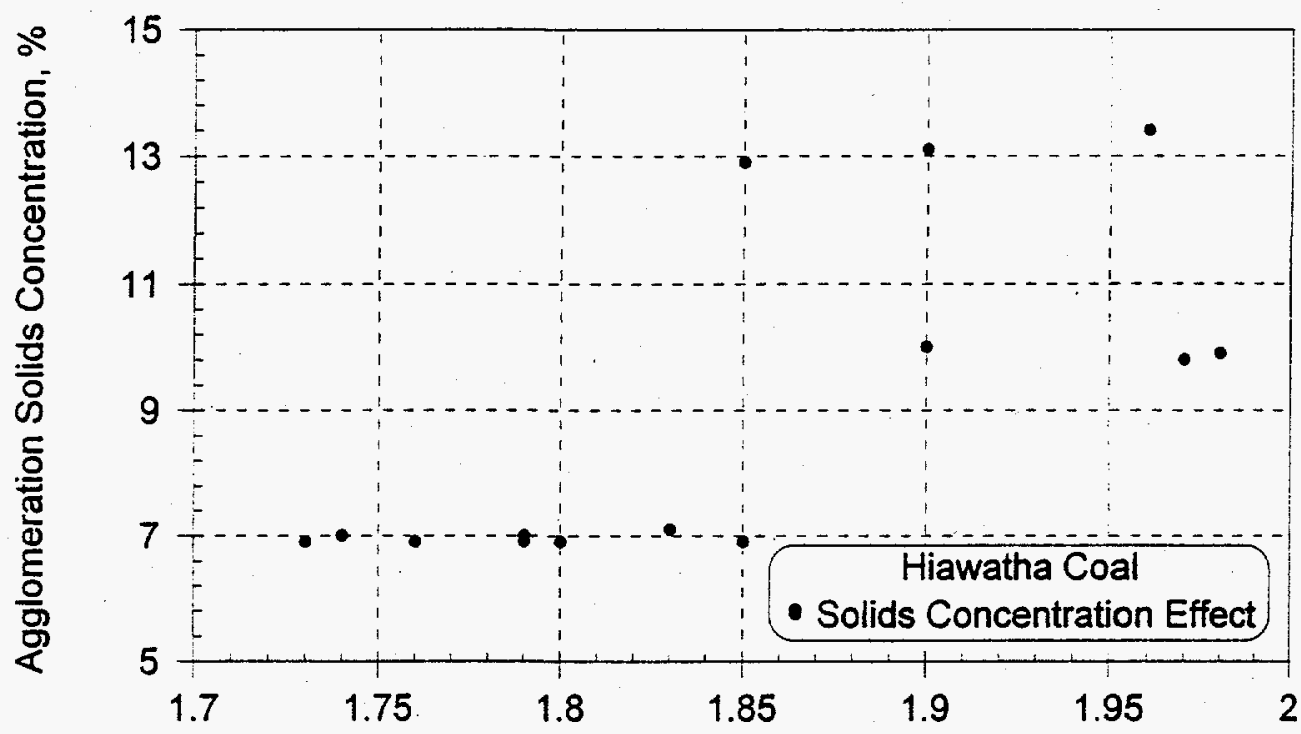

Product Ash Content, lb/MBtu

Figure 20. Hiawatha Coal - Agglomeration Solids Concentration Effect

As can be seen from the data in Figure 20, lower product ashes were achieved when agglomeration was completed at $7 \%$ solids than at $10 \%$ and $13 \%$ solids. This is attributed to the greater concentration of mineral matter present in the aqueous phase during agglomeration at the higher solids concentration levels. As such, any water trapped within the agglomerates during low-shear growth, or entrained in the agglomerate bed during screening carries a greater amount of mineral matter to the product stream.

\section{Agglomeration Variable Effects}

This section of the report discusses the general relationship between the various selective agglomeration parameters. The trends discussed here, are independent of the coals tested and are presented to illustrate the nature of the selective agglomeration process as tested during the course of Subtask 6.5. 


\section{Solids Concentration}

The effect of solids concentration on the selective agglomeration process as tested during Subtask 6.5 is two-fold.

During high shear, higher solids concentrations are beneficial in that they reduce the total energy required to achieve inversion. This reduction in energy is due to the greater particle to particle contact achieved at higher solids concentration for the same energy input. There is no apparent increase in product ash as a result of using higher high-shear solids concentration.

Considering low shear, it was found that lower solids concentrations resulted in lower product ash levels. This is due to the lower concentration of mineral matter in the aqueous phase, some of which gets trapped within the agglomerates themselves, and some of which is carried over to the product in the agglomerate bed during screening. It was also found that higher solids concentrations resulted in more agglomerate growth with all other low-shear conditions remaining constant, making heptane dosage very critical and agglomerate growth much more difficult to control.

\section{Heptane Concentration}

It was found during the Subtask 6.5 testing that the heptane concentration used has no effect on the product ash content directly. However, the heptane dosage used must be sufficient to achieve inversion during high shear, which in the case of higher rank coals is often insufficient to achieve agglomerate growth during low shear. Typically, as the feed coal particle size distribution becomes finer, more heptane is required to achieve inversion. Similarly, as the coal rank becomes lower, more heptane is also required.

It was also found that ultimately, the heptane dosage used determines the size of the agglomerates formed during low shear, which was found to affect product ash content drastically, with more heptane resulting in larger agglomerates and a lower product ash content.

If too little heptane is used, agglomerate growth is minimal resulting in poor drainage of mineral-matter bearing process water during screening and a higher product ash content. Also, If agglomerates are too small, incomplete formation occurs (powdery appearance) resulting in coal loss through the screen deck during agglomerate recovery. However, if too much heptane is used, the agglomerate growth is excessive and their handleability poor. Agglomerates containing too much heptane also are generally poorly formed (sticky appearance), resulting in poor screening performance and a higher product ash content.

As such, heptane dosage must be tailored to the specific high- and low-shear operating conditions being used. In particular, heptane dosage should be such that agglomerates in the 2 to $3 \mathrm{~mm}$ size range are consistently produced during low shear. 


\section{High Shear Agitation Intensity}

The amount of energy used during high-shear agglomeration must be sufficient to achieve inversion, such that agglomerate growth will occur during the subsequent lowshear unit operation. Typically, impeller tip speeds in the 6 to $18 \mathrm{~m} / \mathrm{s}$ range are required to achieve inversion. The actual tip speed needed, however, is dependent primarily on the type of coal used, with lower rank coals requiring higher $(18 \mathrm{~m} / \mathrm{s})$ agitation intensity to achieve inversion and easy to agglomerate coals like the Taggart achieving inversion at tip speeds as low as $6 \mathrm{~m} / \mathrm{s}$. Other factors influencing the required agitation intensity include the slurry solids concentration (higher solids concentration requires less energy), coal particle size distribution (finer coal particles may require higher energy), and high-shear residence time (more residence requires less energy input).

For some coals that are particularly easy to agglomerate like the Taggart, complete inversion during high shear is not necessary to achieve growth during low shear. This is because the agitation intensity during low shear, in itself, is sufficient to promote growth for such coals. In cases like this, however, these reduced levels of high-shear agitation ultimately result in lower Btu recoveries due to the incomplete inversion during high shear, i.e., some coal particles do not become completely coated with heptane and subsequently do not form larger agglomerates during low shear.

\section{High Shear Residence Time}

The residence time required during high shear is dependent on the agitation intensity utilized. Generally, at higher impeller tip speeds, lower residence times produce the same results. The relationship between these two parameters is an important factor for consideration during the design of an agglomeration circuit. The critical parameters are that sufficient total energy is utilized during high shear and that the impeller tip speed be sufficient to achieve inversion.

\section{Low Shear Agitation Intensity}

The agitation intensity (impeller tip speed) utilized during low-shear agglomeration was found to effect both the size and quality of the agglomerates formed. In general, if the impeller tip speed used was too high, agglomerate growth would be minimal, resulting in small agglomerates $(0.5 \mathrm{~mm}$ or less), from which drainage of the associated mineralmatter bearing process water was difficult. However, if agitation intensity was too low, the agglomerates were generally poorly formed, had poor strength, and formed a thicker agglomerate bed during screening. These poorly formed agglomerates also contained more mineral bearing process water resulting in higher product ash contents.

As such, it was found that a low-shear impeller tip speed of $5 \mathrm{~m} / \mathrm{s}$ produced well formed agglomerates of good strength for screening. 


\section{Low Shear Residence Time}

The effect of low-shear residence time on the overall performance of the selective agglomeration process was found to be minimal. Generally, for all of the coals tested, low-shear residence time variations were overcome by adjustments in heptane concentration. However, since longer residence times (4 to 7 minutes) were found to make heptane dosage more critical and agglomerate growth much more difficult to control, low-shear residence times on the order of 2 to 3 minutes are recommended.

\section{Screen Deck Inclination}

The recovery of product agglomerates on a vibrating screen is easily achieved as long as the agglomerates are well formed, so that they afford good drainage of the mineralmatter bearing process water discharging from the low-shear vessel. While screen deck inclinations in the 35 to 45 degrees downhill from horizontal range were evaluated during Subtask 6.5 testing, these settings are purely a function of the screen utilized. It was found during the testing that the vibratory action of the screen used was insufficient to move the agglomerates across the screen. It is anticipated, however, that the use of a dewatering screen with a stronger forward linear motion and a slight downhill orientation would result in good agglomerate transport across the screen deck.

\section{Screen Spray Water Flow Rate}

Due to poor control of low-shear growth during much of the Subtask 6.5 testing, i.e., the production of inconsistently sized agglomerates, evaluation of screen spray water effect on product ash content was virtually impossible. It is anticipated, however, that given the production of well formed agglomerates in the 2 to $3 \mathrm{~mm}$ range and the use of a dewatering screen, spray water requirements would be minimal.

\section{BATCH STRIPPER TESTING}

This section of the report discusses the heptane characterization work completed as well as the batch stripper testing carried out during Subtask 6.5.

In an effort to better quantify the residual bridging liquid concentrations remaining with a stripped agglomerated product, a number of batch stripper tests were carried out. These batch tests were found to provide a better indication of some parameter effects on residual heptane concentrations since more control over the tests was possible. Several different types of batch stripper tests were completed as follows:

- Boiling of recovered agglomerates in an open stirred beaker for a set period of time@ $94^{\circ} \mathrm{C}$

- Thermal drying at $110^{\circ} \mathrm{C}$ for a set period of time

- Autoclave treatment at 115 to $120^{\circ} \mathrm{C}$ for a set period of time 


\section{Heptane Characterization}

During the course of the Subtask 6.5 testing, two types of heptane were used. The first type tested was a commercial grade heptane with a bulk cost of about $\$ 1.00$ per gallon. The second type tested was a pure grade heptane with a bulk cost of about $\$ 6.00$ per gallon.

\section{Feed Heptane Analyses}

Characterization of these two heptane types was carried out by Phoenix Laboratories of Broomfield, Colorado. The results of these analyses, two for the commercial grade and one for the pure grade, are shown in Table 19.

Table 19. Feed Heptane Analyses

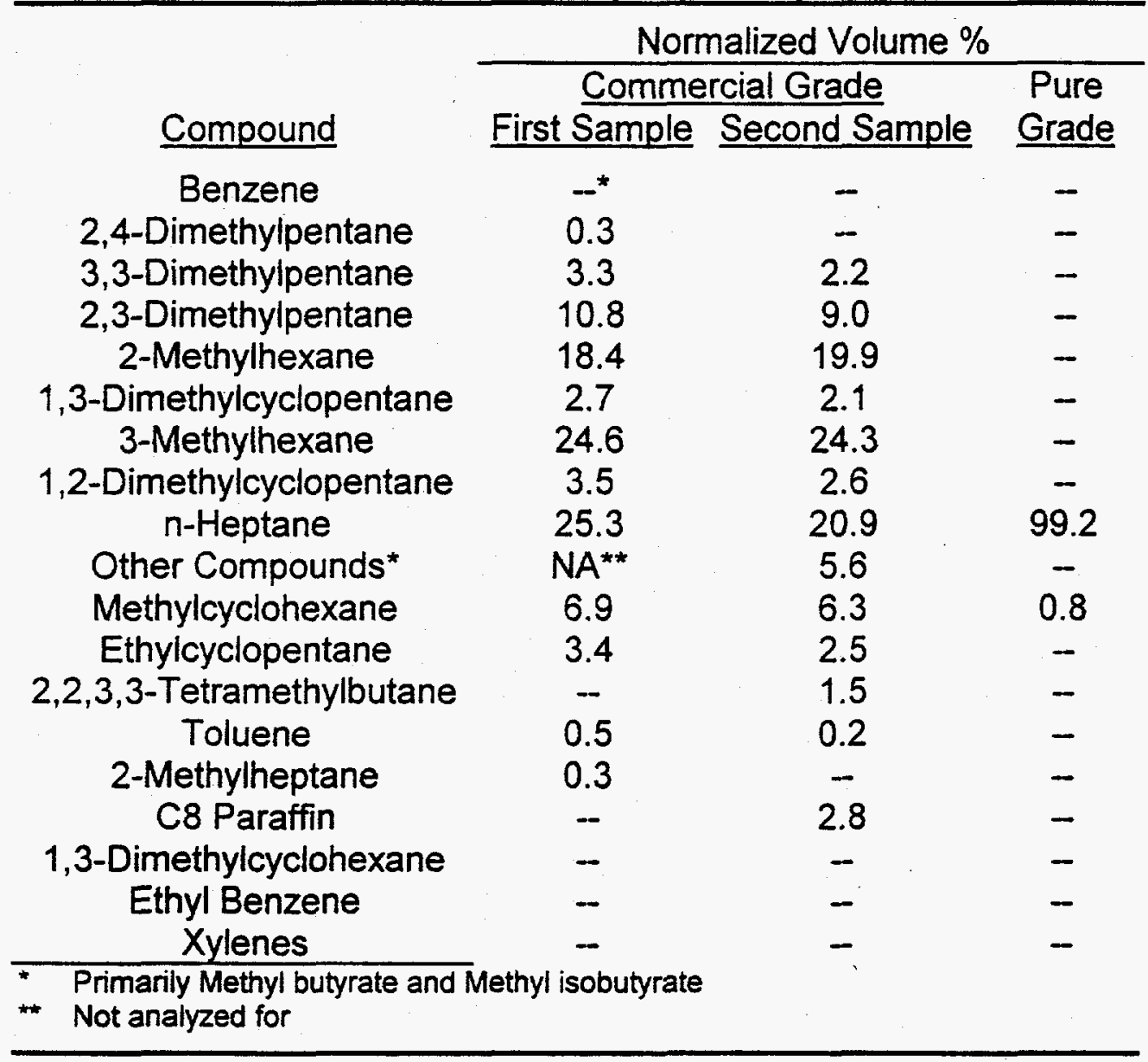

As can be seen in Table 19, the n-heptane content of the commercial grade heptane was in the 21 to $25 \%$ range, while the pure grade heptane contained greater than $99 \%$ $\mathrm{n}$-heptane. The differences between the two separate commercial grade analyses are attributed to different samples and different operators. 


\section{Residual Heptane Analyses}

In an effort to achieve reliable analysis of residual heptane on steam stripped products, Huffman Laboratories of Golden, Colorado was contacted. After discussions with Huffman, it was determined that given the many compounds present in the commercial grade heptane, it was not economical to analyze for all components regularly.

As such, it was decided that the samples would be analyzed for $n$-heptane only, and the amount of total residual hydrocarbon calculated based on the percentage of total hydrocarbons that were $n$-heptane. As a first estimate, it was assumed that $n$-heptane remained on the product in approximately the same proportion, $25 \%$, as it was present in the original commercial grade heptane sample.

In order to confirm this assumption, the distribution of the various residual hydrocarbon components remaining on different types of stripper products was determined. This work was carried out by Phoenix Labs. The samples submitted for these residual distribution analyses covered a wide range of stripped products as follows:

- Coal slurry with no heptane added - boiled for 15 minutes

- Continuous stripper product (commercial heptane) processed as follows:

- Single pass through stripper

- Two passes through stripper

- Two passes through stripper and thermally dried

- Batch agglomeration products boiled for 15 minutes:

- Agglomerated with and without asphalt (commercial heptane)

- Agglomerated with and without asphalt (pure heptane)

- Batch agglomeration product (pure heptane) boiled in an autoclave at 115 to $120^{\circ} \mathrm{C}$ for 10 minutes after an initial 5 minute boiling period in an open beaker

- Continuous stripper product (commercial heptane) boiled in an autoclave at 115 to $120^{\circ} \mathrm{C}$ for 10 minutes

Results for these hydrocarbon distribution analyses along with the feed heptane distribution analyses are shown in Table 20. These results indicated that the original assumption that the residual hydrocarbons (commercial heptane) were $25 \% \mathrm{n}$-heptane was slightly conservative for samples that were continuously stripped only, with the actual $n$-heptane content of the residual hydrocarbons in the 30 to $33 \%$ range.

For samples agglomerated with commercial heptane and then subsequently batch boiled or continuously stripped followed by autoclave treatment at increased temperature and pressure, however, the assumption was off by a factor of almost 2, with the actual $n$-heptane content in the 43 to $50 \%$ range. For samples agglomerated with commercial heptane and then subsequently thermally dried, it was found that only about $8 \%$ of the remaining hydrocarbons were $n$-heptane. For all of the samples agglomerated with pure heptane, $n$-heptane represented at least $90 \%$ of the residual hydrocarbons. 
Table 20. Hydrocarbon Distribution for Various Stripped Products

\begin{tabular}{|c|c|c|c|c|c|c|c|c|c|c|c|c|c|c|c|c|}
\hline & \multirow{2}{*}{\multicolumn{3}{|c|}{ Commercial }} & \multirow{3}{*}{\multicolumn{2}{|c|}{$\begin{array}{l}\text { No Heptane } \\
\text { Boiled } 15 \mathrm{~min}\end{array}$}} & \multirow{2}{*}{\multicolumn{3}{|c|}{$\begin{array}{c}\text { Sunnyside Coal } \\
\text { Commercial Heptane } \\
\text { Continuous Stripper Products }\end{array}$}} & \multirow{2}{*}{\multicolumn{2}{|c|}{$\begin{array}{l}\text { Sunnyside Batch Prod } \\
\text { Commercial Heptane } \\
\text { Boiled } 15 \mathrm{~min}\end{array}$}} & \multicolumn{3}{|c|}{$\begin{array}{l}\text { Pure Heptane Batch } \\
\text { Boiled } 15 \mathrm{~min}\end{array}$} & \multicolumn{3}{|c|}{$\begin{array}{l}\text { Autoclave @ } 115-120^{\circ} \mathrm{C} \\
\text { for } 10 \text { min following: }\end{array}$} \\
\hline & & & & & & & & & & & Sunn & side & Indian & Comm ! & leptane & Pure Hept \\
\hline & \multicolumn{2}{|c|}{ Heptane } & \multirow{2}{*}{$\begin{array}{c}\text { Pure } \\
\text { Heptane }\end{array}$} & & & \multirow{2}{*}{$\begin{array}{l}\text { One } \\
\text { Pass }\end{array}$} & \multirow{2}{*}{$\begin{array}{c}\text { Two } \\
\text { Passes }\end{array}$} & \multirow{2}{*}{$\begin{array}{l}\text { Two Passes } \\
\text { \& Thermal }\end{array}$} & \multicolumn{2}{|c|}{ Asphalt (lb/t) } & \multicolumn{3}{|c|}{ Asphalt (lb/ton) } & \multicolumn{2}{|c|}{ Cont Stripping } & \multirow{2}{*}{$\frac{5 \min B o i l}{\text { Sun }}$} \\
\hline & 1 & $\mathbf{2}$ & & \multicolumn{2}{|c|}{ Sunny Indiana } & & & & $\mathbf{Q}$ & 10 & $\underline{0}$ & 10 & 10 & Ind & Sun & \\
\hline \multicolumn{17}{|l|}{ Compound } \\
\hline Benzene & $-\infty$ & - & - & 12.4 & 12.5 & 1.0 & 0.8 & 0.1 & 0.5 & 0.6 & 1 & 0.5 & 0.3 & 0.5 & 0.4 & 0.3 \\
\hline 2,4-Dimethylpentane & 0.3 & - & - & - & - & - & - & - & - & - & - & - & - & - & - & - \\
\hline 3,3-Dimethylpentane & 3.3 & 2.2 & - & - & - & - & 1.4 & 7.4 & - & 1.1 & - & - & - & 0.9 & 0.9 & - \\
\hline 2.3-Dimethylpentane & 10.8 & 9.0 & $=$ & - & - & - & - & 19.8 & - & - & - & - & - & 2.9 & - & - \\
\hline 2-Methylhexane & 18.4 & 19.9 & - & $=$ & $=$ & 14.5 & 12.0 & 14.9 & 5.9 & - & - & - & - & 8.5 & 15.7 & - \\
\hline 1,3-Dimethylcyclopentane & 2.7 & 2.1 & - & - & - & - & - & 1.9 & 1.2 & 1.4 & - & - & - & - & 1 & - \\
\hline 3-Methylhexane & 24.6 & 24.3 & - & - & - & 27.3 & 27.0 & 2.0 & 14.2 & 21.3 & - & - & - & 20.9 & 19.4 & 0.7 \\
\hline 1,2-Dimethylcyclopentane & 3.5 & 2.6 & $=$ & - & - & 1.3 & - & 4.6 & 1.9 & 2.2 & - & - & - & 1.2 & 2.5 & - \\
\hline n-heptane & 25.3 & 20.9 & 99.2 & - & 13 & 29.9 & 33.0 & 7.9 & 49.2 & 45.7 & 91.7 & 93.3 & 96.3 & 46.5 & 43.6 & 95.7 \\
\hline Other Compounds** & $N A^{* * *}$ & 5.6 & - & 29.9 & 42.1 & 12.3 & 12.7 & 20.2 & 2.2 & 5.2 & 2.2 & 3.4 & 1.5 & 1.5 & 1.6 & 1.4 \\
\hline Methylcyclohexane & 6.9 & 6.3 & 0.8 & - & - & 6.7 & 6.2 & 13.6 & 10.7 & 9.9 & - & - & 1.1 & 6 & 5 & 1 \\
\hline Ethylcyclopentane & 3.4 & 2.5 & - & - & - & 2.0 & 1.7 & 2.1 & 4.6 & 2.5 & - & - & - & 1.5 & 1.1 & - \\
\hline $2,2,3,3-$ Tetramethylbutane & - & 1.5 & - & - & - & 1.7 & 2.0 & 4.6 & 2 & 2.4 & - & - & - & 2.2 & 2.1 & - \\
\hline Toluene & 0.5 & 0.2 & - & 25.2 & 24.6 & 2.4 & 1.7 & 0.4 & 2 & 2.4 & 2.3 & 1.1 & 0.7 & 1.2 & 1 & 0.7 \\
\hline 2-Methylheptane & 0.3 & - & : & - & - & - & $\therefore$ & - & - & $\cdot$ & - & - & - & - & - & - \\
\hline C8 Paraffin & - & 2.8 & - & - & - & - & - & - & 4.5 & 4.7 & - & - & - & 4.8 & 5.5 & - \\
\hline 1,3-Dimethylcyclohexane & - & - & - & $\cdot$ & - & - & - & - & - & - & - & - & - & 1.2 & - & - \\
\hline Ethylbenzene & - & - & - & 10.7 & 7.9 & 0.6 & 0.5 & 0.1 & 0.3 & 0.4 & 0.9 & 0.5 & 0.2 & 0.3 & 0.2 & 0.2 \\
\hline $\begin{array}{l}\text { Xylenes } \\
\text { Total }\end{array}$ & $\begin{array}{c}= \\
100.0\end{array}$ & 99.9 & $\begin{array}{c}= \\
100.0\end{array}$ & $\frac{21.8}{100.0}$ & $\begin{array}{c}= \\
100.1\end{array}$ & $\frac{0.3}{100.0}$ & $\frac{1.1}{100.1}$ & $\frac{0.4}{100.0}$ & $\frac{0.8}{100.0}$ & $=$ & $\frac{2}{100.1}$ & $\frac{1.2}{100.0}$ & $\begin{array}{c}= \\
100.1\end{array}$ & $=$ & $=$ & $=$ \\
\hline \multicolumn{17}{|c|}{ Not Detected } \\
\hline \multicolumn{17}{|c|}{$\begin{array}{l}\text { Primarily Methyl butyrate and Methyl isobutyrate } \\
\text { Nol Analyzed For }\end{array}$} \\
\hline
\end{tabular}


One important point to note is that this data indicated that the Benzene, Ethyl Benzene, and Xylenes detected in the stripped product samples originated from the coal upon heating. As such, their presence in the stripped products cannot be avoided.

Upon analysis of these stripped samples, Phoenix classified some of the hydrocarbons as "other compounds", and identified them primarily as Methyl butyrate and Methyl isobutyrate. While these compounds represented anywhere from 12 to $42 \%$ of the total hydrocarbons present, they were suspected to originate from the plastic sample jar lids.

The following is a summary of conclusions made based on these residual hydrocarbon distribution analyses:

- n-heptane represented from 20.9 to $25.3 \%$ of the original commercial grade heptane used.

- The original pure grade heptane contained $99.2 \% \mathrm{n}$-heptane and $0.8 \%$ methylcyclohexane.

- When coal agglomerated with commercial grade heptane was thermally dried, n-heptane represented only $7.9 \%$ of the total residual hydrocarbons.

- When coal agglomerated with the commercial grade heptane was treated in the continuous $25 \mathrm{lb} / \mathrm{hr}$ steam stripper, n-heptane represented from 29.9 to $33.0 \%$ of the total residual hydrocarbons remaining.

- When plain coal slurry (no heptane) was boiled for 15 minutes, 50 to $59 \mathrm{ppm}$ of hydrocarbons on a dry coal basis were detected. These hydrocarbons consisted primarily of benzene, toluene, ethylbenzene, and xylenes. Some heptane was also present along with the non-hydrocarbon compounds methyl butyrate and methyl isobutyrate.

- The stripping of pure heptane from coal resulted in a residual hydrocarbon distribution of which over $90 \%$ was $n$-heptane. Also consistently detected in these products were benzene, toluene, ethylbenzene and the non-hydrocarbon methylbutyrates.

- Coal agglomerated with commercial heptane and then either boiled for 15 minutes, or boiled and then autoclaved at a higher temperature, had a residual hydrocarbon distribution in which 44 to $49 \%$ was n-heptane. Numerous other hydrocarbons present in the original commercial heptane feed were also found in these products.

- It was found that the best way to consistently determine the quantity of total residual hydrocarbons in a stripped product was to utilize a pure grade of heptane in the testing. By so doing, the analyses for residual $n$-heptane would most accurately reflect the total residual hydrocarbons present.

\section{Initial Batch Testing}

In an effort to better define residual hydrocarbon (n-heptane) concentrations, batch stripper testing was carried out. For this initial work, samples of product agglomerated 
Based on the results shown in Table 22, the following conclusions were drawn:

- On a dry coal basis, thermal drying provides significantly lower residual nheptane concentrations than boiling.

- Storage of the product for 2 days prior to stripping results in higher residual nheptane concentrations than immediate stripping.

- The use of asphalt resulted in lower residual heptane contents after boiling.

- Pentane can be removed to very low levels under all conditions tested.

\section{Asphalt Effects}

To confirm the data indicating that the presence of asphalt results in reduced residual heptane concentrations, additional batch testing was carried out. For this work, products agglomerated with and without asphalt, were either boiled or thermally dried for two hours. Results of these tests; along with previous data, are shown in Table 23. It should be noted that for the commercial heptane data in Table 23, only the n-heptane fraction is reported, meaning that total hydrocarbon contents were significantly higher.

\section{Table 23. Batch Stripper Results - Asphalt Effects}

\begin{tabular}{|c|c|c|c|c|c|}
\hline \multirow{3}{*}{$\begin{array}{c}\text { Heptane } \\
\text { Type } \\
\text { Commercial* }^{\star}\end{array}$} & \multirow{3}{*}{$\begin{array}{l}\text { Asphalt } \\
\qquad \begin{array}{c}\mathrm{ib} / \mathrm{t} \\
- \\
8\end{array}\end{array}$} & \multirow{3}{*}{$\begin{array}{l}\text { Coal } \\
\text { Indiana } \\
\text { Indiana }\end{array}$} & \multirow{3}{*}{$\begin{array}{l}\text { Stripping } \\
\text { Method } \\
\text { Boil-2hrs** } \\
\text { Boil-2hrs }\end{array}$} & \multicolumn{2}{|c|}{ n-heptane, ppm } \\
\hline & & & & sample & $\underline{\mathrm{dcb}}$ \\
\hline & & & & $\begin{array}{l}31 \\
7.6\end{array}$ & $\begin{array}{c}1161 \\
262\end{array}$ \\
\hline & $\overline{8}$ & $\begin{array}{l}\text { Indiana } \\
\text { Indiana }\end{array}$ & $\begin{array}{l}\text { Thermal } \\
\text { Thermal }\end{array}$ & $\begin{array}{c}220 \\
35\end{array}$ & $\begin{array}{c}220 \\
35\end{array}$ \\
\hline & $\overline{8}$ & $\begin{array}{l}\text { Sunnyside } \\
\text { Sunnyside }\end{array}$ & $\begin{array}{l}\text { Boil-2hrs } \\
\text { Boil-2hrs }\end{array}$ & $\begin{array}{c}33 \\
118\end{array}$ & $\begin{array}{l}1000 \\
4097\end{array}$ \\
\hline & - & $\begin{array}{l}\text { Sunnyside } \\
\text { Sunnyside }\end{array}$ & $\begin{array}{l}\text { Boil-15min }{ }^{* *} \\
\text { Boil-15min }\end{array}$ & $\begin{array}{l}203 \\
103\end{array}$ & $\begin{array}{l}2509 \\
1533\end{array}$ \\
\hline \multirow[t]{3}{*}{ Pure } & $\overline{10}$ & $\begin{array}{l}\text { Sunnyside } \\
\text { Sunnyside }\end{array}$ & $\begin{array}{l}\text { Boil-15min } \\
\text { Boil-15min }\end{array}$ & $\begin{array}{l}390 \\
284\end{array}$ & $\begin{array}{l}5660 \\
4051\end{array}$ \\
\hline & $\overline{5}$ & $\begin{array}{l}\text { Sunnyside } \\
\text { Sunnyside }\end{array}$ & $\begin{array}{l}\text { Thermal } \\
\text { Thermal }\end{array}$ & $\begin{array}{l}459 \\
409\end{array}$ & $\begin{array}{l}459 \\
409\end{array}$ \\
\hline & $\overline{5}$ & $\begin{array}{l}\text { Sunnyside } \\
\text { Sunnyside }\end{array}$ & $\begin{array}{l}\text { Boil-2hrs } \\
\text { Boil-2hrs }\end{array}$ & $\begin{array}{l}75 \\
24\end{array}$ & $\begin{array}{c}2038 \\
792\end{array}$ \\
\hline $\begin{array}{l}\text { Analysis fo } \\
\text { Screen pro } \\
* \text { Screen pro }\end{array}$ & $\begin{array}{l}\text { eptal } \\
\text { resic } \\
\text { filter }\end{array}$ & only, total hy & ocarbons ab & $\begin{array}{l}.5 \text { tim } \\
\text { is } \\
\text { ir } 2 \text { ho }\end{array}$ & \\
\hline
\end{tabular}

As can be seen from these results, in every case except one, the presence of asphalt during agglomeration resulted in lower residual heptane concentrations whether the stripping was done thermally or by boiling. 


\section{Pressure Effects}

Since significantly lower trace heptane contents are realized when thermal drying at $110^{\circ} \mathrm{C}$ over boiling at $94^{\circ} \mathrm{C}$, batch stripper tests were carried out in which agglomerated products were boiled under pressure to maintain a slurry temperature in the 115 to $120^{\circ} \mathrm{C}$ range. To achieve these high temperatures, the tests were completed in a Parr Autoclave fixed with a 15 psi pressure relief valve. Heat was applied to the autoclave containing a fixed amount of slurry, and as such, a continuous vapor discharge was released by the pressure relief valve to maintain the desired temperature. Results for these tests are shown in Table 24.

Table 24. Batch Stripper Results - Pressure Effects

\begin{tabular}{|c|c|c|c|c|c|}
\hline Solvent & $\begin{array}{c}\text { Asphalt } \\
\text { Ib/t }\end{array}$ & Coal & $\begin{array}{c}\text { Autoclave } \\
\text { Ret Time (min) }\end{array}$ & \multicolumn{2}{|c|}{ n-heptane, ppm } \\
\hline Commercial Heptane* & $\begin{array}{l}7.5 \\
7.5 \\
7.5 \\
7.5\end{array}$ & $\begin{array}{l}\text { Ind } \\
\text { Ind } \\
\text { Ind } \\
\text { Ind }\end{array}$ & $\begin{array}{l}0 * \star \\
10 \\
20 \\
30\end{array}$ & $\begin{array}{l}208 \\
82 \\
74 \\
29\end{array}$ & $\begin{array}{l}1949 \\
804 \\
604 \\
334\end{array}$ \\
\hline & $\begin{array}{l}- \\
- \\
-\end{array}$ & $\begin{array}{l}\text { Sun } \\
\text { Sun } \\
\text { Sun } \\
\text { Sun }\end{array}$ & $\begin{array}{l}0 * * \\
10 \\
20 \\
30\end{array}$ & $\begin{array}{l}155 \\
61 \\
45 \\
55\end{array}$ & $\begin{array}{l}2583 \\
893 \\
575 \\
589\end{array}$ \\
\hline Pure Heptane & $\begin{array}{l}- \\
- \\
-\end{array}$ & $\begin{array}{l}\text { Sun } \\
\text { Sun } \\
\text { Sun } \\
\text { Sun }\end{array}$ & $\begin{array}{l}0^{* \star \star \star \star} \\
10 \\
20 \\
30\end{array}$ & $\begin{array}{l}887 \\
242 \\
301 \\
227\end{array}$ & $\begin{array}{l}8153 \\
2995 \\
3053 \\
1903\end{array}$ \\
\hline $\begin{array}{l}\text { Analysis for } n \text {-heptane } \\
\text { Temperature in autoc } \\
\text { Autoclave feed - Cont } \\
\text { Autoclave feed - Batc }\end{array}$ & $\begin{array}{l}\text { nly, tot } \\
\text { e @ } 1 \\
\text { uous st } \\
\text { aglom }\end{array}$ & $\begin{array}{l}\text { hydroc } \\
-120^{\circ} \mathrm{C} \\
\text { ping co }\end{array}$ & $\begin{array}{l}\text { arbons about } 2.5 \\
\text { lumn product } \\
\text { oduct boil @ } 94^{\circ}\end{array}$ & 5 higher & \\
\hline
\end{tabular}

As can be seen from this data, additional treatment in the autoclave at increased temperature and pressure resulted in reduced residual hydrocarbon concentrations as compared to the continuously stripper product, generated at ambient pressure. Based on these results, a two-stage stripping circuit was constructed as part of the benchscale continuous test unit.

\section{Storage Effects}

As part of the scope of this project, clean coal produced by selective agglomeration needs to be formulated into highly loaded coal-water-slurry fuels (CWF) to replace premium fuels such as oil and gas. As an estimate to determine the fate of any heptane remaining on the coal after stripping, Sunnyside coal continuous stripper product was filtered and formulated into a slurry of approximately $55 \%$ solids. The 
heptane concentration of this slurry was monitored over a 14 day period. Table 25 presents the results of this work.

Table 25. CWF Residual Heptane Concentration

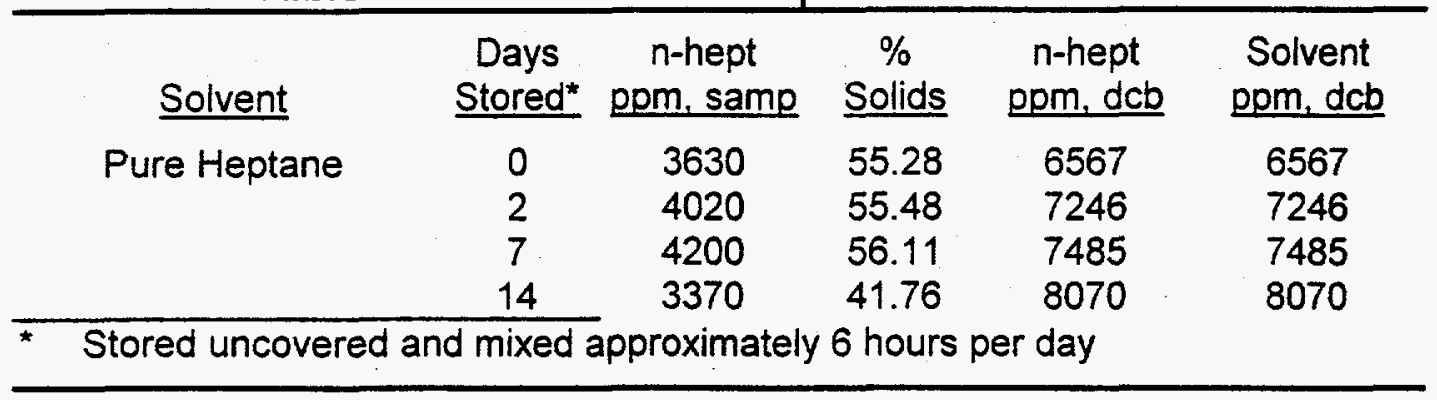

As can be seen from this data, there appeared to be a slight increase in residual heptane concentration over time. While this is not possible, it was encouraging that the heptane level did not decrease, indicating that the storage of highly loaded CWF slurries formulated from agglomerated products should not pose safety and environmental related risks.

\section{Solids Concentration Effects}

To reduce the amount of steam required during heptane recovery from agglomerated products, it was planned to perform steam stripping at the $2 \mathrm{t} / \mathrm{hr}$ PDU scale at approximately $25 \%$ solids. As such, a brief series of tests was completed to determine if solids concentration had any effect on the residual heptane concentrations. Batch agglomerated Sunnyside coal was used for these tests and each of these products was boiled at $94^{\circ} \mathrm{C}$ for 15 minutes. Results are shown in Table 26 .

As can be seen from this data, stripping (or boiling) at $25 \%$ solids concentration resulted in virtually the same levels of residual heptane as when stripping was carried out at $10 \%$ solids. This held true whether the sample was agglomerated with pure or commercial heptane.

Table 26. Batch Stripper - Solids Concentration Effect

\begin{tabular}{|c|c|c|c|}
\hline \multirow[b]{2}{*}{ Solvent $^{*}$} & \multirow{2}{*}{$\begin{array}{c}\% \\
\text { Solids }\end{array}$} & \multicolumn{2}{|c|}{$\mathrm{n}$-heptane ppm } \\
\hline & & sample & $\frac{d c b}{d}$ \\
\hline Commercial Heptane ${ }^{*}$ & 25 & 248 & 3225 \\
\hline & 10 & 229 & 2884 \\
\hline \multirow{2}{*}{ Pure Heptane } & 25 & 544 & 7545 \\
\hline & 10 & 563 & 7312 \\
\hline $\begin{array}{l}\text { Analysis for } n \text {-heptane } \\
\text { Solids concentration of }\end{array}$ & $\begin{array}{l}\text { ydrocar } \\
\text { g proc }\end{array}$ & 2.5 times & \\
\hline
\end{tabular}




\section{CONTINUOUS STRIPPER TESTING}

This section of the report discusses the procedures utilized during, and results obtained from, continuous stripper testing in the bench-scale agglomeration test unit.

\section{Procedures}

The following procedures were used to carry out the contiguous steam stripper testing during Subtask 6.5 .

\section{Feed Preparation}

The bulk of the continuous steam stripping testing was carried out independently of the continuous agglomeration circuit. As such, agglomerated product was stored in sealed 55-gallon drums until needed for steam stripping testing. From these drums, the agglomerates were manually transferred to a 15-gallon stripper feed tank and pulped to a solids concentration of $25 \%$. This tank was then agitated to mix the agglomerates for pumping to the first stage steam stripper via a peristaltic pump.

\section{Stripper Testing}

When operating the two-stage stripper, feed to the system was delivered intermittently to prevent the plugging that occurred in the stripper feed line at the low target feed rate of approximately 1 liter per minute. As such, the feed was cycled on and off as required to maintain a first-stage stripper slurry temperature of between 90 and $95^{\circ} \mathrm{C}$.

Feed to the second-stage steam stripper was set at a fixed volumetric flow rate to control total system throughput. The second-stage stripper feed pump was a progressive cavity (Moyno) pump.

The pressure and temperature in the second-stage stripper was controlled manually via a vapor discharge valve which was adjusted to maintain the target operating pressure and temperature in the vessel. The slurry level in the second-stage stripper, and therefore the residence time, was also controlled by a manual discharge valve which was adjusted to maintain the appropriate slurry level.

The steam rate was set to maintain the appropriate first-stage stripper vapor stream temperature. In this manner, the use of excessive amounts of steam was avoided.

\section{Sampling and Analyses}

Due to the intermittent nature of feed to the stripping circuit, a feed sample was taken only for determination of feed solids concentration. In addition to the feed sample, a first-stage stripper product sample was taken for heptane determination and solids 
concentration. A second-stage stripper sample was also taken for heptane and solids concentration determination. The flowrate of the final product stream was then recorded for system throughput determination.

In addition, all pertinent slurry and vapor temperatures were recorded, either automatically via the data acquisition system, or manually.

\section{Start-Up Testing and System Modifications}

This section of the report presents the start up testing observations for the continuous bench-scale stripping circuit. Any system modifications made to eliminate operating problems encountered are also discussed.

\section{Stripping Circuit Feed}

Much difficulty was encountered in feeding the agglomerated product to the steam stripper during initial testing. The progressive cavity (Moyno) pump purchased for this task proved to be incapable of pumping the agglomerates. It was found that due to the tendency of the agglomerates to float, they continually plugged the pump suction line, the pump itself, and to a lesser degree the pump outlet discharge line. One additional reason for these plugging problems was the relatively large sizes of the pump suction and discharge lines, 1-inch and 3/4-inch, respectively. Given these diameters, the flow velocities were too low to provide continuous flow. It was also noted that even at the highest flow rates tested, plugging still occurred within the pump itself.

To rectify these plugging problems, the Moyno pump was replaced with a peristaltic pump using a $3 / 8$-inch diameter hose. This pump proved to provide feed to the steam stripper without any serious plugging problems (due to its smaller line size and higher flow velocities). It was found that when utilizing this peristaltic pump, flows as low as 0.8 liters per minute could be fed to the stripper.

In order to allow testing of the stripper circuit independently of the agglomeration circuit, the system used a 55-gallon drum to collect the vibrating screen product. Once collected, the material in this drum was diluted, mixed, and pumped to the stripper. During early testing, it was found that the agglomerates were very difficult to mix in the drum, with a constant layer of agglomerates floating on the surface. In an effort to improve the mixing in the drum, three 6-inch impellers were used with the mixer instead of the original two 4-inch impeller configuration. Two of these 6 -inch impellers were of the cutting/dispersing type to help prevent additional agglomerate growth in the drum (an anticipated concern which was proven unfounded). The third impeller was a sixbladed $45^{\circ}$ pitch axial flow impeller.

It was found that these different impellers, while improving the mixing, still did not provide the vigorous agitation needed due to the lower mixing rpm attained with the additional impellers. As such, a more powerful motor (4 hp rather than $1.5 \mathrm{hp}$ ) was 
installed. While this larger mixer motor improved mixing, the highest feed solids concentration achieved when pumping from the drum was still only 10 to $15 \%$.

Another problem encountered when mixing the stripper feed was a phenomenon in which as the pumping rate increased, so did the solids concentration of the material being pumped. No explanation for this phenomenon was found except that it was related to the poor mixing in the drum.

One additional problem resolved during start-up testing was the tendency of the stripper feed line to plug as it discharged into the stripper. The original design utilized a $90^{\circ}$ right angle in the feed pipe to provide a downward discharge in the stripper. This arrangement was found to plug, and was therefore replaced with a straight pipe discharge at the approximate center of the stripper column.

\section{Steam Strippers}

Single Stage Stripping Circuit - Once the feed problems were resolved to the point where agglomerates could be pumped to the stripper, preliminary steam stripping testing commenced. Initial testing utilized a packed bed of 5/8-inch pall rings, approximately 24-inches high. Stripper feed entered the vessel two inches above the top of the pall rings and the slurry level in the stripper was maintained just below the pall rings, i.e., about six inches above the stripper discharge and approximately level with the steam inlet. In this scenario, the stripper operated with a continuous steam phase through which the agglomerates flowed down as discrete droplets or particles. It was found that with this arrangement, the incoming agglomerates were held up at the top of the pall rings while their associated water drained immediately to the vessel discharge. As such, the upper portion of the column would fill with agglomerates and plug the column and feed line.

To resolve this problem, four to six inches of pall rings were removed from the stripper and the slurry level was raised. While this resolved the plugging problem, operations with this arrangement would not provide a steady-state continuous operation due to the siphoning effect of the U-tube discharge arrangement used to maintain the slurry level in the column. Therefore, a vent line was added to the highest point of the discharge line along with a separate hose to provide a level indication in the column. These changes resolved the siphoning problem resulting in steady-state operation.

Additional preliminary testing operated the vessel flooded, i.e., with a slurry level near the feed inlet point. In this scenario, the column contained a continuous slurry phase with steam bubbling through it. This operating scenario proved acceptable and allowed the testing of various slurry residence times in the stripper column.

Two-Stage Steam Stripping Circuit - As testing progressed, it was found via batch testing that stripping at elevated pressures, allowing higher operating temperatures, removed more heptane than stripping at ambient pressure boiling temperatures. As such the stripping circuit was modified to include an additional stripping vessel prior to 
the above described column, which was also slightly modified. This allowed the bulk of the heptane to be removed in the first stage of stripping, producing a coal slurry that was more easily metered to the second-stage stripping column which was then operated at elevated pressures. This new two-stage circuit also better simulated the 2 thr PDU stripping circuit design being developed at that time.

This modified stripping circuit was fed with a peristaltic pump from a newly constructed feed tank. While it was originally planned to operate the stripping circuit feed in a continuous mode, due to feed line plugging problems at the relatively low feed rate, an intermittent feed mode of operation was used. Under this scenario, the feed was turned on intermittently to maintain the first-stage stripper target operating level and temperature.

The product from the first-stage stripper was then pumped to the second-stage stripper by the progressive cavity pump used as the circuit feed pump in the original single stage design. This intermediate pump was operated at a fixed speed.

The stripped first-stage product was then processed through the second-stage stripping column which was lengthened to increase its residence time to approximately 10 minutes. This column was also modified allowing its operation at a positive pressure of 15 to $20 \mathrm{psig}$, resulting in operating temperatures in the 115 to $120^{\circ} \mathrm{C}$ range. The operating level of the second-stage stripper was maintained via manual operation of a product discharge valve while the operating pressure and temperature were maintained by manual operation of a vapor discharge valve.

Generally, operation of this two-stage stripping circuit proceeded smoothly. The main difficulties encountered were as follows:

- Manually maintaining the proper first-stage stripper operating temperature and level via intermittent feeding.

- Manually maintaining the target second-stage stripper temperature via the vapor discharge valve.

- Manually maintaining the target second-stage stripper operating level via the product discharge valve.

- Preventing the second-stage stripper discharge valve from plugging.

\section{Condenser}

Operation of the condenser, which condensed the evaporated heptane and its associated water vapor proceeded smoothly from initial start-up. The condenser utilized had sufficient capacity to both condense and cool the incoming vapor stream. During typical operations, the stripper vapor product temperature averaged from 93 to $104^{\circ} \mathrm{C}$ and the condensate temperature about $10^{\circ} \mathrm{C}$. 
It was found that under most stripper conditions evaluated, some coal was carried over to the condenser. This however, did not cause any plugging problems and was addressed by including a de-mister pad in the $2 \mathrm{thr}$ PDU design.

\section{Gravity Separator}

Once condensed, the water and heptane mixture entered the center of a gravity separator column. Operation of this separator proceeded smoothly with the water/heptane interface easily observed. Utilizing a U-tube discharge of the water from the bottom of the separator, steady-state operation resulted in consistent flows of both water from the bottom and heptane from the top. Analysis of the recovered heptane (commercial grade) indicated that it was virtually identical in $n$-heptane content to the fresh heptane. Analysis of water samples taken from the separatory column had a total organic content of about $8 \mathrm{ppm}$, indicating minimal solubility of the heptane in water.

\section{Preliminary Testing Results - Elkhorn No. 3 Coal}

During preliminary testing with the single-stage stripping circuit, an estimate of the stripping column capacity was obtained. It was determined, that this unit could process a coal feed rate approaching $20 \mathrm{lb} / \mathrm{hr}$ without plugging. If the coal feed rate was set too high, the stripper would plug indicating there was insufficient steam available to break up the agglomerates (remove the bulk of the heptane) so that the coal could flow freely through the column.

One preliminary stripper test was carried out to generate stripper product samples for residual hydrocarbon determination. For this test the stripper feed rate was set to approximately $1 \mathrm{liter} / \mathrm{min}$, at a solids concentration of $9.3 \%$, or approximately $13 \mathrm{lb} / \mathrm{hr}$ of coal and $125 \mathrm{lb} / \mathrm{hr}$ of associated water. The stripper was then operated with a steam feed rate of $41 \mathrm{lb} / \mathrm{hr}$, the maximum steam flow achievable from the available boiler. A 20 -inch section of pall rings was used in the stripper and the slurry level maintained near the bottom of the column.

In this manner the stripper was operated with a continuous steam phase through which the coal flowed. During this test, the column product flowrate was cyclic, with little discharge under most conditions, followed by surges every few minutes. Therefore, stripper product samples were taken during both of these discharge conditions. Analytical results for these two product samples are shown in Table 27.

As can be seen from this data, while there was a significant change in solids concentration between typical and surging discharge conditions, the residual n-heptane content was similar, ranging from 1369 to $2086 \mathrm{ppm}$ on a dry coal basis. It should be noted that since this test used the commercial heptane, it is estimated that the nheptane reported in Table 27 represents only about 30 to $50 \%$ of the total residual hydrocarbons. Overall, while these analyses indicated that a significant quantity of heptane remains with the product, it was promising that the bulk of the heptane was removed. 
Table 27. Preliminary Continuous Stripping Results

\begin{tabular}{ccc}
\hline Solids Concentration, \% & $\begin{array}{c}\text { Typical } \\
\text { Discharge }\end{array}$ & $\begin{array}{c}\text { Surging } \\
\text { Discharge }\end{array}$ \\
n-heptane concentration, ppm, sample basis & 2.6 & 21.0 \\
n-heptane concentration, ppm, dry coal basis & 35.6 & 438 \\
\hline
\end{tabular}

\section{Single-Stage Stripper Results}

In an effort to quantify the effects of various stripper operating parameters on residual heptane concentrations, a number of single-stage stripper tests were carried out. This work used Sunnyside, Taggart, and Indiana VII coals with pall ring height, slurry level, and steam rate varied. Operating conditions and results for these tests are shown in Table 28.

For data analysis, product flowrates and solids concentrations were used to determine feed rates since the feed to the stripping column intermittently plugged and was therefore inconsistent. Also, since the product samples and flowrates were taken over much longer time periods, the product stream provided a more accurate determination of column throughput.

It should be noted that residual heptane results reported in Table 28 represent only the n-heptane portion of the total hydrocarbons present. The total residual hydrocarbons would typically be 2 to 3 times greater than that reported here. However, for the three tests completed with the pure heptane, these values are approximately the same.

\section{Sunnyside Coal}

As can be seen from the data in Table 28 , when carrying out continuous steam stripping of Sunnyside coal agglomerated with commercial heptane, residual n-heptane concentrations in the 1200 to $2700 \mathrm{ppm}$ on a dry coal basis (dcb) were achieved, or approximately 3500 to $8000 \mathrm{ppm}$ dcb of total residual hydrocarbons. Similar ranges of total residual hydrocarbons, 4700 to $5400 \mathrm{ppm}$ dcb, were achieved for the three tests in which the pure grade heptane was used.

For several of the Sunnyside stripper tests, stripper product was processed through the unit a second time as indicated by the longer residence times. The results of these tests indicate that while some additional reduction in residual heptane content was realized, the reductions were not substantial. 


\section{Table 28. Continuous Single-Stage Steam Stripping Conditions and Results}

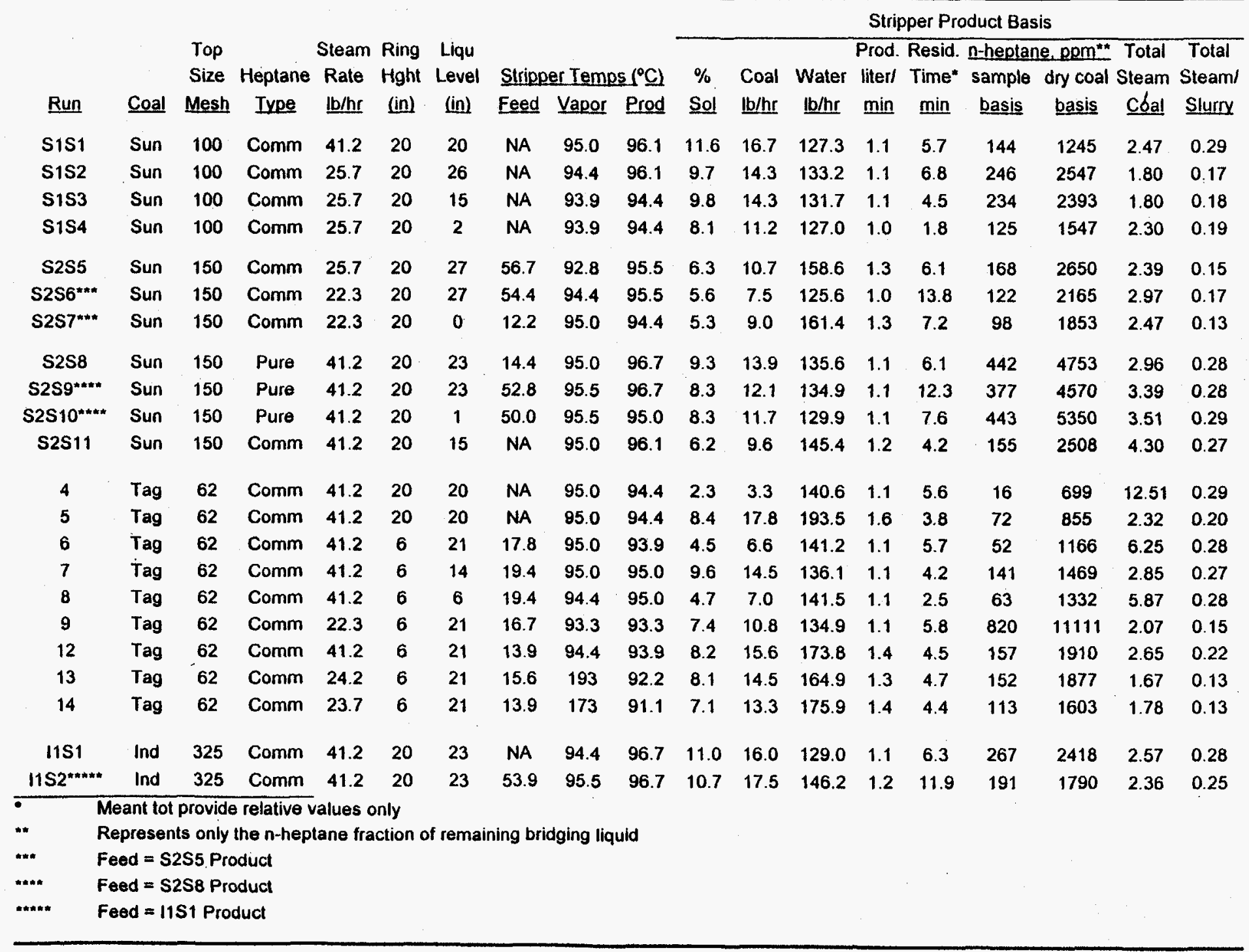




\section{Taggart Coal}

As can be seen from the data in Table 28, steam stripping of the 62-mesh topsize Taggart coal achieved residual n-heptane concentrations in the 700 to $2000 \mathrm{ppm}$ dcb range, or about 2000 to $6000 \mathrm{ppm}$ dcb of total residual hydrocarbons. The result for Test 9 is considered an anomaly. All of these tests represent a single pass through the stripping column.

Generally, there are no obvious trends relating residence time to product heptane concentration. Also, with residence time determined by the column slurry level, there is no apparent difference in performance between operating the column flooded (high slurry level) vs in the continuous steam mode (low slurry level).

It was found during this testing that the quantity of excess steam used (steam utilized beyond the theoretical requirement), could be tracked by the temperature of the exiting vapor stream. Theoretically, the boiling point of a heptane/water azeotrope at Golden's elevation is $74^{\circ} \mathrm{C}$, so under ideal conditions, only enough steam would be used to achieve this vapor temperature. However, it was believed that as the coal heptane content decreased, excess steam would be required to remove additional heptane.

This data indicates, however, that a significant increase in the exiting vapor temperature, from 78.3 to $95^{\circ} \mathrm{C}$ did not result in lower residual heptane contents. The steam to coal ratio, which varied from as high as 12.5 to as low as 1.7 for this Taggart coal testing also indicates that no benefit was realized from the use of large quantities of excess steam.

\section{Indiana VII Coal}

Two continuous stripping tests were carried out using agglomerated Indiana VII coal. As anticipated, the results for these two tests, one a single pass and the other a double pass through the stripper, resulted in similar residual heptane concentrations as those achieved with the other two coals. Residual n-heptane detected for these two tests were approximately 2400 and $1800 \mathrm{ppm}$, respectively, equivalent to 7000 and $5000 \mathrm{ppm}$ of total residual hydrocarbons on a dry coal basis.

\section{Two-Stage Stripper Testing}

This section of the report presents results for continuous two-stage steam stripper testing which was limited to the Elkhorn No. 3, Hiawatha, and Indiana VII coals. 


\section{Elkhorn No. 3 Coal}

Three tests were carried out using the modified two-stage stripping circuit with the Elkhorn No. 3 coal. Results for these three tests are shown in Table 29. It should be noted that the primary heptane analyses are from Huffman Laboratories, while the heptane analyses in parenthesis are from Analytica (formerly Phoenix Labs).

For the first test (E1S2), Elkhorn coal agglomerated with commercial heptane was used as the feedstock. It should be noted that this feedstock had been agglomerated several days prior to its use for this testing. For the other two continuous tests (E1S3 and E1S4), the agglomeration circuit screen product was fed directly to the stripping circuit feed tank. In this manner, the entire agglomeration/stripping unit was run simultaneously. Test E1S3 utilized commercial heptane and test E1S4 utilized pure heptane.

Table 29. Two-Stage Stripper Testing Results

\begin{tabular}{|c|c|c|c|c|c|c|c|c|c|c|}
\hline \multirow[b]{2}{*}{$\begin{array}{l}\text { Test } \\
\text { ID }\end{array}$} & \multirow[b]{2}{*}{$\begin{array}{l}\text { Hept } \\
\text { Type }\end{array}$} & \multirow{2}{*}{$\begin{array}{l}\text { Prod } \\
\text { Coal } \\
\text { lb/hr }\end{array}$} & \multicolumn{4}{|c|}{ Stripper 1} & \multicolumn{4}{|c|}{ Stripper 2} \\
\hline & & & $\begin{array}{l}\text { Temp } \\
{ }^{\circ} \underline{\mathrm{C}}\end{array}$ & $\begin{array}{l}R T \\
\text { min }\end{array}$ & $\begin{array}{l}\text { Prod } \\
\% \text { sol }\end{array}$ & $\begin{array}{c}n \text {-hept } \\
\text { ppm, dcb }\end{array}$ & $\begin{array}{l}\text { Temp } \\
{ }^{\circ} \underline{C}\end{array}$ & $\begin{array}{l}\mathrm{RT} \\
\text { min } \\
\end{array}$ & $\begin{array}{l}\text { Prod } \\
\% \text { sol }\end{array}$ & $\begin{array}{c}\text { n-hept } \\
\text { ppm, dcb }\end{array}$ \\
\hline $\mathrm{E} 1 \mathrm{~S} 2$ & Comm & 37.5 & 93 & 5.5 & 20.6 & $1650(823)^{\star \star}$ & 117 & 10 & 22.6 & $1175(598)$ \\
\hline E1S3 & Comm & 30.0 & 92 & 4.5 & 18.9 & $505(868)$ & 115 & 8 & 20.1 & $384(350)$ \\
\hline$\frac{\text { E1S4* }}{* * \text { Rest }}$ & $\frac{\text { Pure }}{\text { sin pat }}$ & $\frac{29.0}{\text { nthesi }}$ & $\begin{array}{c}92 \\
\text { om } A\end{array}$ & $\begin{array}{l}5.0 \\
\text { alytica }\end{array}$ & 17.5 & $1250(3066)$ & 117 & 9 & 19.0 & 1031 (1128) \\
\hline
\end{tabular}

Based on these results, two stages of steam stripping achieved lower trace heptane concentrations than a single stage of steam stripping. This was due to the increased temperature in the second stage.

\section{Hiawatha Coal}

One continuous steam stripping test utilizing the Hiawatha coal was carried out under Subtask 6.5. The results of this test indicated that the Stripper 1 and Stripper 2 products contained approximately 4300 and $3000 \mathrm{ppm}(0.43$ and $0.3 \%)$ of residual total hydrocarbons on a dry coal basis, respectively.

\section{Indiana VII Coal}

One continuous steam stripping test utilizing the Indiana VII coal was carried out under Subtask 6.5. The results of this test indicated that the Stripper 1 and Stripper 2 products contained approximately 5500 and $1800 \mathrm{ppm}(0.55$ and $0.18 \%)$ of residual total hydrocarbons on a dry coal basis, respectively. 


\section{Steam Stripping Variable Effects Summary}

In summary the following conclusions are drawn concerning the removal of heptane from agglomerated products via steam stripping:

- When steam stripping heptane from agglomerated products at ambient boiling temperatures, no benefit is gained by providing residence times greater than approximately five minutes.

- Steam stripping at elevated temperatures, as achieved by increased operating pressures, results in lower residual heptane concentrations.

- Increasing the solids concentration at which steam stripping is carried out has no detrimental effect on residual heptane concentrations.

- The presence of asphalt (used as an activator during agglomeration) results in lower residual hydrocarbon concentrations under otherwise similar stripping conditions.

- Similar total residual hydrocarbon concentrations are achieved regardless of whether a commercial or pure grade of heptane is used during the agglomeration step.

\section{TAILINGS HEPTANE ANALYSIS}

For the design of a tailings disposal system, at both PDU and commercial scales, it is important to know the heptane content of the selective agglomeration process tailings. As such, one set of samples of agglomeration tailings (froth skimmer underflow) was analyzed for residual heptane content. These samples originated from an Elkhorn No. 3 coal agglomeration test using commercial heptane. The ash content of this tailings sample was about $50 \%$.

Samples submitted included as produced tailings, tailings filter cake, tailings filtrate, and tailings samples that had been boiled for 5,10 , and 20 minutes. Less than 10 ppm of $n$-heptane was detected in all of the tailings samples, except for the filter cake, which contained $380 \mathrm{ppm} n$-heptane at $67 \%$ solids, or $567 \mathrm{ppm} n$-heptane on a dry solids basis. There was less than $1 \mathrm{ppm}$ of $n$-heptane detected in the tailings filtrate. These results indicate that tailings disposal in conventional waste disposal sites should not be a problem.

\section{TOXIC TRACE ELEMENTS DISTRIBUTION}

The reduction in toxic trace element (TTE) concentrations accomplished by selective agglomeration was studied by assaying the products from selected parametric bench-scale tests and calculating the distribution of the elements between the clean coal and tailings. Products from the tests shown in Table 30 were used for this work. 
Except for the Elkhorn No. 3 coal, the grind sizes for these tests were the same as the grind sizes of the coals examined for TTE reduction during the bench-scale column flotation testing $[8,9]$.

Table 30. Subtask 6.5 Tests Used for Trace Elements Analysis

\begin{tabular}{|c|c|c|c|c|}
\hline Test & Coal & $\begin{array}{l}\text { Nominal } \\
\text { Top-Size }\end{array}$ & $\begin{array}{c}\text { Residual Ash } \\
\text { lb/MBtu }\end{array}$ & $\begin{array}{c}\text { Heating Value } \\
\text { Rec., \% }\end{array}$ \\
\hline $\begin{array}{c}E 1 A 28 \\
\text { IAA4 }\end{array}$ & $\begin{array}{l}\text { Elkhorn No. } 3 \\
\text { Indiana VII }\end{array}$ & $\begin{array}{l}100 \text { mesh } \\
325 \text { mesh }\end{array}$ & $\begin{array}{l}1.80 \\
1.95\end{array}$ & $\begin{array}{l}98.1 \\
99.0\end{array}$ \\
\hline S2A14 & Sunnyside & 150 mesh & 1.76 & 99.1 \\
\hline 10 & Taggart & 62 mesh & 0.97 & 99.9 \\
\hline W1A11 & Winifrede & $20 \mu \mathrm{m}$ & 1.91 & 99.2 \\
\hline
\end{tabular}

The TTEs of interest were antimony, arsenic, beryllium, cadmium, chromium, cobalt, lead, manganese, mercury, nickel, selenium and chlorine. The analyses were done by Huffman Laboratories since they reported consistent results and low detection limits on a previous set of samples [8,9]. Huffman used perchloric acid decomposition and inductively coupled plasma (ICP) spectroscopy for most of the analyses. Mercury was by cold vapor spectroscopy, and chlorine was by a total halides coulometric method.

A listing of elemental concentration ranges and mass balance closures for the raw coal, agglomeration feed, clean coal, and tailings streams for all coals tested are shown in Table 31. The average of all of the mass balance closures was $104 \%$, and the closures were generally within $20 \%$ of the amount reported in the feed to the agglomeration circuit. Mass balance closures were not possible for mercury in the Taggart, Sunnyside, and Indiana VII coals because the amounts present in the clean coals were below the detection limit $(0.01 \mathrm{ppm}$ or $10 \mathrm{ppb})$. Mass balances were not calculated for cadmium since it was not detected in any of the samples except the Elkhorn No. 3 and Indiana VII raw coals. 
Table 31. Selective Agglomeration Trace Element Concentration Results

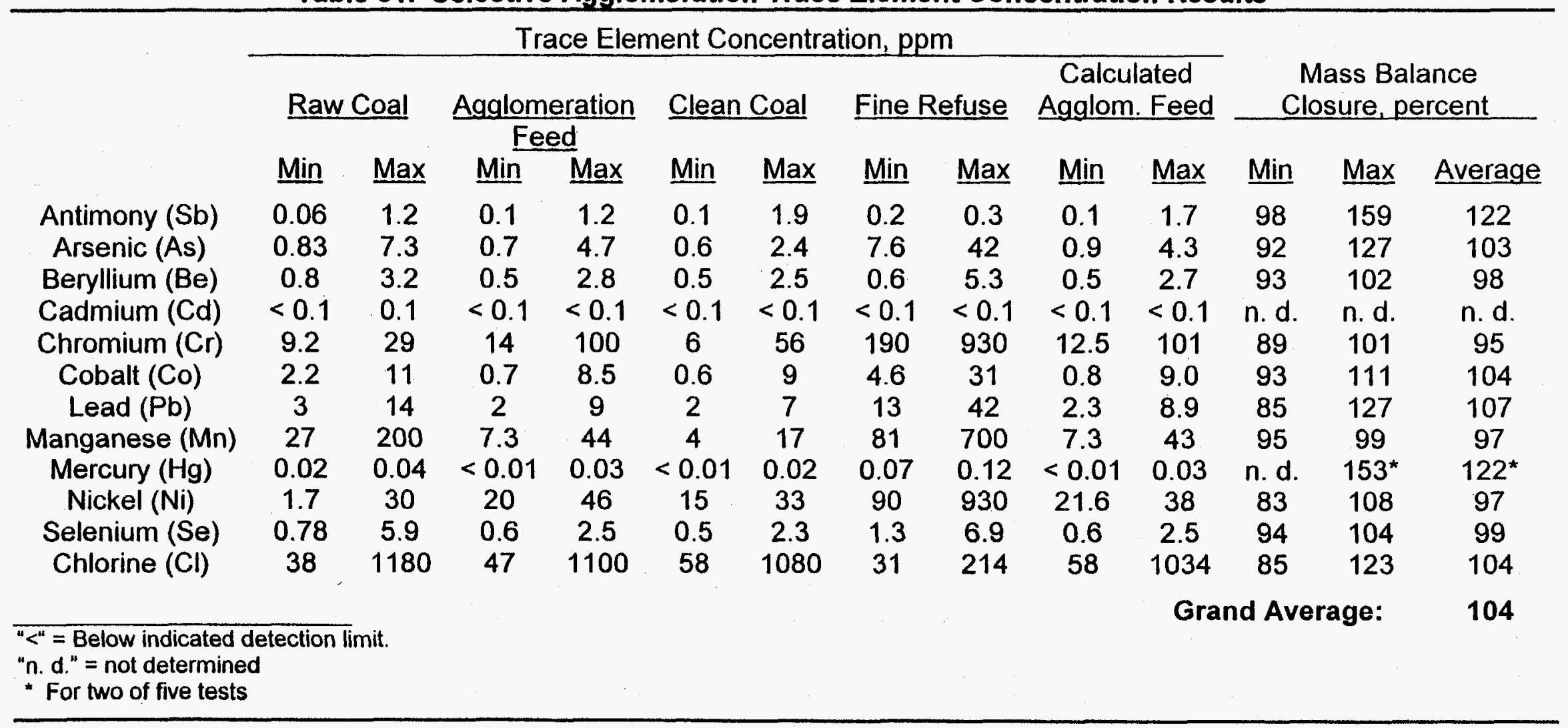


The residual concentrations of the TTEs in the various clean coals from agglomeration are compared in Figure 21, shown on the following pages.
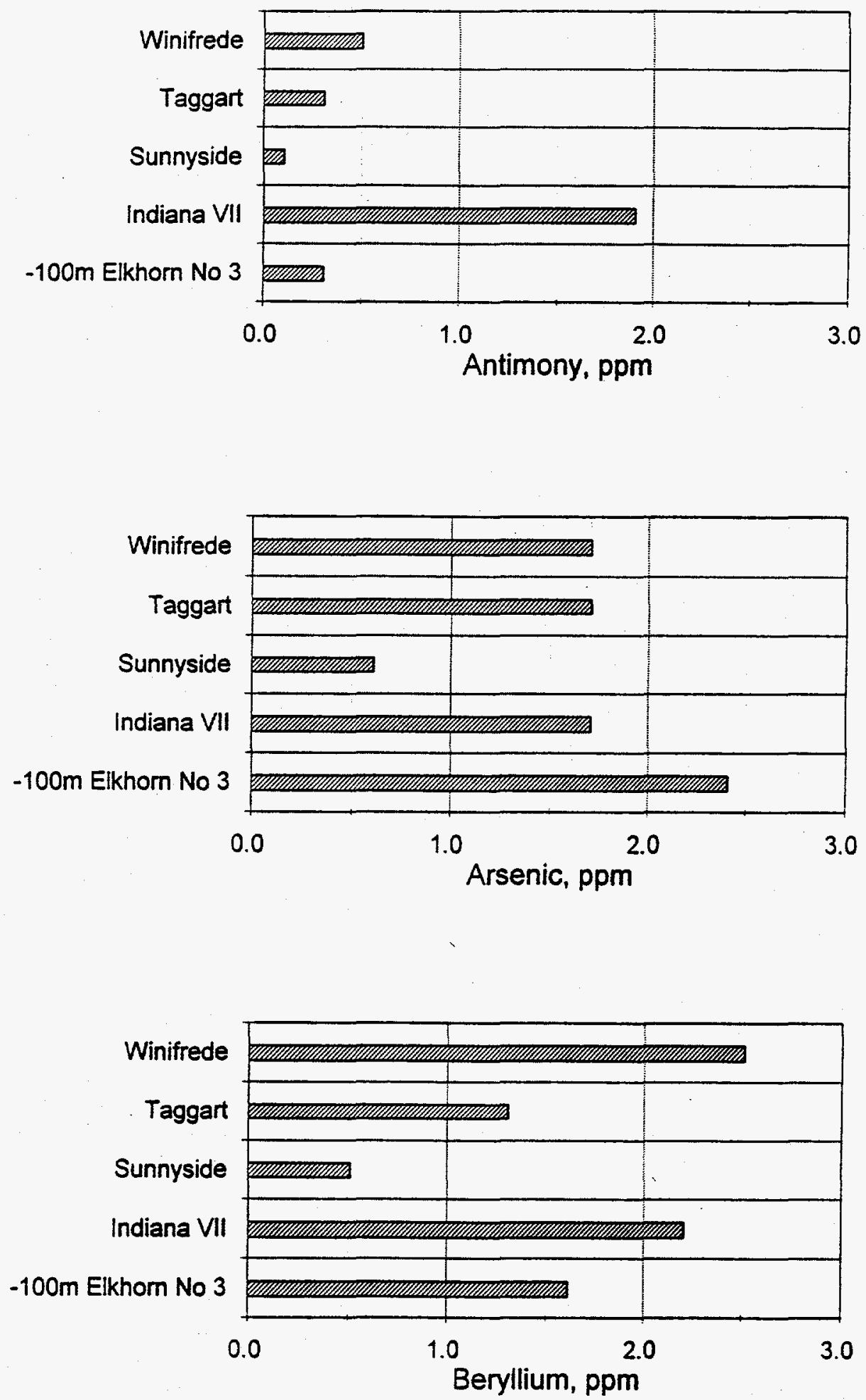

Figure 21. Residual Toxic Trace Elements in Clean Coals 

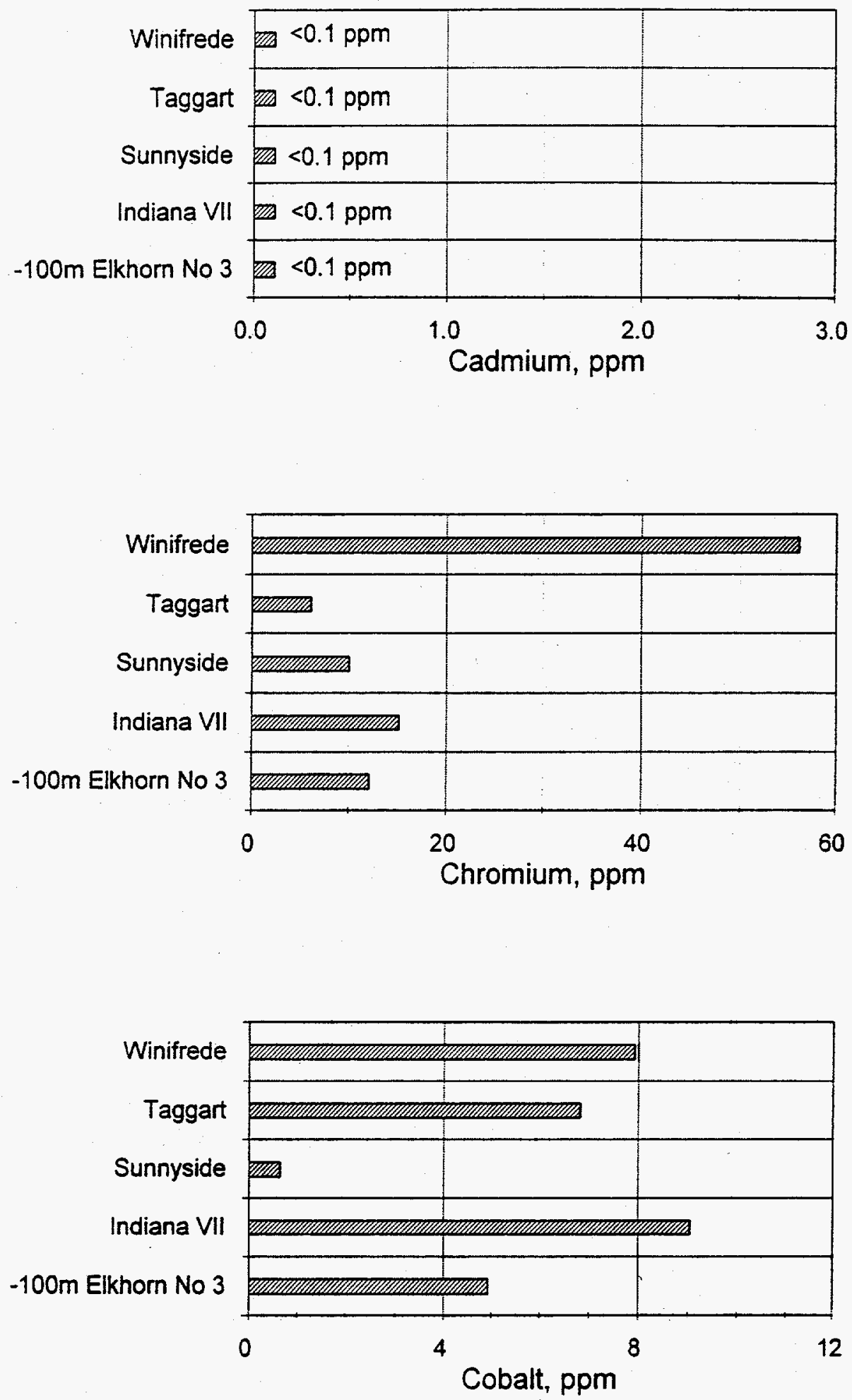

Figure 21 (Cont'd). Residual Toxic Trace Elements in Clean Coals 

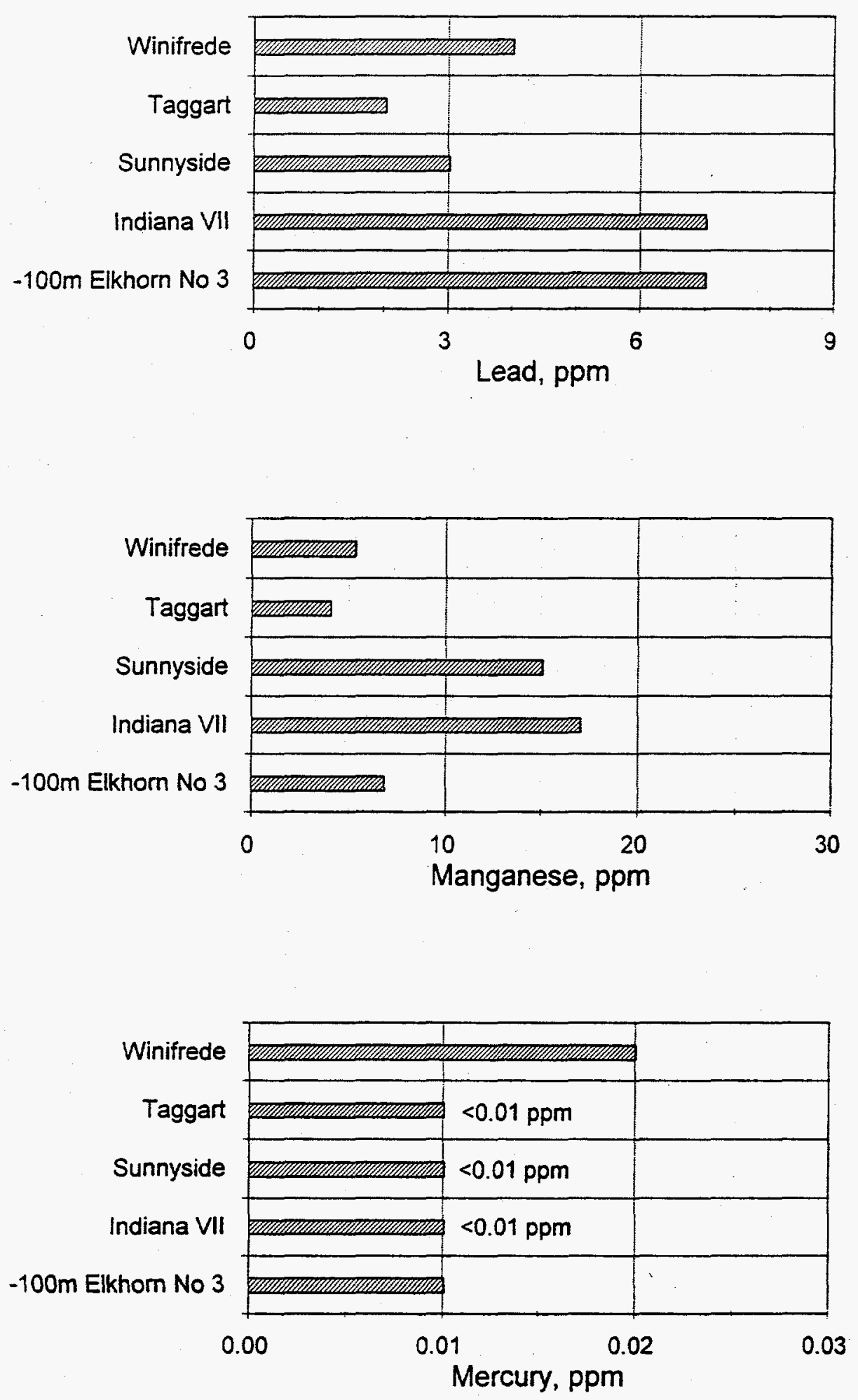

Figure 21. (Cont'd). Residual Toxic Trace Elements in Clean Coals 

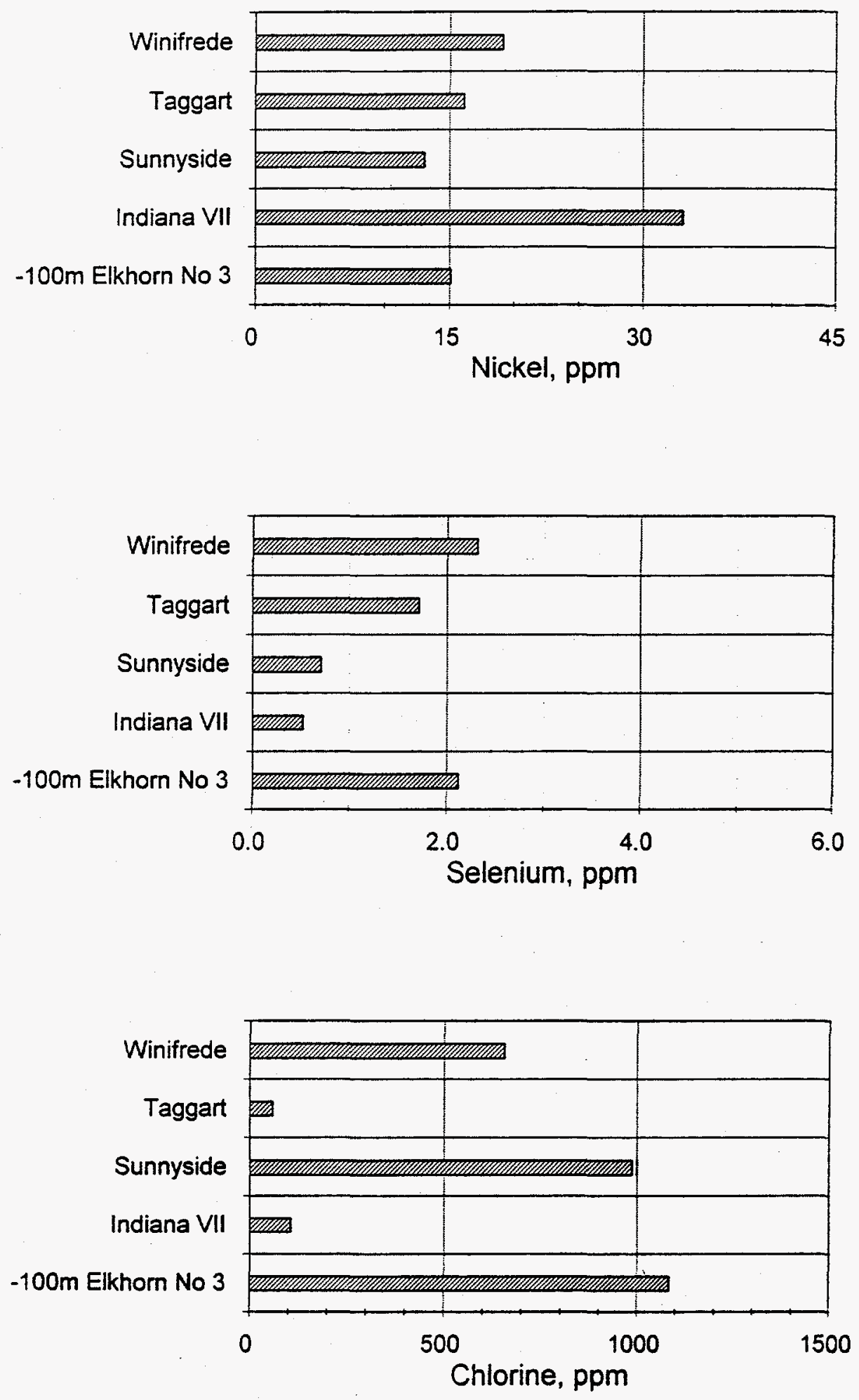

Figure 21 (Cont'd). Residual Toxic Trace Elements in Clean Coals 
The reductions in the various TTE concentrations accomplished during the selective agglomeration tests were calculated on a heating value basis. The calculated TTE reductions from the raw coal and from the washed selective agglomeration feeds are shown in Table 32, along with similar data from the advanced flotation trace element reduction study [9]. In general, the concentrations of arsenic, beryllium, cobalt, lead, manganese, mercury, and selenium in the raw coals were clearly reduced by the combined conventional washing and advanced cleaning steps. Much of the reduction, however, was accomplished during washing at the mine-site preparation plant. Very definitely, selective agglomeration reduced the concentrations of arsenic, chromium, manganese, and nickel remaining in the ground washed coals. It appears that chromium and nickel may have been introduced into the coal slurries during grinding and this could account for the erratic reduction in the concentrations of these two elements in the final clean coal.

Selective agglomeration had little impact upon the beryllium, cobalt, lead, mercury, and selenium concentrations, and it appears at times that the antimony and chlorine concentrations increased on a heating value basis. Such results could indicate a preferential association of these seven elements with the carbonaceous portion of the coal.

Overall, the residual amounts of the TTEs in the clean coals were found to be dependent upon the source coal. For example, there was about four times as much antimony in the Indiana VII clean coal as found in the other four clean coals and a third as much or less arsenic in the Sunnyside clean coal as in the other clean coals.

In comparing the TTE reductions achieved by selective agglomeration and advanced flotation, with a few exceptions, advanced flotation and agglomeration clean coals prepared from the same test coals contained about the same amounts of the trace elements. The exceptions were lead in the Elkhorn No. 3 coal, arsenic and nickel in the Sunnyside coal, selenium in the Taggart coal, and chromium and selenium in the Winifrede coal.

Reductions from the concentrations found in the ROM parent coals were generally greater than the reductions from the as-received test coals on a heating value basis. There were substantial reductions, 25 to $90 \%$, in the concentrations of arsenic, beryllium, chromium, cobalt, lead, manganese, mercury, and selenium from the amounts in the ROM coals. On the other hand, there was little or no reduction, less than $25 \%$, in the amount of antimony. The reduction of nickel and chlorine varied from coal to coal. Nickel reduction in Elkhorn No. 3, beryllium and chromium in Sunnyside, and chromium and selenium in Winifrede were exceptions. 
Reduction on Heating Value Basis, \%

Clean Coal Analysis

From Test Coal

From ROM Coal

Flotation Agglomeration Flotation Agglomeration Flotation Agglomeration

Ash, \%
S(tot), \%
S(pyr), \%
Sb, ppm
As, ppm
Be, ppm
Cd, ppm
Cr, ppm
Co, ppm
Pb, ppm
Mn, ppm
Hg, ppm
Ni, ppm
Se, ppm
Cl, ppm

Taggart Coal

$1.52 \quad 1.58$

0.63

0.65

0.14

0.12

0.3

1.7

1.7

1.8

$<0.1$

4.2

8.0

2

4

0.01

10

1.3

$<0.1$

3.1

6

6.8

4.0

$<0.01$

68

16

1.7

58

Winifrede Coal

Ash, \%

S(tot), $\%$

2.96

2.76

0.89

0.94

0.19

0.13

$\mathrm{Sb}, \mathrm{ppm}$

0.55

As, ppm

1.5

0.5

Be, ppm

2.9

$<0.1$

1.7

Cd, ppm

28

$\mathrm{Cr}, \mathrm{ppm}$

Co, ppm

$\mathrm{Pb}, \mathrm{ppm}$

7.6

$\mathrm{Mn}, \mathrm{ppm}$

$\mathrm{Hg}, \mathrm{ppm}$

$\mathrm{Ni}$, ppm

Se, ppm

$\mathrm{Cl}$, ppm

5

4

0.03

2.5

$<0.1$

56

7.9

4

15

5.3

0.02

5.2

19

940

2.3

651

Elkhorn No. 3 Coal

Ash, $\%$

S(tot), $\%$

S(pyr), \%

2.63

2.57

0.92

0.24

0.93

Sb, ppm

0.48

0.12

As, ppm

2.5

$\mathrm{Be}, \mathrm{ppm}$

1.9

Cd, ppm

$<0.1$

0.3

$\mathrm{Cr}, \mathrm{ppm}$

9.6

5.6

Co, ppm

2

10

$\mathrm{Mn}, \mathrm{ppm}$

$\mathrm{Hg}, \mathrm{ppm}$

0.02

2.4

1.6

$\mathrm{Ni}, \mathrm{ppm}$

14

2.1

Se, ppm

1240

$<0.1$

12

4.9

7

6.8

0.01

15

2.1

$\mathrm{Cl}, \mathrm{ppm}$

1080

29

2

neg

11

neg

35

neg

1

43

1
24

24

neg

23
2
neg
1
15
8

57
1
1
45
24
1
neg

68

14

15

neg

46

18

53

22

6

77

6

44

18

0

55

13

11

neg

35

3

38

11

36

61

36

25

12

neg = negative number

$\begin{array}{lll}69 & 92 & 93\end{array}$

$\begin{array}{lll}10 & 28 & 24\end{array}$

$\begin{array}{lll}39 & 57 & 70\end{array}$

neg neg neg

$\begin{array}{lll}45 & 78 & 75\end{array}$

$16 \quad 33 \quad 42$

$48 \quad 20 \quad$ neg

$3 \quad 37 \quad 34$

$\begin{array}{lll}47 & 59 & 67\end{array}$

$\begin{array}{lll}55 & 89 & 86\end{array}$

$38 \quad 45 \quad 63$

41 neg neg

$14 \quad 35 \quad 71$

$15 \quad 34 \quad 54$

$\begin{array}{lll}56 & 97 & 97\end{array}$

$6 \quad 42 \quad 42$

$\begin{array}{lll}\text { neg } & 69 & 84\end{array}$

3 neg 16

$\begin{array}{lll}51 & 82 & 83\end{array}$

$3 \quad 56 \quad 63$

$\begin{array}{ll}>47 & >47\end{array}$

$54 \quad 82 \quad 78$

$\begin{array}{lll}12 & 73 & 76\end{array}$

$\begin{array}{lll}3 & 73 & 7\end{array}$

$\begin{array}{lll}61 & 97 & 98\end{array}$

$3 \quad 65 \quad 82$

$28 \quad 33 \quad 28$

$\begin{array}{lll}19 & 76 & 76\end{array}$

$5 \quad 24 \quad 33$ 
Table 32 (Cont'd). IMPURITIES IN CLEAN COALS

Reduction on Heating Value Basis, \%

Clean Coal Analysis

From Test Coal

From ROM Coal

Flotation Agglomeration Flotation Agglomeration Flotation Agglomeration Indiana VII coal

Ash, \%
S(tot), \%
S(pyr), \%
Sb, ppm
As, ppm
Be, ppm
Cd, ppm
Cr, ppm
Co, ppm
Pb, ppm
$\mathrm{Mn}, \mathrm{ppm}$
$\mathrm{Hg}, \mathrm{ppm}$
$\mathrm{Ni}, \mathrm{ppm}$
$\mathrm{Se}, \mathrm{ppm}$
$\mathrm{Cl}, \mathrm{ppm}$

2.86

0.57

2.74

0.63

0.19

0.14

2.3

1.7

2.7

$<0.1$

14

9.2

5

14

0.02

36

0.78

76

1.9

1.7

2.2

$<0.1$

15

9.0

7

17

$<0.01$

33

0.5

101

Winifrede Coal

Ash, \%

S(tot), \%

2.69

2.54

0.65

S(pyr), \%

0.65

Sb, ppm

0.13

0.10

0.14

As, ppm

0.15

Be, ppm

0.8

Cd, ppm

$<0.1$

$\mathrm{Cr}, \mathrm{ppm}$

5.9

1.3

Co, ppm

$\mathrm{Pb}, \mathrm{ppm}$

$\mathrm{Mn}, \mathrm{ppm}$

2

12

$\mathrm{Hg}, \mathrm{ppm}$

$\mathrm{Ni}$, ppm

$<0.01$

3.3

Se, ppm

0.71

1120

0.1

0.6

0.5

$<0.1$

10

0.6

3

15

$<0.01$

13

0.7

Cl, ppm

982

73
21
43
neg
76
4

50
8
34
61
38
12
20
neg

74

20

56

neg

46

8

55

2

28

55

$>8$

34

23

neg

96

56

78

neg

75

30

$>40$

62

50

79

94

40

29

40

neg

96

52

83

6

75

43
$>41$

59

51

70

93

$>70$

35

62

neg

neg = negative number

49
4
neg
neg
54
3

41
10
3
62
$>51$
58
neg
1

53

5

neg

3

17

3

83

4
6

neg

84

13

69

17

3

44

49

57

75

$>57$

neg

31

17

84

4
0

neg

37

46

6

76

35

69

$>57$

neg

32

28 


\section{CONCLUSIONS}

This section of the report presents a brief summary of conclusions drawn form the Subtask 6.5 studies. They are presented under three headings.

\section{AGGLOMERATION}

The results of the Subtask 6.5 agglomeration test work indicate that the product ash specification of 1 to $2 \mathrm{lb} / \mathrm{MBtu}$, as well as the Btu recovery goal of at least $80 \%$ on a run-of-mine basis were met for all six of the coals tested. Of paramount importance in achieving these product ash levels is the size to which the coal is ground. As for any coal cleaning process, if sufficient mineral-matter liberation is not achieved, the desired product grade can not be attained, except at the expense of significant Btu losses to the tailings stream. The coarsest particle size distribution to which each coal was ground to achieve the project goals are summarized in Table 33. Included in Table 33 are typical product ash and Btu recovery values attained when operating at optimized conditions for the grind sizes shown.

Table 33. Agglomeration Results Summary

\begin{tabular}{|c|c|c|c|c|c|c|c|}
\hline \multirow[b]{2}{*}{ Coal } & \multicolumn{4}{|c|}{ PSD Summary, Microns } & \multirow{2}{*}{$\begin{array}{c}\text { Ash } \\
\text { lb/MBtu }\end{array}$} & \multicolumn{2}{|c|}{ Btu Recovery \% } \\
\hline & $\underline{D}_{20}$ & $\underline{D}_{50}$ & $\underline{D}_{80}$ & $\underline{M M D}$ & & Agglomeration & Run-of-Mine \\
\hline Taggart & 5.9 & 16.2 & 32.8 & 23.0 & 0.95 & 99.1 & 93.5 \\
\hline Sunnyside & 8.0 & 24.9 & 59.6 & 34.3 & 1.79 & 98.3 & 88.6 \\
\hline Indiana VII & 4.2 & 10.4 & 21.9 & 14.5 & 1.95 & 99.0 & 89.6 \\
\hline Elkhorn No. 3 & 10.7 & 29.6 & 68.0 & 39.4 & 1.69 & 96.8 & 91.6 \\
\hline Winifrede & 2.0 & 4.2 & 12.4 & 7.1 & 1.91 & 99.2 & 88.8 \\
\hline Hiawatha & 11.5 & 32.9 & 65.2 & 40.9 & 1.85 & 99.6 & 89.7 \\
\hline
\end{tabular}

Operating conditions required to achieve these typical agglomeration results were found to be various, i.e., several combinations of residence times, energy inputs, and heptane levels could ultimately achieve similar results.

It was found, however, that the following guidelines should be followed to insure that consistent results are achieved:

1. Sufficient heptane must be used during high shear to form microagglomerates and achieve phase inversion, i.e., the formation of two distinct phases - heptane coated coal and mineral matter bearing process water. Typically, the heptane required increases with decreasing coal size and decreasing coal rank.

2. Sufficient energy (agitation intensity or impeller tip speed) must be applied during high shear to achieve complete dispersion of the heptane and enough 
particle to particle contact to form microagglomerates. Typically, to achieve these objectives, impeller tip speeds in the range of 10 to $18 \mathrm{~m} / \mathrm{s}$ are required.

3. Sufficient residence time must be provided in high shear to allow microagglomerates to form. While this is a function of the agitation intensity applied, i.e., higher tip speeds will reduce residence time requirements, typically, on the order of 30 to 60 seconds are necessary, depending primarily on coal fineness and rank.

4. The use of higher, up to $13 \%$, solids concentration during high shear reduces energy input requirements. While these higher solids loadings also resulted in higher product ash levels, this is attributed to the low shear operation, i.e., operation of high shear at high solids followed by dilution for low shear is recommended.

5. For lower rank and oxidized coals like the Indiana VII, the use of an agglomeration promoter like asphalt may be required to achieve phase inversion during high shear.

6. Sufficient heptane must be provided to allow agglomerate growth during low shear to the 2 to $3 \mathrm{~mm}$ size range. Over the course of the Subtask 6.5 testing this was found to vary between 25 and $60 \%$ heptane on a dry ash free coal basis, depending primarily on the coal particle size distribution and rank.

7. The formation of consistent agglomerates in the 2 to $3 \mathrm{~mm}$ size range is paramount in achieving low product ashes. If agglomerates are too small, drainage of mineral-matter bearing process water will not occur. If agglomerates are too large, their handleability decreases effecting downstream operations.

8. Impeller tip speed (agitation intensity) during low shear typically needs to be in the $5 \mathrm{~m} / \mathrm{s}$ range to allow the growth of well formed agglomerates of sufficient strength for vibrating screen recovery. If agitation is too mild, weak agglomerates with high water contents are formed while if agitation is too intense, agglomerate growth will not occur. The low-shear unit operation appears to be independent of the coal rank, and only slightly effected by coal size with finer feedstocks generally forming stronger better formed agglomerates.

9. Residence time in low shear was found to have little effect on agglomerate growth, since ultimately, agglomerate formation is controlled by heptane dosage and low-shear agitation intensity. However, residence times no greater than 2 to 3 minutes are recommended since longer residence times make agglomerate growth very difficult to control.

10. The design of the low-shear vessel should be such that the discharge is located at the same elevation as the impeller. This will insure that continual low-shear discharge occurs under all potential operating conditions.

11. The use of higher, $13 \%$, solids concentrations in low shear results in higher product ash levels than if operated at lower solids concentrations. High solids loadings during low shear also makes agglomerate growth very difficult to control. 
12. The vibrating screen used for agglomerate recovery must have sufficient forward linear motion to provide good transport of agglomerates across the screen deck. If good agglomerate movement is not achieved, the agglomerate bed depth will increase reducing the drainage of associated mineral-matter bearing process water.

13. Screen spray water is required to rinse the mineral matter associated with the process water to the tailings stream. The amount of rinse water necessary has not been quantified, but is believed to be relatively low.

14. The use of a froth skimmer to recover coal from the screen tailings was shown to result in Btu recovery increases on the order of 1 to $3 \%$, depending on the coal and operating conditions used. Application of a froth skimmer also helps reduce tailings heptane contamination. However, the usefulness of a froth skimmer is ultimately determined by the amount of coal present in the screen underflow with potential sources of coal contamination in the screen underflow being coal not agglomerated during low shear, and coal degradation during screening. Therefore, process optimization should focus on minimizing the introduction of coal to the screen tailings rather than reliance on a froth skimmer. If utilized, a froth skimmer must be of the appropriate design to insure the formation of a removable froth layer.

Overall, the selective agglomeration process was found to be very robust in that it either works well or doesn't work at all. Therefore, as long as the coal grind provides sufficient mineral-matter liberation and a consistent low-shear product of the appropriate size is produced, the desired product grade along with consistently high Btu recoveries will be achieved.

\section{STEAM STRIPPING}

In general, steam stripping to remove heptane from agglomerated products is a straight forward operation. The steam is applied directly to the reslurried agglomerates to evaporate heptane along with water, and the ratio of heptane to water in the exiting vapor phase from the stripping circuit is minimized to insure that steam consumption is kept as low as possible.

It was determined that due to the advantage of carrying out steam stripping at elevated pressures and temperatures (lower residual heptane concentrations), a two-stage system should be used. In this scenario, the first-stage stripper was agitated to keep the buoyant agglomerates dispersed throughout the vessel, and operated at ambient pressure to facilitate pumping of the difficult to handle agglomerate feed into this vessel. During this first-stage stripping, the bulk of the heptane was removed disintegrating the agglomerates and providing a handleable first-stage product slurry that could be easily pumped into the second-stage stripper which was operated at elevated pressure and temperature to remove small amounts of additional heptane. This second stage stripper was of a plug flow packed column design to provide greater mass transfer efficiency while insuring minimal back-mixing and good steam distribution across the column's entire cross section. A counter-current steam flow was used with the fresh 
steam feeding the second stripper, and its vapor product feeding the first stripper. The first-stage stripper vapor product was then the feed to the condenser and gravity separation heptane recovery column.

Continuous two-stage stripper testing was carried out at operating temperatures of approximately $92^{\circ} \mathrm{C}$ and $115^{\circ} \mathrm{C}$ in the first- and second-stage strippers, respectively. Residence times in these strippers were 5 and 10 minutes for the first and second stages, respectively. Under these conditions, residual hydrocarbon concentrations on the order of 2000 to $6000 \mathrm{ppm}(0.2$ to $0.6 \%)$ and 1000 to $3000 \mathrm{ppm}(0.1$ to $0.3 \%)$ on a dry coal basis were achieved in the intermediate and final products, respectively. These residual concentrations appeared to be independent of the coal tested and the type of heptane used, pure grade or commercial grade.

The effect of various steam stripping operating variables on the residual heptane content of the stripped products is summarized as follows:

- When steam stripping heptane from agglomerated products at ambient boiling temperatures, no benefit is gained by providing residence times greater than approximately five minutes.

- Steam stripping at elevated temperatures, as achieved by increased operating pressures, results in lower residual heptane concentrations.

- Increasing the solids concentration at which steam stripping is carried out has no detrimental effect on residual heptane concentrations.

- The presence of asphalt (used as an activator during agglomeration) results in lower residual hydrocarbon concentrations under otherwise similar stripping conditions.

- Regardless of whether a commercial or pure grade of heptane is utilized during agglomeration, total residual hydrocarbon concentrations achieved are similar.

It was found that the only major problem encountered during the continuous stripping testing was feeding the circuit. First, it was very difficult to mix the reslurried agglomerates due to their tendency to float in the feed tank. As such, continuous feeds solids concentrations never exceeded 10 to $15 \%$, compared to the original target feed solids concentration of $25 \%$. This resulted in higher than anticipated steam consumption due to the extra water that needed to be heated. Second, plugging of the stripper circuit feed lines occurred consistently even at the low feed solids concentrations used.

It is anticipated that both of these problems could be overcome at larger-scale operations by the use of a diaphragm pump. Since these pumps can transport material of a very thick consistency, the agglomeration screen overflow product would be diluted with a fixed amount of water and pumped as is, i.e., without mixing, to the stripping circuit. It is also anticipated that at a larger scale of operation, feed line plugging would cease because of the much larger pipe/agglomerate diameter ratios. 
Beyond feeding the stripping circuit, no other major operational difficulties were encountered during the stripper testing during Subtask 6.5. Vapor condensation and liquid cooling were achieved in a tube coil submersed in a water bath serviced by utility water. Complete condensation was consistently achieved with minimal carryover of coal from the stripping circuit. Separation of the condensed water and heptane was easily accomplished in a gravity separator column with the heptane overflowing from the top and the water exiting the bottom. This separation was complete with only minimal solubility $(<10 \mathrm{ppm})$ of heptane into the water phase.

\section{TOXIC TRACE ELEMENTS DISTRIBUTION}

The reduction in toxic trace element (TTE) concentrations accomplished by selective agglomeration was studied by assaying the products from selected parametric benchscale tests and calculating the distribution of the TTE between the clean coal and tailings. In tracking the TTE through the selective agglomeration process, the average of all of the mass balance closures was $104 \%$, and the closures were generally within $20 \%$ of the amount reported in the feed to the agglomeration circuit.

The reductions in the various trace element concentrations accomplished were calculated on a heating value basis. In general, the concentrations of arsenic, beryllium, cobalt, lead, manganese, mercury, and selenium in the raw coals were clearly reduced by the combined conventional washing and selective agglomeration steps. Much of the reduction, however, was accomplished during washing at the minesite preparation plant. Selective agglomeration reduced the concentrations of arsenic, chromium, manganese, and nickel remaining in the ground washed coals (some chromium and nickel were introduced into the coal during grinding). Agglomeration had little impact upon the beryllium, cobalt, lead, mercury, and selenium concentrations, and possibly increased antimony and chlorine concentrations on a heating value basis. Such results indicate preferential association of these seven elements with the carbonaceous portion of the coal.

Overall, the residual amounts of the elements in the clean coals were found to be dependent upon the source coal. For example, there was about four times as much antimony in the Indiana VII clean coal as found in the other four clean coals and a third as much or less arsenic in the Sunnyside clean coal as in the other clean coals.

In comparing the TTE reductions achieved by the selective agglomeration and advanced flotation, with a few exceptions, products prepared from the same parent coals contained about the same amounts of the trace elements.

There were substantial reductions, 25 to $90 \%$, in the concentrations of arsenic, beryllium, chromium, cobalt, lead, manganese, mercury, and selenium from the amounts in the ROM coals. On the other hand, there was little or no reduction, less than $25 \%$, in the amount of antimony with the reduction of nickel and chlorine varying from coal to coal. 


\section{REFERENCES}

1. Jha, M. C., Smit, F. J., Getsoian, J. A., and Keller, D. V., "Engineering Development of Advanced Physical Fine Coal Cleaning for Premium Fuel Applications," Subtask 6.1 Agglomerating Agent Selection Topical Report, U. S. Department of Energy Contract No. DE-AC22-92PC92208, June 24, 1993.

2. Smit, F. J. and Jha, M. C., "Engineering Development of Advanced Physical Fine Coal Cleaning for Premium Fuel Applications," Subtask 6.2 Grinding Topical Report, U. S. Department of Energy Contract No. DE-AC22-92PC92208, August $11,1994$.

3. Smit, F. J., Jha, M. C., Keller, D. V., and Getsoian, J. A., "Engineering Development of Advanced Physical Fine Coal Cleaning for Premium Fuel Applications," Subtask 6.3 Selective Agglomeration Process Optimization Research Topical Report, U. S. Department of Energy Contract No. DE-AC2292PC92208, September 28, 1995.

4. Smit, F. J., Moro, N., and Jha, M. C., "Engineering Development of Advanced Physical Fine Coal Cleaning for Premium Fuel Applications," Subtask 6.4 CWF Formulation Studies Topical Report, U. S. Department of Energy Contract No. DEAC22-92PC92208, November 25, 1996.

5. Bechtel Corporation, "Engineering Development of Advanced Physical Fine Coal Cleaning for Premium Fuel Applications," Subtask 6.6 Conceptual Design of the PDU Selective Agglomeration Module Topical Report, U.S. Department of Energy Contract No. DE-AC22-92PC92208, September 13, 1994.

6. Smit, F. J. and Jha, M. C., "Engineering Development of Advanced Physical Fine Coal Cleaning for Premium Fuel Applications," Subtask 2.1 Coal Selection Plan and Recommendations, Contract No. DE-AC22-92PC92208, April 29, 1993.

7. Jha, M. C., and Smit, F. C., "Selection of Feed Coals for Production of Premium Fuel Using Column Flotation and Selective Agglomeration Processes," Published in Proceedings of "High Efficiency Coal Preparation: An International Symposium," (Editor S. K. Kawatra), SME, 1995, pp. 391-400.

8. Smit, F. J., Shields, G. S., and Jha, M. C., "Engineering Development of Advanced Physical Fine Coal Cleaning for Premium Fuel Applications," Subtask 4.4 Bench-Scale Testing and Process Scale-up Topical Report, U.S. Department of Energy Contract No. DE-AC22-92PC92208, February 6, 1996.

9. Smit, F. J., Shieids, G. S., Moro, N., Jha, M. C., and Feeley, T. J., "Reduction of Toxic Trace Elements in Coal by Advanced Cleaning," Pittsburgh Coal Conference, September 3-7, 1996. 
APPENDIX A

WINIFREDE COAL AGGLOMERATION RESULTS 
Winifrede Coal - $25 \mathrm{lb} / \mathrm{hr}$ Continuous Agglomeration Test Conditions and Results

\begin{tabular}{|c|c|c|c|c|c|c|c|c|c|c|c|c|c|c|c|c|c|c|c|c|c|}
\hline \multirow[b]{4}{*}{ Run } & & & & & \multicolumn{2}{|c|}{ High Shear } & \multicolumn{4}{|c|}{ Low Shear Agglorneration } & \multicolumn{2}{|c|}{ Vibrat Screen } & \multirow{2}{*}{\multicolumn{2}{|c|}{$\begin{array}{l}\text { Agglomerated } \\
\text { Product }\end{array}$}} & \multirow{2}{*}{\multicolumn{2}{|c|}{ Product Ash }} & \multirow{4}{*}{$\begin{array}{c}\text { Tails } \\
\text { Ash } \\
\underline{\%}\end{array}$} & \multicolumn{2}{|c|}{ Agglom Perf } & \multicolumn{2}{|c|}{ ROM Perf } \\
\hline & \multicolumn{3}{|c|}{ Circuil Feed Slurry } & \multirow{3}{*}{$\begin{array}{c}\text { Heptane } \\
\% \text { daf }\end{array}$} & \multirow{3}{*}{$\begin{array}{c}\text { Tip } \\
\text { Speed } \\
\mathrm{m} / \mathbf{s}\end{array}$} & \multirow{3}{*}{$\begin{array}{l}\text { Res } \\
\text { Time } \\
\text { min }\end{array}$} & \multirow{3}{*}{$\begin{array}{c}\text { Tip } \\
\text { Speed } \\
\underline{m / s}\end{array}$} & \multirow{3}{*}{$\begin{array}{c}\text { Operat } \\
\text { Level }\end{array}$} & \multirow{3}{*}{$\begin{array}{c}\text { Res } \\
\text { Time } \\
\text { min }\end{array}$} & \multirow{3}{*}{$\begin{array}{l}\text { Agglom } \\
\text { Growth }\end{array}$} & \multirow{3}{*}{$\begin{array}{l}\text { Incline } \\
\text { Down } \\
\text { deg }\end{array}$} & \multirow{3}{*}{$\begin{array}{c}\text { Spray } \\
\text { Water } \\
\text { lb/hr }\end{array}$} & & & & & & & BTU & & BTU \\
\hline & & & $\%$ & & & & & & & & & & \multirow{2}{*}{$\begin{array}{c}\% \\
\text { Solids } \\
\end{array}$} & \multirow{2}{*}{$\begin{array}{l}\text { Size } \\
\text { mm }\end{array}$} & & $\overline{\mathrm{Ib} /}$ & & Yield & $\operatorname{Rec}$ & Yield & $\operatorname{Rec}$ \\
\hline & $\%$ & $\underline{\mathrm{lb} / \mathrm{hr}}$ & ash & & & & & & & & & & & & $\underline{\%}$ & MBtu & & $\%$ & \% & $\%$ & \% \\
\hline W1A1 & 9.9 & 25.2 & 8.68 & 60.2 & 15.0 & 1.4 & 4.8 & Full & 6.9 & Continuous & 40 & 51.6 & 43.2 & 2.5 & 2.90 & 2.00 & 85.8 & 93.0 & 99.6 & 64.7 & 89.1 \\
\hline W1A2 & 8.9 & 22.7 & 8.70 & 62.4 & 18.0 & 1.4 & 4.8 & Full & 6.9 & None & 40 & 51.6 & 19.5 & $<.5$ & 4.47 & 3.13 & 87.7 & 94.9 & 99.8 & 66.0 & 89.3 \\
\hline W1A3 & 9.9 & 25.5 & 8.69 & 56.5 & 18.0 & 1.4 & 4.8 & Full & 6.8 & Continuous & 40 & 51.6 & 37.3 & 1 & 3.09 & 2.13 & 87.3 & 93.3 & 99.7 & 64.9 & 89.2 \\
\hline W1A4" & 9.8 & 24.7 & 8.67 & 53.2 & 18.0 & 1.4 & 4.8 & Full & 7.1 & Continuous & 38 & 51.6 & 46.8 & 2 & 2.88 & 1.98 & 86.4 & 93.1 & 99.6 & 64.7 & 89.2 \\
\hline W1A5 & 10.0 & 25.5 & 8.67 & 56.3 & 18.0 & 1.4 & 8.0 & Half & 3.2 & Cyclic & 40 & 51.6 & 40.6 & 4 & 2.77 & 1.91 & 84.6 & 92.8 & 99.4 & 64.5 & 89.0 \\
\hline W1A6 & 9.9 & 25.2 & 8.68 & 55.2 & 18.0 & 1.4 & 8.0 & Half & 3.3 & Cyclic & 38 & 51.6 & 38.4 & 1.5 & 2.87 & 1.97 & 84.2 & 92.9 & 99.4 & 64.5 & 89.0 \\
\hline W1A7 & 10.2 & 19.5 & 8.67 & 53.2 & 18.0 & 1.8 & 8.0 & Half & 4.3 & Cyclic & 38 & 51.6 & 40.7 & $.5-3.5$ & 2.83 & 1.95 & 85.4 & 92.9 & 99.5 & 64.6 & 89.1 \\
\hline WIAB & 12.8 & 32.3 & 8.69 & 54.7 & 18.0 & 1.4 & 8.0 & Half & 3.3 & Cyclic & 38 & 51.6 & 31.2 & $<.5$ & 3.80 & 2.64 & 88.5 & 94.2 & 99.8 & 65.5 & 89.3 \\
\hline & & & & & & & & & & & & & 41.6 & 3 & 2.87 & 1.98 & 85.0 & 92.9 & 99.5 & 64.6 & 89.0 \\
\hline W1A9 & 6.9 & 17.2 & 8.53 & 55.7 & 18.0 & 1.4 & 8.0 & Half & 3.4 & Continuous & 38 & 51.6 & 27.2 & 2 & 3.12 & 2.15 & 78.5 & 92.8 & 98.9 & 64.5 & 88.5 \\
\hline & & & & & & & & & & & 35 & & 31.8 & 2.5 & & & & & & & \\
\hline W1A10 & 6.9 & 17.5 & 8.42 & 57.4 & 19.8 & 1.4 & 9.6 & Half & 3.3 & Continuous & 38 & 51.6 & 35.2 & 2 & 2.73 & 1.87 & 82.7 & 92.9 & 99.3 & 64.6 & 88.9 \\
\hline & & & & & & & & & & & & & 35.4 & 1 & & & & & & & \\
\hline & & & & & & & & & & & & & 31.8 & 0.5 & & & & & & & \\
\hline W1A11 & 6.9 & 12.6 & 8.49 & 58.5 & 18.0 & 2.0 & 8.0 & Half & 4.6 & Steady & 38 & 47.6 & 37.6 & 2.5 & 2.78 & 1.91 & 82.3 & 92.8 & 99.2 & 64.5 & 88.8 \\
\hline & & & & & & & & & & Steady & & & 37.2 & 2.5 & 2.74 & 1.88 & 82.2 & 92.8 & 99.2 & 64.5 & 88.8 \\
\hline W1A12 & 6.9 & 19.7 & 8.45 & 61.3 & 19.1 & 1.2 & 4.8 & Full & 6.2 & Continuous & 38 & & 38.8 & 2 & 2.78 & 1.91 & 65.9 & 91.0 & 97.3 & 63.2 & 87.0 \\
\hline W1A13 & 12.9 & 32.4 & 8.45 & 54.5 & 18.0 & 1.4 & 4.8 & Full & 7.0 & None & 38 & 47.6 & 24.1 & $<.5$ & 4.42 & 3.10 & 47.6 & 90.7 & 95.1 & 63.0 & 85.1 \\
\hline W1A14 & 9.9 & 25.0 & 8.38 & 57.2 & 18.0 & 1.4 & 4.8 & Half & 3.3 & Cyclic & 38 & 47.6 & 33.9 & 1.5 & 3.04 & 2.09 & 72.3 & 92.3 & 98.3 & 64.1 & 87.9 \\
\hline W1A15 & 10.0 & 25.2 & 8.37 & 51.8 & 18.0 & 1.4 & 4.8 & Full & 7.0 & Cyclic & 38 & 47.6 & 42.5 & 0.5 & 3.27 & 2.26 & 88.6 & 94.0 & 99.8 & 65.3 & 89.3 \\
\hline & & & & & & & & & & & 34 & & 36.1 & 0.5 & & & & & & & \\
\hline & & & & & & & & & & & 30 & & 36.2 & 0.5 & & & & & & & \\
\hline W1A16 & 10.0 & 32.4 & 8.36 & 54.4 & 18.0 & 1.1 & 4.8 & Full & 5.5 & Continuous & 38 & 47.6 & 49.6 & 2 & 3.03 & 2.09 & 87.4 & 93.7 & 99.7 & 65.1 & 89.3 \\
\hline & & & & & & & & & & & & & 51.4 & 4.5 & & & & & & & \\
\hline $\begin{array}{l}\text { - Utilize } \\
\text { Constan }\end{array}$ & & all $p e$ & $n f e$ & & & & & & & & & & & & & & & & & & \\
\hline Foed Co & PSD & $30=$ & $\mathrm{m}$ & & & & & & & & & & & & & & & & & & \\
\hline Heplane & Type: & mmer & al Grac & & & & & & & & & & & & & & & & & & \\
\hline High She & ar Imp & 2 & nch dia & ter, 4 & $\theta, r$ & flow & & & & & & & & & & & & & & & \\
\hline Low She & I Impe & 4.8 & dia & $x, 4$ & , rac & & & & & & & & & & & & & & & & \\
\hline Screen & 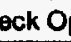 & $\mathrm{g}:$ & esh & & & & & & & & & & & & & & & & & & \\
\hline
\end{tabular}




\section{APPENDIX B}

ELKHORN NO. 3 COAL AGGLOMERATION RESULTS 
Elkhorn No. 3 Coal - $25 \mathrm{lb} / \mathrm{hr}$ Continuous Agglomeration Test Conditions and Results

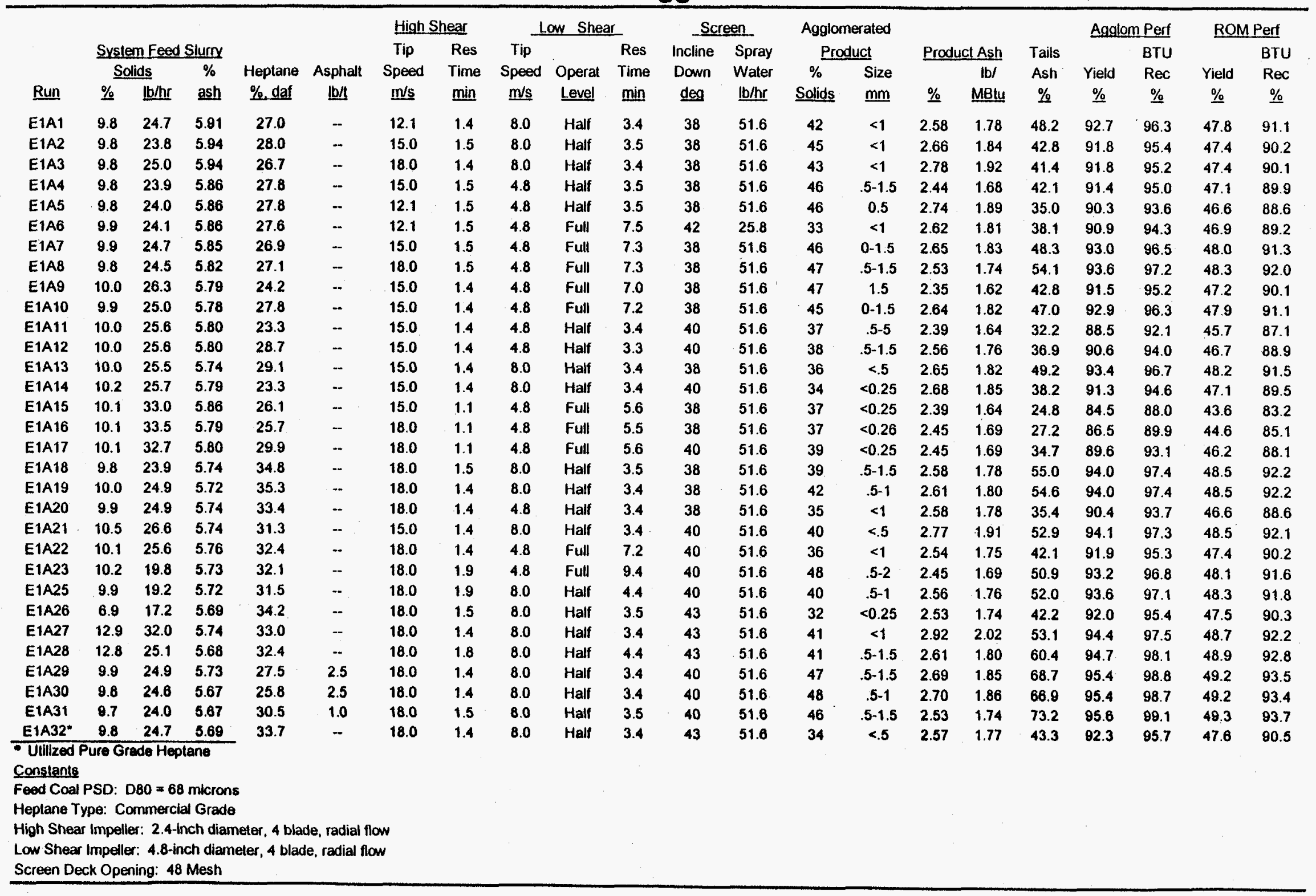


APPENDIX C

SUNNYSIDE COAL AGGLOMERATION RESULTS 


\section{Sunnyside Coal - $25 \mathrm{lb} / \mathrm{hr}$ Continuous Agglomeration Test Conditions and Results}

\begin{tabular}{|c|c|c|c|c|c|c|c|c|c|c|c|c|c|c|c|c|c|c|c|c|}
\hline \multirow[b]{4}{*}{ Run } & \multirow{4}{*}{$\begin{array}{l}\text { Grind } \\
\text { D80 } \\
\text { micron }\end{array}$} & & & & & \multicolumn{2}{|c|}{ High Shear } & \multicolumn{4}{|c|}{ Low Shear Agglomeration } & \multirow{2}{*}{\multicolumn{2}{|c|}{$\begin{array}{c}\text { Agglomerated } \\
\text { Product }\end{array}$}} & & \multirow{4}{*}{$\begin{array}{c}\text { Tails } \\
\text { Ash } \\
\%\end{array}$} & \multicolumn{2}{|c|}{ Agglom Perf } & \multicolumn{2}{|c|}{ ROM Perf } \\
\hline & & \multicolumn{3}{|c|}{ System Feed Slurry } & \multirow{3}{*}{$\begin{array}{c}\text { Heplane } \\
\% \text { daf }\end{array}$} & \multirow{3}{*}{$\begin{array}{l}\text { Tip } \\
\text { Speed } \\
\underline{\mathbf{m} / \mathbf{s}}\end{array}$} & \multirow{3}{*}{$\begin{array}{l}\text { Res } \\
\text { Time } \\
\text { min }\end{array}$} & \multirow{3}{*}{$\begin{array}{c}\text { Tip } \\
\text { Speed } \\
\underline{m} / \mathbf{s}\end{array}$} & \multirow{3}{*}{$\begin{array}{l}\text { Operat } \\
\text { Level }\end{array}$} & \multirow{3}{*}{$\begin{array}{l}\text { Res } \\
\text { Time } \\
\text { min }\end{array}$} & \multirow{3}{*}{$\begin{array}{l}\text { Agglom } \\
\text { Growlh }\end{array}$} & & & & & & \multirow{3}{*}{$\begin{array}{l}\text { Yield } \\
\underline{\%}\end{array}$} & \multirow{3}{*}{$\begin{array}{c}\text { BTU } \\
\text { Rec } \\
\%\end{array}$} & \multirow{3}{*}{$\begin{array}{c}\text { Yield } \\
\%\end{array}$} & BTU \\
\hline & & Sol & & $\%$ & & & & & & & & \multirow{2}{*}{$\begin{array}{c}\% \\
\text { Solids }\end{array}$} & \multirow{2}{*}{$\begin{array}{l}\text { Size } \\
\text { mm }\end{array}$} & \multicolumn{2}{|c|}{$\frac{\text { Product Ash }}{\mathrm{b} /}$} & & & & & $\operatorname{Rec}$ \\
\hline & & $\%$ & $\underline{\mathrm{lb} / \mathrm{hr}}$ & ash & & & & & & & & & & \% & MBtu & & & & & $\%$ \\
\hline S1A1 & 59.6 & 10.1 & 25.2 & 5.08 & 26.2 & 14.0 & 1.5 & 8.0 & Half & 3.5 & Cyclic & 50.0 & $1-2.5$ & 2.89 & 2.01 & 57.1 & 96.0 & 98.4 & 76.0 & 88.7 \\
\hline $\mathrm{S} 1 \mathrm{~A} 2$ & 59.6 & 5.0 & 24.4 & 4.91 & 29.9 & 22.3 & 0.7 & 8.0 & Half & 1.8 & Cyclic & 40.5 & 1 & 2.75 & 1.91 & 60.2 & 96.3 & 98.7 & 76.2 & 88.9 \\
\hline S1A3 & 59.6 & 7.1 & 24.5 & 4.82 & 27.7 & 19.1 & 1.1 & 6.1 & Half & 2.5 & Cyclic & 49.4 & $2-2.5$ & 2.59 & 1.79 & 55.4 & 95.8 & 98.3 & 75.9 & 88.6 \\
\hline S1A4 & 59.6 & 13.2 & 32.7 & 4.92 & 25.5 & 13.4 & 1.5 & 8.0 & Half & 3.4 & Cyclic & 50.9 & $1-3$ & 2.97 & 2.07 & 55.3 & 96.3 & 98.5 & 76.3 & 88.7 \\
\hline S2A5 & 42.9 & 10.0 & 24.5 & 5.74 & 27.9 & 12.1 & 1.5 & 8.0 & Half & 3.5 & Cyclic & 47.4 & $0.5-4$ & 2.76 & 1.91 & 61.9 & 95.0 & 98.3 & 75.2 & 88.6 \\
\hline S2A6 & 42.9 & 7.0 & 25.1 & 5.33 & 28.0 & 16.0 & 1.0 & 6.1 & Half & 2.4 & Variable & 51.5 & 2 & 2.54 & 1.75 & 64.1 & 95.5 & 98.6 & 75.6 & 88.8 \\
\hline S2A7 & 42.9 & 12.9 & 30.4 & 5.50 & 28.3 & 11.8 & 1.5 & 8.0 & Half & 3.6 & Cyclic & 51.1 & 1 & 2.80 & 1.94 & 64.4 & 95.6 & 98.7 & 75.7 & 88.9 \\
\hline$S 2 A 8^{*}$ & 42.9 & 9.9 & 25.4 & 5.49 & 26.5 & 13.1 & 1.4 & 8.0 & Half & 3.4 & Cyclic & 41.2 & $0.5-4$ & 2.93 & 2.04 & 71.6 & 96.3 & 99.2 & 76.2 & 89.4 \\
\hline S2A9 & 42.9 & 10.3 & 26.1 & 5.43 & 23.6 & 18.0 & 1.4 & 4.8 & Full & 7.3 & None & 33.0 & 0.5 & 2.86 & 1.98 & 64.0 & 95.8 & 98.7 & 75.9 & 88.9 \\
\hline & & & & & & & & 3.2 & & & None & & $0.5-P$ & & & & & & & \\
\hline$S 2 A 10$ & 42.9 & 10.3 & 25.8 & 5.37 & 25.3 & 18.0 & 1.4 & 3.2 & Full & 7.3 & None & 30.7 & $0.5-P$ & 2.77 & 1.92 & 64.7 & 95.8 & 98.7 & 75.9 & 89.0 \\
\hline S2A11 & 42.9 & 10.2 & 25.6 & 5.31 & 25.5 & 18.0 & 1.4 & 4.8 & Full & 7.3 & Continuous & 64.1 & $3-3.5$ & 2.55 & 1.76 & NA & NA & NA & NA & NA \\
\hline S2A12 & 42.9 & 10.0 & 24.7 & 5.51 & 26.5 & 18.0 & 1.5 & 4.8 & Full & 7.4 & Continuous & 57.8 & 3 & 2.62 & 1.82 & 64.6 & 95.3 & 98.6 & 75.5 & 88.8 \\
\hline $\mathrm{S} 2 \mathrm{~A} 13$ & 42.9 & 10.0 & 48.9 & 5.37 & 27.3 & 20.4 & 0.7 & 4.8 & Full & 3.7 & None & 50.0 & $0.5-1.5$ & 2.79 & 1.93 & 66.7 & 96.0 & 98.9 & 76.0 & 89.1 \\
\hline S2A14 & .42 .9 & 10.0 & 37.8 & 5.39 & 26.5 & 19.1 & 1.0 & 4.8 & Full & 4.8 & Continuous & 52.0 & 1.5 & 2.54 & 1.76 & 71.2 & 95.9 & 99.1 & 75.9 & 89.3 \\
\hline S2A15 & 42.9 & 9.9 & 24.9 & 5.27 & 27.4 & 15.3 & 1.4 & 4.8 & Malf & 3.4 & Cyclic & 51.6 & $1.5-2$ & 2.51 & 1.73 & 59.0 & 95.1 & 98.2 & 75.3 & 88.5 \\
\hline & & & & & & & & & & & Cyclic & 38.7 & 0.5 & 2.82 & 1.96 & 61.1 & 95.8 & 98.6 & 75.9 & 88.8 \\
\hline$S 2 A 16$ & 42.9 & 12.9 & 32.9 & 5.05 & 26.0 & 14.7 & 1.4 & 8.0 & Half & 3.4 & Cyclic & 50.5 & 1 & 2.42 & 1.67 & 61.9 & 95.6 & 98.5 & 75.7 & 88.8 \\
\hline S2A17 & 42.9 & 12.9 & 32.9 & 5.05 & 26.0 & 14.7 & 1.4 & 6.4 & Half & 3.4 & Continuous & 58.3 & 1.5 & 2.42 & 1.67 & 57.7 & 95.2 & 98.2 & 75.4 & 88.5 \\
\hline $\mathrm{S} 2 \mathrm{~A} 18$ & 42.9 & 9.8 & 24.5 & 5.26 & 27.0 & 15.3 & 1.5 & 4.8 & Full & 7.3 & Continuous & 56.6 & 1.5 & 2.38 & 1.64 & 59.4 & 95.0 & 98.2 & 75.2 & 88.5 \\
\hline Utilized & ure $\mathrm{Gr}$ & de Hep & & & & & & & & & & & & & & & & & & \\
\hline Constant & & & & 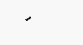 & & & & & & & & & & & & & & & & \\
\hline Heptane & pe: $\mathrm{Co}$ & nmercla & brade & & & & & & & & & & & & & & & & & \\
\hline High She & ar Impeller & 2.4-in & ch dian & er, 4 & e, rad & low & & & & & & & & & & & & & & \\
\hline Low Shea & ir Impeller: & 4.8-ine & h diam & ler, $4 \mathrm{~b}$ & a, radi & flow & & & & & & & & & & & & & & \\
\hline Screen D & eck Opene & eing: 48 & mesh & & & & & & & & & & & & & & & & & \\
\hline Screen in & clination F & rom $\mathrm{Ho}$ & izontal: & $8 \mathrm{de}$ & don & & & & & & & & & & & & & & & \\
\hline
\end{tabular}


APPENDIX D

TAGGART COAL AGGLOMERATION RESULTS 
Taggart Coal - $25 \mathrm{lb} / \mathrm{hr}$ Continuous Agglomeration Test Conditions and Results

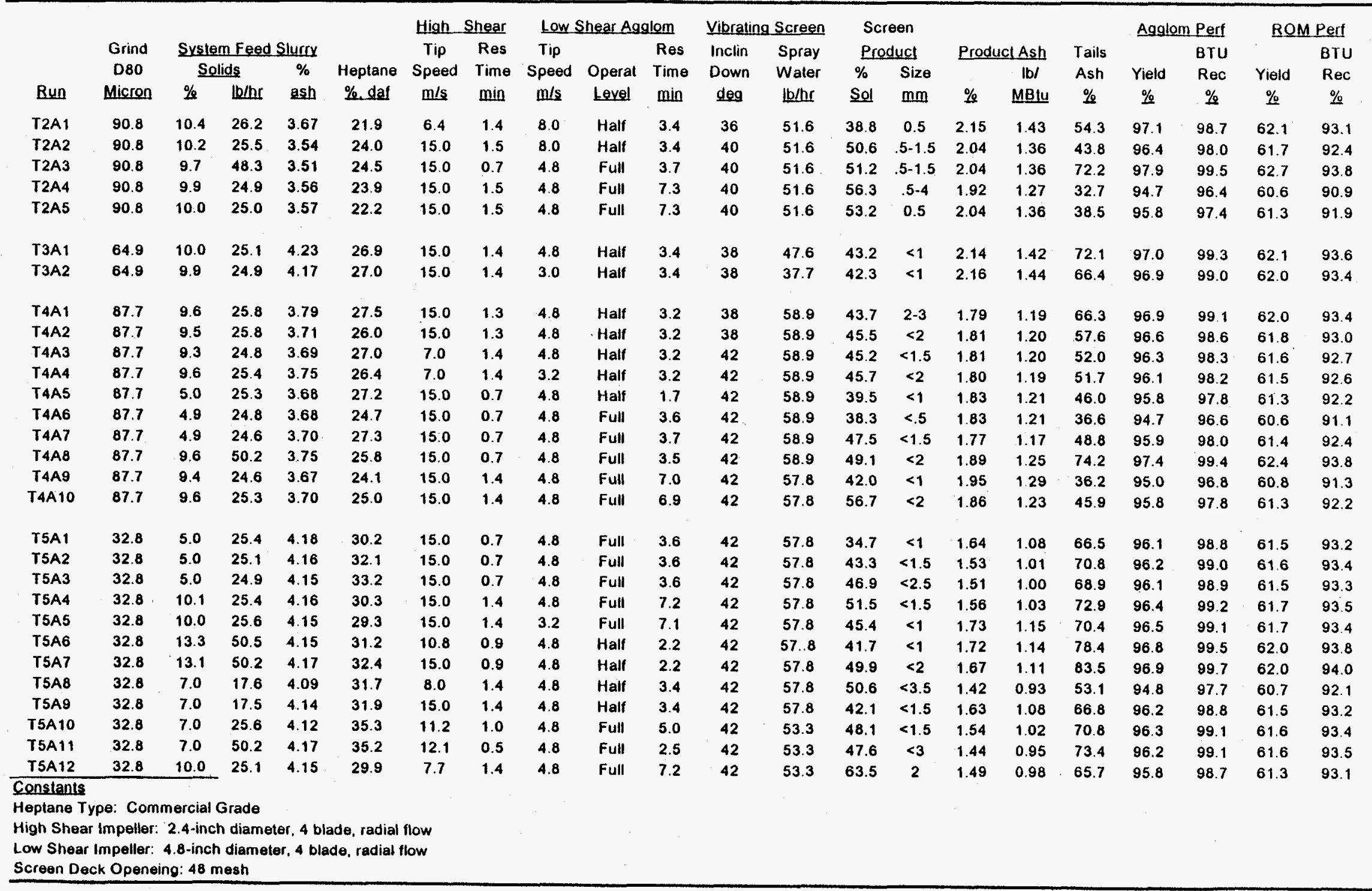


APPENDIXE

INDIANA VII COAL AGGLOMERATION RESULTS 


\section{Indiana VII Coal - $25 \mathrm{lb} / \mathrm{hr}$ Continuous Agglomeration Test Conditions and Results}

\begin{tabular}{|c|c|c|c|c|c|c|c|c|c|c|c|c|c|c|c|c|c|c|c|c|c|c|c|c|}
\hline \multirow[b]{4}{*}{ Run } & \multirow{4}{*}{$\begin{array}{l}\text { Grind } \\
\text { D80 } \\
\text { Micron }\end{array}$} & \multirow{2}{*}{\multicolumn{3}{|c|}{ Syslem Fed Slurn }} & \multirow{2}{*}{\multicolumn{2}{|c|}{ Heplane }} & \multirow{4}{*}{$\begin{array}{l}\text { Asphalt } \\
\text { Ib/ton } \\
\text { Coal }\end{array}$} & \multicolumn{2}{|c|}{ Hiah Shear } & \multicolumn{3}{|c|}{ Low Shear Agglom } & \multicolumn{3}{|c|}{ Vibrating Screen } & \multicolumn{2}{|c|}{ Agglom } & \multirow{2}{*}{\multicolumn{2}{|c|}{ Product Ash }} & \multirow{4}{*}{$\begin{array}{c}\text { Tails } \\
\% \\
\text { ash }\end{array}$} & \multicolumn{2}{|c|}{ Agglom Perf } & \multicolumn{2}{|c|}{ BOMPenf } \\
\hline & & & & & & & & \multirow{3}{*}{$\begin{array}{c}\text { Tip } \\
\text { Speed } \\
\underline{m / s}\end{array}$} & \multirow{3}{*}{$\begin{array}{c}\text { Res } \\
\text { Time } \\
\text { min }\end{array}$} & \multirow{3}{*}{$\begin{array}{l}\text { Tip } \\
\text { Speed } \\
\mathrm{m} / \mathbf{s}\end{array}$} & \multirow{3}{*}{$\begin{array}{l}\text { Operat } \\
\text { Level }\end{array}$} & \multirow{3}{*}{$\begin{array}{l}\text { Res } \\
\text { Time } \\
\text { min }\end{array}$} & \multirow{3}{*}{$\begin{array}{l}\text { Screen } \\
\text { Deck } \\
\text { Mesh }\end{array}$} & \multirow{3}{*}{$\begin{array}{l}\text { Incline } \\
\text { Down } \\
\text { deg }\end{array}$} & \multirow{3}{*}{$\begin{array}{l}\text { Spray } \\
\text { Water } \\
\mathrm{lb} / \mathrm{hr}\end{array}$} & \multicolumn{2}{|c|}{ Product } & & & & \multirow{3}{*}{$\begin{array}{c}\text { Yield } \\
\underline{\%}\end{array}$} & BTU & & BTU \\
\hline & & & & $\%$ & & $\%$ & & & & & & & & & & $\%$ & Size & \multicolumn{2}{|c|}{ Troductasin } & & & Rec & Yield & $\operatorname{Rec}$ \\
\hline & & $\%$ & $\underline{\mathrm{l} / \mathrm{h} / \mathrm{r}}$ & ash & Iyes & daf & & & & & & & & & & Sol & $(\mathrm{mm})$ & $\%$ & MBtu & & & $\%$ & $\%$ & $\%$ \\
\hline$|1 A|$ & 21.9 & 9.9 & 24.1 & 9.83 & Comm & 34.0 & 10.0 & 18.0 & 1.5 & 8.0 & Half & 3.5 & 48 & 38 & 51.75 & 51.1 & 3 & 2.73 & 1.94 & 84.8 & 91.4 & 99.3 & 51.4 & 89.8 \\
\hline IIA2 & 21.9 & 9.9 & 23.5 & 9.73 & Comm & 34.7 & 10.0 & 18.0 & 1.5 & 4.8 & Full & 7.6 & 48 & 38 & 51.75 & 46.0 & 1 & 2.96 & 2.10 & 89.1 & 92.1 & 99.7 & 51.9 & 90.3 \\
\hline IIA3 & 21.9 & 9.8 & 24.5 & 9.78 & Comm & 33.4 & 7.5 & 18.0 & 1.4 & 4.8 & Full & 7.3 & 48 & 38 & 51.75 & 48.6 & 3 & 2.71 & 1.92 & 79.0 & 90.7 & 98.5 & 51.1 & 89.2 \\
\hline I1A4 & 21.9 & 10.0 & 23.8 & 9.84 & Comm & 34.3 & 10.0 & 18.0 & 1.5 & 4.8 & Full & 7.6 & 48 & 38 & 51.8 & 43.9 & 1.1 .5 & 2.75 & 1.95 & 82.3 & 91.1 & 99.0 & 51.3 & 896 \\
\hline I1AS & 21.9 & 9.9 & 23.8 & 9.90 & Comm & 34.0 & 10.0 & 18.0 & 1.5 & 4.8 & Full & 7.6 & 100 & 38 & 51.8 & 39.1 & 1 & 2.87 & 2.04 & 79.7 & 90.9 & 98.6 & 51.1 & 89.3 \\
\hline I1AG & 21.9 & 9.9 & 23.6 & 9.73 & Comm & 32.4 & 15.0 & 13.4 & 1.5 & 4.8 & Full & 7.7 & 100 & 38 & 51.8 & 55.4 & 1.5 & 2.84 & 2.01 & 88.1 & 91.9 & 99.6 & 51.7 & 90.2 \\
\hline I1A7 & 21.9 & 7.0 & 25.0 & 9.77 & Comm & 31.1 & 15.0 & 14.7 & 1.0 & 4.8 & Full & 5.1 & 100 & 38 & 51.8 & 18.5 & $<.5$ & 3.54 & 2.53 & 88.6 & 92.7 & 99.7 & 52.2 & 90.2 \\
\hline I1AB & 21.9 & 6.9 & 24.8 & 9.71 & Comm & 33.0 & 15.0 & 14.7 & 1.0 & 4.8 & Full & 5.1 & 100 & 38 & 51.8 & 37.4 & $0.5-1$ & 3.26 & 2.33 & 89.5 & 92.5 & 99.8 & 52.1 & 90.3 \\
\hline I1A9 & 21.9 & 6.9 & 16.7 & 9.65 & Comm & 33.7 & 10.0 & 18.0 & 1.5 & 4.8 & Full & 7.5 & 100 & 38 & 51.8 & 36.6 & $0.5-2.5$ & 2.96 & 2.10 & 82.0 & 91.5 & 99.0 & 51.5 & 89.6 \\
\hline |1A10 & 21.9 & 12.7 & 33.4 & 9.65 & Comm & 30.0 & 10.0 & 17.9 & 1.4 & 4.8 & Full & 7.0 & 100 & 38 & 51.8 & 45.8 & $0.5-1$ & 3.17 & 2.26 & 89.0 & 92.5 & 99.7 & 52.1 & 90.3 \\
\hline |1A11 & 21.8 & 12.8 & 24.8 & 9.85 & Comm & 30.4 & 7.5 & 16.0 & 1.9 & 8.0 & Half & 4.4 & 48 & 38 & 51.6 & 26.8 & 1 & 4.32 & 3.12 & 65.6 & 91.0 & 97.1 & 51.2 & 87.9 \\
\hline $\mid 1 A 12$ & 21.9 & 13.1 & 32.9 & 9.86 & Comm & 31.7 & 10.0 & 18.0 & 1.4 & 4.8 & Half & 3.4 & 48 & 38 & 51.6 & 32.6 & $<.5$ & 3.84 & 2.76 & 85.2 & 92.6 & 99.4 & 52.1 & 90.0 \\
\hline $11 \mathrm{~A} 13$ & 21.9 & 13.4 & 33.6 & 9.81 & Comm & 31.4 & 10.0 & 18.0 & 1.4 & 4.8 & Full & 7.2 & 48 & 38 & 51.6 & 33.3 & 0.5 & 3.97 & 2.86 & 87.1 & 93.0 & 99.6 & 52.3 & 90.1 \\
\hline I2A1 & 26 & 10.0 & 25.1 & 9.93 & Pure & 33.4 & 20.0 & 18.0 & 1.4 & 4.8 & Half & 3.4 & 48 & 42 & 37 & 35.1 & $.5-4$ & 3.78 & 2.71 & 73.4 & 91.2 & 98.0 & 51.3 & 88.7 \\
\hline 12A2 & 26 & 10.0 & 17.6 & 9.92 & Pure & 32.7 & 20.0 & 18.0 & 2.1 & 4.8 & Half & 4.9 & 48 & 42 & 37 & 49.0 & $<2$ & 3.16 & 2.25 & 75.4 & 90.6 & 98.1 & 51.0 & 88.8 \\
\hline $12 A 3$ & 26 & 6.9 & 12.3 & 9.82 & Pure & 34.8 & 20.0 & 18.0 & 2.0 & 4.8 & Half & 4.8 & 48 & 42 & 37 & 52.0 & $1-7$ & 3.08 & 2.19 & 64.8 & 89.1 & 96.4 & 50.1 & 87.2 \\
\hline $12 A 4$ & 26 & 7.0 & 12.5 & 9.87 & Pure & 32.8 & 20.0 & 15.0 & 2.0 & 4.8 & Half & 4.8 & 48 & 42 & 37 & 42.5 & $1-6$ & 3.27 & 2.33 & 65.4 & 89.4 & 96.6 & 50.3 & 87.4 \\
\hline 1246 & 26 & 7.0 & 12.5 & 9.82 & Pure & 34.3 & 20.0 & 18.0 & 2.0 & 3.2 & Half & 4.8 & 48 & 42 & 60.8 & 26.2 & $<3$ & 3.54 & 2.53 & 48.1 & 85.8 & 92.5 & 48.4 & 83.7 \\
\hline $12 A 7$ & 26 & 7.0 & 12.4 & 9.96 & Pure & 33.0 & 20.0 & 18.0 & 2.0 & 6.4 & Half & 4.8 & 48 & 42 & 60.8 & 39.1 & $<4.5$ & 3.22 & 2.29 & 68.0 & 89.6 & 97.0 & 50.4 & 87.8 \\
\hline 12A8 & 26 & 7.0 & 12.3 & 9.80 & Pure & 33.2 & 20.0 & 18.0 & 2.1 & 3.2 & Half & 4.8 & 48 & 42 & 60.8 & 42.1 & $.5-2.5$ & 3.33 & 2.38 & 76.2 & 81.0 & 98.3 & 51.2 & 88.9 \\
\hline Constar & & & & & & & & & & & & & & & & & & & & & & & & \\
\hline
\end{tabular}


APPENDIX F

HIAWATHA COAL AGGLOMERATION RESULTS 
Hiawatha Coal - $25 \mathrm{lb} / \mathrm{hr}$ Continuous Agglomeration Test Conditions and Results

\begin{tabular}{|c|c|c|c|c|c|c|c|c|c|c|c|c|c|c|c|c|c|c|c|c|c|}
\hline \multirow[b]{3}{*}{ Run } & \multirow{3}{*}{$\begin{array}{c}\text { Grind } \\
\text { D80 } \\
\text { Micron }\end{array}$} & \multirow{2}{*}{\multicolumn{3}{|c|}{ System Feed Slurry }} & \multirow{3}{*}{$\begin{array}{c}\text { Heptane } \\
\% \\
\text { daf }\end{array}$} & \multicolumn{2}{|c|}{ High Shear } & \multicolumn{3}{|c|}{ Low Shear Agglom } & \multicolumn{2}{|c|}{ Vibrat Screen } & \multirow{2}{*}{\multicolumn{2}{|c|}{$\begin{array}{l}\text { Agglom } \\
\text { Product }\end{array}$}} & \multirow{2}{*}{\multicolumn{2}{|c|}{ Producl Ash }} & \multirow{3}{*}{$\begin{array}{c}\text { Tails } \\
\% \\
\text { ash }\end{array}$} & \multirow{2}{*}{\multicolumn{2}{|c|}{$\frac{\text { Agglom Perf }}{\text { BTU }}$}} & \multicolumn{2}{|c|}{ ROMPerf } \\
\hline & & & & & & \multirow{2}{*}{$\begin{array}{l}\text { Tip } \\
\text { Speed } \\
\mathrm{m} / \mathrm{s}\end{array}$} & \multirow{2}{*}{$\begin{array}{l}\text { Res } \\
\text { Time } \\
\text { min }\end{array}$} & \multirow{2}{*}{$\begin{array}{c}\text { Tip } \\
\text { Speed } \\
\mathrm{m} / \mathrm{s}\end{array}$} & \multirow[b]{2}{*}{$\begin{array}{l}\text { Operat } \\
\text { Level }\end{array}$} & \multirow{2}{*}{$\begin{array}{l}\text { Res } \\
\text { Time } \\
\text { min }\end{array}$} & \multirow{2}{*}{$\begin{array}{l}\text { Incline } \\
\text { Down } \\
\text { deg }\end{array}$} & \multirow{2}{*}{$\begin{array}{l}\text { Spray } \\
\text { Water } \\
\underline{\mathrm{lb} / \mathrm{hr}}\end{array}$} & & & & & & & & & BTU \\
\hline & & $\underline{\mathrm{S}}$ & $\frac{\mathrm{lids}}{\mathrm{lb} / \mathrm{hr}}$ & $\begin{array}{c}\% \\
\text { ash }\end{array}$ & & & & & & & & & $\begin{array}{l}\% \\
\text { Sol }\end{array}$ & $\begin{array}{l}\text { Size } \\
(\mathrm{mm})\end{array}$ & $\begin{array}{c}\% \\
\text { ash }\end{array}$ & $\begin{array}{c}\text { Mb/ } \\
\text { MBtu }\end{array}$ & & $\begin{array}{c}\text { Yield } \\
\%\end{array}$ & $\begin{array}{c}\text { Rec } \\
\%\end{array}$ & $\begin{array}{c}\text { Yield } \\
\%\end{array}$ & $\begin{array}{c}\mathrm{Rec} \\
\%\end{array}$ \\
\hline HIA1 & 46.6 & 10.5 & 26.9 & 8.50 & 24.4 & 8.3 & 1.4 & 8.0 & Half & 3.3 & 38 & 47.6 & 52.5 & $.5-2$ & 2.49 & 1.73 & 83.2 & 92.6 & 99.1 & 73.3 & 89.2 \\
\hline H1A2 & 46.6 & 10.3 & 26.1 & 8.21 & 24.6 & 18.0 & 1.4 & 8.0 & Half & 3.4 & 38 & 47.6 & 37.4 & $0-1$ & 3.18 & 2.22 & 81.8 & 93.6 & 99.0 & 74.1 & 89.2 \\
\hline H1A3 & 46.6 & 10.0 & 25.4 & 8.09 & 24.9 & 15.0 & 1.4 & 4.8 & Full & 7.2 & 38 & 30.0 & 56.5 & $.5-1$ & 2.64 & 1.84 & 84.6 & 93.4 & 99.3 & 73.9 & 89.5 \\
\hline H1A4 & 46.6 & 10.0 & 50.1 & 8.13 & 24.1 & 15.0 & 0.7 & 4.8 & Full & 3.7 & 38 & 47.6 & 38.4 & 0.5 & 3.14 & 2.19 & 84.4 & 93.9 & 99.3 & 74.3 & 89.5 \\
\hline H1A5 & 46.6 & 10.0 & 50.5 & 7.89 & 24.6 & 15.0 & 0.7 & 4.8 & Full & 3.6 & 38 & 47.6 & 42.9 & $0-1$ & 2.83 & 1.97 & 86.5 & 94.0 & 99.5 & 74.4 & 89.6 \\
\hline H1A7 & 46.6 & 9.8 & 24.5 & 7.69 & 28.5 & 15.0 & 1.4 & 6.4 & Half & 3.4 & 38 & 47.6 & 39.2 & $0-1$ & 2.89 & 2.02 & 84.9 & 94.1 & 99.4 & 74.6 & 89.6 \\
\hline H1A8 & 46.6 & 10.0 & 25.6 & 7.47 & 28.8 & 15.0 & 1.4 & 6.4 & Half & 3.3 & 38 & 47.6 & 49.2 & $0-3$ & 2.57 & 1.79 & 86.0 & 94.1 & 99.5 & 74.6 & 89.7 \\
\hline H1A9 & 46.6 & 10.1 & 25.8 & 7.66 & 28.2 & 15.0 & 1.4 & 6.4 & Half & 3.3 & 38 & 47.6 & 55.4 & $0-3$ & 2.40 & 1.67 & 86.2 & 93.7 & 99.5 & 74.2 & 89.7 \\
\hline H1A10 & 46.6 & 9.9 & 25.3 & 7.68 & 25.6 & 15.0 & 1.4 & 4.8 & Half & 3.4 & 38 & 47.6 & 40.8 & $.5-1.5$ & 2.67 & 1.86 & 81.8 & 93.7 & 99.2 & 74.2 & 89.3 \\
\hline HIA1OR & 46.6 & 10.0 & 25.3 & 7.45 & 25.5 & 15.0 & 1.4 & 4.8 & Half & 3.4 & 38 & 40.0 & 42.9 & 0.1 .5 & 2.63 & 1.83 & 85.1 & 94.2 & 99.5 & 74.6 & 89.6 \\
\hline H1A11 & 46.6 & 9.9 & 24.8 & 7.39 & 26.1 & 15.0 & 1.4 & 4.8 & Full & 7.2 & 38 & -- & 71.4 & $3-6$ & 2.13 & 1.47 & 86.9 & 93.8 & 99.6 & 74.3 & 89.8 \\
\hline H1A12 & 46.6 & 10.0 & 25.5 & 7.40 & 26.5 & 15.0 & 1.4 & 4.8 & Half & 3.4 & 38 & 47.6 & 49.1 & $0-3$ & 2.36 & 1.64 & 84.2 & 93.8 & 99.4 & 74.3 & 89.6 \\
\hline H1A13 & 46.6 & 10.1 & 25.5 & 7.35 & 26.5 & 15.0 & 1.4 & 3.0 & Half & 3.4 & 38 & 47.6 & 42.7 & $0-3$ & 2.69 & 1.87 & 84.3 & 94.3 & 99.4 & 74.7 & 89.6 \\
\hline $\mathrm{H} 2 \mathrm{~A} 1$ & 65.2 & 9.9 & 25.0 & 7.97 & 25.6 & 15.0 & 1.4 & 4.8 & Half & 3.4 & 42 & 52.3 & 49.5 & $.5-1$ & 2.84 & 1.98 & 78.9 & 93.3 & 98.8 & 73.9 & 89.0 \\
\hline $\mathrm{H} 2 \mathrm{A2}$ & 65.2 & 9.8 & 25.2 & 7.63 & 23.7 & 7.3 & 1.4 & 4.8 & Half & 3.3 & 42 & 52.3 & 46.1 & 1 & 2.83 & 1.97 & 73.1 & 93.2 & 98.4 & 73.8 & 88.7 \\
\hline H2A3 & 65.2 & 6.9 & 25.0 & 7.65 & 26.3 & 15.0 & 1.0 & 4.8 & Half & 2.4 & 42 & 52.3 & 53.9 & $.5-3$ & 2.50 & 1.73 & 80.4 & 93.4 & 99.0 & 74.0 & 89.2 \\
\hline H2A3R & 65.2 & 6.9 & 25.3 & 7.62 & 26.0 & 15.0 & 1.0 & 4.8 & Half & 2.3 & 42 & 52.3 & 46.3 & 1 & 2.66 & 1.85 & 76.6 & 93.3 & 98.7 & 73.9 & 88.9 \\
\hline $\mathrm{H} 2 \mathrm{~A} 4$ & 65.2 & 6.9 & 24.0 & 7.56 & 24.2 & 8.9 & 1.0 & 4.8 & Half & 2.5 & 42 & 48.9 & 53.2 & $.5-3$ & 2.53 & 1.76 & 72.1 & 92.8 & 98.3 & 73.5 & 88.5 \\
\hline H2A4R & 65.2 & 7.1 & 25.7 & 7.05 & 22.0 & 8.9 & 1.0 & 4.8 & Half & 2.4 & 42 & 48.9 & 44.4 & $.5-2$ & 2.63 & 1.83 & 56.5 & 91.8 & 96.6 & 72.7 & 87.0 \\
\hline H2A5 & 65.2 & 6.9 & 17.5 & 7.56 & 21.6 & 7.0 & 1.4 & 4.8 & Malf & 3.4 & 42 & 48.9 & 47.6 & $.5-3$ & 2.59 & 1.80 & 60.9 & 91.5 & 96.8 & 72.4 & 87.2 \\
\hline H2A6 & 65.2 & 13.1 & 33.0 & 7.49 & 22.0 & 6.7 & 1.4 & 4.8 & Half & 3.4 & 42 & 48.9 & 53.9 & $<2$ & 2.74 & 1.90 & 68.2 & 92.7 & 97.9 & 73.4 & 88.2 \\
\hline H2A7 & 65.2 & 12.9 & 75.8 & 7.33 & 26.0 & 15.0 & 0.6 & 4.8 & Half & 1.5 & 42 & 48.9 & 58.5 & $.5-2.5$ & 2.66 & 1.85 & 86.4 & 94.4 & 99.6 & 74.8 & 89.7 \\
\hline $\mathrm{H} 2 \mathrm{AB}$ & 65.2 & 6.9 & 24.7 & 7.17 & 23.8 & 8.9 & 1.0 & 3.0 & Half & 2.4 & 42 & 48.9 & 40.9 & $<1.5 \mathrm{~s}$ & 2.58 & 1.79 & 63.0 & 92.4 & 97.4 & 73.2 & 87.7 \\
\hline H2A9 & 65.2 & 13.4 & 26.0 & 6.83 & 23.2 & 15.0 & 1.9 & 4.8 & Half & 4.4 & 42 & 48.9 & 51.2 & $<1.5$ & 2.82 & 1.96 & 72.8 & 94.3 & 98.7 & 74.7 & 88.9 \\
\hline H2A 10 & 65.2 & 7.0 & 25.2 & 6.82 & 25.1 & 15.0 & 1.0 & 3.0 & Half & 2.4 & 42 & 48.9 & 48.3 & $.5-2$ & 2.57 & 1.79 & 72.7 & 93.9 & 98.6 & 74.4 & 88.9 \\
\hline H2A11 & 65.2 & 7.0 & 50.0 & 6.70 & 23.7 & 9.6 & 0.5 & 4.8 & Full & 2.6 & 42 & 48.9 & 48.4 & $<2$ & 2.50 & 1.74 & 63.2 & 93.1 & 97.7 & 73.7 & 88.0 \\
\hline $\mathrm{H} 2 \mathrm{~A} 12$ & 65.2 & 10.0 & 49.8 & 6.65 & 23.0 & 15.0 & 0.7 & 4.8 & Full & 3.7 & 42 & 48.9 & 47.3 & $<2$ & 2.74 & 1.90 & 76.1 & 94.7 & 99.0 & 75.0 & 89.2 \\
\hline ow $\mathrm{Sh}$ & pe & T. 2. & ash & $\boldsymbol{U}_{1}$ & no, 1 & & & & & & & & & & & & & & & & \\
\hline
\end{tabular}

